\title{
Defining Wilderness:
}

The Landscapes \& Boundaries of Banff National Park

by

\author{
Felix Ferdinand Mayer
}

A thesis submitted to the Faculty of Graduate and Postdoctoral Affairs in partial fulfillment of the requirements for the degree of

\author{
Master of Architecture
}

in

Azrieli School of Architecture \& Urbanism

\author{
Carleton University \\ Ottawa, Ontario
}

(C) 2021

Felix Ferdinand Mayer 
Wilderness is a term that holds undeniable significance within Canadian culture and has become a celebrated aspect of its' national identity. This thesis is an examination of wilderness, utilizing Banff National Park as a case study in examining how federal park boundaries act as legal and spatial tools to regulate and control territory, rather than solely preserve landscapes or ecologies. Park boundaries are investigated through their interactions with industrial interests, cultural landmarks, and historical narratives, dissecting their capacities to control intensely layered and contested areas. The thesis argues that this complex layering of histories and interests can be understood through a singular- - though perhaps ambiguous-prevailing pursuit; to create, control and commercialize a spatial experience of Wilderness. Through cartography, analytical mapping and a proposed series of new design interventions for the site, the dynamics of power, exclusion, exploitation, and commercialization inherent to the defining of landscapes and boundaries are investigated. 


\section{ACKNOWLEDGEMENTS}

No matter how I write and re-write this page, it seems to fall short of expressing my gratitude to the many important people that have helped me throughout my education. .

Thank you to the many friends that I've made during my winding way through architecture school. It's been a long journey, one which I never could have completed without the support and encouragement of so many amazing people.

Thank you to Piper Bernbaum, for her guidance and for her patience, and for being able to understand what I meant when even I didn't understand what I meant. Thank you for your kindness and for your support.

Thank you to my Uncle and Aunt, who welcomed me into their practice early on in my architectural education and allowed me to learn from my mistakes, of which there were many.

Thank you to the amazing faculty, staff and student community at the Azrieli School of Architecture and Urbanism, who have put so much work into creating a truly open and engaging environment. A special thanks to Catherine Bonnier and Ozayr Saloojee, for their guidance and encouragement throughout my time at the school.

Lastly, thank you to my family for their never-ending support, love and encouragement throughout my education. It has given me not only the opportunity to pursue my interests, but the constant belief that chasing these goals was the right thing to do, even when things were difficult. 


\section{TABLE OF CONTENTS}

Abstract
Acknowledements
Table of Contents
Glossary of Terms
List of Figures
Prologue

Prologue

Part I. Icons \& Images

Introduction ....................................................................... 02

Banff Hot Springs Reserve ........................................ 07

A New Eden 17

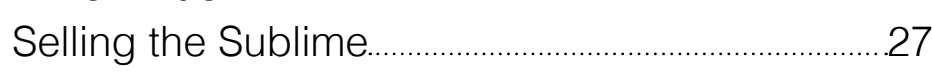

Selective Space ........................................................

Part II. A New Atlas

05 Mapping As Method ........................................................5

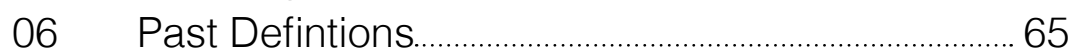

07 Present Dichotomies …...................................... 87

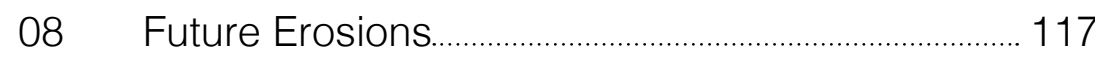

Part III. Trails \& Mechanisms

09 A New Wilderness

10 Mechanism 01_...................................................179

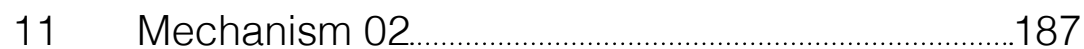

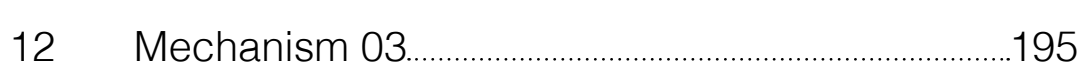

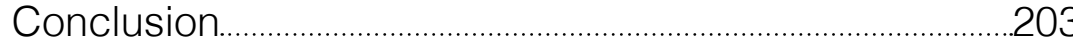

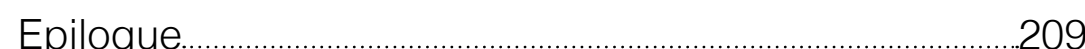




\section{GLOSSARY OF TERMS}

Anthropocene Contested new geological epoch, defined by significant human impacts on the Earth's geology and ecosystems, including anthropogenic climate change. An age where human industries act as the dominating force at the scale of the planet.

\section{Anthropogenic Originating in human activity.}

Boundary A delineation of space, physical or theoretical, that defines where an area ends and another area begins. A point or limit that indicates where two things become different.

Barrier A spatial division or contrast between two thing (landscapes, territories, resources, industries) that are or are represented as being opposed, different.

Dichotomy A division or contrast between two things that are or are represented as being opposed or entirely different; a separation.

Commodity A raw material or resource that has direct economic incentive. A product that can be bought and sold.

Comercialize To manage or exploit in a way designed to make an economic profit.

Conservation Prevention of wasteful use of a resource. A carefu preservation and protection of something especially : planned management of a natural resource to prevent exploitation, destruction, or neglect.

Climate Change

A change in global or regional climate patterns, in particular a change apparent from the mid to late 20th century onwards and attributed largely to human activities and industries. 
Erosion The gradual destruction or diminution of something. The process in which established materials, patterns, industries or ideals are worn away and transported by natural forces over time.

Industry Economic activity concerned with the processing of raw materials and manufacture of goods in factories; Any human activity concerned with the generation of economic profit, either through the processing of raw materials or through the commercialization of an experience of space.

Park A designation for a protected landscape by means of long-term planning, sustainable use and an absence or long-term planning, sustainable
restriction of human industry.

Preservation

Protected Area A clearly defined geographical space, recognized, dedicated and managed, through legal or other effective means, to achieve the long-term conservation of nature means, to achieve the long-term conservation of nature
with associated ecosystem services and cultural values.

Wilderness

An theoretical, ambiguous and evolving notion of uninhabited space, often associated with idealized, spiritual or romanticized ideas of experiencing nature and sublime. 


\section{LIST OF FIGURES}

Figure Page Title

1.1.1 IV Camp on Pope's Pass, July 10th 1901, Whyte Archive

Part I

\begin{tabular}{|c|c|c|}
\hline 1.1 .2 & XXII & CPR Tunnel, Selkirk Mountains, Whyte Archive \\
\hline 1.1 .3 & 6 & Banff Springs Hotel Grounds, Whyte Archive \\
\hline 1.1 .4 & 11 & Evolving Park Boundary Map, Wilderness \& Waterpower \\
\hline 1.1 .5 & 15 & Adventure Camp at Laggan, Whyte Archive \\
\hline 1.2.1 & 16 & Expulsion from the Garden of Eden, 1828, Thomas Cole \\
\hline 1.2 .2 & 16 & A Tornado in the Wilderness, 1835 , Thomas Cole \\
\hline 1.2 .3 & 20 & Rocky Mountain Landscape, 1870, Albert Bierstadt \\
\hline 1.2 .4 & 24 & View From Banff Hot Springs, Whyte Archive \\
\hline 1.3.1 & 26 & CPR Poster, Travel Canadian Pacific \\
\hline 1.3 .2 & 30 & CPR Poster, Hunt Big Game \\
\hline 1.3.3 & 32 & CPR Poster, Banff Lake-Louise Ski Areas \\
\hline 1.3.4 & 34 & CPR Poster Timeline \& Catalogue \\
\hline 1.3.5 & 35 & CPR Poster Timeline \& Catalogue \\
\hline 1.3.6 & 36 & Trail Riding, Whyte Archive \\
\hline 1.3.7 & 37 & Banff Springs Hotel Grounds, Whyte Archive \\
\hline 1.3.8 & 37 & Banff Springs Hotel Grounds, Whyte Archive \\
\hline 1.4.1 & 38 & Banff Winter Carnival, Whyte Archive \\
\hline 1.4.2 & 42 & Banff Big Game Hunters, Whyte Archive \\
\hline 1.4 .3 & 46 & Stoney Nakoda Hunters, Whyte Archive \\
\hline 1.4.4 & 48 & Lake Agnes Teahouse, Whyte Archive \\
\hline 1.4.5 & 48 & Lake Agnes Tea House, Whyte Archive \\
\hline
\end{tabular}


1.4.7 $49 \quad$ Banff Winter Carnival, Whyte Archive

$\begin{array}{ll}1.4 .8 & 50 \\ 1.4 .9 & 50\end{array}$

$1.4 .10-51$

$\begin{array}{ll}1.4 .10 & 51 \\ \mathbf{1 . 4 . 1 1} & 51\end{array}$

Rocky Mountains Park, Eastern Gate, Whyte Archive

Banff Trail Riders, Whyte Archive

Big Horn Sheep Hunter, Whyte Archive

Banff Big Game Hunters, Whyte Archive

\section{Part II}

\begin{tabular}{|c|c|c|}
\hline 2.1 .1 & 54 & Lake Minnewanka Flooding Overlay \\
\hline 2.1.2 & 56 & Historical Map Overlay \\
\hline 2.1.3 & 60 & Map of Boundaries and Industries, Field B.C. \\
\hline 2.1.4 & 62 & Banff National Park Sattelite Imagery \\
\hline 2.1.5 & 64 & Mines at Anthracite, Whyte Archive \\
\hline 2.1 .6 & 68 & CPR Railway Along River Valley, Whyte Archive \\
\hline 2.1.7 & 69 & Atlas Timeline 01 \\
\hline 2.1.8 & 71 & Atlas Entry 01: Deep Time I \\
\hline 2.1 .9 & 73 & Atlas Entry 02: Deep Time II \\
\hline 2.1.10 & 75 & Atlas Entry 03: Deep Time III \\
\hline 2.1.11 & 77 & Atlas Entry 04: Historical Treaties I \\
\hline 2.1.12 & 79 & Atlas Entry 05: Historical Treaties II \\
\hline 2.1.13 & 81 & Atlas Entry 06: Historical Treaties III \\
\hline 2.1.14 & 83 & Atlas Entry 07: Historical Treaties IV \\
\hline 2.1.15 & 85 & Atlas Entry 08: Railway Routes \\
\hline 2.3.1 & 86 & Banff Hydro-Facility Section, Lake Minnewanka \\
\hline 2.3.2 & 88 & Devil's Gap Dam, Lake Minnewanka \\
\hline 2.3.3 & 90 & Grassi Lakes Hike \& Hydro-Infrastructure I \\
\hline 2.3.4 & 92 & Grassi Lakes Hike \& Hydro-Infrastructure II \\
\hline 2.3.5 & 94 & Grassi Lakes Hike \& Hydro-Infrastructure III \\
\hline 2.3.6 & 96 & Grassi Lakes Hike \& Hydro-Infrastructure IV \\
\hline
\end{tabular}

2.3.7 98

2.3.8 98

2.3 .9

99

2.3.10 101

2.3.11 103

2.3.12 105

2.3.13 107

2.3.14 109

2.3.15 111

2.3.16 113

2.3.17 115

2.4.1

2.4 .2

2.4.3 122

2.4.4 123

2.4.4 125

2.4.5 127

2.4.6 129

2.4.7 131

$\mathbf{2 . 4 . 8} 133$

2.4.9 135

2.4.10 137

2.4.11 139

2.5.1 140

2.5.2 141

2.5.3 142

2.5.4 142
Grassi Lakes Hike \& Hydro-Infrastructure V Grassi Lakes Hike \& Hydro-Infrastructure VI Atlas Timeline 02

Atlas Entry 09: Hydro-Dichotomies I Atlas Entry 10: Hydro-Dichotomies II Atlas Entry 11: Hydro-Dichotomies III Atlas Entry 12: Hydro-Dichotomies IV Atlas Entry 13: Resource Extraction I Atlas Entry 14: Resource Extraction II Atlas Entry 15: Resource Extraction III Atlas Entry 16: Resource Extraction IV

Canmore Flooding, 2013, CBC News Hiking Trail \& Bridge in Paradise Valley, Banff Creek Sketch Atlas Timeline

Atlas Entry 17: Future Flood Series I Atlas Entry 18: Future Flood Series II Atlas Entry 19: Future Flood Series III Atlas Entry 20: Future Flood Series IV Atlas Entry 21: Future Fire Series I Atlas Entry 22: Future Fire Series II Atlas Entry 23: Future Drought Series I Atlas Entry 24: Future Drought Series II

Hydro-Facility \& Pipeline Construction, Whyte Archive Horseshoe Falls Dam \& Hydro-Facility

Spray Lakes Reservoir, Canal Spray Lakes Reservoir, Canal 
2.5.5 142 Canmore \& Mining Operations, Bow River Valley

2.5.6 143

2.5.7 143

2.5.8 143

$\mathbf{2 . 5 . 9} \quad 144$

$\mathbf{2 . 5 . 1 0} 145$

$\mathbf{2 . 5 . 1 1} \quad 145$

2.5.12 145

2.5.13 146

2.5.14 146

$\mathbf{2 . 5 . 1 5} 146$

2.5.16 146

2.5.17 147

5.18

2.5.19 147

2.5.20

147

3.1.1 150

3.1.2 152

3.1.3 156

3.1.4 160

3.1.5 162

3.1.6 164

3.1.7 168

3.1.8 170

3.1.9 172

3.1.10 174

3.1.11 176
Rocky Mountains \& Foothills From TCH-1

Spray Lakes Reservoir Infrastructure \& Dam

Spray Lakes Reservoir Infrastructure \& Dam

Hydro-Facility at Lake Minnewanka, Whyte Archive

Lake Minnewanka Hydro-Infrastructure \& Reservoir

Lake Minnewanka Hydro-Infrastructure \& Reservoir

Lake Minnewanka Hydro-Infrastructure \& Reservoir

Spray Lakes Reservoir Infrastructure, Powerlines

Spray Lakes Reservoir Infrastructure, Dam

Transalta Hydro-Facility from Trans-Canada Highway 1

Spray Lakes Reservoir Infrastructure, Powerlines

Transalta Hydro-Facility Infrastructure, Tower

Spray Lakes Reservoir Infrastructure, Powerlines

ake Minnewanka Dam Hydro-Infrastructure

Spray Lakes Reservoir, Ice Fishers

\section{Part III}

Exshaw Cement Plant, Lac Des Arcs

Ski Resort Infrastructure Satellite Image, Banff

Ski Resort Infrastructure Satellite Image, Banff

Ski Resort Infrastructure Satellite Image Series, Banff

Ski Resort Infrastructure Satellite Image, Banff

Paradise Valley Trail Map Collage

Hiking Trail Photo Series

Hiking Trail Photo Series

Trail \& Mechanism Concept Sketches

New Trail Map \& Existing Networks

New Trail Map \& Existing Networks II
3.2.1 178

3.2.2

3.2.3

3.24

3.2 .5

3.2.6

3.3 .1

3.3.2

3.3.3

3.3.5

3.3.6

3.4.1

3.4.2

3.4 .3

3.4 .4

3.4 .5

3.5.6

3.5.1

3.5 .2
Mechanism 1 Site Vignette

Mechanism 1 Concept Sketches

Atlas Entry 25: Mechanism 1 Location Plan

Atlas Entry 26: Mechanism 1 Site Plan

Mechanism Diptych 1-1

Mechanism Diptych 1-2

Mechanism 2 Site Vignette

Mechanism 2 Concept Sketches

Atlas Entry 27: Mechanism 2 Location Plan

Atlas Entry 28: Mechanism 2 Site Plan

Mechanism Diptych 2-1

Mechanism Diptych 2-2

Mechanism 3 Site Vignette

Mechanism 3 Concept Sketches

Atlas Entry 29: Mechanism 3 Location Plan

Atlas Entry 30: Mechanism 3 Site Plan

Mechanism Diptych 3-1

Mechanism Diptych 3-2

Creek Sketch

Lake Reflection, Lake Louise 


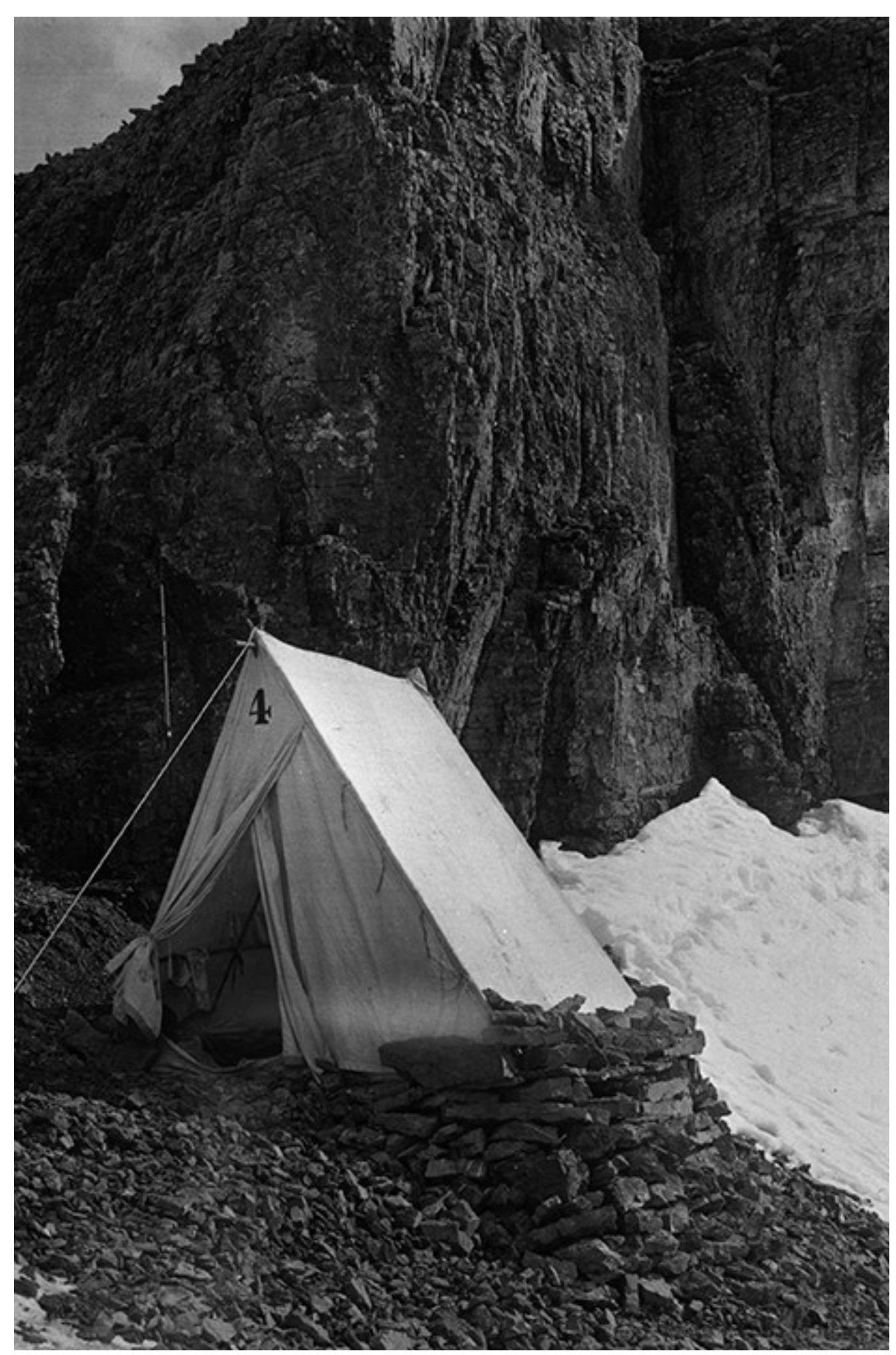

\section{PROLOGUE}

This research began with an interest in isolation and seclusion; with the ideas and images that I myself pictured when I thought of wild spaces across Canada. I wanted to explore how these romantic images of the great outdoors that are so deeply engrained in Canadian culture, might contradict or misrepresent these landscapes and their current or future conditions.

I quickly became interested in Banff National Park, not only because it had personal significance to me-having grown up in Alberta—but because of its iconic place within Canadian culture and history. When I first began to look at the history of Banff, I soon became aware of many of my own biases surrounding perceptions of Banff National Park and this pocket of wild space that I had grown up so close to. Wilderness and Banff were words that, for me, immediately conjured images of summer campfires, family ski trips and swimming in freezing mountain lakes. Growing up in a family of avid skiers, climbers, hikers and mountaineers, I had thought that these connections were unique to my own experience. While they remain cherished and important memories for me, I have come to realize how transcendent they are across Canadian culture and the Canadian experience. Almost everybody has a wild space of their own-a summer swim spot, a favourite hiking trail, a hidden creek, a family cottage..

Fig.1.1.1. Camp on Pope's Pass, July 10th 1901, Whyte Archive 
This attachment of personal and often spiritual significance is perhaps why wild spaces have become so fiercely protected and celebrated within Western, North-American culture. This significance and personalized sanctity has evolved in our collective understanding of nature and wilderness over time. It is a collective understanding of wild space that has grown ever since the American conservationist and author Henry David Thoreau declared wildness "the preservation of the world" and, as environmental historian William Cronon wrote, we began to see "the mountain as Cathedral". ${ }^{12}$ The natural progression of this newfound spiritual significance meant protecting these spaces as if they were houses of worship. To deface them with industry or garish reminders of human influence over landscape became profane. Similar to places of worship, the establishment of National Parks sanctified the wild; a perceptively boundless space to experience or seek personal meaning - a sort of revelation. National Parks created spaces to reflect and to meditate, at the cost of restrictions that limited their uses and occupations from human industries. They became zones of experience, or travel destinations, set aside from ever-expanding human settlement. We became visitors and tourists that only sought these spaces when we wanted to disconnect, to destress, to unplug and revitalize.
This thesis is an exploration of this separation, the attachment of value to a specific territory or landscape that it establishes, and the inevitable dichotomy that it creates. More specifically, the thesis explores a dichotomy of landscape that is based on the treatment of natural resources as either commodities of scenery or tools of industry. The National Park Boundary represents a threshold between this dichotomy; between the sacred and the mundane. The origins of this dichotomy will be explored throughout the work, analyzing its' present impacts, and the future ramifications it has on our physical and cultural landscapes. The erosion of this dichotomy will also be explored, as both ecotourism and industrial resource development are impacted by rapidly occurring changes in the environment of the site. These changes are destabilizing the park boundaries and the rigid definitions that they have come to represent. The thesis examines how these events are changing not only the physical landscapes of the site, but the constructed images of wilderness that have been so carefully crafted around premises of unchanging, sublime and inviolable space.

Through mapping Banff National Park and drawing its past, present and future, the thesis aims to dissect the spatial and cultural machine that creates and commodifies wilderness while consuming landscape. 
For my parents,

Who taught me how to think critically,

And for my brothers,

Who kept me from critically overthinking. 
Suddenly we come upon them grand and stern and close at hand. For more than six hundred miles [965 km] and until we reach the Pacific they will be constantly with us. We enter an almost bidden portal, and find ourselves in a valley between two great mountain ranges. $A t$ every turn of the valley, which is an alternation of precipitous gorges and wide parks a new picture presents itself... serrated peaks, and vast pyramids of rock with curiously contorted and folded strata, are followed by gigantic, castellated masses, down whose side cascades fall thousands of feet. The marvellous clearness of the air brings out the minutest detail of this Titanic sculpture... The mountains would be oppressive in their grandeur, their solemnity, and their solitude, but for an occasional mining town or sportsman's tent, which give a buman interest to the scene. ${ }^{3}$

- The New Highway East

Fig.1.1.2. CPR Tunnel, Selkirk Mountains, Whyte Archive 


\section{INTRODUCTION}

This research looks at wilderness, and Canadian relationships with wild spaces through an examination of Banff National Park. The research uses Canada's oldest national Park as a central case study to examine how park boundaries have acted as legal and spatial tools to regulate and create space, rather than preserve landscape or environment. Banff's park boundaries have been predicated upon industrial interests, cultural landmarks and historical narratives since its foundation in order to control an intensely layered and contested landscape. This thesis argues that this complex layering of histories and interests can be understood through a singular, though perhaps ambiguous, prevailing pursuit: to create, control and commercialize a spatial experience of wilderness. This thesis argues that this crafted experience of place has created a dichotomy between sacred wilderness and the uncelebrated, industrialized landscape that surrounds it, presenting unique challenges in attempting to understand the current and future conditions of the site.

The thesis is structured into three sections which explore the site of Banff National Park and the notions of wilderness that it has come to represent. These three sections each seek to understand wilderness as a spatial construct that has had tremendous impacts on Canadian culture and the defining, commodification and treatment of territories within Canada. Fundamentally, it aims to understand how an abstract or idealized definition of space, such as wilderness, can inform site, its spatial definitions, and the challenges that these definitions might pose in the future.

Part one of the research is an examination of the history of Banff National Park, its origins and context within broader North American attitudes towards wilderness, along with the motivations and central catalysts for its establishment. Through historical catalogues and timelines, the section explores the significance of imagery and depiction in the construction of the national park and its spatial narratives. Through an examination of the economic forces that created an industry of "selling scenery," part one establishes how a crafted or manicured image of the site and wilderness have had direct and tangible consequences in the formation of economic and industrial systems. Through a brief understanding of these economic forces, the section aims to communicate the processes of marketization, representation and commodification through which park space became a symbol of a Canadian national identity. This section of the research asks where Canadian notions of wild spaces have come from, how they have become so engrained in Canadian culture, and what histories and aspects of landscapes have been omitted or supressed. 
Part two of this research is a collection of cartographic analyses which comprise an atlas of boundaries for Banff National Park. Drawing the territories of the national park across the past, present and projected future of the site, this section explores the spatial repercussions and consequences of creating an allocated zone of wilderness. The atlas examines the boundary of the National Park as an agent of spatial control and the forces that have dictated its evolution over time. These influences have created rigid definitions of space and use along either side of an invisible boundary. Lastly, it maps and explores how a shifting landscape is beginning to drastically erode these established definitions of space, with anthropogenic climate change posing new challenges for landscapes on both sides of the boundary. This section of the project asks how wilderness has informed not only Canadian culture, but how it has had direct consequences in the shaping of spaces such as Banff National Park, creating dichotomies across landscapes and acting as a fundamental force in the shaping of territories, industries and economic networks.

Part three-the culmination of the thesis-is a speculative design proposal, interpreting the possible futures of Banff National Park in a world defined by anthropogenic climate change. Following the future evolutions of the space and the increasing ecological pressures being placed on the site, it examines the colliding forces of wild ecotourism and manufactured resource development as they begin to intersect at the edges of this federal territory. The proposal explores how notions of wilderness might adapt to include human interventions and industries, as the separation between human and non-human worlds becomes untenable in a rapidly shifting landscape. Through three different design proposals along a new trail network, the increasing and intangible pressures being placed on the site become evident through architectural interventions and mechanisms that navigate between cultural, industrial and ecological realms.

This thesis is titled "Defining Wilderness," not because it aims to find a singular, conclusive definition of the term, but because it explores the challenges, histories and impacts of attempting to define such an ambiguous idea of land and territory. It is a place and spatial experience that has consumed Canadian culture since its earliest beginnings and has defined entire territories such as Banff National Park through a consistent ambition of trying to craft, define and sell this abstract notion of space. 

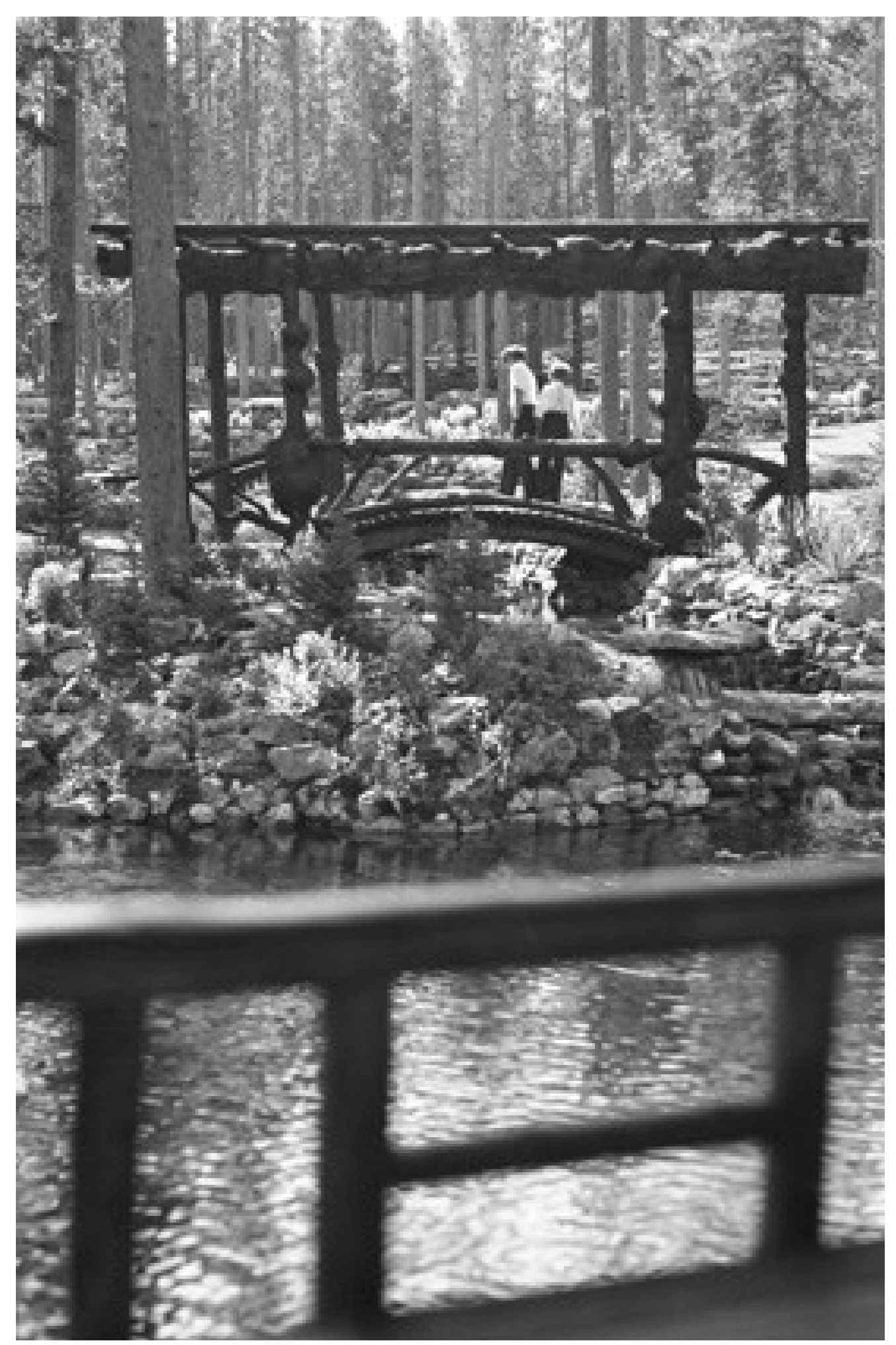

Fig.1.1.3. Banff Springs Hotel Grounds, Whyte Archive

\section{1 // BANFF HOT SPRINGS RESERVE}

I went to the woods because I wished to live deliberately, to front only the essential facts of life, and see if I could not learn what it had to teach, and not, when I came to die, discover that I bad not lived.

- Henry David Thoreau

The history of Banff National Park is enormously complex. The territory is a unique landscape comprised of valuable resources, creating a space subject to endless economic, industrial and political interests from countless parties that date back to the parks' origins. As a site of massive historical, ecological and cultural significance, the establishment of Banff National Park has had far-reaching consequences across the country, playing a central role in efforts of cultural nation-building. Banff National Park is often viewed as a successful example of nature conservation, an icon of Canadian wilderness, and a romanticized natural tourist attraction. However, the history of the Banff National Park is one of power, control, politics and exclusion. Its evolution and various conflicts can be best understood through the establishment 
and chronological evolution of the park boundary.

Located along the continental divide and the Canadian Rocky Mountains, Banff has a unique landscape defined by ecological and geological forces, events and timespans that dwarf human history and scale. Before European explorers and settlers ever set foot on the land, it was significant for several indigenous communities. As described by historian Chief John Snow of the Stoney Nakoda Nation in "These Mountains Are Our Sacred Places,"

Several aboriginal communities had connections to the area that became Banff National Park. Ancestors of the Ktunaxa (Kutenai) almost certainly traveled and hunted in the region before the smallpox pandemic of 1781, although it is not clear how much use they made of that region after the epidemic. Some Cree bands were familiar with the region too- the park was along the southwestern edge of their territores. The Niitsitapiki (also known as the Blackeet or the Blackfoot) are best known as a plains people, but they have connections with the Rocky Mountains that certainly extend back hundreds, and perhaps thousands of years. The area that has become Banff National Park was along the western periphery of their territory. The Siouanspeaking Stoney (Nakoda) probably arrived in historic times-almost certainly after 1790 , and perhaps not until the mid-1800s— but they knew the place well by $1870 .{ }^{5}$

The scope of the history and breadth of the landscape within Banff National Park is immense, therefore, the research conducted throughout this document is inevitably bound to only capture a fragment of the complexity of this territory. Faced with a multiplicity of contexts, this thesis focuses specifically on the histories and industries that have had direct consequences on the establishment of Banff National Park and its evolution as a territory. Banff National Park's history begins with the Canadian Pacific Railroad and its impact in shaping the site as we know it today. This key moment of infrastructural development, and the primary focus in the history of this site, is not intended to be envisioned as the beginning of the site's long and complex history, but an evaluation of the central catalyst for the creation of Banff National Park as a construct, as well as its role in the construction of the North-American notions of wilderness.

Banff National Park's establishment was heavily connected to the history of the Canadian Pacific Railway (CPR) and the route that it found through the Rocky Mountains. The creation of the transcontinental railway in the 1880's connected British Columbia to the rest of the newly established confederation of Canada and unified the independent settlements across the continent, linking the young nation together. It was a massive infrastructural undertaking, with the Rocky Mountains posing some of the most significant challenges to the entire project. Many of the obstacles and constraints 
encountered during the construction of the railway contributed to first non-indigenous settlements established within the territory that would eventually become Banff National Park. The construction of the railway necessitated makeshift camps and towns to be established. Even after the completion of the railway, these camps and towns would remains critical rest stops along the route, ensuring the operation of the new rail network. In order to ensure safe operation, the railway infrastructure required a restrictive $5 \%$ maximum grade change, which was a struggle to establish in the depths of the mountains. In addition, the steep terrain made it impossible to operate heavy dining cars during voyages; both factors resulted in requiring rest stops and hotels along the route to assist in providing safe passage. ${ }^{6}$ The infrastructure needed to complete this network, such as survey and labor camps for the construction of the railway led to the creation of the hamlets and chateaus that would eventually became the main settlements of Banff National Park.

The creation of the park itself came in 1885, shortly after three CPR workers discovered the Cave and Basin Hot Springs located at the base of Sulphur Mountain. ${ }^{7}$ The Hot Springs became a central catalyst for federal intervention in the area. Regulation was necessary in order to resolve conflicting claims of ownership over the newly discovered

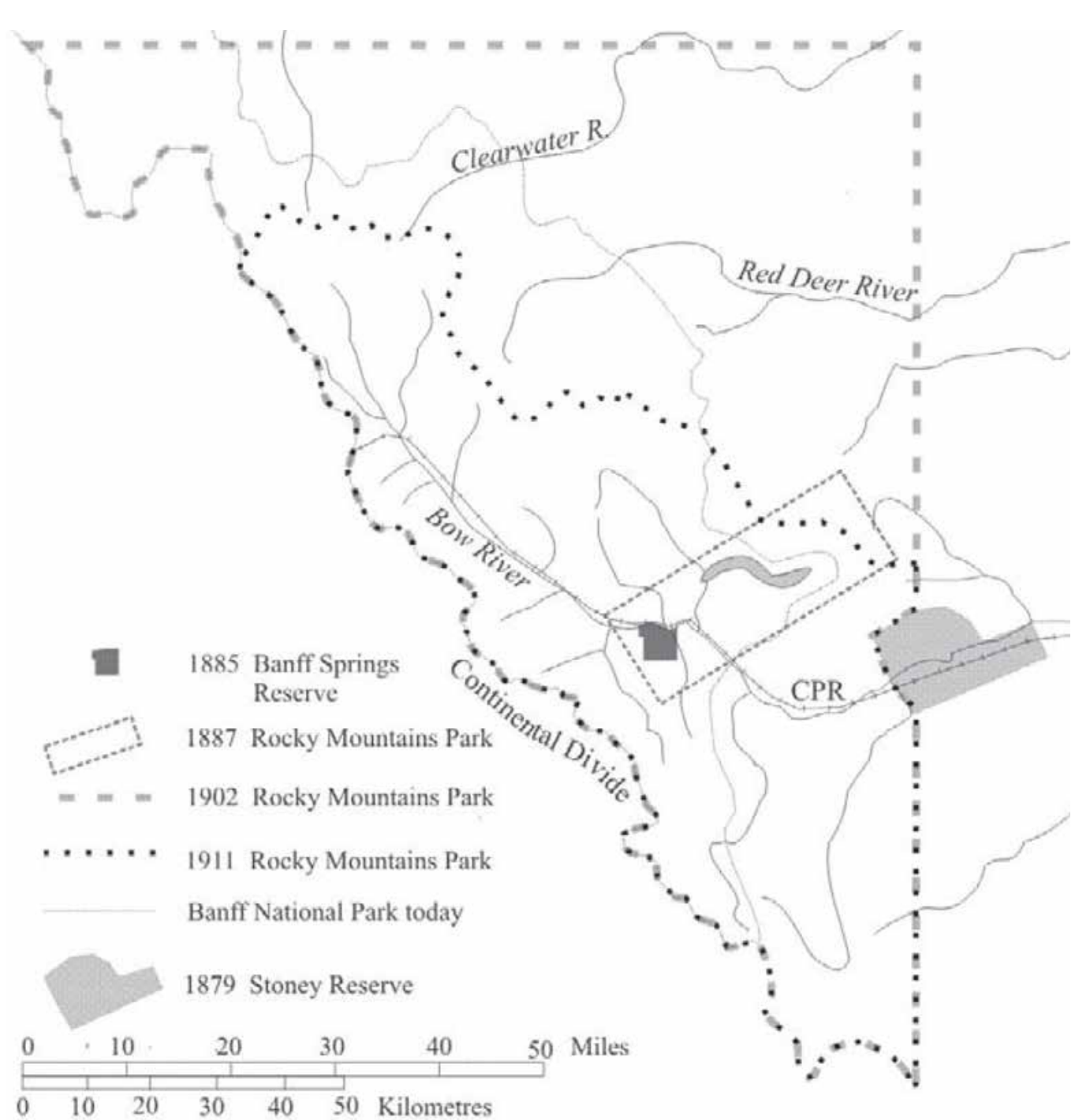

Fig.1.1.4. Evolving Park Boundary Map, Wilderness \& Waterpower 
geothermal resource. ${ }^{8}$ In 1885, a twenty-six-square kilometer parcel of land around the springs was declared the Banff Hot Springs Reserve, creating Banff National park in its first iteration. ${ }^{9}$ This area of protected land would be enlarged to 673 square kilometres in 1887 to include Devils' Lake, which today is known as lake Minnewanka. ${ }^{10}$ In 1902 it was further expanded eastwards to the point of the Stoney Nakoda First Nations reserve. ${ }^{11}$ The creation and subsequent expansions of the territory had been encouraged by William Van Horne- then president of the CPR — who immediately thought the site had potential as a tourist destination. Under the guise of preserving the site, the expanding park boundary became a means to lay claim to territory, gaining control over the area and staking ownership over any potential economic benefit, with the CPR and Canadian government being the primary beneficiaries.

Though today National Parks are zones often dedicated to preservation and natural ecologies, the initial ambitions of creating Banff National Park had little to do with efforts of conservation. When it was first established, Banff Hot Springs Reserve was primarily a means of controlling the hot springs and resolving conflicting claims of ownership over the location and any economic value it might hold, rather than any effort to preserve the site. ${ }^{12}$ Conserving wilderness was simply a by-product of claiming land for its unique and valuable geothermal resources. The same arguments that had been used to create Yellowstone National Park in 1872-similarly seeking to give control over the space to the government and railway agencieswere used in the proposition for Banff. As described by history and environmental studies professor Roderick Nash, the formation of the park at Yellowstone was far more concerned with claiming the resources of the site than its preservation...

$$
\begin{aligned}
& \text { Yellowstone's initial advocates were not concerned with } \\
& \text { wilderness; they acted to prevent private acquisition and } \\
& \text { exploitation of geysers, hot springs, waterfalls, and similar } \\
& \text { curiosities. In New York the decisive argument concerned } \\
& \text { the necessity of forested land for an adequate water supply. } \\
& \text { In both places wilderness was preserved unintentionally. } \\
& \text { Only later did a few persons begin to realize that one of } \\
& \text { the most significant results of the establishment of the } \\
& \text { first national and state parks had been the preservation of } \\
& \text { wilderness. }{ }^{13}
\end{aligned}
$$

Similarly, at Banff, the park was initially created to claim the hot springs after their discovery, inadvertently creating the national park through ambitions of claiming the site and the resources that it held. Similarly, the establishment of the Northern Pacific Railroad had a significant 
role in the creation of Yellowstone Park about a decade earlier. The CPR was an essential lobbyist in the creation of Banff National Park. The CPR had invested heavily in the establishment of the railway that, for the time being, was the only easy means of accessing the park. With this infrastructure in place and a network of accommodations and hospitality venues established, the CPR stood to benefit significantly from sustained restriction of site access. As described by historian Leslie Bella in her history of Canadian national parks, Parks For Profit,

[Canadian National Parks] were built [...] to centralize control of that landscape in the hands of the railroads. That control was used to reduce competition in the parks, and to restrict access to the mountains. Businesses that might be patronized by the working class were not sufficiently aesthetic. Access to the mountains was provided instead

to upper- and middle-income tourists willing to pay substantial sums for a sanitized view of the mountains ${ }^{14}$

From its very beginnings, Banff National Park was tied to the infrastructure and economics of the railway and eco-tourism industries that the CPR sought to establish. The need for the CPR and the Canadian Government to not only celebrate the site, but to market it to the tourist, meant that the space of the park became more than a mere landscape, it became a commodity, an object, and a business operation. Central to this effort to sell the natural beauty of the site to the tourist was a selling of narratives of spirituality, mysticism and adventure that Canadian society began to attach to wild spaces. Banff National Park became an industry of selling wilderness.

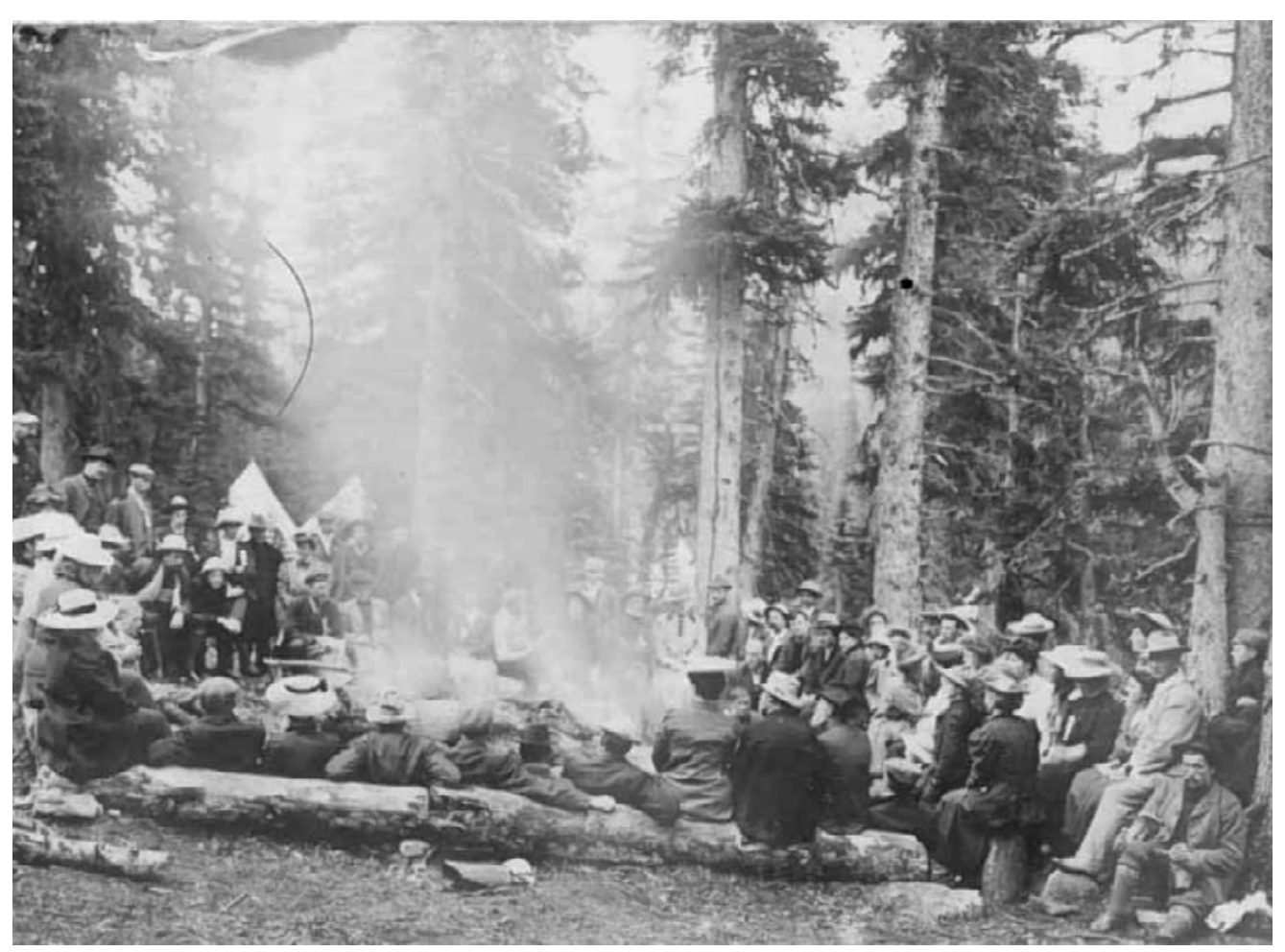

Fig.1.1.5. Adventure Camp at Laggan, Whyte Archive 


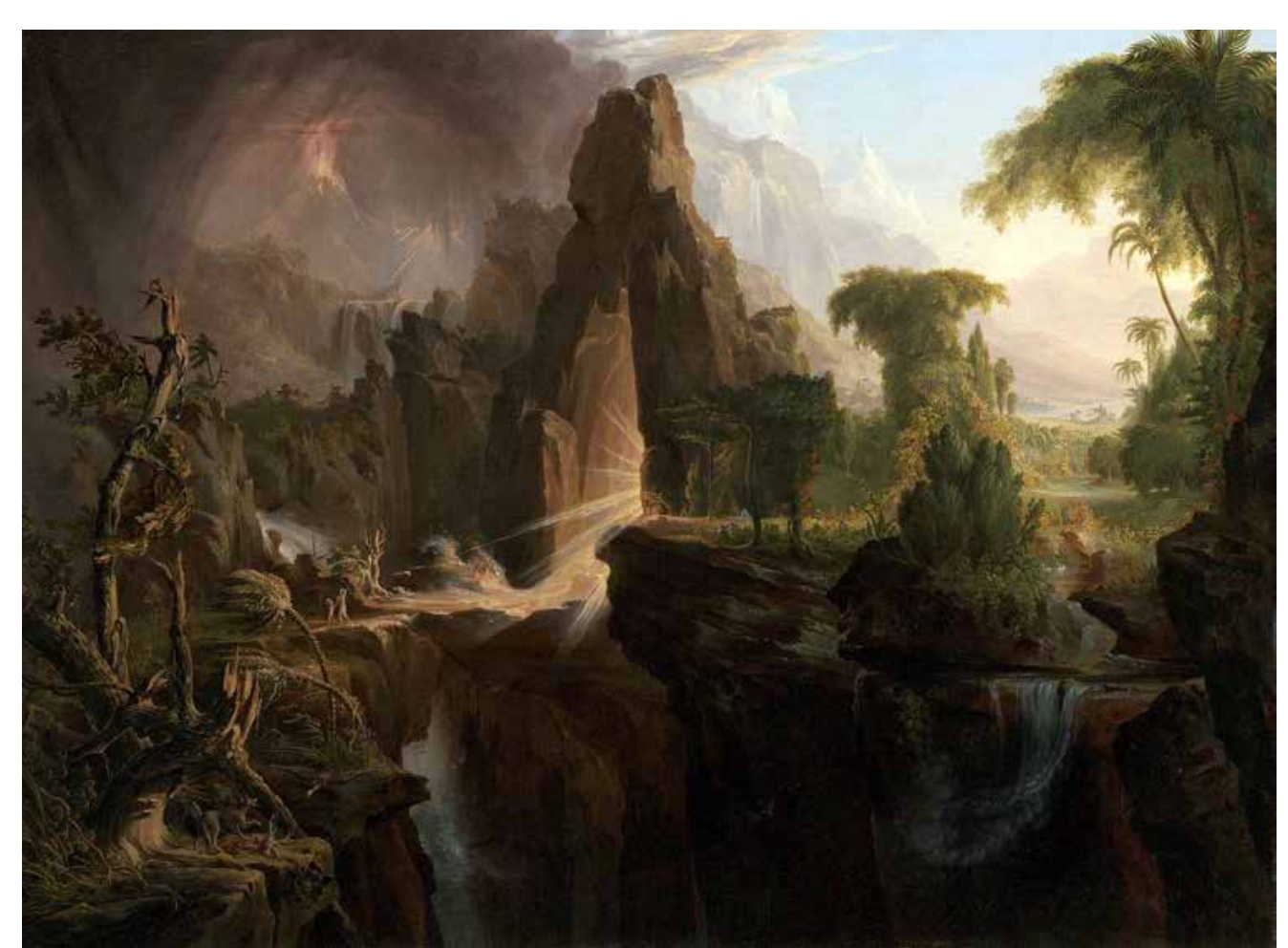

Fig.1.2.1. Expulsion from the Garden of Eden, 1828, Thomas Cole

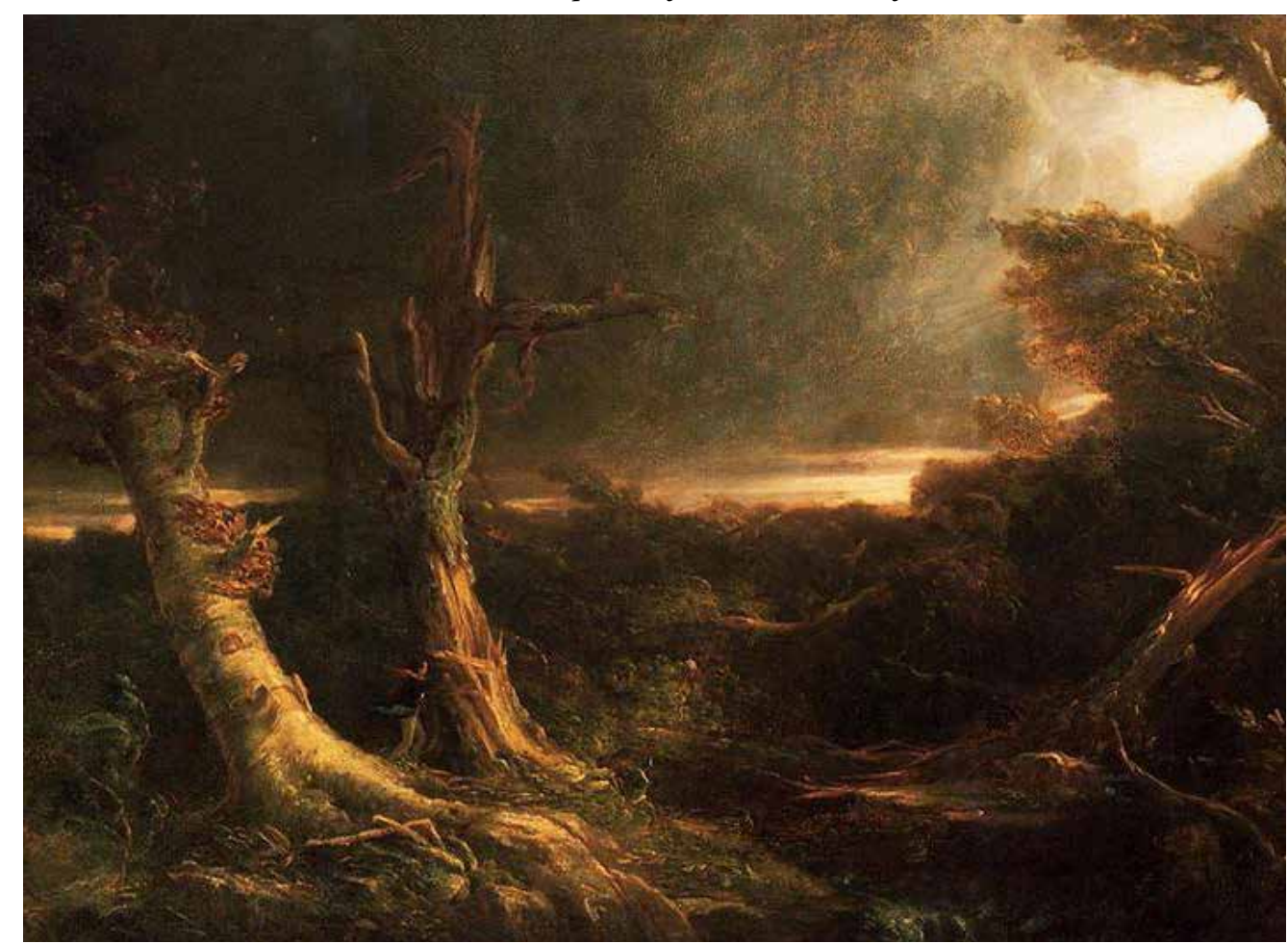

Fig.1.2.2. A Tornado in the Wilderness, 1835, Thomas Cole
02 /I A NEW EDEN

\begin{abstract}
No pain here, no dull empty hours, no fear of the past, no fear of the future. These blessed mountains are so compactly filled with God's beauty, no petts personal hope or experience has room to be..$^{15}$
\end{abstract}

- John Muir

The creation of the Banff Hot Springs Reserve marked a significant moment within a broader, ongoing North-American cultural shift in attitudes towards landscapes and wild spaces. Wilderness, which had once been generally regarded as the central antagonist to the North American colonial mission of settlement expansion, began to take on a new meaning within North American culture. New literary, artistic and philosophical movements painted a new picture of these previously vilified wild spaces that remained prominent across the continent. Conservationism became the new credo for the United States and Canada.

The iconography surrounding wild spaces transformed from hostile and disruptive, to a poetic space of tranquility and spirituality. 
The wild became both place and state of being, where a self-reliant individual might discover hidden truths about the natural world and their own place within it. Wilderness became a sacred space. Some of the most significant contributors to this emerging brand of American Conservationism were naturalists, writers and poets such as John Muir, Ralph Waldo Emerson, and Henry David Thoreau. The latter perhaps making the most prominent contributions with his publication of "Walden" or "A Life in the Woods" in 1854. Within this work, Thoreau extolled the virtues of independence, self-reliance and spirituality that he believed the natural world had to offer. In "The Trouble With Wilderness" (1996), the American environmental historian William Cronon further elaborates upon the contexts of nature and the origins of narratives surrounding wilderness of the mid- $19^{\text {th }}$ century. Cronon writes,

That Thoreau in 1862 could declare wildness to be the preservation of the world suggests the sea change that was going on. Wilderness had once been the antithesis of all that was orderly and good - it had been the darkness, one might say, on the far side of the garden wall - and yet now it was frequently likened to Eden itself. ${ }^{16}$

The fact that these philosophical values ascribed to wilderness in the early $19^{\text {th }}$ century are so closely aligned with current Canadian cultural values speaks to the lingering success of these movements, but at the time that these shifts were occurring it marked dramatic and unprecedented change. Previous connotations for wilderness were rooted deep in Judeo-Christian values, and fundamentally symbolized space that was immoral or wicked. The term wilderness referred to space, and experience of space, that was synonymous with a loss of faith and sacrilege. This is supported by further assertations by Cronon,

Many of the word's strongest associations then were biblical, for it is used over and over again in the King James Version to refer to places on the margins of civilization where it is all too easy to lose oneself in moral confusion and despair. The wilderness was where Moses had wandered with his people for forty years, and where they had nearly abandoned their God to worship a golden idol. ${ }^{17}$

Before this re-branding of wilderness, associations surrounding the term were the very antithesis of all that was good and holy. It was the idea of a place saturated with fear, violence and desolation. The very concept and etymology of the word bewilderment is a direct reflection of this experience of place, an experience of disorientation, spiritual confusion, and devoid of any virtue or morality. Yet, over the course of mere decades, wilderness in North America went from profane to sacred space, from a place of loss and wandering to a place of 


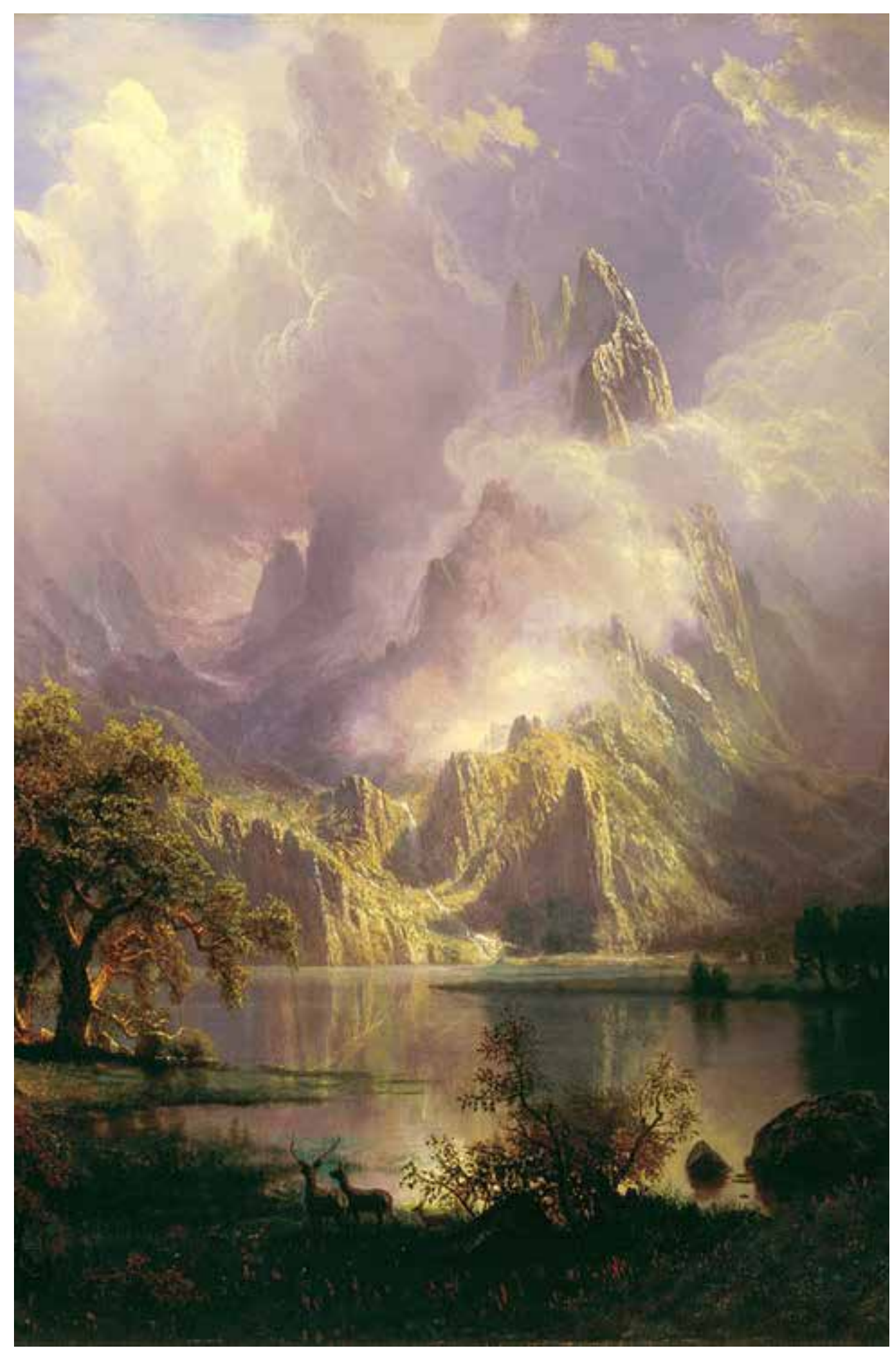

Fig.1.2.3 Rocky Mountain Landscape, 1870, Albert Bierstadt discovery. This dramatic change in definition of wild space would go on to fundamentally influence every aspect of its use and celebration in North American culture, laying the foundation for the establishment of National Parks such as Banff.

Throughout the $19^{\text {th }}$ and $20^{\text {th }}$ century, a new North American emphasis on self-reliance, capitalistic independence and cultural individualism became sacred doctrine for the continent's nations. Individual experiences of the world began to have newfound significance and profundity. New emerging philosophies, such as Transcendentalism, posed a direct challenge to the bewildering experience of nature, arguing instead that it was a space of spiritual awakening where human intuition and observation might reconnect with fundamental truths. As wild space ceased to be an existential threat to human settlement, it instead began to offer an escape from the confines of established religious and social hierarchies. Nature came to embody space where one might break free from these trappings and the restrictive institutions for pure, uncorrupted experiences of God's creation and the wisdom and sanctity that it held. This sense that, in wild spaces, one might have a religious experience at any moment, and that the supernatural lay hidden just beyond detection, was expressed through the concept of the sublime. ${ }^{18}$ 
This celebration of independent experience was coupled with a growing concern that expansion across the continent might threaten these "natural" experiences that made North America such a unique and great landscape. As Cronon writes,

It is no accident that the movement to set aside nationa parks and wilderness areas began to gain real momentum at precisely the time that laments about the passing frontie reached their peak. To protect wilderness was in a very real sense to protect the nation's most sacred myth of origin. ${ }^{19}$

Among the core elements of the frontier myth was the powerful sense that Wilderness was the last bastion of rugged individualism that had made America a landscape of such limitless possibility. It was not simply that these beautiful landscapes began to take on a spiritual significance, or the development of a melancholic sentiment that they represented a disappearing way of life, but a combination of the two that would forever cement the significance of these landscapes within North-American culture. Federally owned and operated National Parks presented a unique opportunity to maintain and preserve not only physical space, but also the mythos and cultural narratives that surrounded them

National Parks represented—and still represent—a longing for simpler times and humble human experience through detachment from modern industry and society. These areas are saturated with narratives of discovery and adventure, of the sanctity of individual experience of the natural world, and of great myths and legends presented through romanticized, manicured versions of nature. The curated and selective application of these narratives to park space has had a profound impact on the landscape of the National Park and how it has been controlled. The experience of wilderness that parks such as Banff sought to embody created a unique spatial condition; a feedback loop where a landscape and the human values attributed to said landscape have become indiscernibly intertwined. It is a unique case study of the space-making capacity of cultural narratives within a territory that embodies the dialectic of a culture defined by wilderness, and a wilderness defined by culture.

Banff National Park, and all National Parks across North America, are a direct reflection of these evolving attitudes towards wilderness and the virtues that North American culture began to attach to wild spaces. The core philosophies and ideas of these spaces that were established in the $19^{\text {th }}$ century and gained further traction in the $20^{\text {th }}$ century have been fundamental to not only the creation of spaces such as Banff National Park, but also to their evolution and federal 


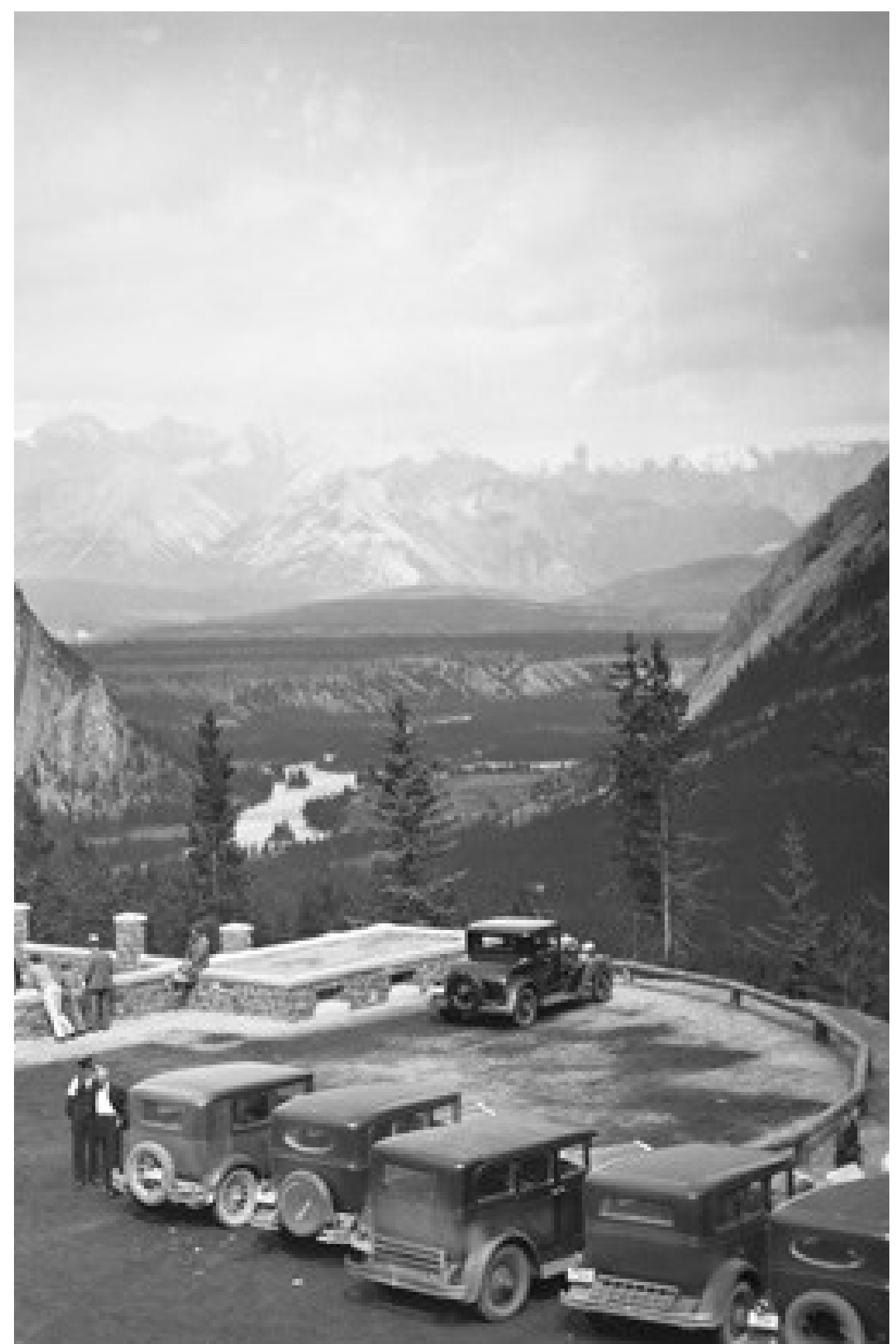

legislation since. The tenets of the sublime and the conservationist movement would have direct consequences, resulting in economic industries and legal landscapes that would further define physical boundaries. The deliberate attempt to take this understanding of wild space and market it, turning a desirable experience of place into a commercial industry dictated by the pressures of a capitalist economy would inform much of the future of Banff National Park and the experience it sought to create inside its boundaries. The notion of the sublime became another natural resource that could be harnessed and exploited. The National Park and its boundaries were the mechanism to do so.

Fig.1.2.4. View From Banff Hot Springs, Whyte Archive 


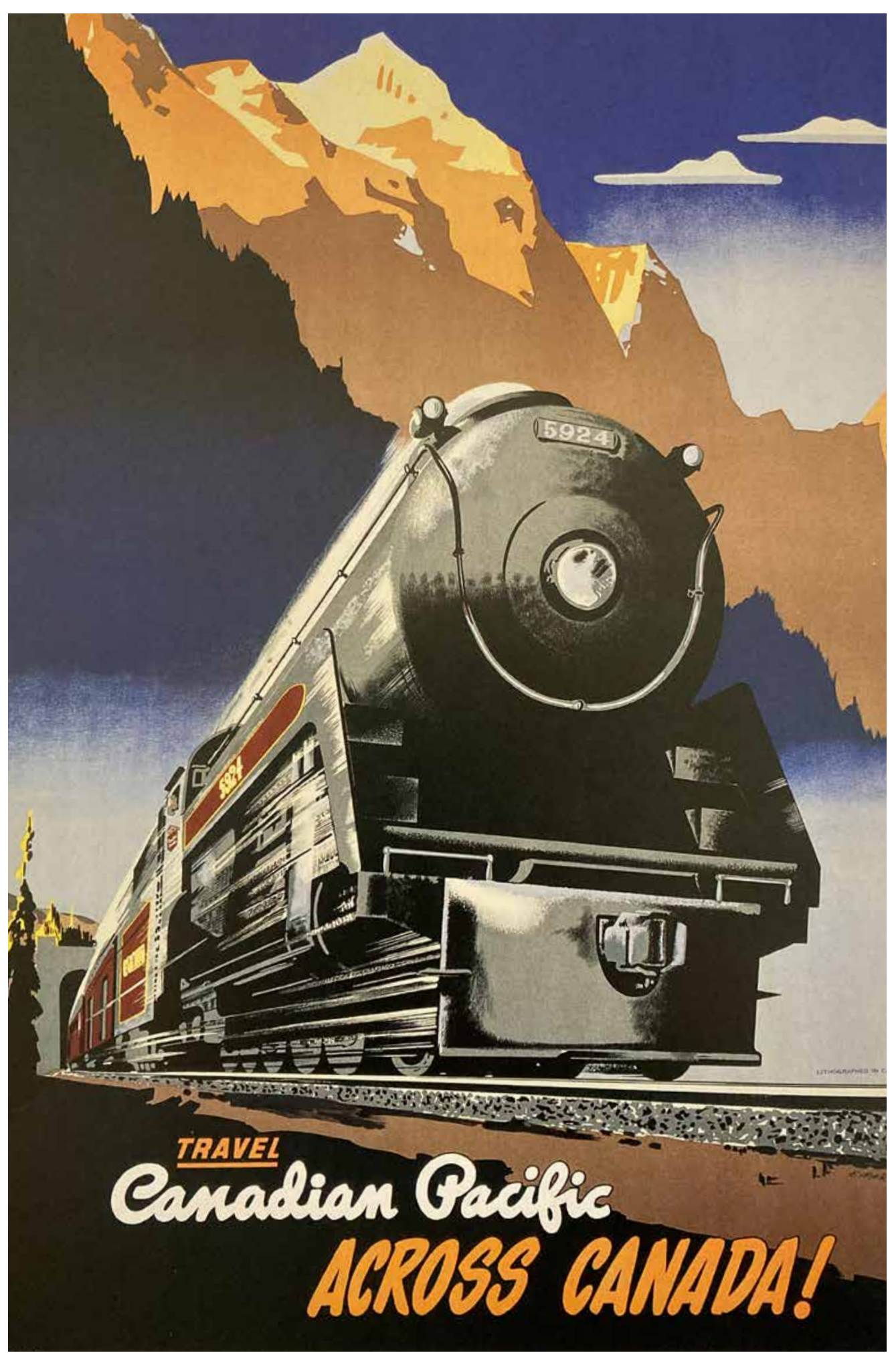

Fig.1.3.1. CPR Poster, Travel Canadian Pacific $\mathbf{0 3}$ // SELLING THE SUBLIME

[National Parks] attract an enormous tourist traffic and tourist traffic is one of the largest and most satisfactory means of revenue a nation can have ... The commercial potentialities of tourist traffic are almost starting ... On every band there is evidence of a powerful and prevailing desire on the part of the people to see and commune with the beauties of nature, their willingness to pay for it and the pecuniary benefit of the locality concerned. ${ }^{20}$

- J.B. Harkin

With the establishment of Banff National Park—-then called Banff Hot Springs Reserve—and the completion of the Transcontinental Railway in 1885 with its chateaus, hotels and major attractions, all the necessary systems and networks had been put into place to make the scenery and experience of the land accessible to the tourist. The wealthy, citydwelling Canadian now had direct access to the same awe-inspiring, spiritual experience of wilderness that had been so eloquently defined by North-American poets and Conservationists. With this network established, and a need for the CPR and Canadian Government to capitalize on the investments that they had put into its creation and maintenance, an industry of "selling scenery" emerged. ${ }^{21}$

William Van Horne, who was the appointed president of 
the CPR in 1888 and who oversaw much of the construction of the transcontinental railway, summarized this new tourism industry and business model, saying 'if we can't export the scenery, we'll import the tourist. ${ }^{, 22}$ This model, however, meant marketing Banff National Park before the visitor ever set eyes on the landscape itself. Advertising, marketing, branding and public image became a cornerstone of Banff's business model. The CPR invested heavily in the depictions and representations of its luxurious chateaus at Banff Springs and Lake Louise, creating posters, postcards, photographs and paintings that would be distributed across the world in order to promote Canada's iconic wilderness.

To promote itself - and Canada - to the world, Canadian Pacific [Railway] produced more than 2,500 stunning lithographic and silkscreen posters. They were displayed in offices and independent travel agencies worldwide, from the 1880s until the 1970s. The posters represented what Canadian Pacific and Canada had to offer: a world of deco-style streamlined locomotives, luxury resorts in the wilderness surroundings, glimpses of distant romance and adventure, ocean liners sailing to faraway locations, magnificent hotels, and the dawning of the jet age. These posters enticed millions to visit and even settle in Canada. ${ }^{2}$ advertising campaigns, the very presence of the CPR immediately began to impact the landscape. Industrial impacts of the railway were deliberately obfuscated in these marketing depictions of the park. Even though the accommodations had yet to reach the scale and luxury that they have today, the landscape immediately began to show the toll of the increased traffic and industry that had developed. In one case, forest fires began to become an issue for the park due to constant sparks generated by the steam engines of the locomotives, leaving several areas along the rail line blackened and scarred. In the late 1880s CPR marketing campaigns required touch-ups to their postcards and photographs of the space, covering the blackened forests and smokefilled valleys with clear skies and lush green foliage. ${ }^{24}$ Even in its earliest stages, Banff National Park constantly struggled to reconcile its image of pure, Canadian wilderness with the economic and industrial frameworks that were its very justification for existing.

At its economic peak in the first half of the $20^{\text {th }}$ century, the CPR was a travel network that had global influence. Through graphic illustration and distribution of images of Banff National Park and landscapes across Canada, the CPR extoled a luxurious, tailored experience of Canada's expansive wilderness around the world. Some of Canada's most famous artists, including members of the Group of 


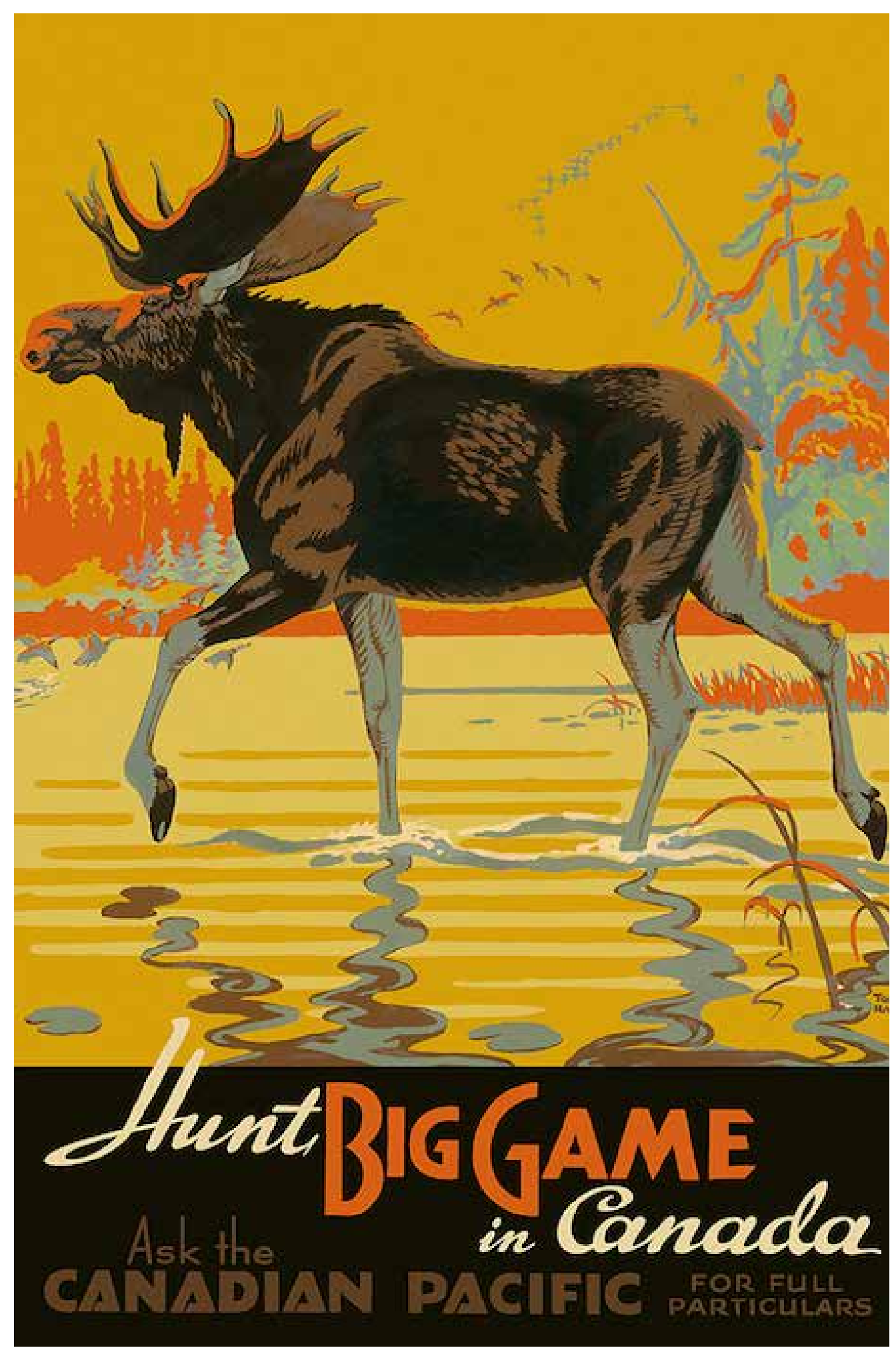

Fig.1.3.2. CPR Poster, Hunt Big Game
Seven, would also contribute to the creation of this image. Artists such as Lawren Harris, A.Y. Jackson and Frank Johnston made several trips to Rocky Mountains Park throughout the 1920s, 30s and 40s, looking to the landscape for a new vision of Canadian nationalism and spiritual rejuvenation. As stated by Lawren Harris,

We live on the fringe of the great North across the whole continent, and its spiritual flow and its clarity, its replenishing power passes through us... Our art is founded on a long and growing love and understanding of the North in an ever clearer experience of onene spirit of the whole land and a strange brooding sense of spint of the whole land ond a strange brooding sense of Mother Nature fostering a new race and a new age. ${ }^{25}$

Banff National Park and the economic significance it held to the business model of the CPR played a massive role in these narratives and explorations surrounding wilderness and the emergence of a clear cultural identity. Parks became icons of national and cultural pride. Whether these paintings and drawings were deliberately aiming to promote Banff National Park, as the CPR posters overtly did, or instead, were the result of other pursuits such as the Group of Seven's attempts to create a distinctly Canadian artistic identity, the results were inevitably the same. The countless representations created an iconized image of Banff National Park that became as significant as the space 


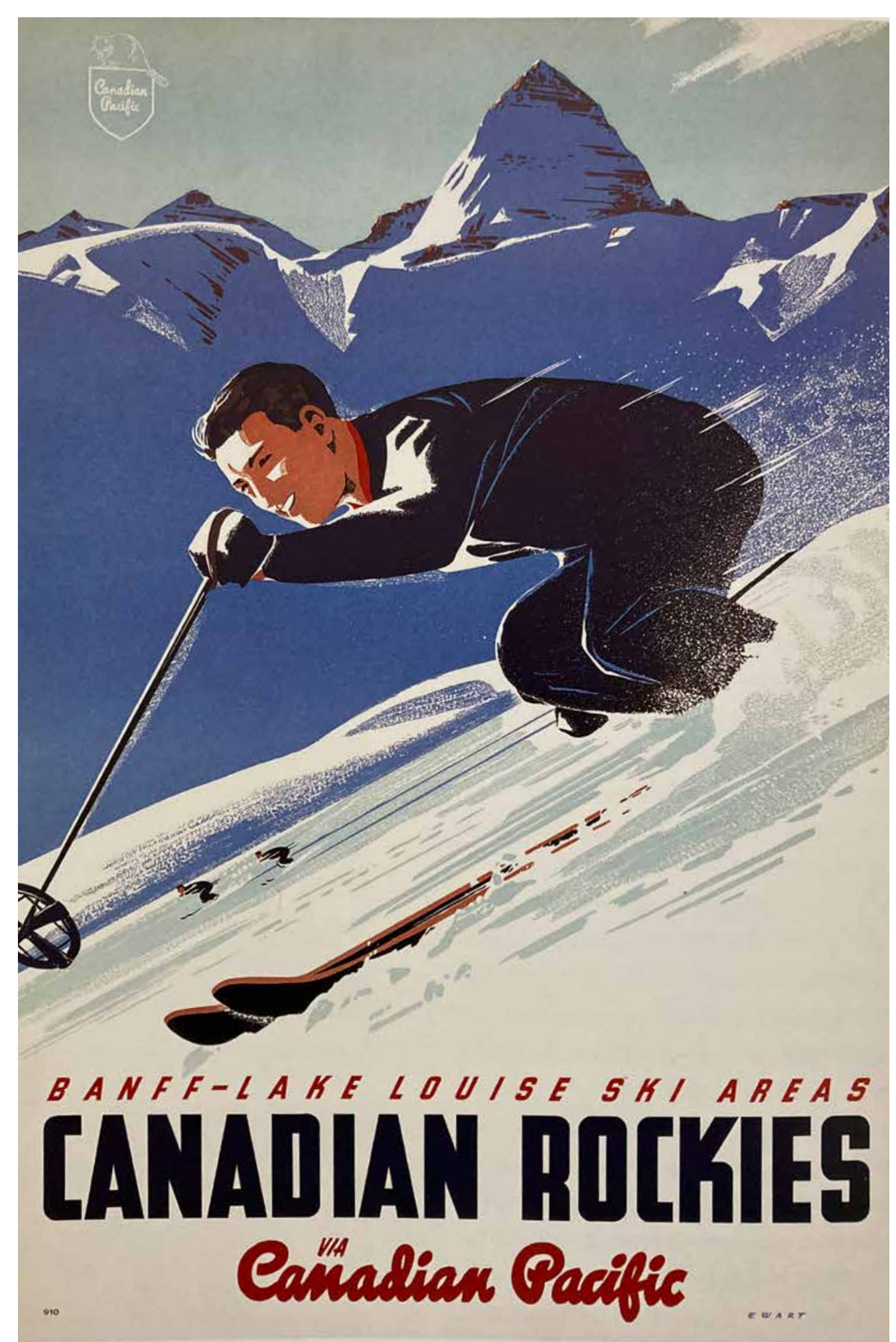

Fig.1.3.3. CPR Poster, Banff-Lake Louise Ski Areas itself. The depictions of the lakes and mountains vistas within the park boundary contributed to a uniquely Canadian mysticism surrounding the landscape. Consequentially, a tradition of cultural nation-building became linked to an obsession with experiencing the Canadian wild.

The need for Banff National Park to embody the wilderness that the depictions promised meant a continued pressure to control the development of the site; restricting or concealing aspects of human occupation that would conflict with this idealized vision of the park. Forms of resource extraction and industry, such as mining, hydro-development and forestry all had the potential to undermine the pristine landscape and scenery that was now firmly at the heart of an equally viable eco-tourism industry. For a brief time these conflicting uses of the site would achieve a delicate coexistence within Banff National Park, with each faction holding opposing values yet sharing a mutual economic interest in the commodification of the landscape. This would later manifest into the strict dichotomy existing along either side of the park boundary, creating firm divisions between a wilderness experience on the inside of the park, and an industrial landscape on the outside. 


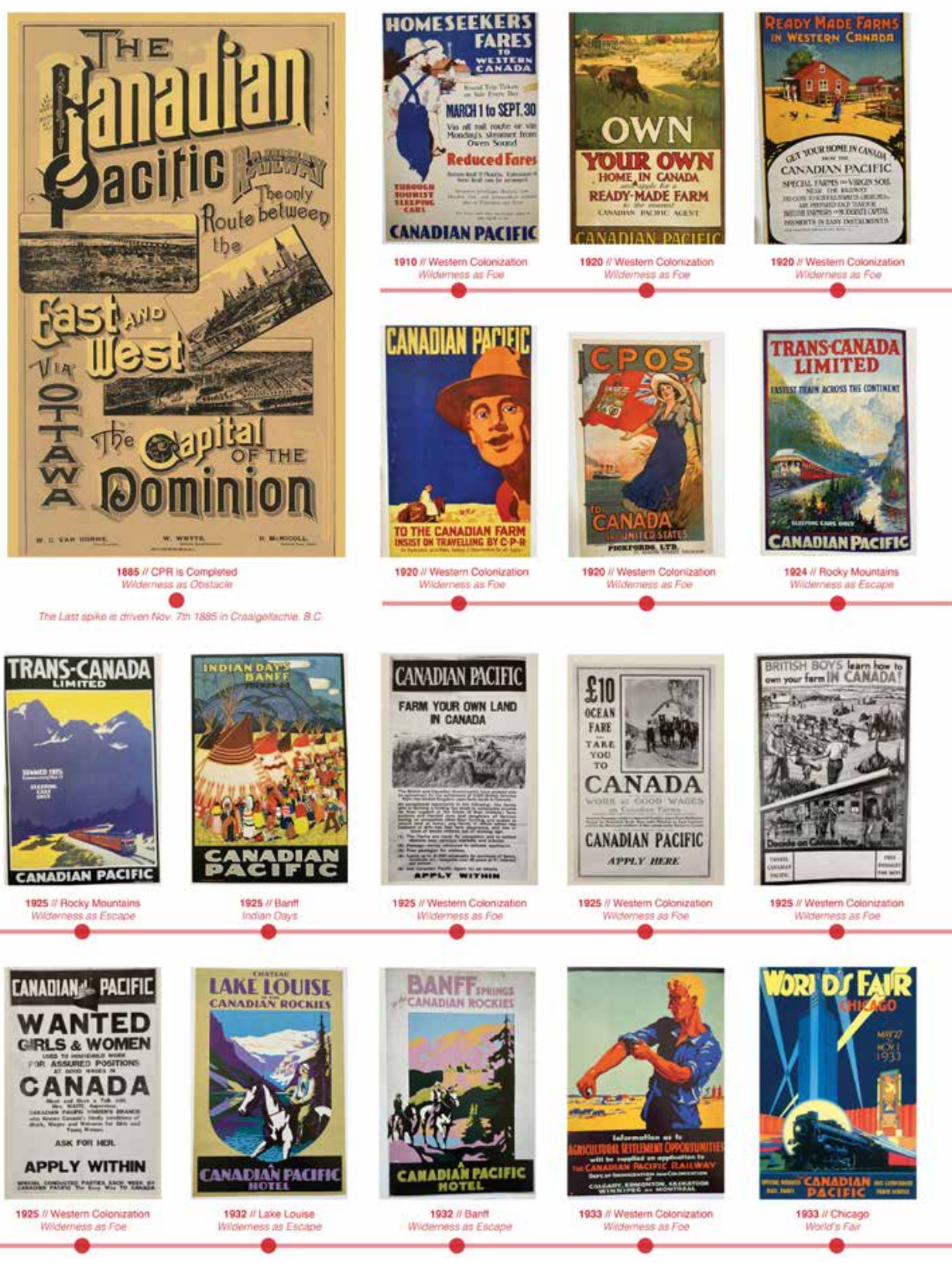

Fig.1.3.4. CPR Poster Timeline \& Catalogue
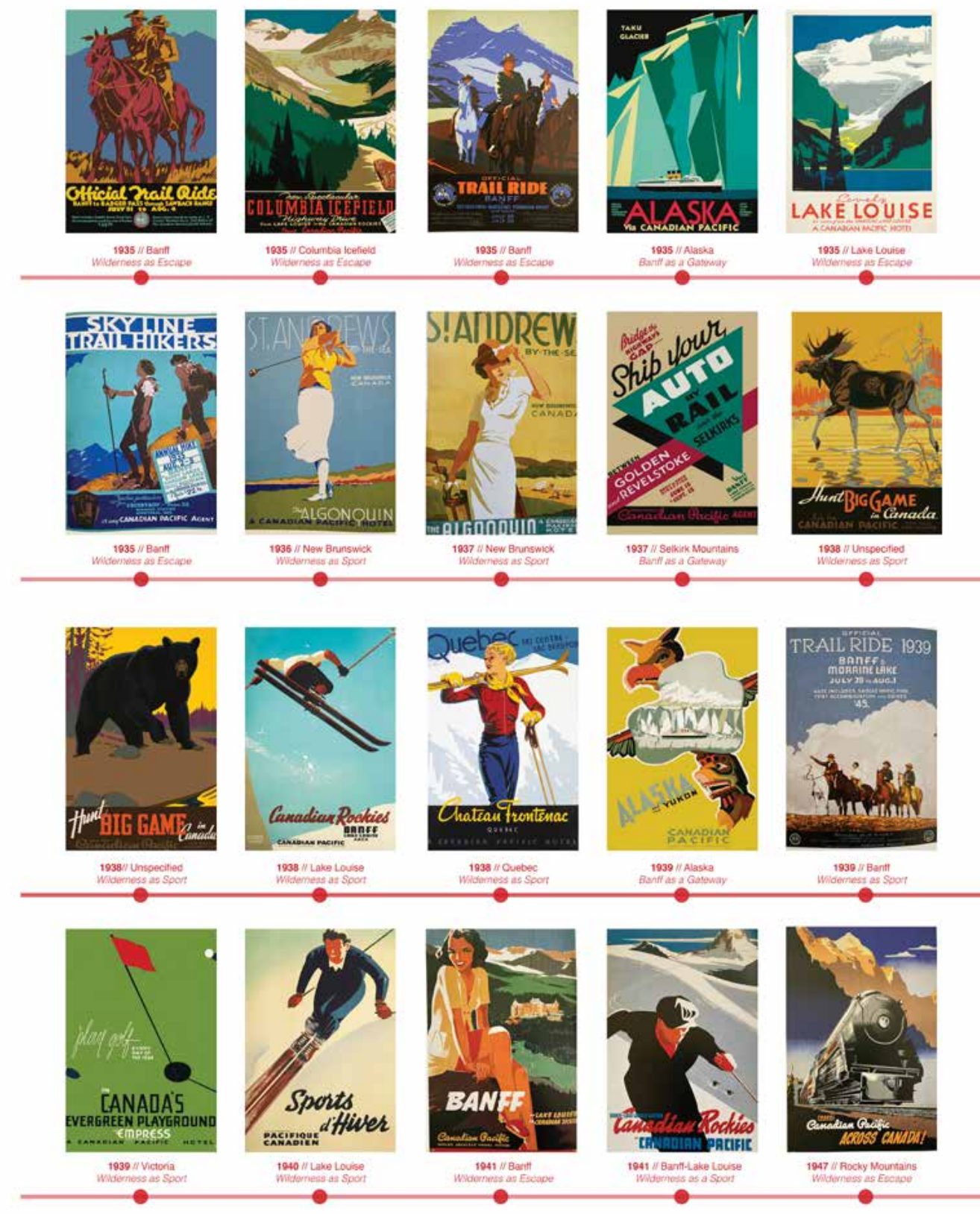

Fig.1.3.5. CPR Poster Timeline \& Catalogue 


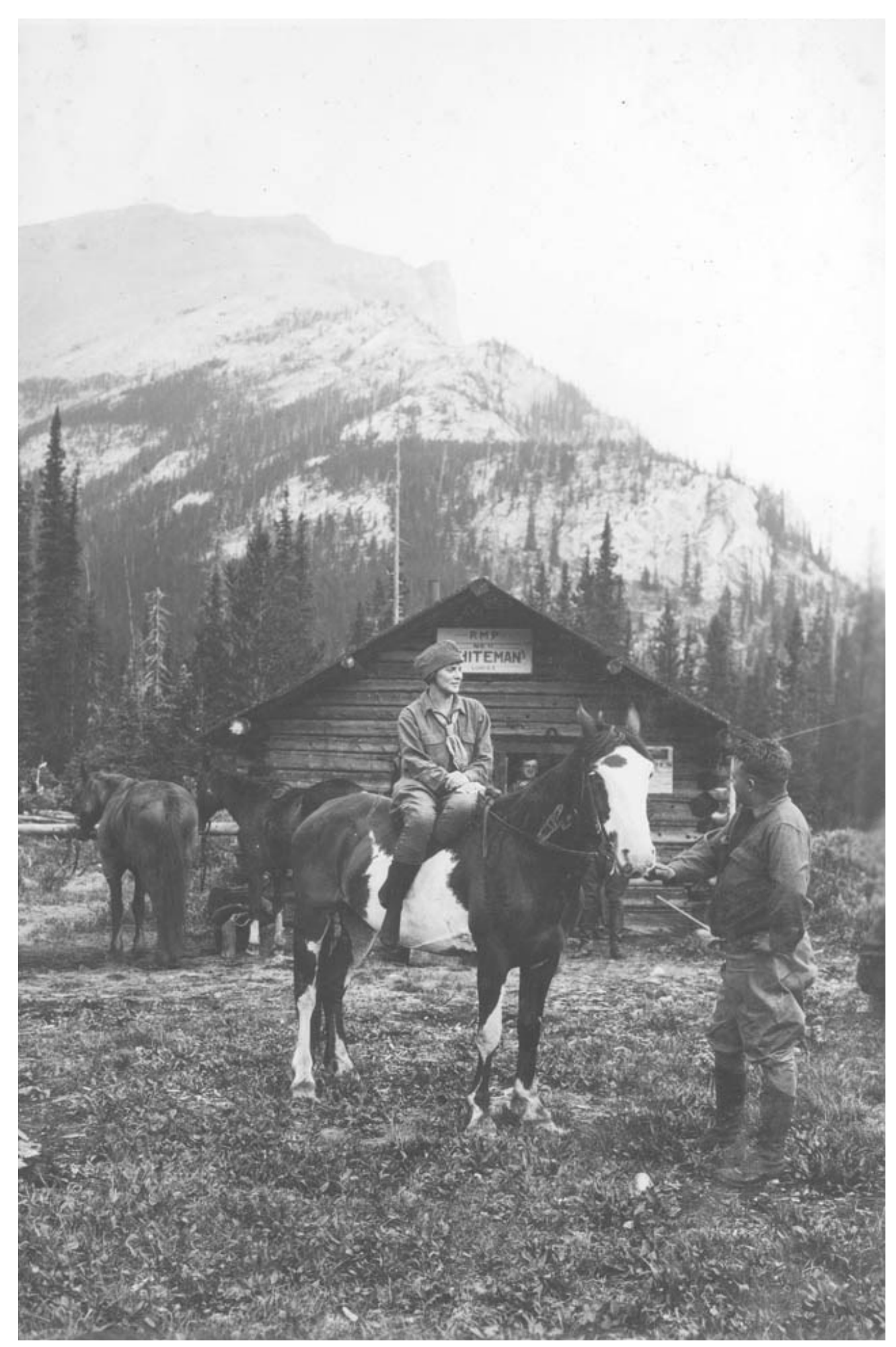

Fig.1.3.6. Trail Riding, Whyte Archive

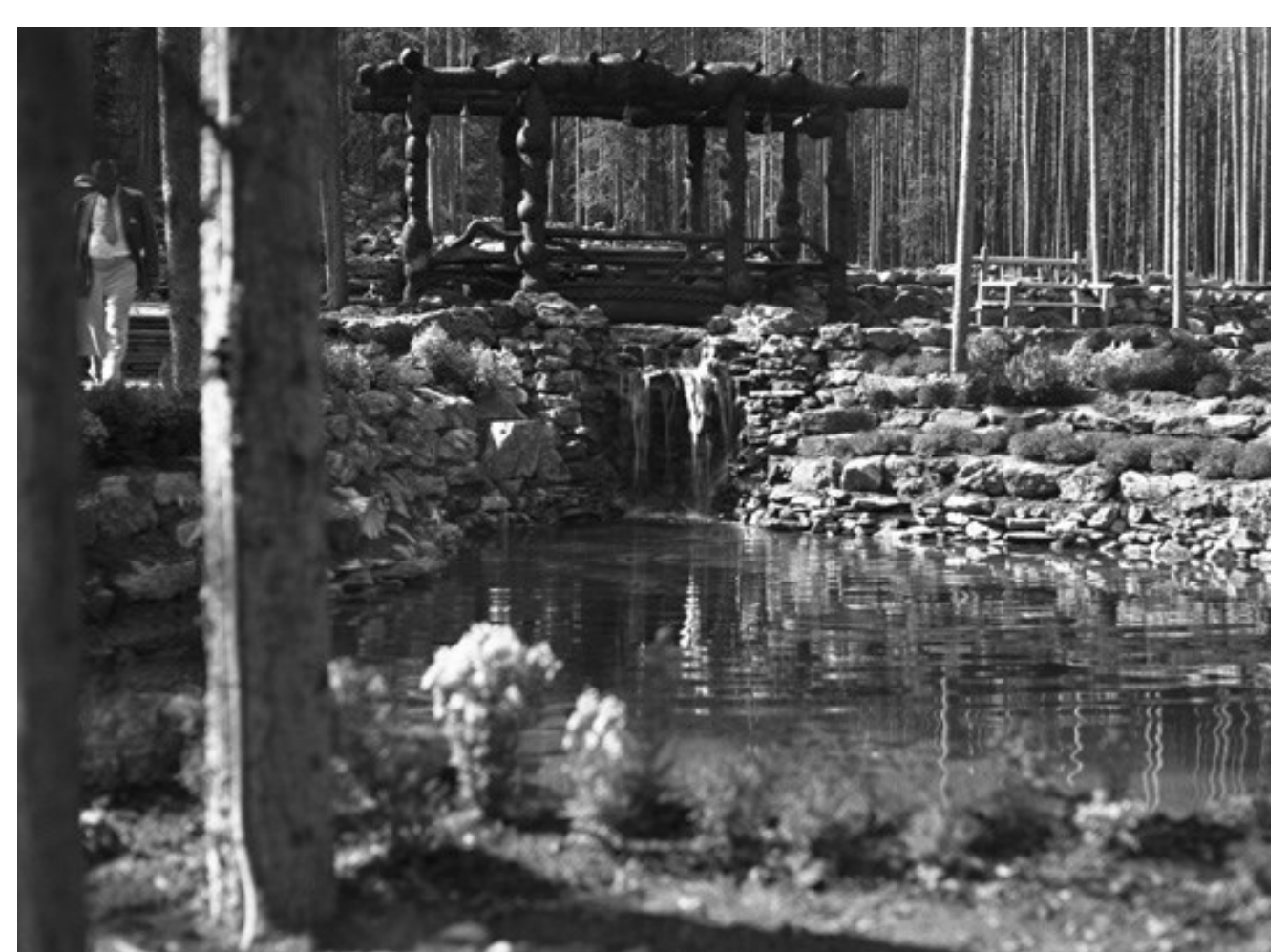

Fig.1.3.7. Banff Springs Hotel Grounds

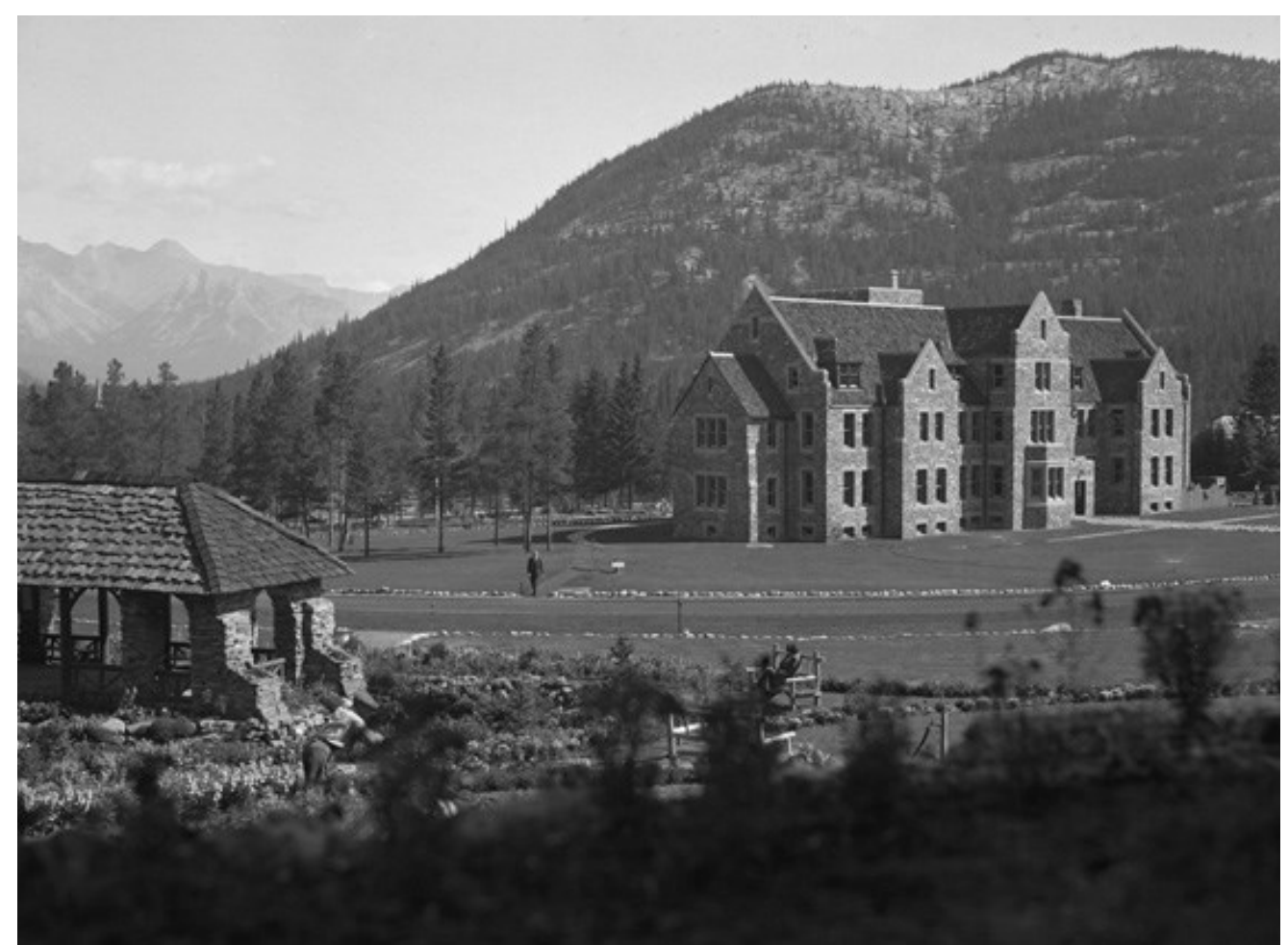

Fig.1.3.8. Banff Springs Hotel Grounds 

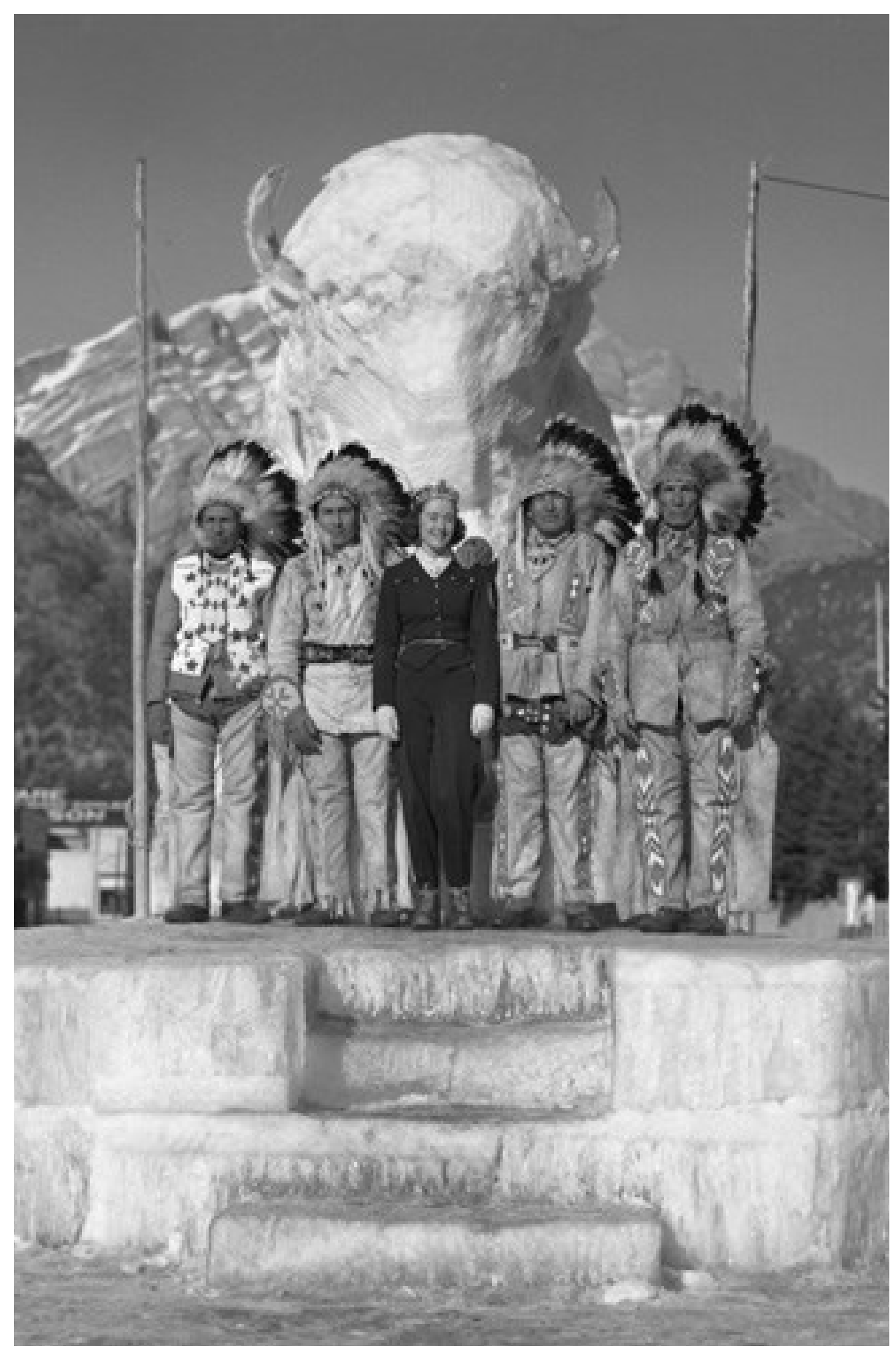

Fig.1.4.1. Banff Winter Carnival, Whyte Archive

\section{4 // SELECTIVE SPACES}

\begin{abstract}
Once set aside within the fixed and carefully policed boundaries of the modern bureaucratic state, the wilderness lost its savage image and became safe: a place more of reverie than of revulsion or fear. Meamwbile, its original inhabitants were kept out by dint of force, their earlier uses of the land redefined as
\end{abstract} inappropriate or even illegal.26

\section{William Cronon}

Much of the history of Banff National Park revolves around varying agendas, ambitions, and claims over the site being exacted under a guise of conservation. The notion of conservationism itself, however, was a term that had yet to reach a unanimous definition in the early $20^{\text {th }}$ century, which posed numerous challenges when it was applied to the territory of Banff National Park. Within the Canadian Government, the varying approaches to conservation in Banff began to cause rifts between departments and political parties, and while some argued for complete preservation of the site from industrial development, conservation for others meant a sustainable extraction of the site's valuable resources, maximizing the potential profits of the park through an incremental level of industry. For some branches 
of the Canadian government, conservation meant managing forests for continual harvesting, regulating watersheds for irrigation and agriculture, and maintaining animal populations to ensure a continued hunting and game industry.

These disagreements would rage on over the earliest decades of Banff National Park and into 1920s and 30s. Similar to the economic influences of the CPR and its industries, conservation of the site was less of a means to set aside the area of the park, as much as it was to direct the policies and future uses of the territory. Though the protection of the landscape might have been a way to reconcile or escape these ambitions, governmental conservationist movements where inherently tied to economic interests, as described by Stoney historian Chief John Snow,

Therefore, with the growth of the conservation movement, my people might have felt that at last we were getting our message across. Surely this movement would help preserve what little we had left that was natural and beautiful. Perhaps it was not too late! But the conservationist movement and the hopes of its non-Indian supporters were very differen from what my people had envisioned. Although legislation was passed to preserve certain areas for conservationist purposes, other government departments continued their mass destruction of the beautiful forests, the open prairies, and the mountainous areas of this continent. And prairies, and the mountainous areas of this continent. And
the movement itself was to prevent it from going to our ceremonial and scared places, which all ended up in a park or another restricted area. It was later to spoil the sacred mountains by creating attractions for the collection of tourist dollars. The problem was that the conservationis movement emerged from a money-oriented society which never learned our ways, our values, our traditions. The sacred waters, the hot springs that we used for healing and cleansing, were to become tourist resorts; our sacred mountains were to become ski areas and parks where we no longer have the right to pursue our religious practice. ${ }^{2}$

The industry of "selling scenery" had now established a vision of the what the space of Banff National Park should be, and an image of untouched or pristine landscape became central to the visitor experience of the park. This narrative of the wilderness that the park would come to represent, as well as the economic incentives tied to the tourism industry that commodified it, meant continuous restrictions placed upon indigenous people, and their significant relationships to the land.

As the CPR continued to define the site as a world-renowned travel destination, the curated approach to the representation and creation of Park space meant a deliberate exclusion of anything that might conflict with this experience. One of the most significant and complex of these histories has been the removal of indigenous communities and cultures from Park space and history. Canadian 


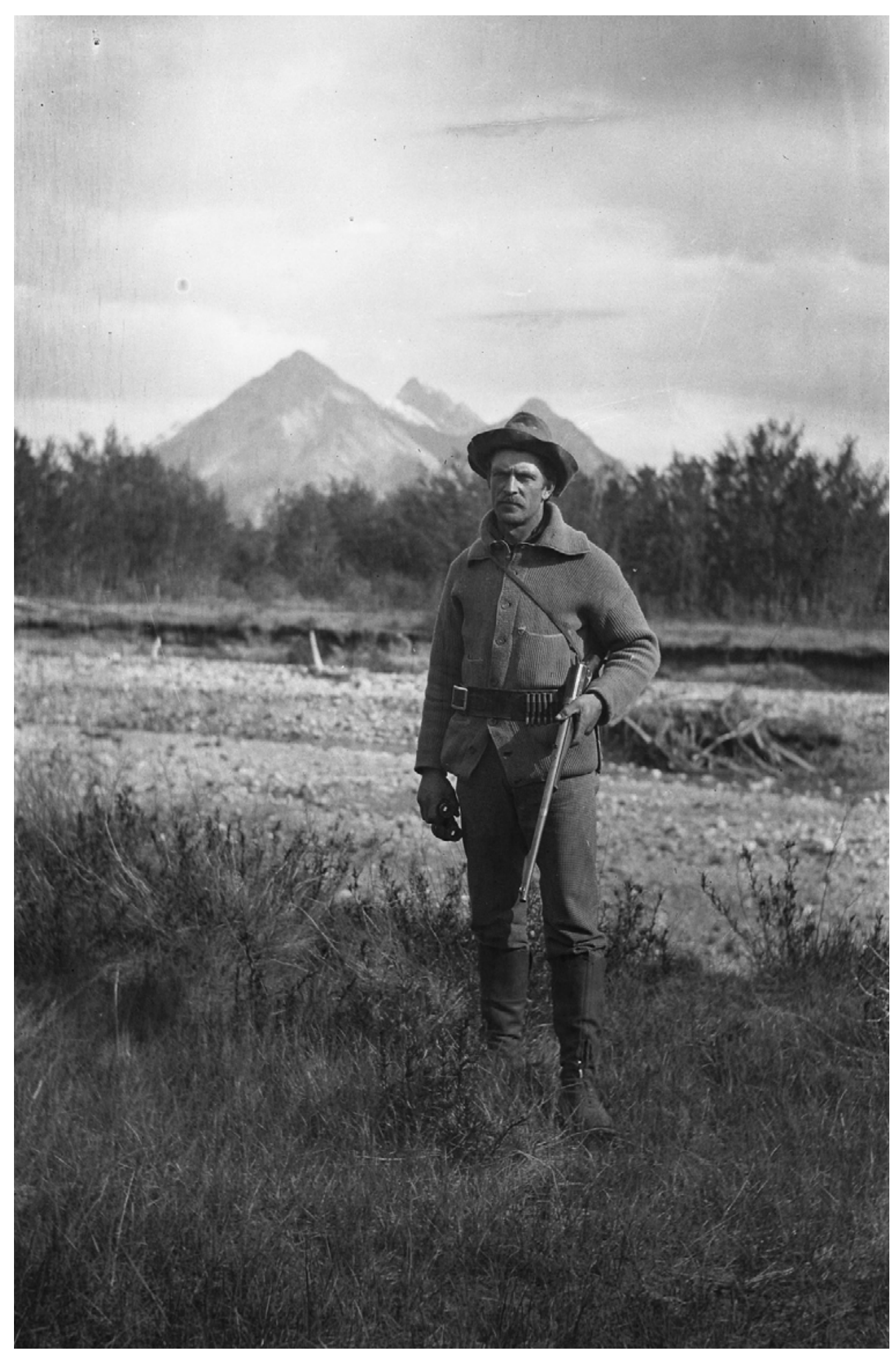

Fig.1.4.2. Banff Big Game Hunters, Whyte Archive celebrations of wilderness and the pretense of conserving wild spaces were frequently employed as a guise and justification for supressing indigenous histories and cultures, and asserting control and dominion over landscapes and their narratives. As stated by Cronon,

The myth of the wilderness as "virgin," uninhabited land had always been especially cruel when seen from the perspective of the Indians who had once called that land home. Now they were forced to move elsewhere, with the result that tourists could safely enjoy the illusion that they were seeing their nation in its pristine, original state, in the new morning of God's own creation. ${ }^{28}$

In the case of Banff National Park—as with many other parks across Canada - the expulsion of indigenous communities from park space occurred through a series of legal restrictions used to control the site. These policies forced changes to traditional ways of life for indigenous people, with the goal of assimilating aboriginal society and culture. Hunting restrictions were one of the primary means through which this agenda was implemented within Banff National Park and its surrounding areas. The central argument for these restrictions was a justification of "Game Conservation", where the hunting methods of the indigenous communities on the site were deemed unsustainable and a direct threat to the future of the space. The laws were deliberately constructed around the mischaracterization that indigenous hunting 
practices were an immediate threat to the future of the wildlife within the park. As described at the time by the Banff Newspaper, The Crag and Canyon,

It is only a blind to allow them free passage to and fro, with all the attributing country between the Reserve and these supposed grazing grounds. Good-by [sic] to the game. In two years there would not be a hoof left... at one stroke of the pen, a very lat . going to be thrown open to a race of people, who do no consider tomorrow. Hundreds of square miles of the fines breeding ground of wild game would be desolated with the slaughter of the Indian, and all the game guardians in Alberta could not prevent it, if the Indians are allowed free access to the trails of the eastern and norther boundaries, inside and out of the Rocky Mountain Park. ${ }^{29}$

Despite the inaccuracy of these claims, the campaign to declare these hunting practices as a threat to the future of Banff National Park was successful in swaying public opinion. The hunting practices and traditions of the indigenous communities of the site, such as the Stoney Nakoda, were declared reckless and would be restricted and legislated by the Canadian government, both inside the park boundary and in the territory directly east of the park.

The history of these restrictions was a direct result of seeking to control the territory, monitoring carefully who might use the park space. However, this also coincided with movements of mass cultural assimilation of indigenous communities across Canada throughout the $20^{\text {th }}$ century across Canada. The goal of these restrictions was often to move indigenous communities away from traditional hunting practices and towards European agrarian social structures. Hunting often entailed more nomadic lifestyles across large swaths of land, which misaligned with the ideals of control pervasive both in the park preservation and movements of assimilating indigenous cultures and communities.

In the early $19^{\text {th }}$ century, the federal branch of the Department of Indian Affairs was continuously frustrated by aboriginal subsistence hunting and aimed to force indigenous communities towards a more sedentary and agrarian lifestyle. Dissuading these communities from hunting and more traditional ways of life was essential to the overarching ambitions of assimilating indigenous culture within Canada. The conservationist arguments of protecting wildlife populations through these restrictions acted as a convenient means to enforce these broader goals and ambitions of the Canadian government while ensuring the profitability of emerging game and tourism industries. Far from a discreet ulterior motive, the aspirations of assimilating aboriginal culture through these restrictions were declared outright by 


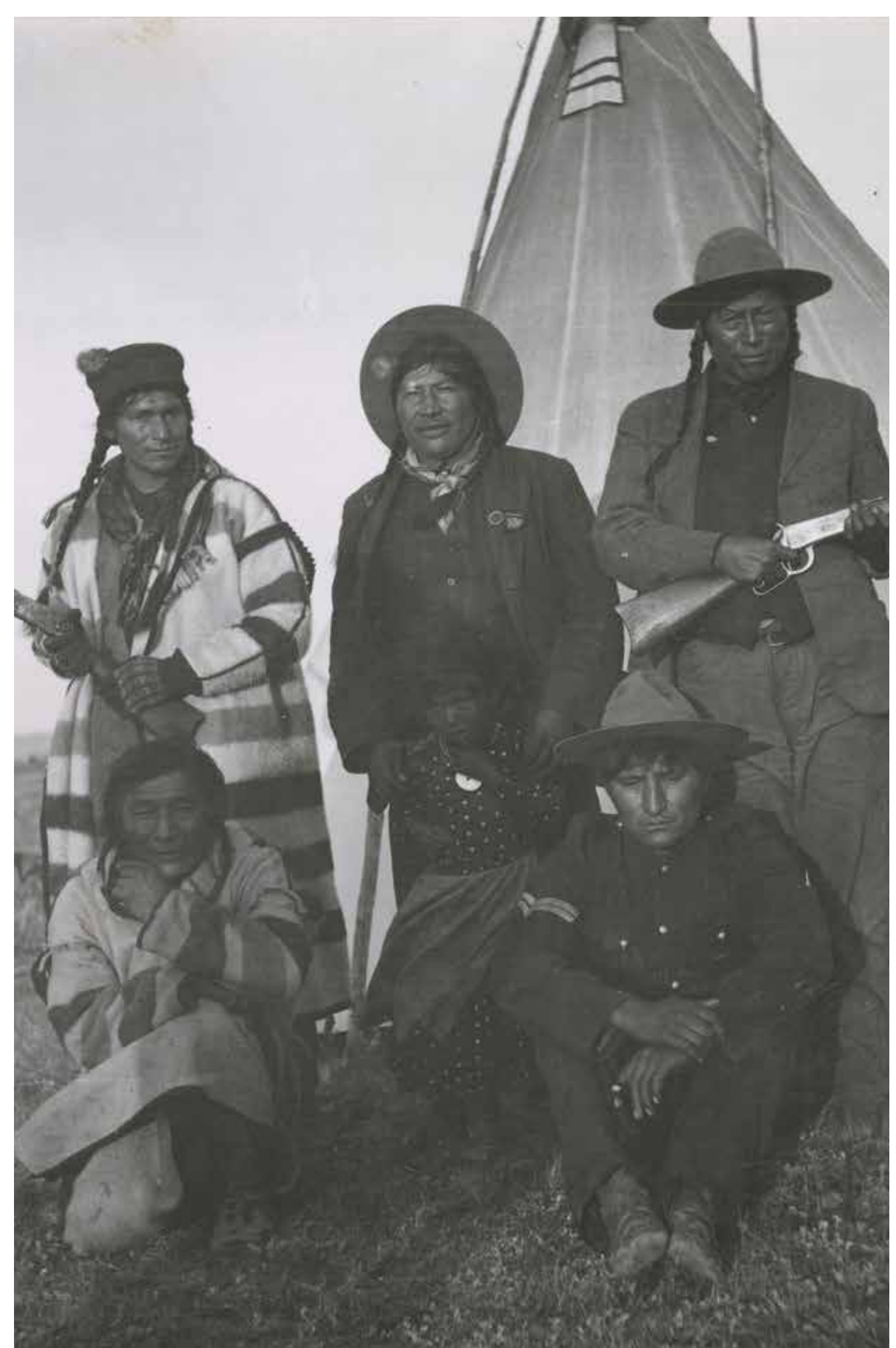

Fig.1.4.3. Stoney Nakoda Hunters, Whyte Archive governmental agents who advocated for restrictions to be enacted at Banff. As described by Chief John Snow,

Our ideas of wilderness and nature are socially constructed, and so we should reflect on how humans have attempted to modify the physical reality to conform to our notions of what willerness and nature ought to ant to national parks and forest reserves before the 1920s, however, aboriginal people were not removed to create uninhabited landscapes, but in the service of efforts to create landscapes abundant in wild game (primarily for sportsmen and tourists), as well as a broader goal of civilizing and assimilating aboriginal societies. ${ }^{30}$

Conservationism was the means to control space and assert power over the landscape, enabling the Canadian federal government and private companies such as the CPR to transform the site as they saw fit. The economic incentives that often steered these policies and restrictions, as well as the repercussions that these transformation had on the territory, can be traced and tracked through the evolution of the park boundary. The history of the boundary represents the tangible consequences of these broader political ambitions and economic drivers. Through mapping these evolutions, the pressure and incentives that have so often steered the development of the territory might be revealed, as new adjacencies, hierarchies and 


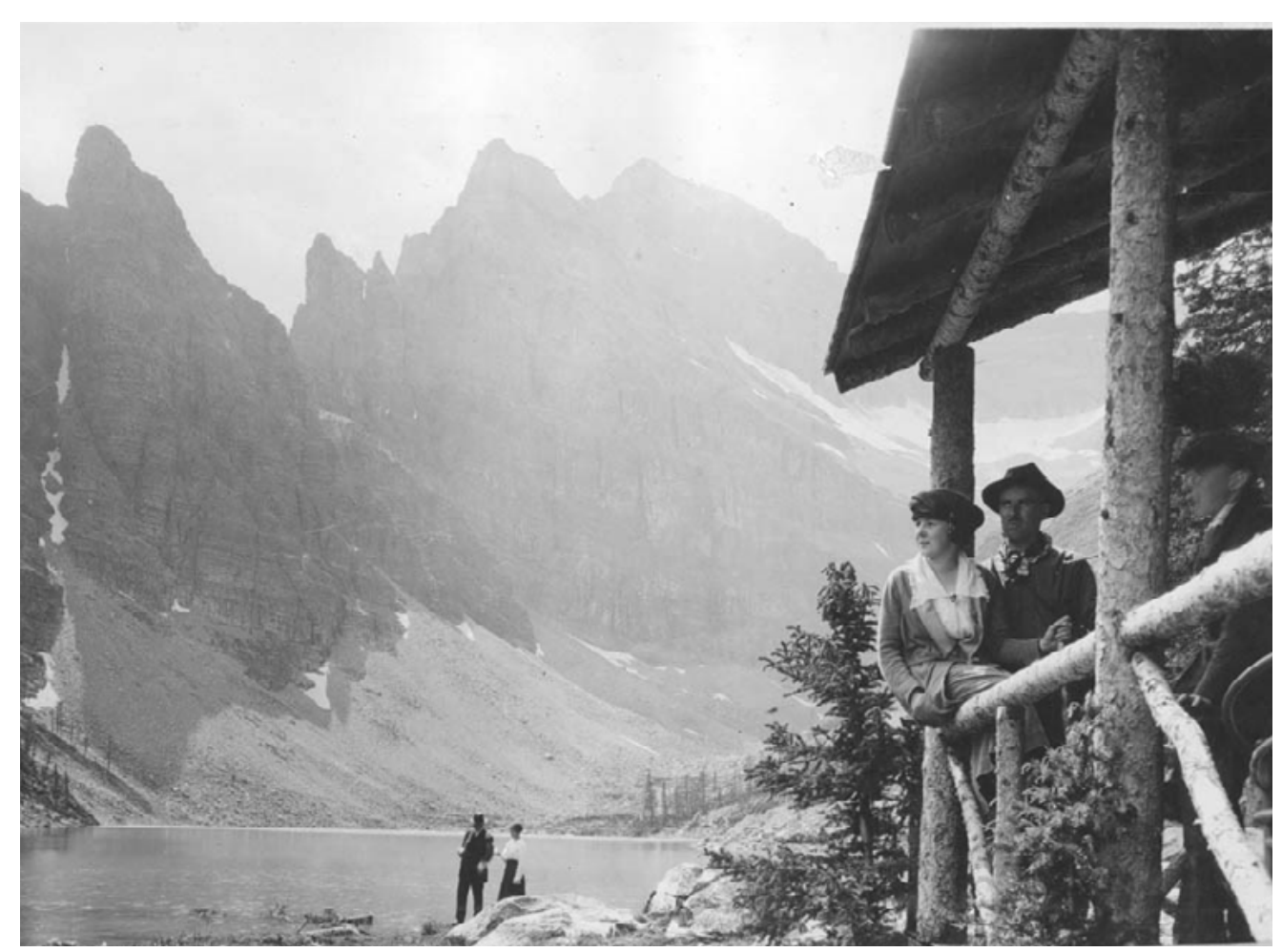

Fig. 1.4.4. Lake Agnes Teahouse, Whyte Archive

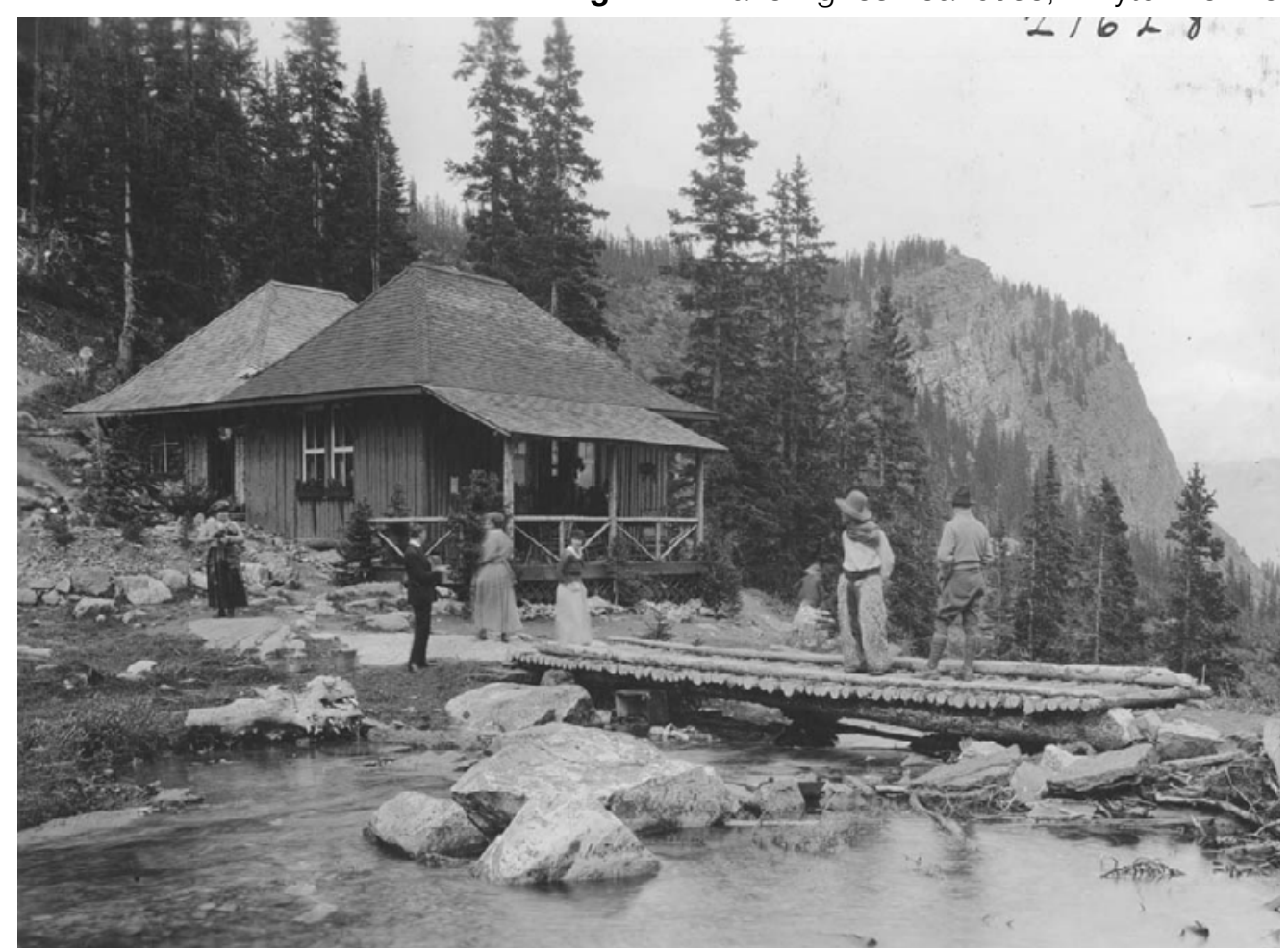

Fig.1.4.5. Lake Agnes Teahouse, Whyte Archive

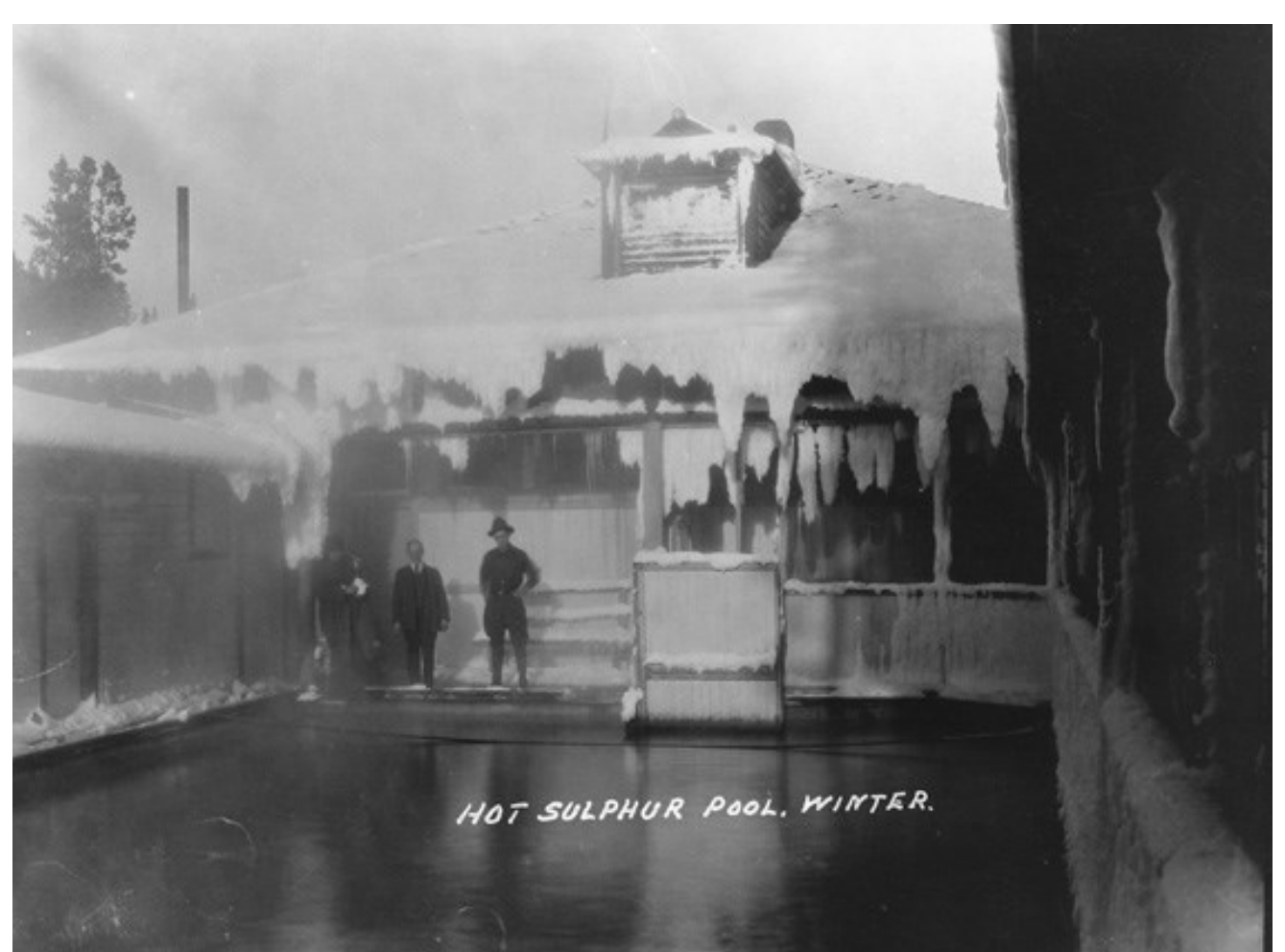

Fig.1.4.6. Banff Hot Springs Facilities, Cave \& Basin, Whyte Archive

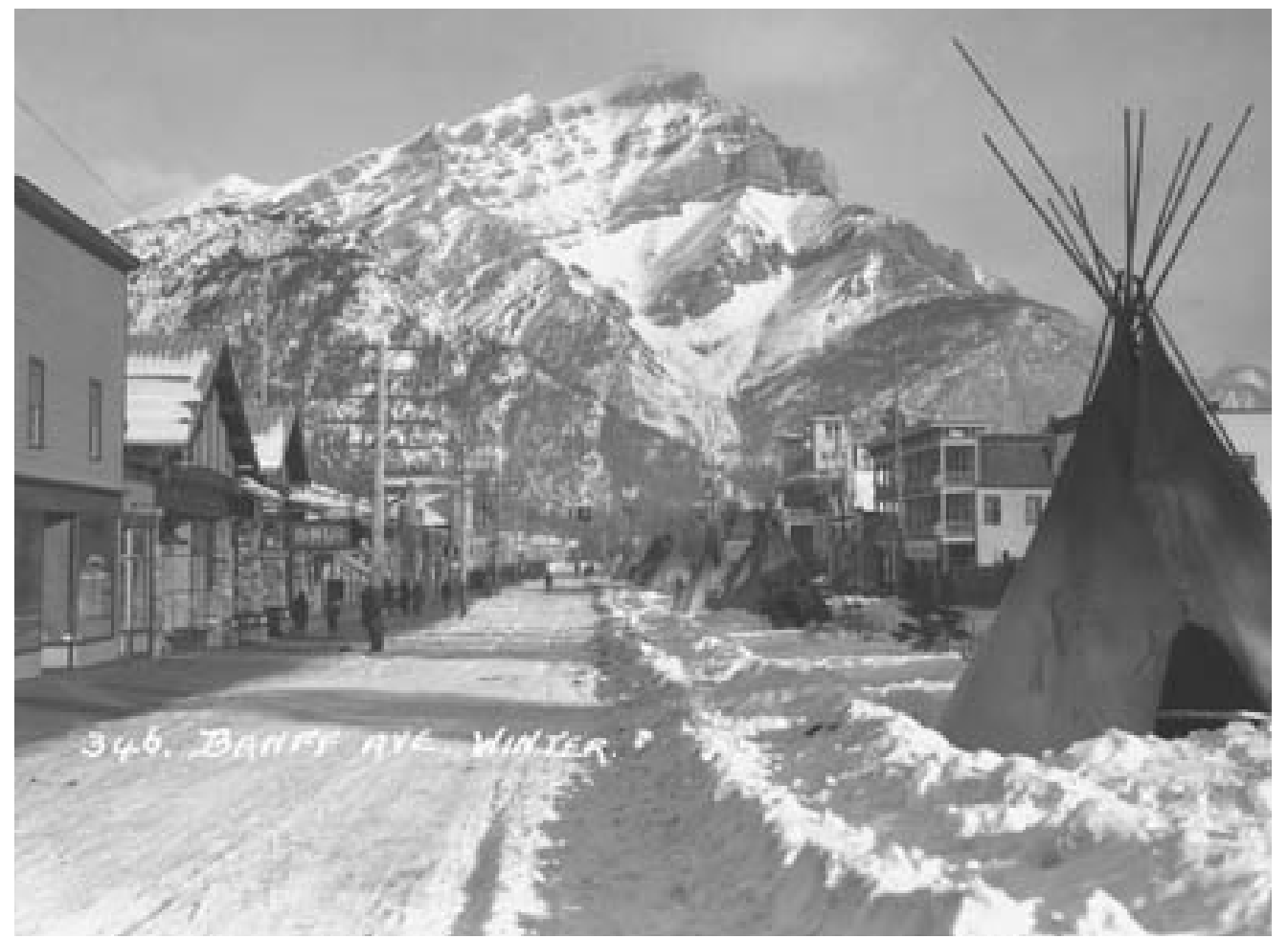

Fig.1 1.4.7. Banff Winter Carnival, Whyte Archive 


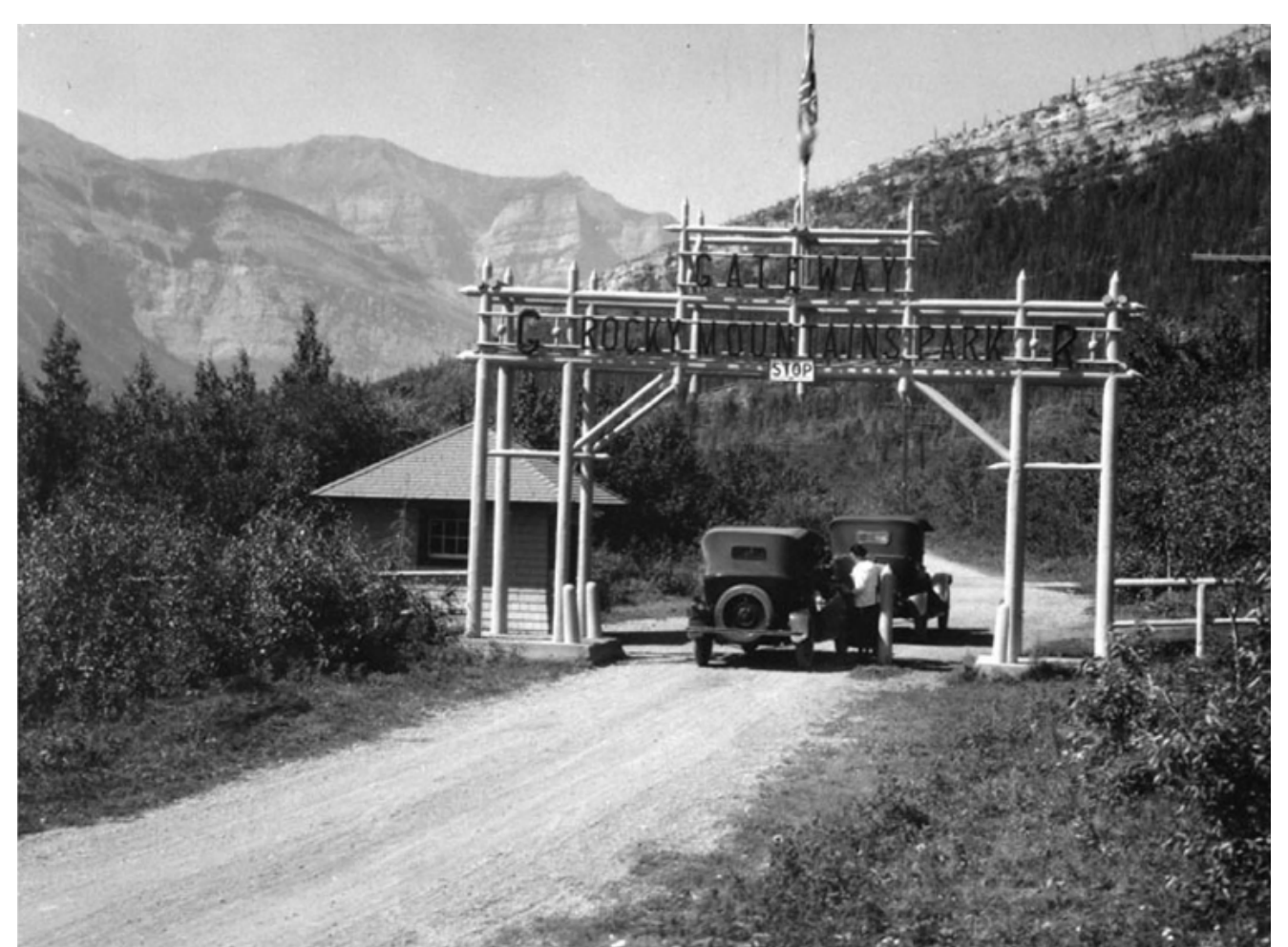

Fig.1.4.8. Rocky Mountains Park, Eastern Gate, Whyte Archive

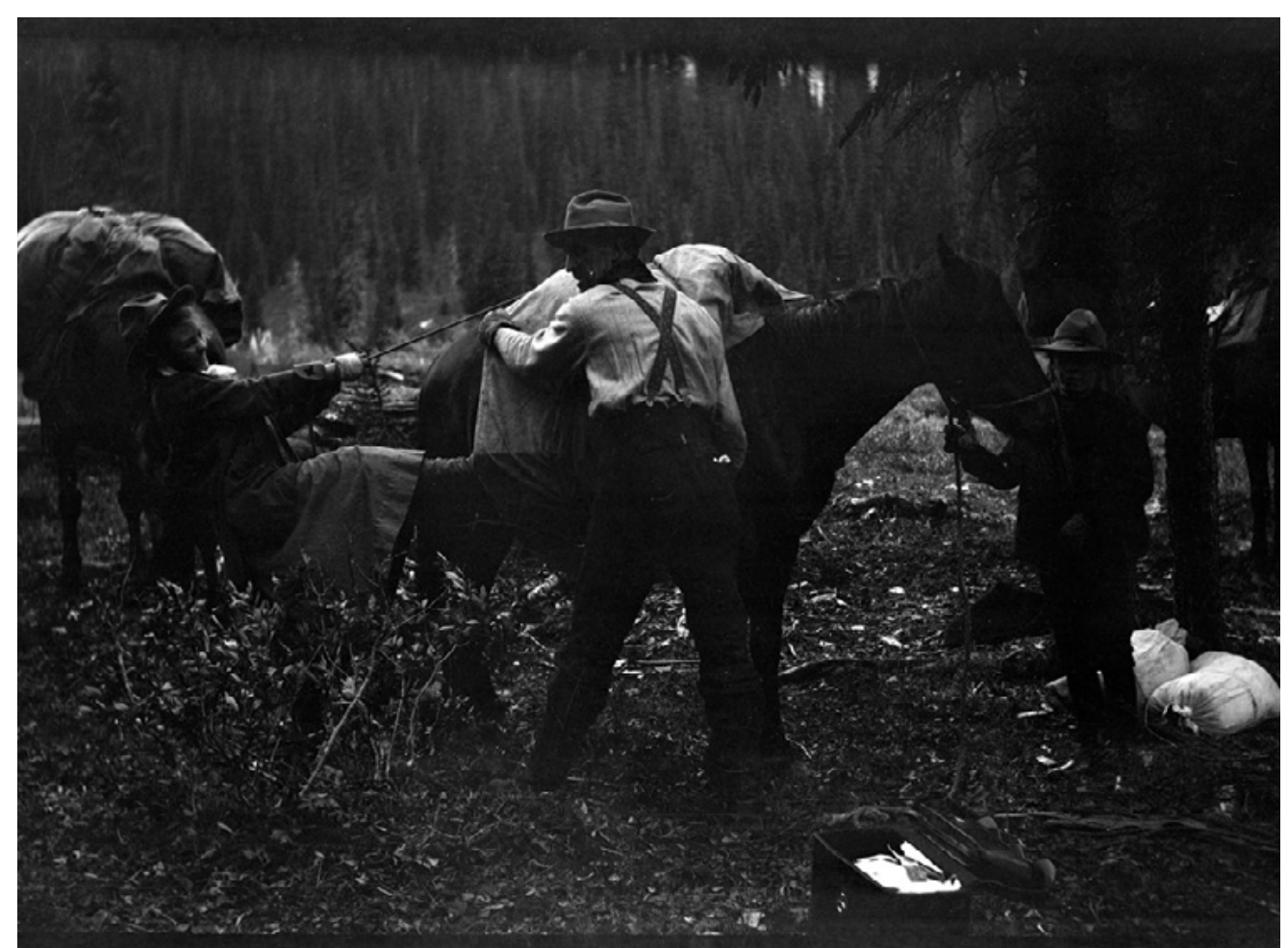

Fig.1.4.9. Banff Trail Riders, Whyte Archive
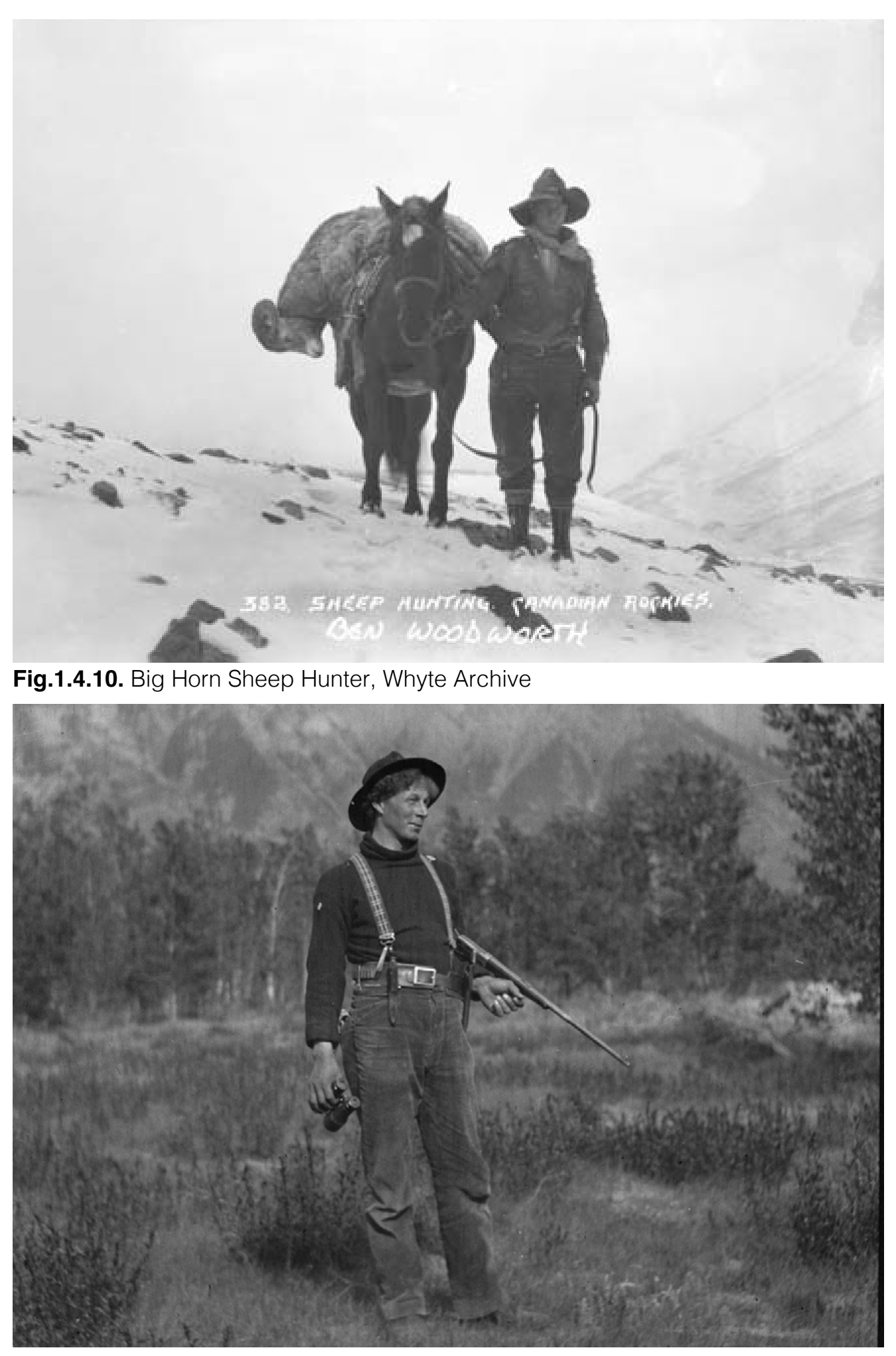

Fig.1.4.11. Banff Big Game Hunter, Whyte Archive 
Henry David Thoreau, Walking (San Francisco: Sierra Club, 1962) 186. William Cronon, "The Trouble with Wilderness; Or, Getting Back to the Wrong Nature," Environmental History, Volume 1, Issue 1 (Jan., 1996): 12.

Canadian Pacific Ralway Company, The Canadian Pacific: The New Highway to the East, Henry David Thoreau. Walden New York: Penguin Books, 2016) 85.

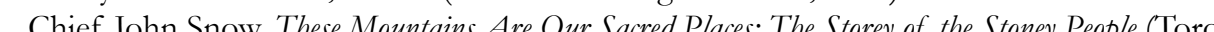
Fifth House, 2005), 25. (? - double check page)

CPR Connecting Canada, "Building the Railway," Timeline. https://cpconnectingcanada.ca/ CPR Connecting Canada, "Tourism \& Recreation," Timeline.

https://cpconnectingcanada.ca/

8 Theodore Binnema, and Melanie Niemi. "Let The Line Be Drawn Now: Wilderness, Conservation and the Exclusion of Aboriginal People from Banff National Park in Canada, Environmental History 11, No. 4 (Oct.,2006): 725.

Binnema, Theodore, and Niemi, "Let The Line Be Drawn Now," 725.

10 Ibid, 725.

11 Ibid, 729

3 Theodore Binnema, and Melanie Niemi, "Let The Line Be Drawn Now: Wilderness, Conservation and the Exclusion of Aboriginal People from Banff National Park in Canada Environmental History 11, No. 4 (Oct.,2006):

14 Theodore Binnema, and Melanie Niemi, "Let The Line Be Drawn Now," 729. William Cronon, "The Trouble with Wilderness; Or, Getting Back to the Wrong Nature," Environmental History, Volume 1, Issue 1 (Jan., 1996): 75. Willian Cronon, "The Trouble with Widerness,",

Ibid, 73 ,

Binnema and Niemi, "Let the Line be Drawn Now (maybe)

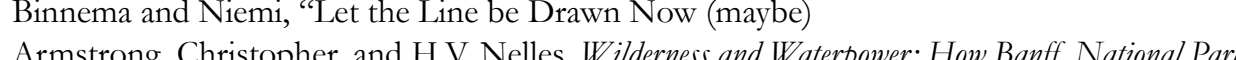
Became a Hydroelectric Storage Reservoir (Calgary: University of Calgary Press, 2013), 96. CPR Connecting Canada, "Building the Railway," Timeline.

https://cpconnectingcanadaca/

Marc H. Choko, and David L. Jones, Posters of the Canadian Pacific, (Buffalo: Firefly, 2004), 13.

Leslie Bella. Parks for Profit (Montreal: Harvest House, 1987) 16

Catherine Mastin, The Group of Seven in Western Canada (Toronto: Prospero Books, 2002), 26. William Cronon, The Trouble with Wilderness, 15.

Chief John Snow, These Mountains Are Our Sacred Places, 106.

William Cronon, The Trouble with Wilderness, 15.

Chief John Snow, These Mountains Are Our Sacred Places, 108. Ibid, 75 . 


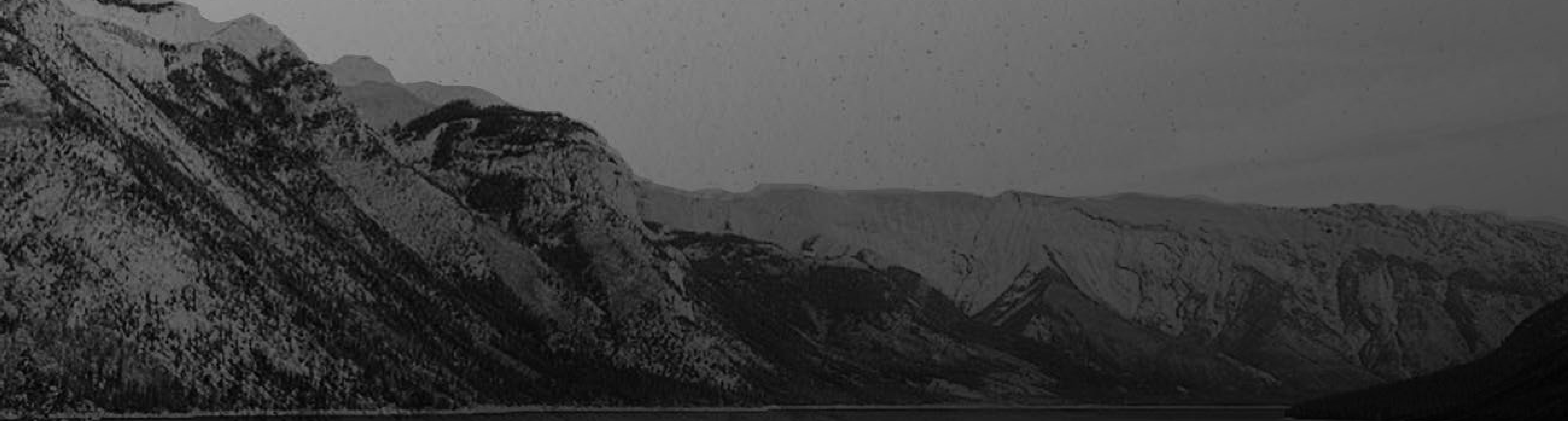

Irony resides, too, in the often-noted ambivalence that Canadians have always exhibited toward the landscapes that surround them. There is so much "nature" in Canada - so vast, so lovely, so challenging, and yet so foreboding - that to tame its resources for

\section{Part II // A NEW ATLAS}

their economic rents remains a national obsession. Canadians have expended huge amounts of energy assaulting and destroying the ecosystems in which they live, while at the same time busily celebrating the beauty and importance of unspoiled nature in shaping the national character. But this story raises the question of whether thi. kind of development is an either-or proposition. ${ }^{1}$

- Wilderness \& Waterpower 


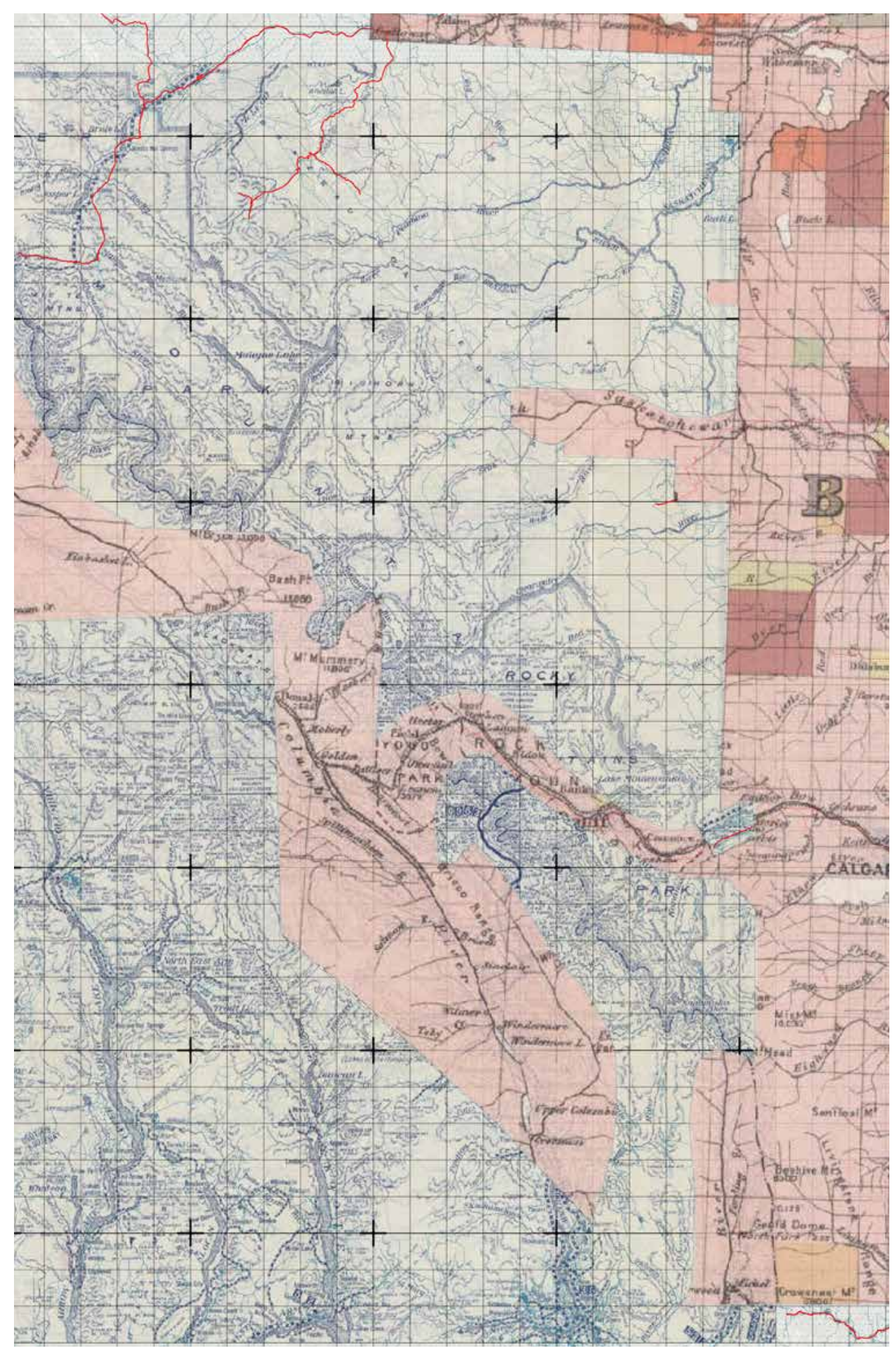

Fig.2.1.2. Historical Map Overlay
05 // MAPPING AS METHOD

To plot is to track, to trace, to set in-relation, to find and to found. In this sense, plotting produces a 're-territorialisation' of sites. ${ }^{2}$

- James Corner

Wilderness may be an abstract or idealized version of space, but its pursuit and commodification within Canadian culture has had direct and tangible consequences. The following section of this thesis uses mapping to explore these consequences, documenting how the landscape and boundaries of the site have been defined over and over by human, industrial, political and national ambitions and interests. It explores the consequences of creating a cohesive zone of selective narratives, the dichotomies of human and non-human worlds created by this constructed and manicured versions of space, and the barriers that have been crafted in an attempt to define these physical, cultural and historical landscapes. At its core, the New Atlas of Banff is an examination of how space, at the scale of the park, might be 
manipulated, constructed, crafted, legislated, and restricted.

The selective approach to developing townsites and human industry within the park boundary often gives the mischaracterization that it is a space that has avoided the influences of political pressures or economic interests. However, as with any landscape that contains desirable resources, numerous claims have been made on the territory and its landscape has been the site of endless vying for control and power. As explained in part one, Banffs boundary reflects the political agenda of Canada as a greater whole. Mapping as a method is uniquely suited to reveal these struggles, the spatial conditions and definitions that the conflicts of political and economic power have created, and their motivations. The objective of the New Atlas of Banff is to reveal these relationships between cultural narratives, spatial definitions, industrial landscapes and mechanisms of control. Most importantly, it reveals what is often purposefully overlooked or omitted from the space, such as the economic drivers and persistent commodification's of the territory's resources. Rather than an atlas in the traditional sense, which often contrast many locations through a consistent method of representation, this atlas focuses on documenting the same site through time and the physical consequences of larger cultural contexts. The atlas looks at the past, present, and a speculative future, reflecting on Banff's boundary as an invisible litmus test of the position around wilderness in Canada. This drawing series will explore the histories of Banff National Park, historical perceptions of Wild spaces, and how these impacts echo throughout Canadian culture.

The explorations focus primarily on the eastern boundary. While the western park boundary has been primarily informed by the continental divide, the eastern boundary of Banff National Park has been subject to a variety of influences and undergone several evolutions. It is the area of the zone that has been subjected to the greatest variety of economic and political pressures and sits at the center of several important contexts directly east of the park, such as its proximity to the urban center of Calgary, the Stoney Nakoda First Nations Reserve, and the prairie farmlands located within its watershed. The complexity of the landscape east of the park has meant that this boundary has been the most prone to economic and political influence. The boundary is an essential marker of space, and is inseparable from the park itself. The atlas offers a means to trace this boundary, its histories and motivations, and the legal frameworks that were carefully implemented through it to control the space. As stated by James Corner,

In this regard, maps have very little to do with representation as depiction. After all, maps look nothing like their subject, not only because of their vantage point but also 


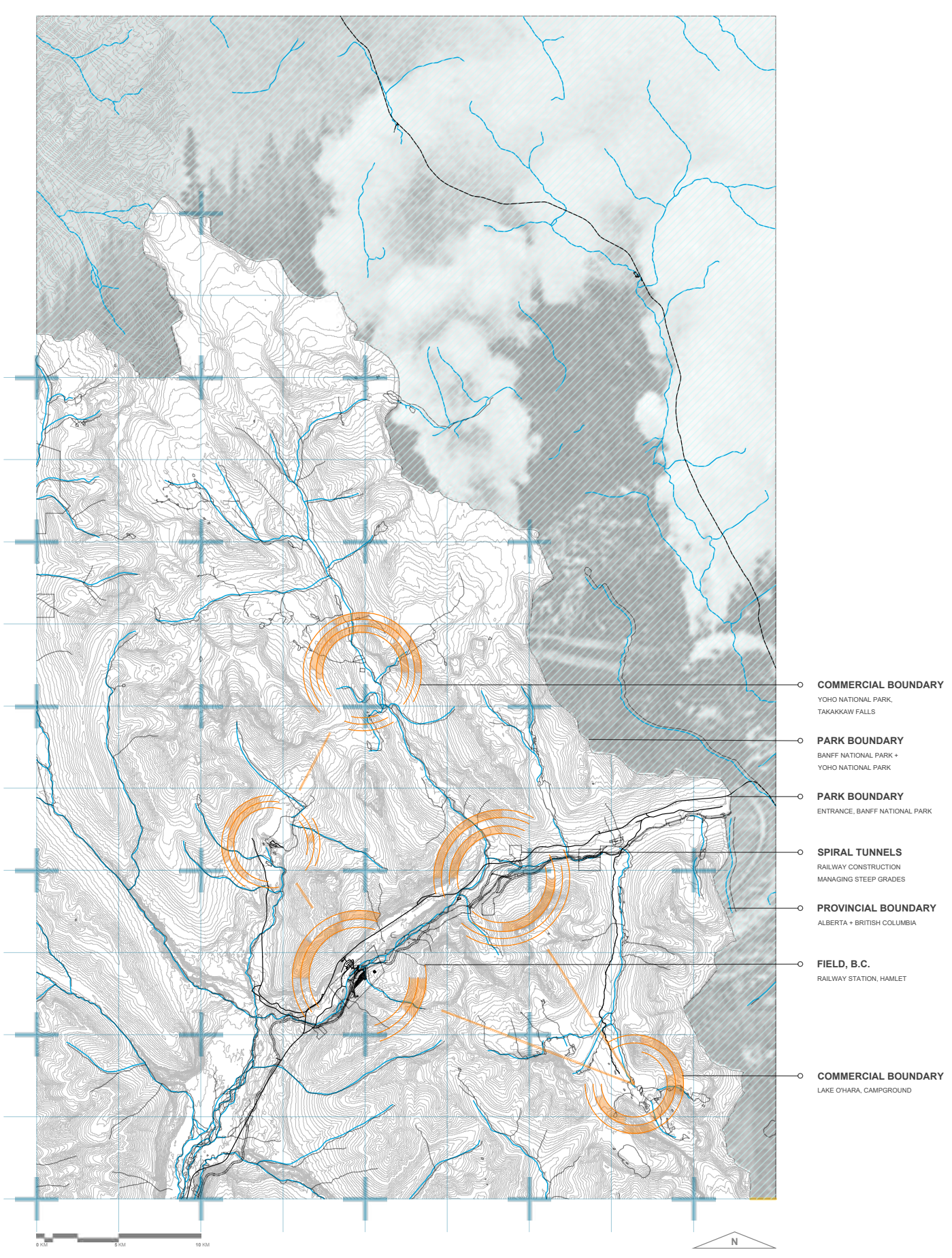

Fig.2.1.3. Map of Boundaries and Industries, Field B.C. because they present all parts at once, with an immediacy unavailable to the grounded individual. But more than this, the function of maps is not to depict but to enable, to precipitate a set of effects in time. Thus, mappings do not represent geographies or ideas; rather they effect their act

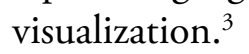

To visit Banff National Park is to experience the territory, but fails to capture the complexity of the landscape that has so often been supressed and purposefully concealed. Mapping the park and its boundaries in its past, present and future, enables an understanding of the economic and political mechanisms that have formed it, the adjacencies and edges that it has necessitated, and the economic resources it is inescapably tied to.

The New Atlas of Banff is an attempt to draw the landscape in all of its complexity, understanding the hidden contexts and networks in which the park exists. The explorations within the atlas range from the geological forces that created the Rocky Mountains millions of years ago, to the mining and petroleum industries that surround the park today, to the projected flooding events of the future. The New Atlas of Banff began out of a necessity to visualize and depict the immensity of these surrounding contexts, seeking to understand the landscape of the park and how it had been controlled. Throughout these explorations it became clear that the park was itself as much a defining force of the 


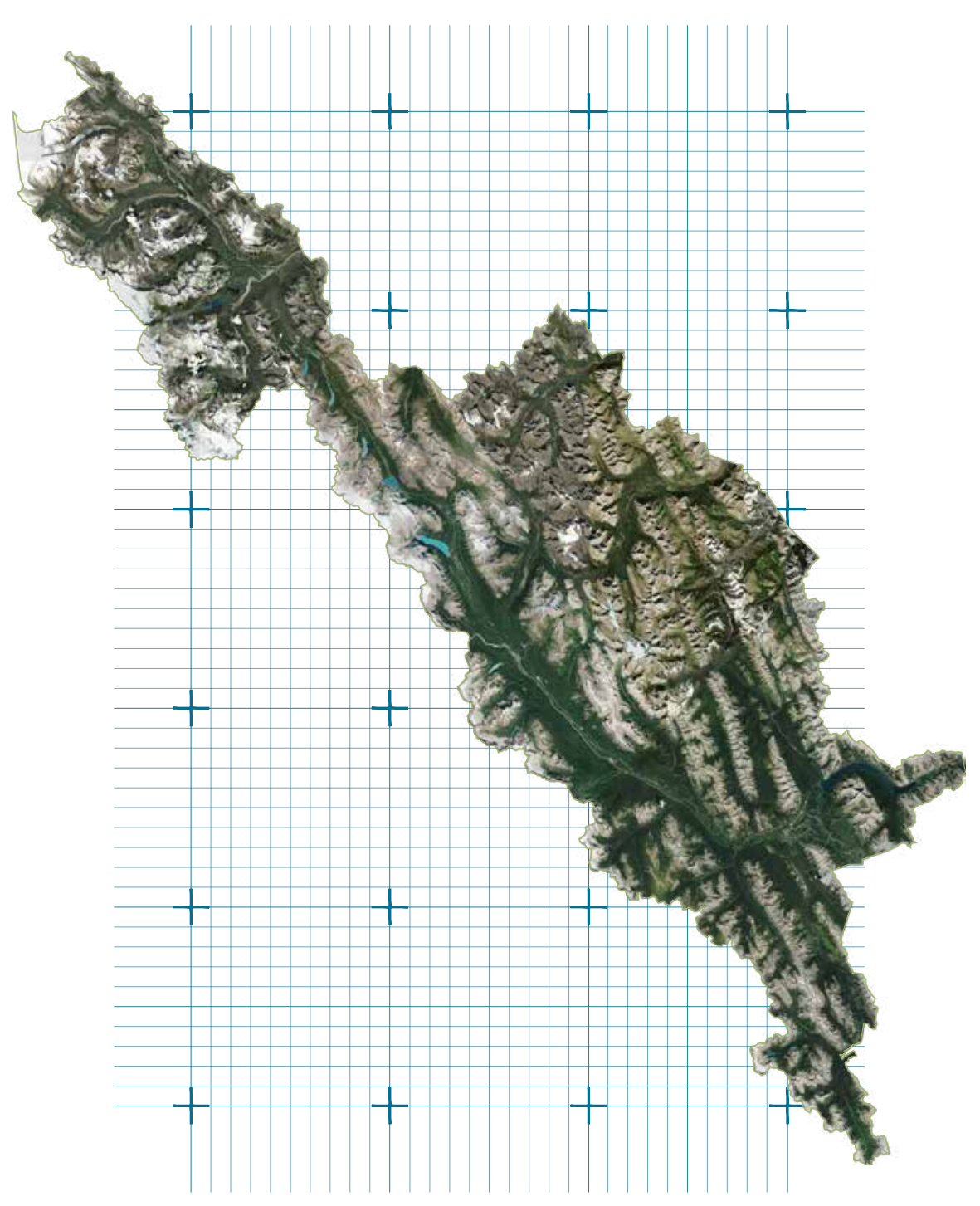

Fig.2.1.4. Banff National Park Satellite Imagery landscape and surrounding contexts as much as it influenced by these factors, a central piece of the political, economic and cultural fabrics that it sat in. The malleable territory of the park and wilderness itself has dictated where dams have been built, valleys flooded, golf courses built, mines and oil wells erected and sacred sites bulldozed. In the early $20^{\text {th }}$ century the advent of new technologies such as hydro-power meant a re-defining of the park territory in order to create a hydro reservoir, or in the 1970s, the collapse of the coal market meant a sudden willingness to sacrifice a previously industrial landscape to the wilderness of the park. The explorations in the atlas are an attempt to depict wilderness for more than the mere romanticized or idealized landscape as which it has been previously understood, but as an invisible mechanism with significant consequences, with an insidious potential to influence entire landscapes through the construction of intangible barriers. 


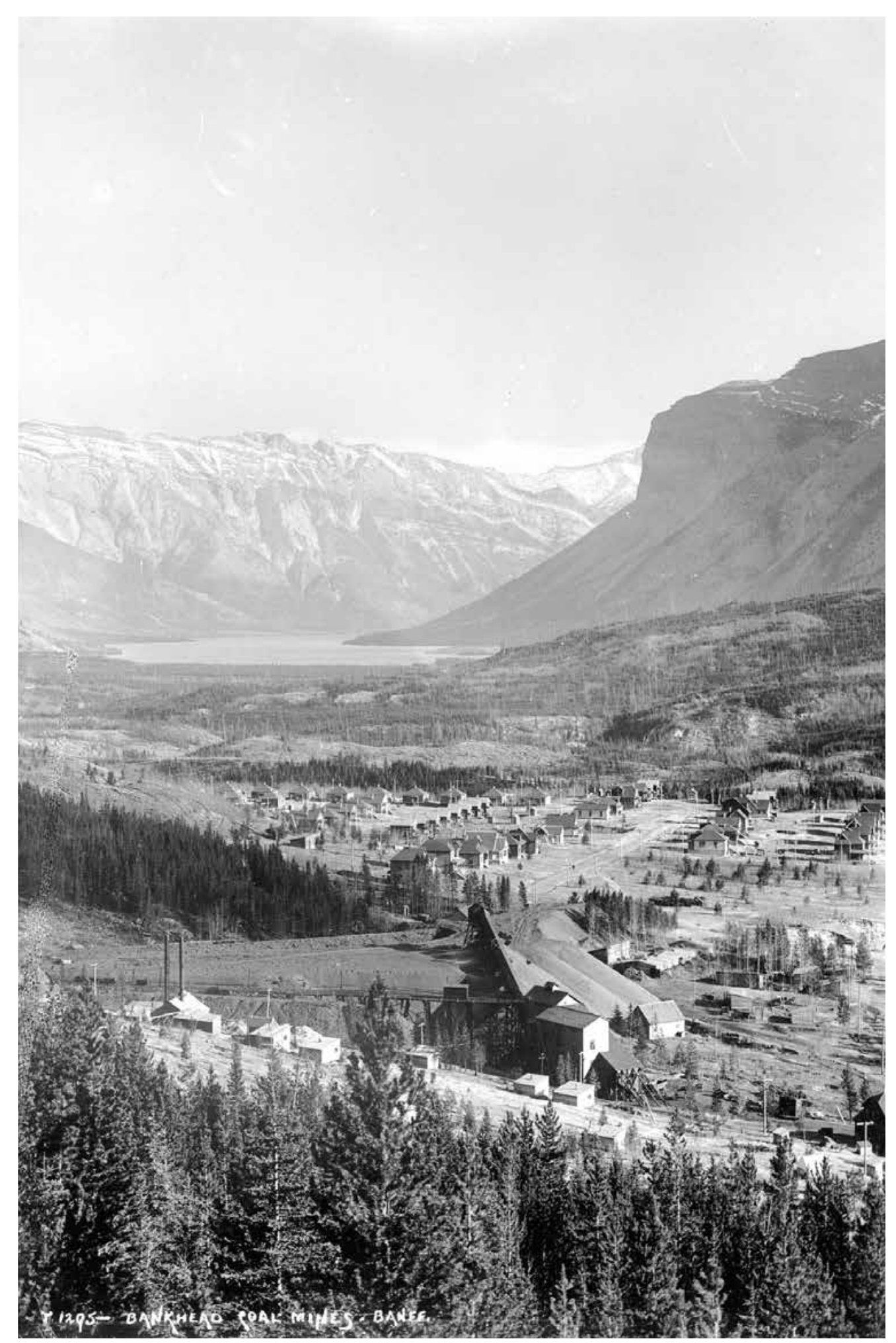

Fig.2.1.5. Mines at Anthracite, Whyte Archive

\section{6 // PAST DEFINTIONS}

\begin{abstract}
It can take time and effort to forget the prejudice induced by a powerful map. ${ }^{4}$
\end{abstract}
- Robert Mcflarane

The first section of this thesis explored the agendas that helped to form Banff National Park and the eventual commodification of its unique brand of wilderness. Through the deconstruction of the image of the park it underscored what the CPR and the Canadian Government sought to create through the establishment of the Park. The following mapping explorations seek to plot these forces and agendas over time, and their evolving influences in the direct shaping of region and its industries. These forces can best be understood through the evolution of the park boundary of Banff National Park, as it has often been the primary tool and method of enforcing this agenda and directing the spatial definitions of the park. In many ways the evolution of this border and edge condition tells the history of the park trying to 
define what it should be, who it should be for, and what it should exclude. It is a meandering history filled with contradictions. These contradictions range from issues such as the hunting restrictions that were placed on indigenous subsistence hunting practices while a new trophy hunting industry was being established within the park, to the rejection of hydro-power developments within the territory while coal mines were still being operated to supply the CPR with fuel for their steam engines. The context of these developments and selective approaches to the creation of space is at times hard to follow. However, almost all of the park policies begin to make sense when seen through the right framing: not necessarily a conservation of landscape but a conservation of an experience of landscape that was consistently tied to direct economic incentives.

The boundary is where these manicured efforts of constructing space and an experience of the site had to come to an end, and the uncelebrated landscape that surrounds the park began. This abrupt transition inevitably creates a dichotomy of landscapes and varying industrial treatments. It is the threshold where the image of the site and the landscape coincide, where preservation ends and modernity begins. In "The Agency of Mapping," James Corner states that maps, through the adjacencies that are expressed or selectively ignored, have the power to reveal political biases, economic interests, class structures and the aspects of landscape that are critical to the human dwelling and industry. ${ }^{5}$ In the case of Banff National Park this bias is clear and has been directly asserted by its earliest founders and financiers $-\mathrm{a}$ focused effort to construct wild space for the benefit of the visitor. The following section of this research aims to explore the spatial implications of this effort, and how the boundaries and borders that have been constructed around the park have shaped the conditions and experiences of the site.

To understand how Banff National Park has bounded and taken hold of landscape, it is equally essential to understand the site was before the creation of the modern park. The following portion of the New Atlas of Banff explores this history and the contexts of the Canadian Rocky Mountains prior to it becoming a National Park, and its early evolutions after becoming a zone of federal intervention and land claim. Through an exploration of what came before, it seeks to understand how the definitions imposed on the landscape by the mechanism of the National Park fundamentally altered the space and an experience of the place. 


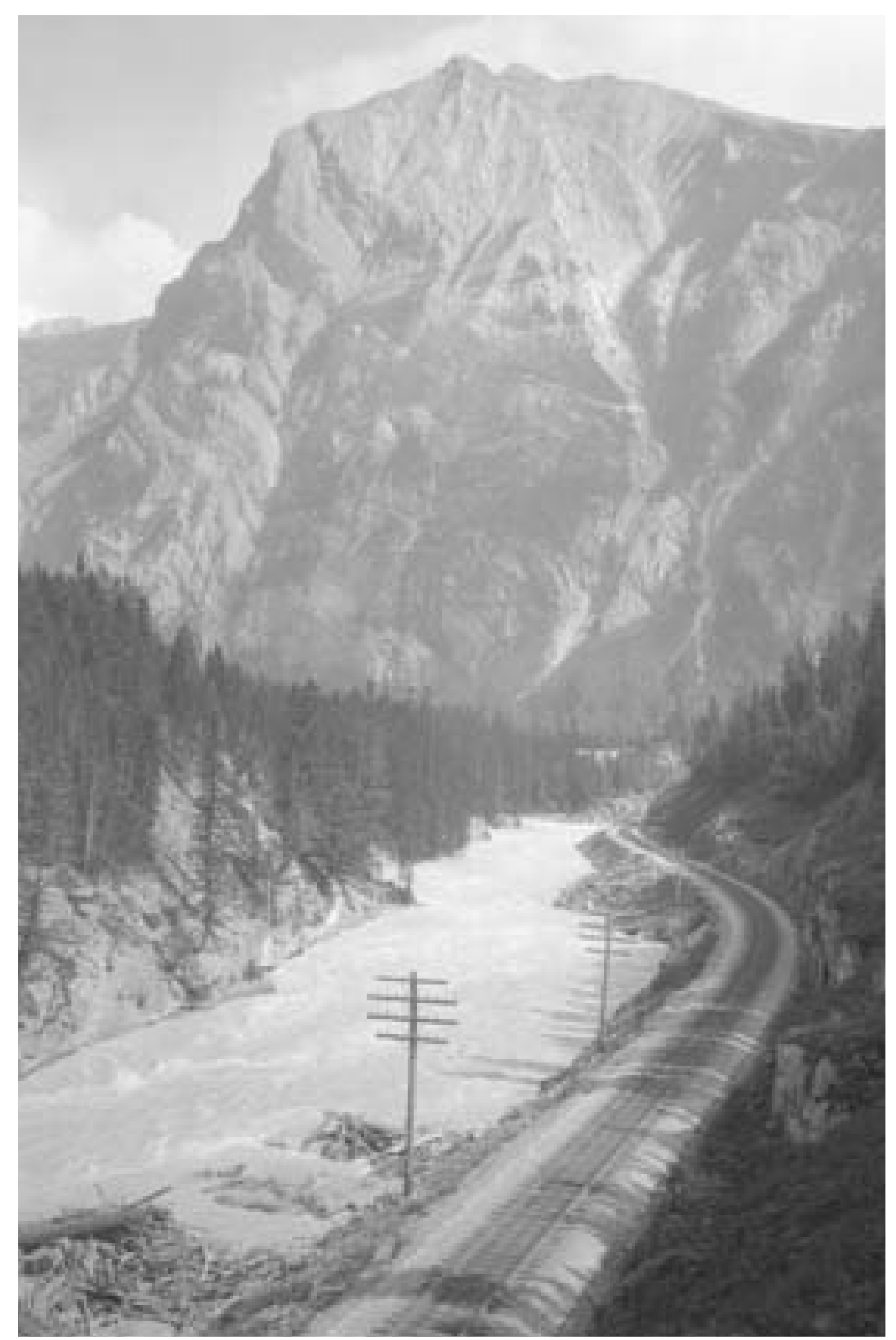

Fig.2.1.6. CPR Railway Along River Valley, Whyte Archive
TIMELINE 01

A CONDENSED HISTORY OF THE LANDSCAPE OF BANFF NATIONAL PARK BEFORE THE FORMATION OF THE TERRITORY

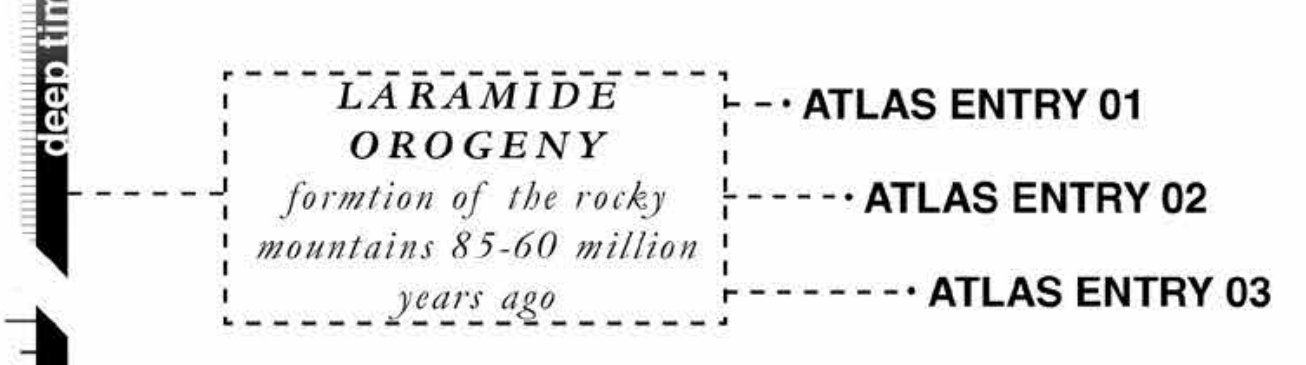

-1820s - European trappers and bunters begin to make contact with Stoney Nakoda Nation

1840s - Fist Missionary, Robert Rundle, arrives to

1850s - Life for Stoney Nakoda Nation and indigenous communities

lers é missionaries

1854 - Walden Published by Henry David Thoreau

1867 - Dominion of Canada is formed

1870s - Permanent Mission Established on Stoney Nakoda Land

$\begin{array}{llll} & \text { NUMBERD } & \text { ATLAS ENTRY } 04\end{array}$

TREATIES
Series of 11 treaties formed

between First Nations and the -..... ATLAS ENTRY 06

British Monarchy between $1871-1921$-......ATLAS ENTRY 07

1872 - U.S. congress establishes Yellowstone National Park

1877 - Treaty 07 signed on september 22nd

1880s - Advent of Hydroelectricity

1881 - Canadian Pacific Railway is Incorporated

1885 Boundary Change // Formation of BanffHot Springs Reserve

1885 CPR Completeted // last spike driven into the Canadian Pacific Railwry

ATLAS ENTRY 08

1887 // Boundary Change // Park Expanded into Rocky Mountains Park

Fig.2.1.7. Atlas Timeline 01 


\section{ATLAS ENTRY 01 // DEEP TIME ॥}

Human occupation of Banff National Park has always been informed by the challenging topography that defines the site. From the earliest settlements located along the Bow River Valley, to the construction of the railway and Trans-Canada Highway, finding level ground within the territory has often steered its development. Many of the trails and roads that traverse the site to this day follow along waterways and valleys, finding the paths of least resistance through the challenging terrain.

The Banff. Jasper and Yoho National Parks now attract millions of tourists annually. Banff and Jasper are located east of the divide in the province of Alberta and Yoho is situated on the western slopes of the Rockies in British Columbia. The parks include snow-capped peaks, summit icefields, slope glaciers, fastperks are Mount Robson (3,954 m) and Mount Colmos. $(3,747 \mathrm{~m}) \cdot[\ldots$

[...] The area is now accessed by major highways which make use of routes pioneered by the railways. The Banff and Yoho parks are situated on the Trans-Canada Highway. Banff and Jasper are linked by the Icefields which passes close to the foot of glaciers fed by the Columbia Icefield.

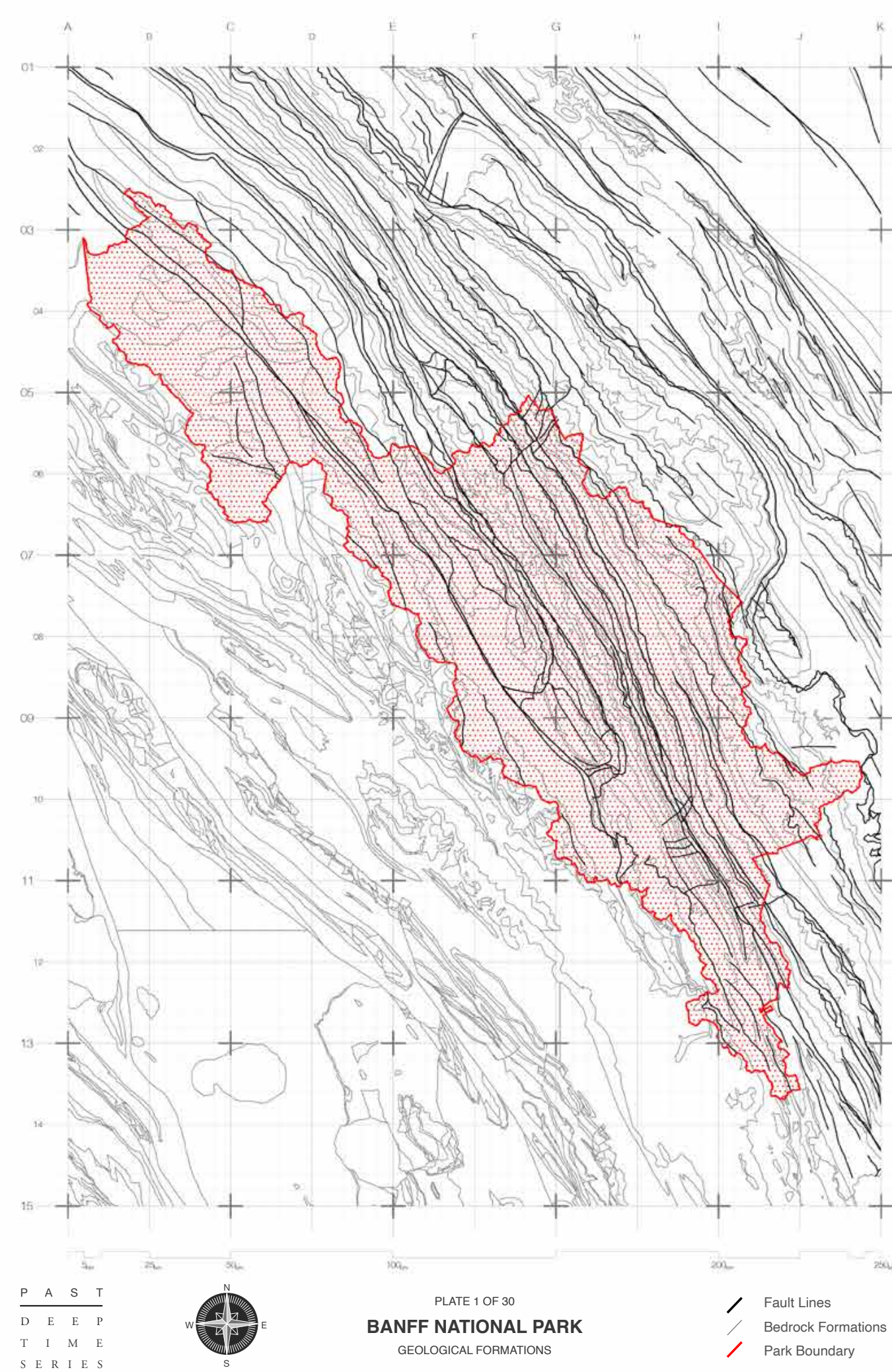

Fig.2.1.8. Atlas Entry 01: Deep Time 


\section{ATLAS ENTRY 02 // DEEP TIME I}

The peaks, glaciers and glacial lakes that create the unique landscape of Banff National Park, with its swirling strata and rugged terrain, have been a defining factor in the history of the site and its uses. These formations have also directly informed the boundary of the park in certain locations, as well as the provincial border between Alberta and British Columbia. The Western boundary of the park traces along the continental divide, the backbone of the Canadian Rocky Mountains. This geological barrier marks the peak of two different watersheds, with water that falls west of the divide flowing to the Pacific Ocean, and water on the eastern side flowing into the prairies and the Saskatchewan River.

The strata exposed in the Banff. Jasper and Yoho National Parks are part of the cratonic platform, thick sequences of sedimentary rocks of the Western Canada basin (Evenchick et al., 2007). The oldest is the Neoproterozoic Miette and Windermere Groups. They are dominated by sandstones, grits, and shales and are overlain by quartsites of the Lower Cambrian Cog Group. In a generalized way, the strata become younger towards the east as the older rocks were thrust over the younger sequences. The central and western parts of Banff and Jasper are dominated by Middle Cambrian through Middle Jurassic rocks. These successions include thick sequences of shales and

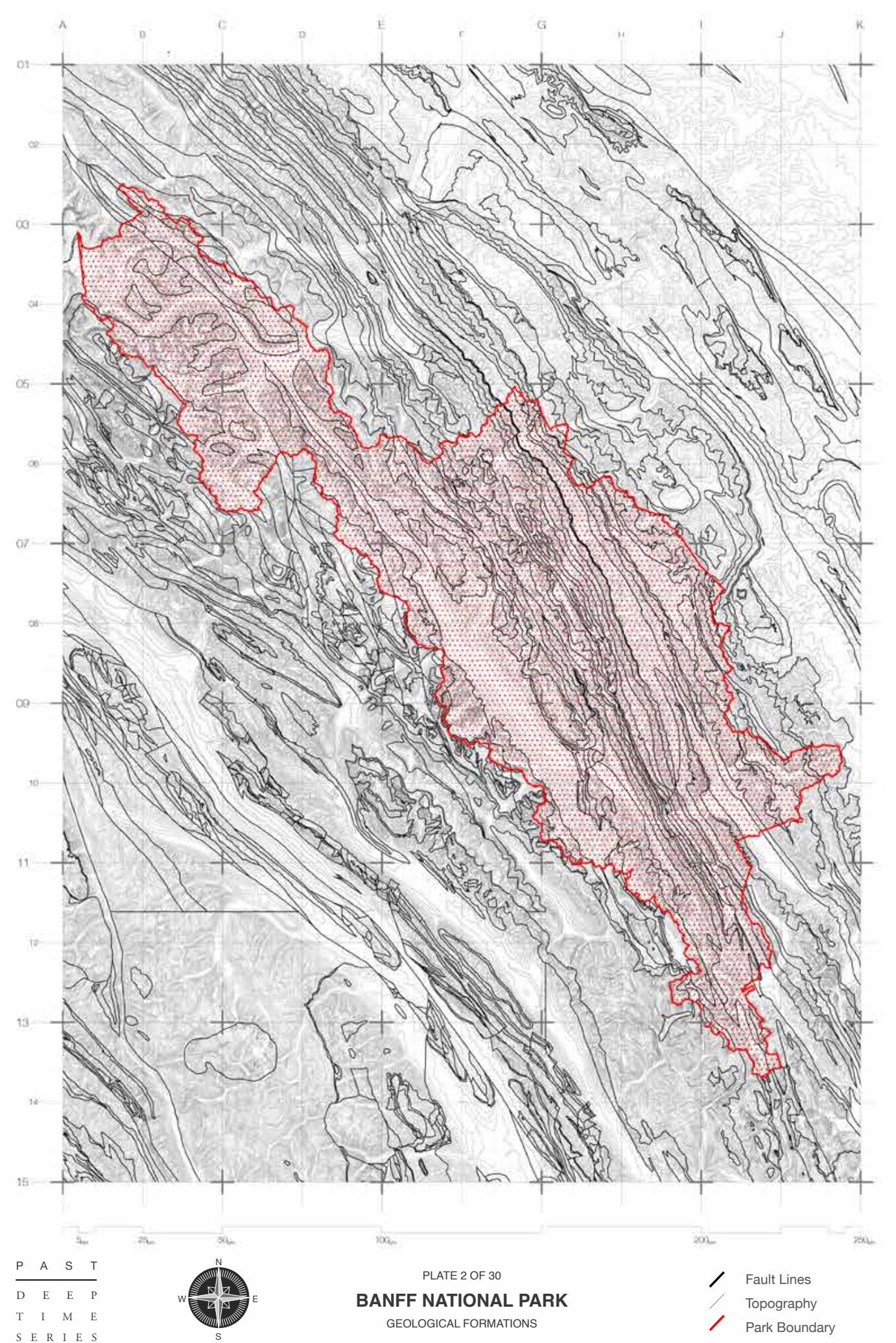

Fig.2.1.9. Atlas Entry 02: Deep Time 


\section{ATLAS ENTRY 03 // DEEP TIME II}

The glacier-fed waters of Banff National Park have historically been one of the sites most significant resources, both important to the tourism industry and hydro-power and irrigation developments. The pristine waters have been one of the sites' most celebrated resources, with sites like Lake Louise and Moraine Lake remaining world-famous tourist destinations. The headwaters that begin in Banff National Park flow across a significant portion of Canada and the Pacific Northwest, acting as an important water source that supplies millions of households.

The bedrock and glacial moraines are continuously being eroded and rivers include sections of rapids with waterfalls. Major rivers including the Athabasca, which flows northward, and the North Saskatchewan and Bow Rivers (the principal headwater of the South Saskatchewan River) which flow eastward and soutbward, respectively, are sourced at Banff and Jasper. These fast flowing rivers are primarily fed by meltwater from ice sheets and glaciers. The rivers occupy steep-sided, U-shaped valleys carved during the Pleistocene Ice ages.

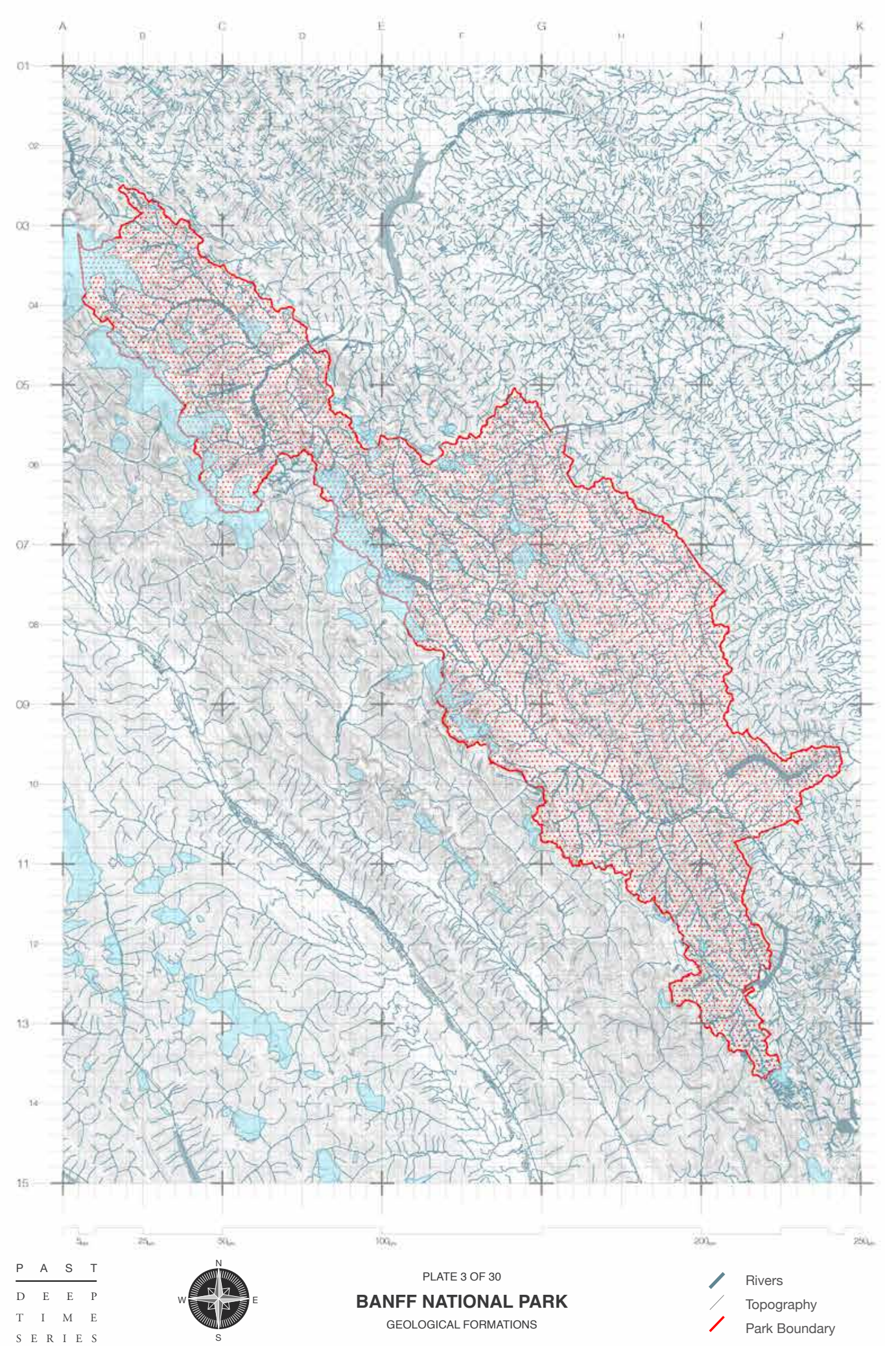

Fig.2.1.10. Atlas Entry 03: Deep Time II 


\section{ATLAS ENTRY 04 // HISTORICAL TREATIES I}

The numbered treaties, or post-confederation treaties, wereaseries of treatiessigned by indigenous communities across Canada and the Canadian Government between 1871 and 1921 . The treaties were primarily means for the government to pursue resource extraction and settlement, granting access to large swaths of land for the expanding new dominion. These treaties often failed to grasp the expansive territories occupied by indigenous communities across North America, as well as promised certain provisions that would never be fully met by the Canadian Government.

[...] Although the Stoneys did not realize it. Treaty Seven meant that we would receive only one reserve, which was to be located at Morleyville. But at the time of signing, Chief Goodstoney expected to receive a similar reserve in the BighornKootenay Plains area for bis people who lived there before the treaty was signed, and chief Bearspaw expected to receive land for his band south or Morley. This was done for different Blackfoot bands, who received reserve land at Gleichen, Cardston, and Brocket; our Chiefs expected the same consideration for the three bands of our tribe [...

[...] We now Know and realize that John McDougall had a personal interest in baving one large reserve established at Morleyville; the Church was there, his home and farm buildings were there, the bay fields were nearby, and a small area was under cultivation. It was apparently his feeling that the Church could not continue effectively Christianizing my people if we did not all settle on one reserve.

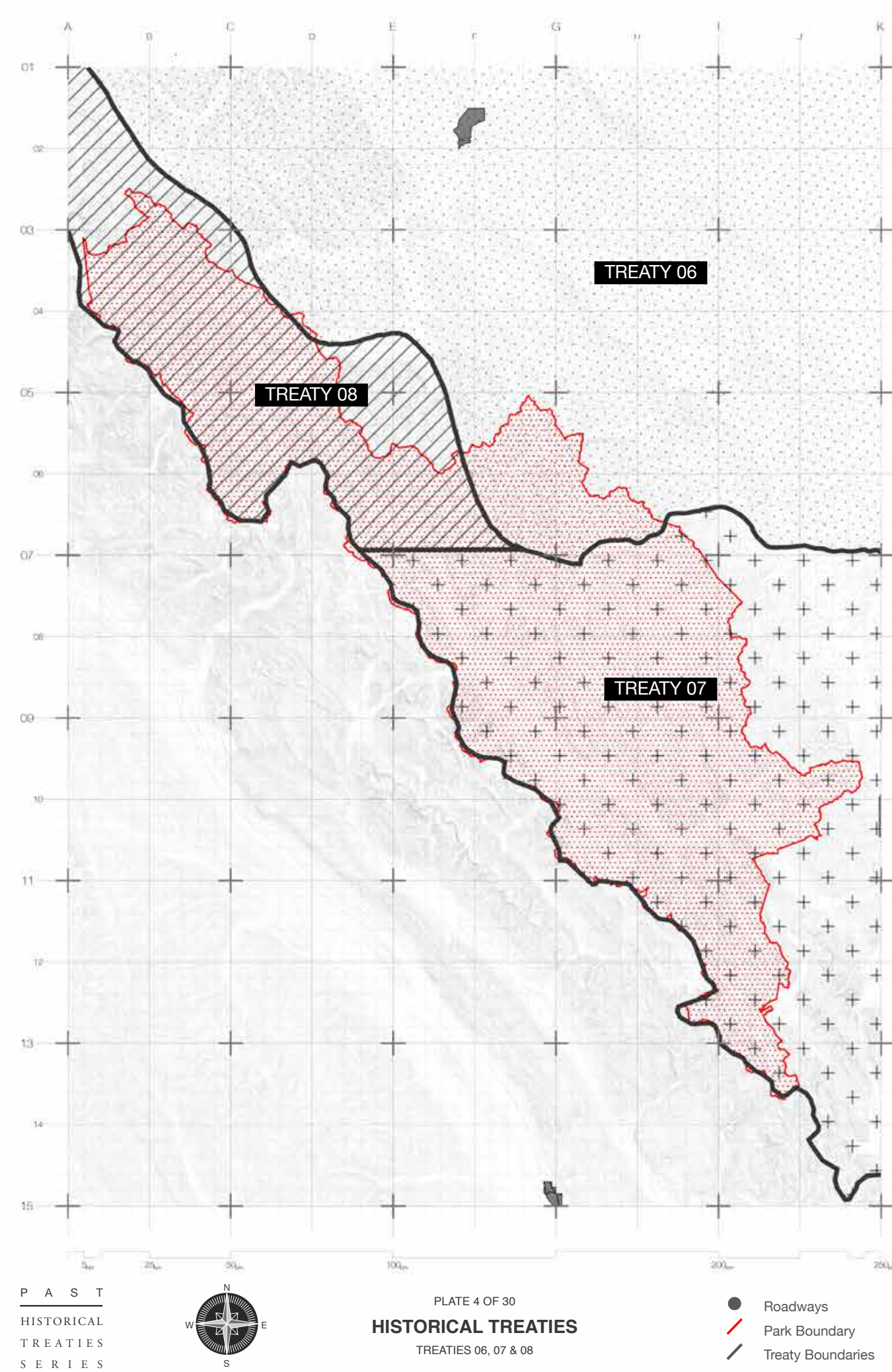

Fig.2.1.11. Atlas Entry 04: Historical Treaties 


\section{ATLAS ENTRY 05 // HISTORICAL TREATIES II}

Multiple challenges during the negotiations of treaty 7 led to significant miscommunication during the process. The largest challenges were the cultural and linguistic barriers between the Stoney Nakoda Nation and government officials. These issues compounded with the fact that government officials were unfamiliar with the territory, leading to disastrous consequences in the establishment of the Stoney Nakoda First Nations Reserve.

The Canadian negotiators in the treaty process discussed the benefits of a treaty and stressed land sharing rather than land surrender. McDougall Reverend John Choutter Mcdougall plaved an important role at the signing of Treaty Seven in Southern Alberta, an agreement that the Stoney Nakoda believed to be a peace treaty. During the negotiations, the chiefs' Stoney had to be translated into Cree to someone who spoke both Cree and English, and then the communication would finally be transferred to the Treaty Seven Commissioners[...]

… The Government of Canada acted quickly in the mid1870 s, as it wanted to extinguish the Indian Title as soon as possible, before thousands of non-Indigenous ranchers and settlers arrived. Unfortunatey, the farming potential of the Upper Bow River Valley remained unknown at the time of Treaty Seven. The basty choice of a reserve on the advice of their missionary John McDousall and federal government officials proved disastrous. Over sixty years later, Reverend E.J. Staley, when he was the United Church Minister at Morley, described the land as "notbing more than a rocky, billy, gravel bed with only the thinnest smattering of soil covering it anywhere, except for a few bundred acres in its southeast corner. ${ }^{10}$

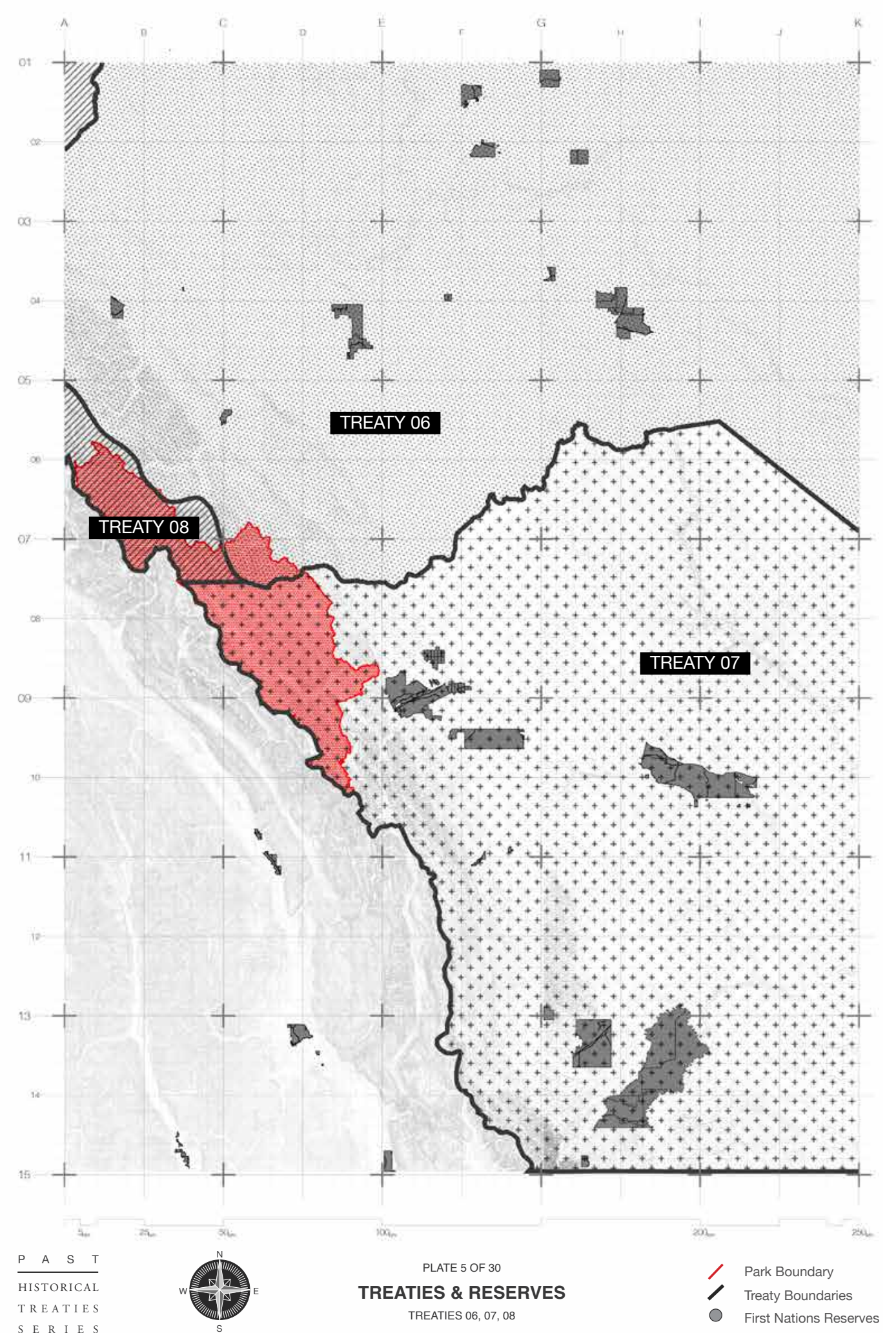

Fig.2.1.12. Atlas Entry 05: Historical Treaties I 


\section{ATLAS ENTRY 06 // HISTORICAL TREATIES III}

While government officials sought to establish the treaties primarily to access new territories and incorporate them under the control of the federal government, the numbered treaties are viewed as sacred agreements by many First Nations communities across Canada. This fundamentally different understanding of the treaties and their cultural significance remains to this day.

Througbout my lifetime the promises of Treaty Seven have never been far from my mind. As far back as I can remember, the Stoney elders have reminded me of the importance of the agreements contained in Treaty Seven and the promises made to my people at Blackfoot Crossing on hundred years ago. My people have told me that they praved, burnt the sweet

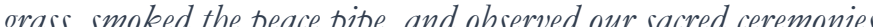
before the attested their signatures to the treaty parchment. The Treaty is a Sacred Covenant made before the Great Creator. Therefore, it should never be broken by either of the parties concerned. But whenever I have heard and interpretation of those agreements and promises from government officials, I have been made aware of how different the officials; view is from that of our tribal elders. The difference separating the two versions is as great as the difference that separates night from day.

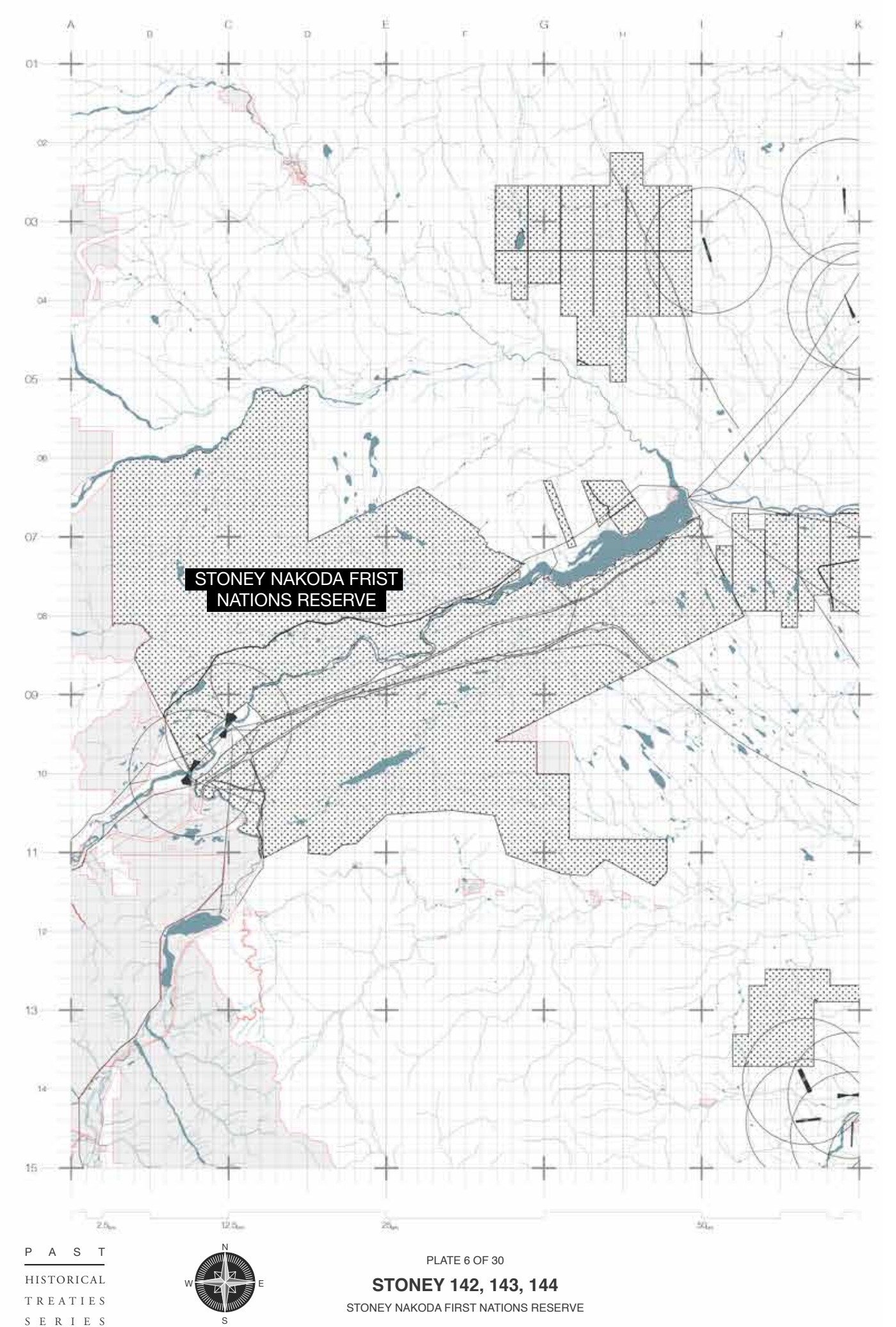

Fig.2.1.13. Atlas Entry 06: Historical Treaties III 


\section{ATLAS ENTRY 07 // HISTORICAL TREATIES IV}

Subsequent restrictions after the creation of the treaties would be placed on the land uses of indigenous communities of the area as Banff National Park expanded, absorbing more and more of the territory that had been used as hunting grounds and sacred sites by the Stoney Nakoda Nation. The park boundary would eventually be expanded directly to the edge of the Stoney Nakoda First Nations Reserve in 1902.

In the park's annual report in 1903, Nakoda bunters are directly blamed for decreases in populations of large mammals (Snow, 2005). By 1909, under rising pressure from sport bunting organizations and stakeholders in the local tourism economy, the government introduced game wardens into the park. The government's keen interest in curbing Nakoda bunting in the region was exemplified by their selection of Howard E. Sibbald as the firstpark, warden. In addition to being the Indian agent at Morley from 1901-1904, Sibbald was not an advocate for Nakoda subsistence land uses (Snow, 2005) [...

...TThe selection of Sibbald as the first game warden is a clear indication th practices as a problem to be solved. Moreover, the appointment of Sibbald also reveals that the government intended to probibit the subsistence land uses of Nakoda peoples to appease the interests of sport bunting organizations and, ultimately, the tourism industry. Again scientific based studies and reports are utilized to document and provide support for discourses of conservation that subjugated Aborioinal peoples and their ways of knowing. In this case, parks explicitly endorse a conservation ethic that is deeply linked to knowledges produced by and through individuals who were invested in the tourism industry. These particular ways of understanding conservation later inform dividing and assimilating practices."

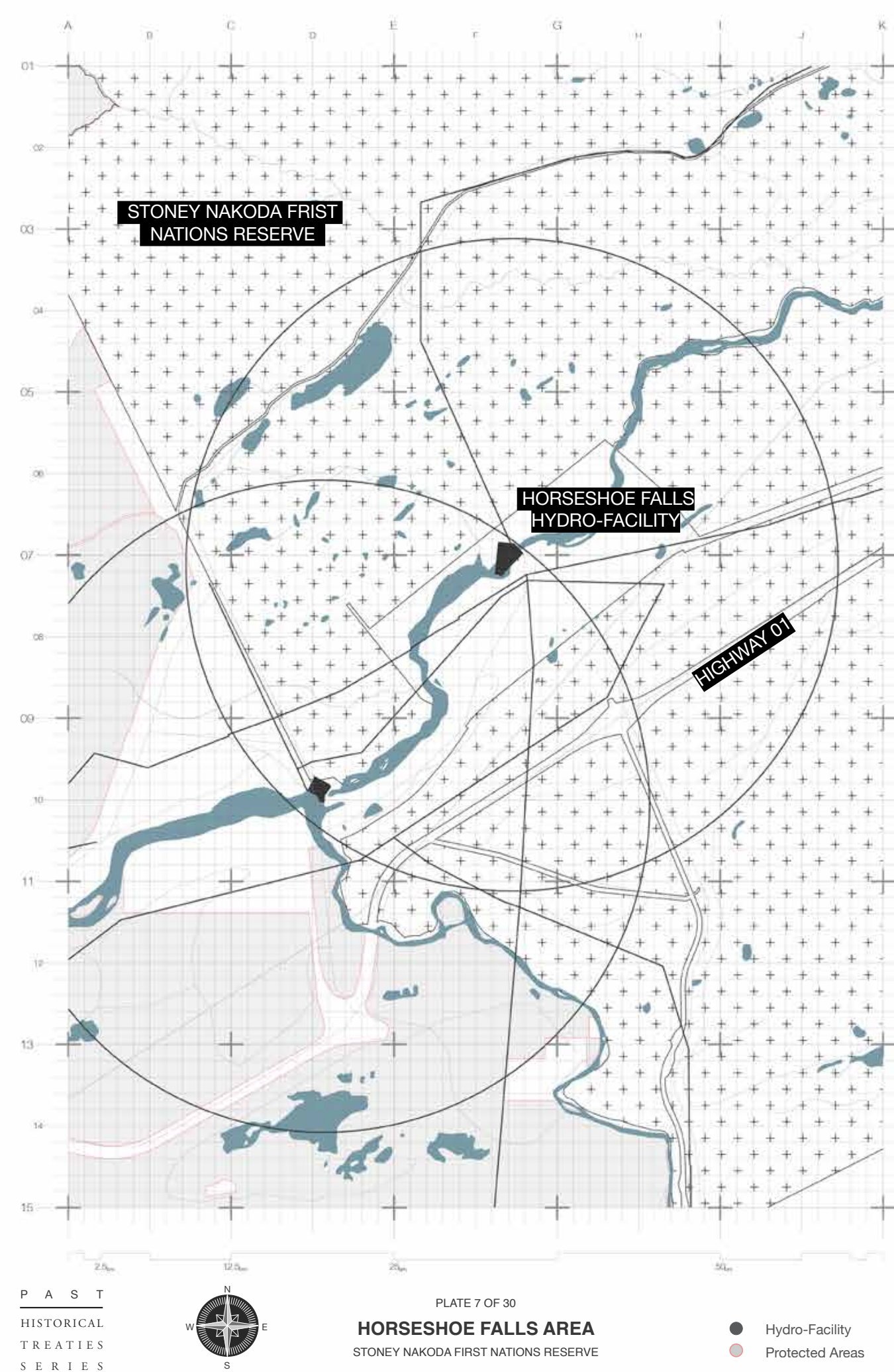

Fig.2.1.14. Atlas Entry 07: Historical Treaties III 


\section{ATLAS ENTRY 08 // THE RAILWAY}

The Canadian Pacific Railway continued to expand its operations in the area throughout the $20^{\text {th }}$ century, establishing more luxurious accommodations and resorts within Banff National Park at sites like Lake Louise and the Banff Springs Hotel. Continued investment and marketing ensured a sustained use of the network, turning park space and the site into a significant tourism industry worth millions of dollars to the CPR and the Canadian Government.

Prime Minister Macdonald in 1871 held together a fragile country, scarcely four million strong, a country divided by deep regional and linguistic differences. Determined to prevent US economic expansion into prairie lands north of the $49^{\text {Li }}$ taralled Canada had expanded tenfold in just four years, from the Atlantic to the Pacific. It became of the world's largest countries after the transfer of Rupert's Land and the Nortb-Western Territory into the Dominion on 15 July 1870, followed by the entry of British Columbia into Confederation on 20 July 1871. To entice British Columbia into the union, the new dominion bad promised to build a transcontinental railway to the new province. Macdonald saw the completion of the railway as the capstone of bis work to build a strong British North American Nation. ${ }^{13}$

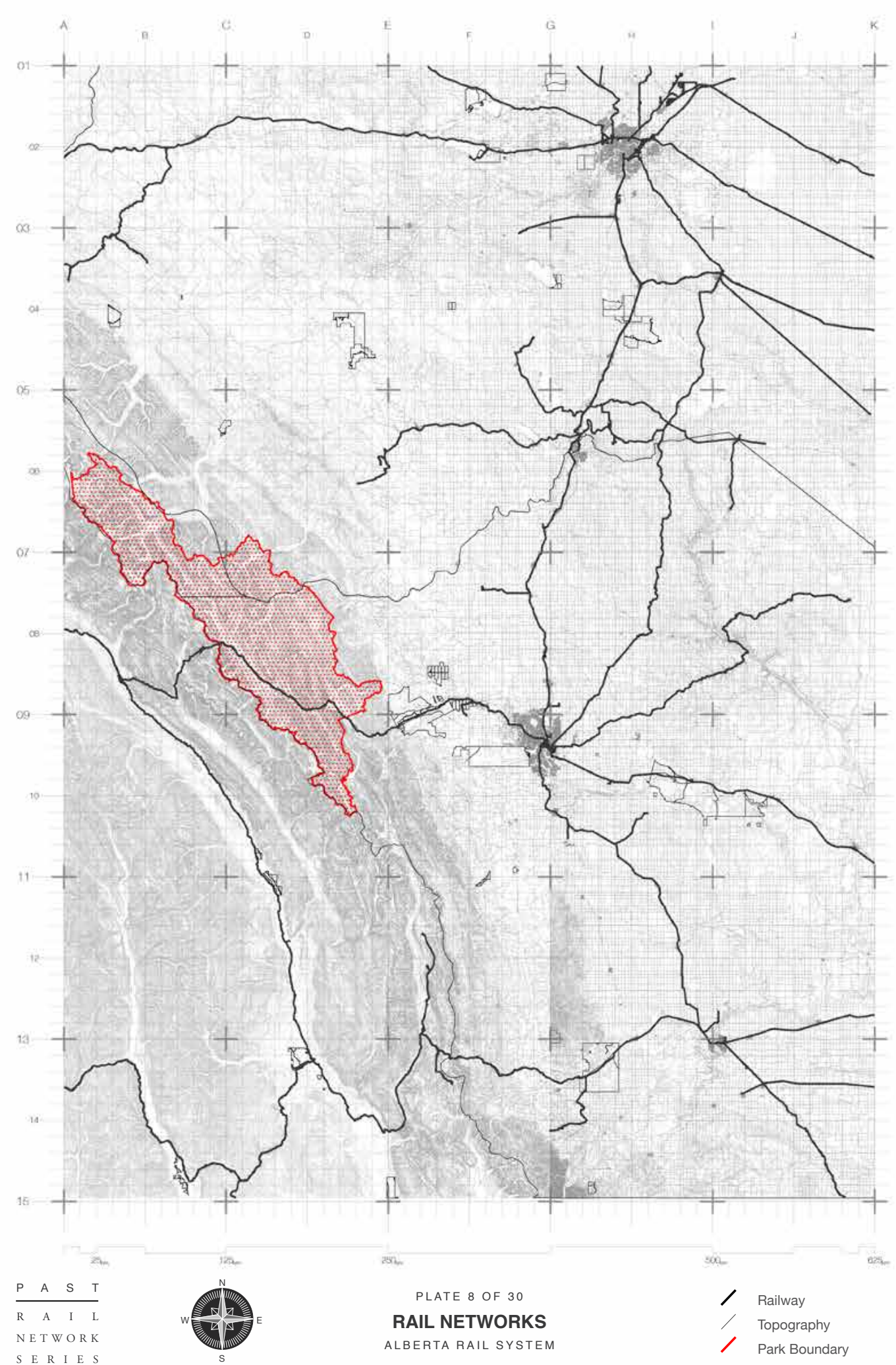

Fig.2.1.15. Atlas Entry 08: The Railway 


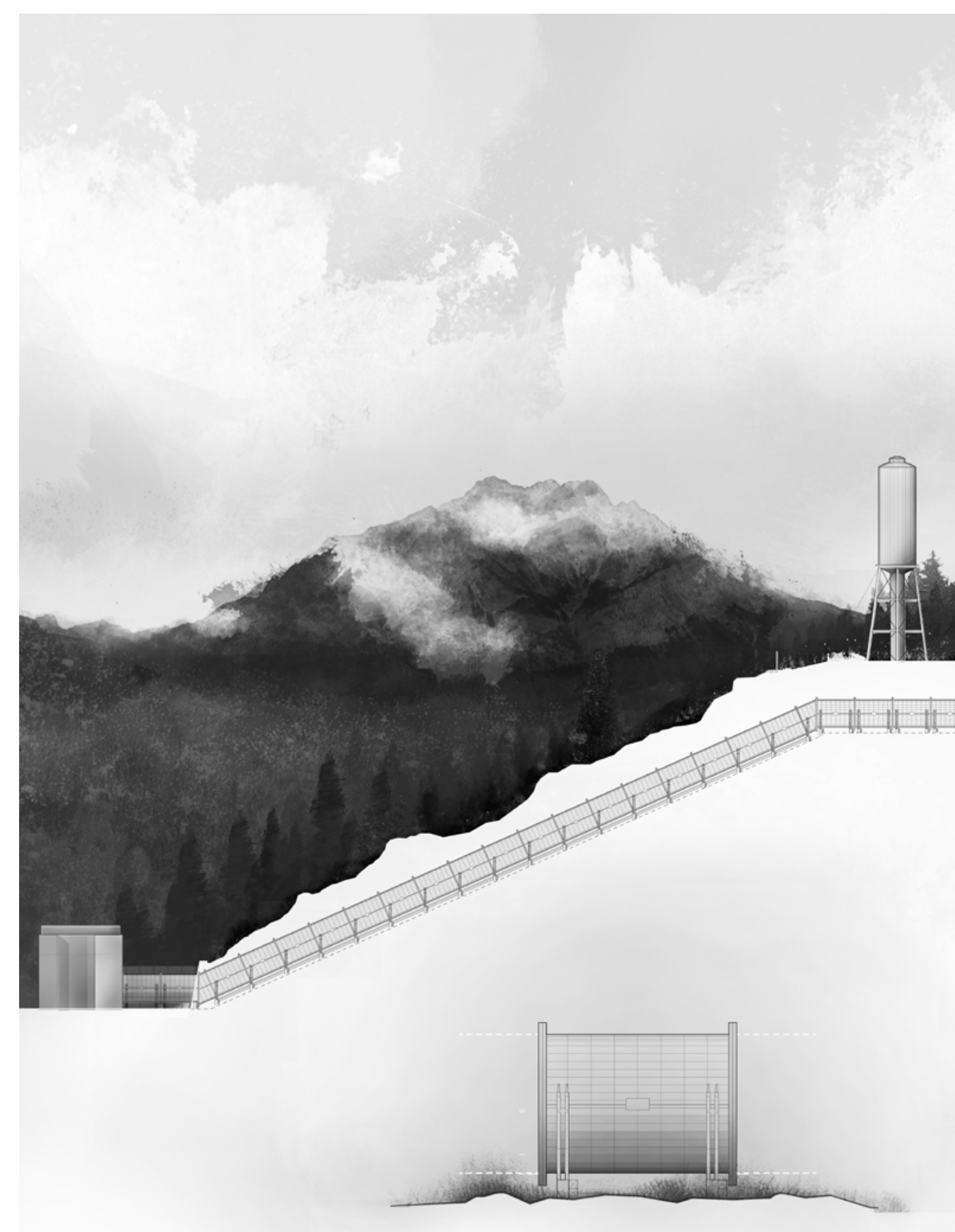

Fig.2.3.1. Banff Hydro-Facility Section, Lake Minnewanka

\section{7 // PRESENT DICHOTOMIES}

The aesthetic of the sublime associated with sites of spectacular nature was gradually displaced in the case of falling water by utilitarian thoughts guided by mechanical engineers and, subsequently, bydroelectric technology. How could that energy, now perceived to be going to waste in conspicuous display, be converted to productive buman ends? How could the genie bottled up in nature be released to be re-employed in the service of bumanity?

- Christopher Armstrong

This section of the New Atlas of Banff explores the current dichotomies and varying treatments of landscapes that exist on either side of the park boundary and the current state of the landscape in and around Banff National Park. While it briefly examines the general dichotomy between wilderness and industry, its primary focus is the treatment of water as a resource both for industrial development and touristic commoditisation's. Water, and varying means of exploiting water for profit, has been at the center of numerous debates concerning the park. It is a resource that a unique value to both the industry of selling scenery within the park and industrial developments and economy outside the park. This section of the atlas focuses on the present understanding of water and its industry within the park, including the more recent 


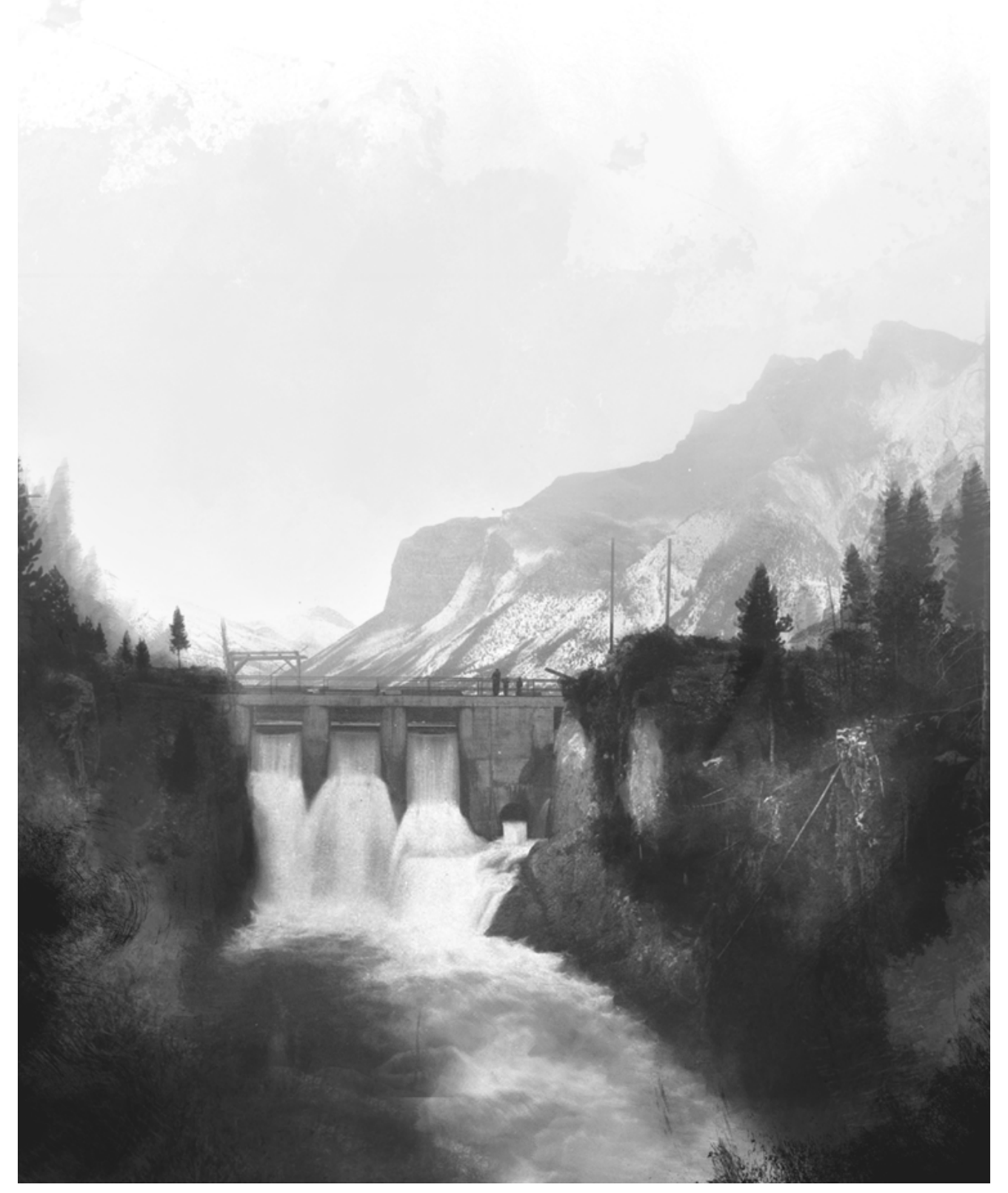

Fig.2.3.2. Devil's Gap Dam, Lake Minnewanka history and origins of policies and frameworks that continue to define the site as an economic resource to this day. It is a snapshot of the landscape as it is currently defined, with the mechanisms and policies of the National Park a firmly established and defining influence over the space of the site.

Water as a resource and its varying commodification's have had a profound effect in the development of Banff National Park, not only in its initial creation as a means to control the hot springs, but also in the ongoing development of its policies and industries. One of the most defined dichotomies that exists on either side of the park boundary to this day is the varying treatments of water as a resource. The creeks, rivers and glacially-fed lakes of the park have long been the most popular attractions of the site, with Lake Louise and Moraine Lake remaining major tourist attractions to this day. Water has also been the subject of industrial ambition, with the Rocky Mountains holding a long history of the expanding populations of southern Alberta seeking to tap into their waters to supply irrigation and power supply demands. ${ }^{15}$

These two different uses of the resource and their respective definitions of what conservation really meant, have at times come into direct conflict with each other, forcing a re-defining of the national park 


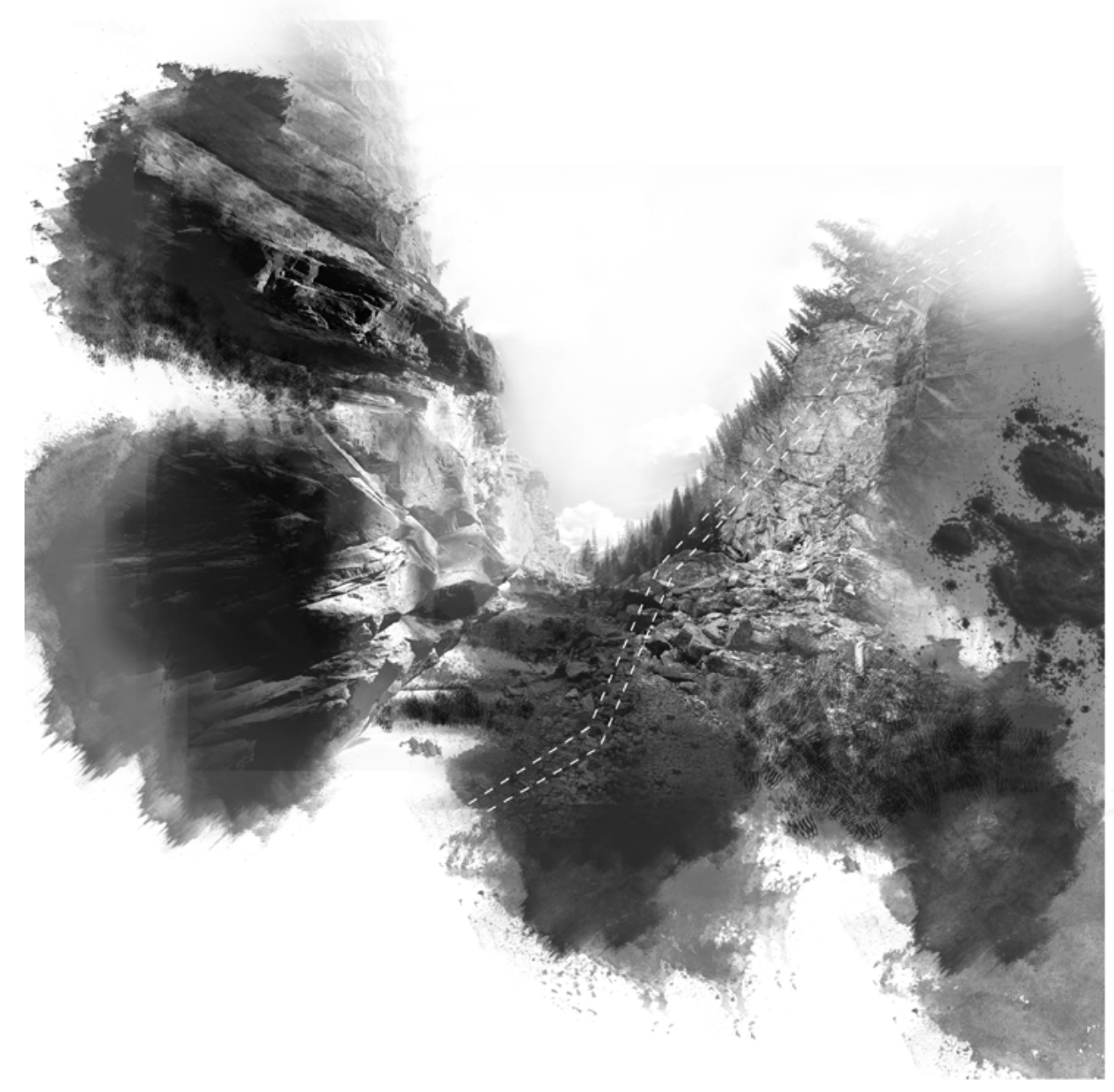

Fig.2.3.3. Grassi Lakes Hike \& Hydro-Infrastructure I and its compatibility with hydro-electrical development during the first half of the 1900's. With the advent of hydro-electrical technology, water suddenly contained economic value along two distinct metrics, one industrial and the other scenic, but it was unclear as to whether or not national parks could capitalize from both simultaneously. These conflicts of the best use of the resource rarely revolved around debates of sustainability or conservation, but rather around the image of the park and the potential of industrial development to shatter an experience of space that was fundamentally meant to be absent of human industry. Politicians and conservationists at the time wishing to preserve the park were concerned first and foremost with how visible these new infrastructures would be and to what extent they might disturb tourists and visitors to the space. Large scale hydro-development had the potential to undermine the illusions and images that had so carefully been crafted into a tourism industry by the C.P.R. and Canadian Federal Government. The policies that were formed during these decades of Banff National Park's early history would come to define the site and National Parks across Canada as we know them today.

As populations in southern Alberta expanded in the early 1900s, the Calgary Power Company sought to tap into the waters that flowed from Banff National Park to supply power to the increasing 


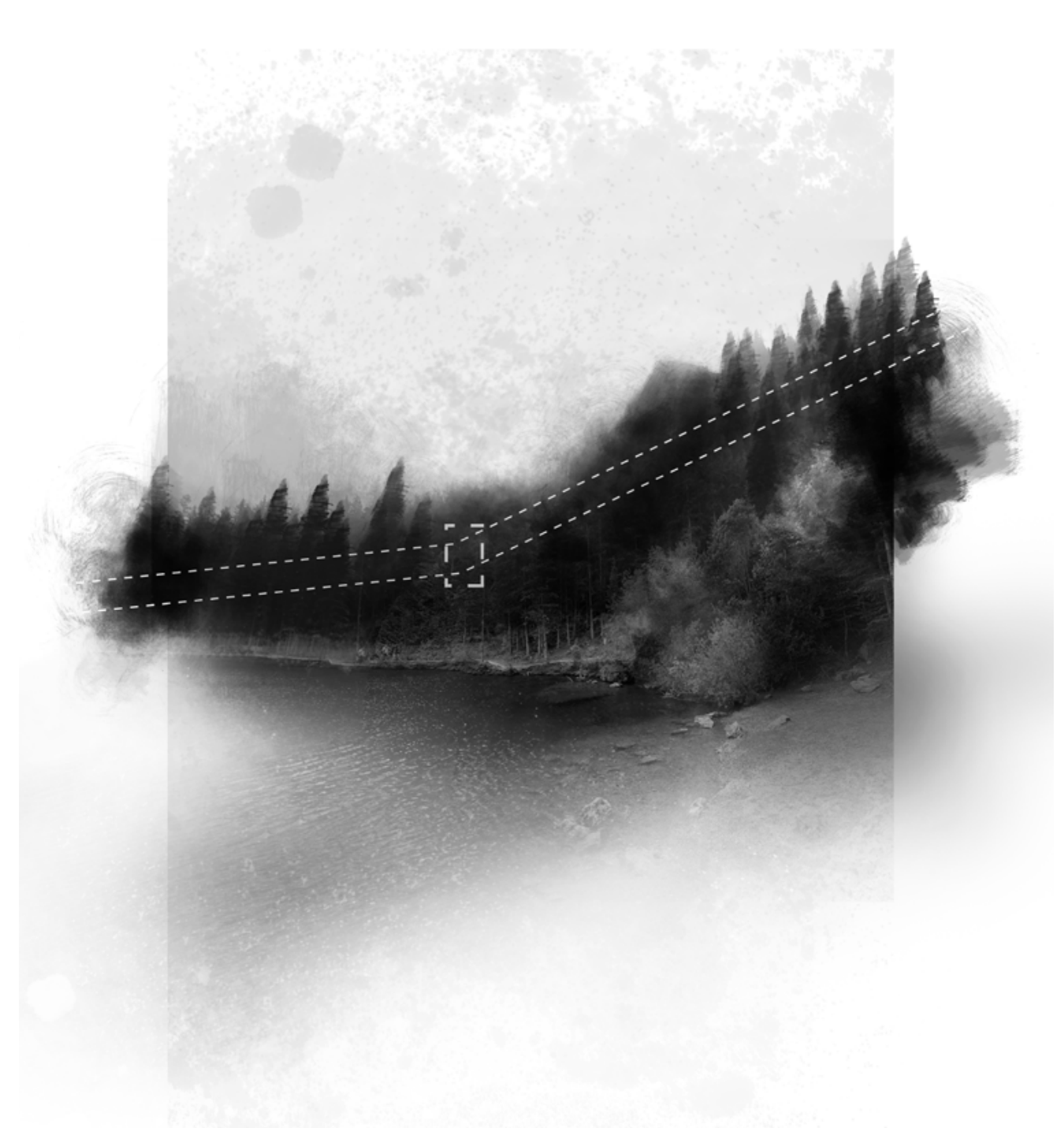

populations and industries of the province. These generating facilities were primarily located just east of the of the Rocky Mountains and Banff National Park, in the foothills where the waters flowed into the prairie and eventually to the Saskatchewan River. However, the inconsistency of flow rates throughout the year due to freeze and thaw cycles meant an unreliable and inconsistent power source. The solution proposed by the Calgary Power Company was simple - reservoirs upstream located within Banff National Park, then still known as Rocky Mountains Park, to moderate the flow rate of the waterways that fed the downstream power generating facilities.

In 1912, when the Calgary Power Company constructed the first of these larger hydro-reservoirs to maximize the power generation of their downstream facilities at Lake Minnewanka, the Parks Department took no issue with the proposed development. The reservoir, which would flood the valley of Devil's Lake, today known as Lake Minnewanka, was approved and concerns over its potential impacts were dismissed primarily on aesthetic biases and rationales, with one member of the Parks department stating..

That Lake Minnewanka has never been regarded as an outstanding beauty spot is shown by the fact that the C.P.R. have never featured it in their advertising [sic]. The reason is that the mountain lakes in the Rockies which are famous for their beauty, such as Lake Louise, are glacia 


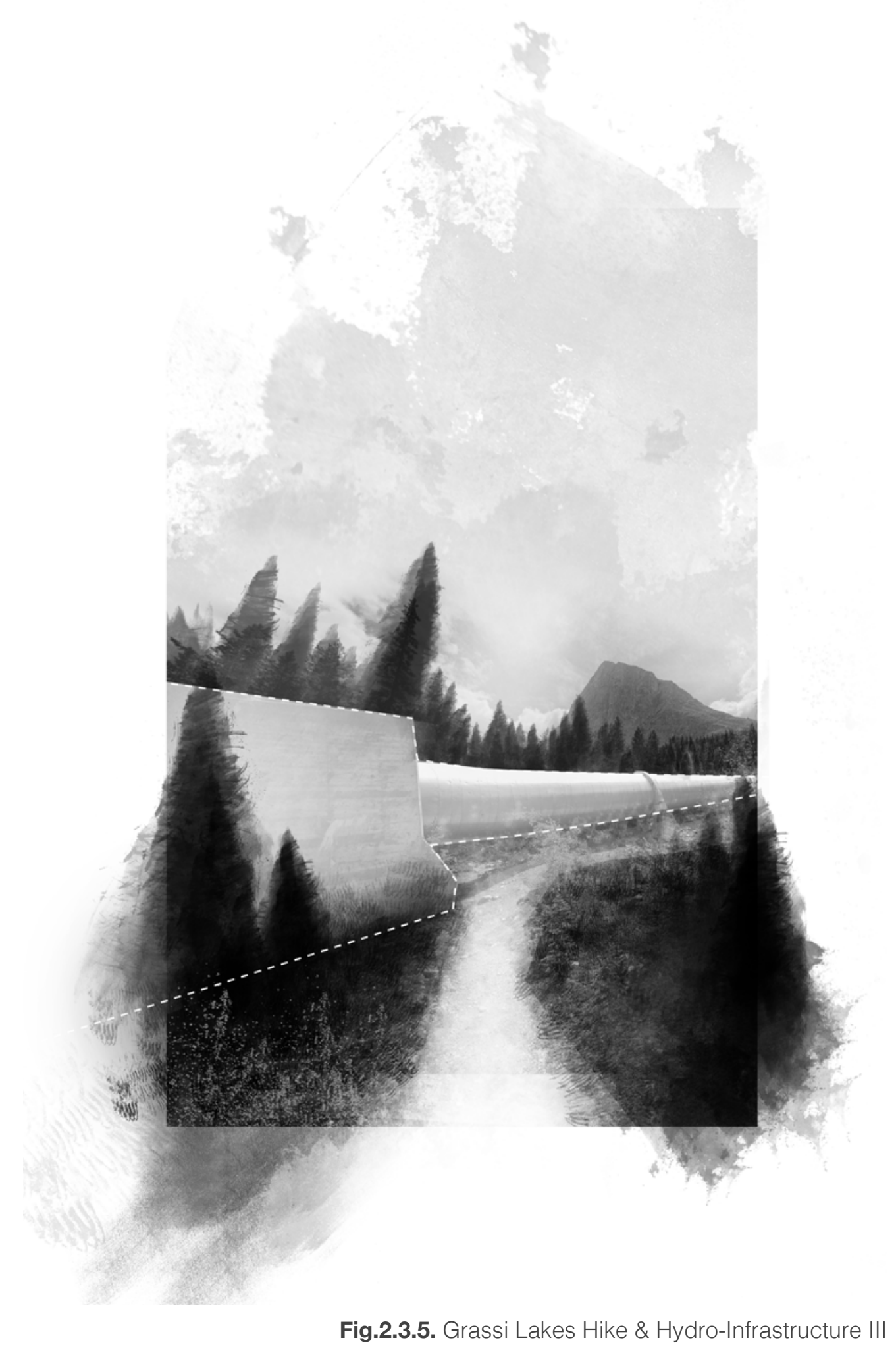

cirques, while Minnewanka is only a flooded river valley. By clearing these flats and raising the water levels as proposed, they will be submerged, and the general appearance of the lake very materially improved.

Not only were these arguments once again primarily concerned with the visual experience of the site, but the park had reached a point where its own past depictions and representations of the site began to influence its continued development. A feedback loop had been established, where an image that had been built from the landscape now began to create a landscape built around an image.

However, over the course of the Lake Minnewanka development the policy of National Parks began to harden, and when the Calgary Power Company proposed the development of a second site at the Spray Lakes Reservoir, the parks department was firmly opposed. The raising and lowering of the water table at Lake Minnewanka had visibly begun to alter the landscape leaving an unattractive shoreline and an inconsistent visitor experience. Rather than this halting the proposed development at the Spray Lakes site, the park boundary was simply redrawn to exclude the new reservoir and its facilities. ${ }^{17}$ The incompatibility of industry was not with the landscape or the environment, but with the image of the park and the visual experience inside its boundaries. These events played a significant role in the 


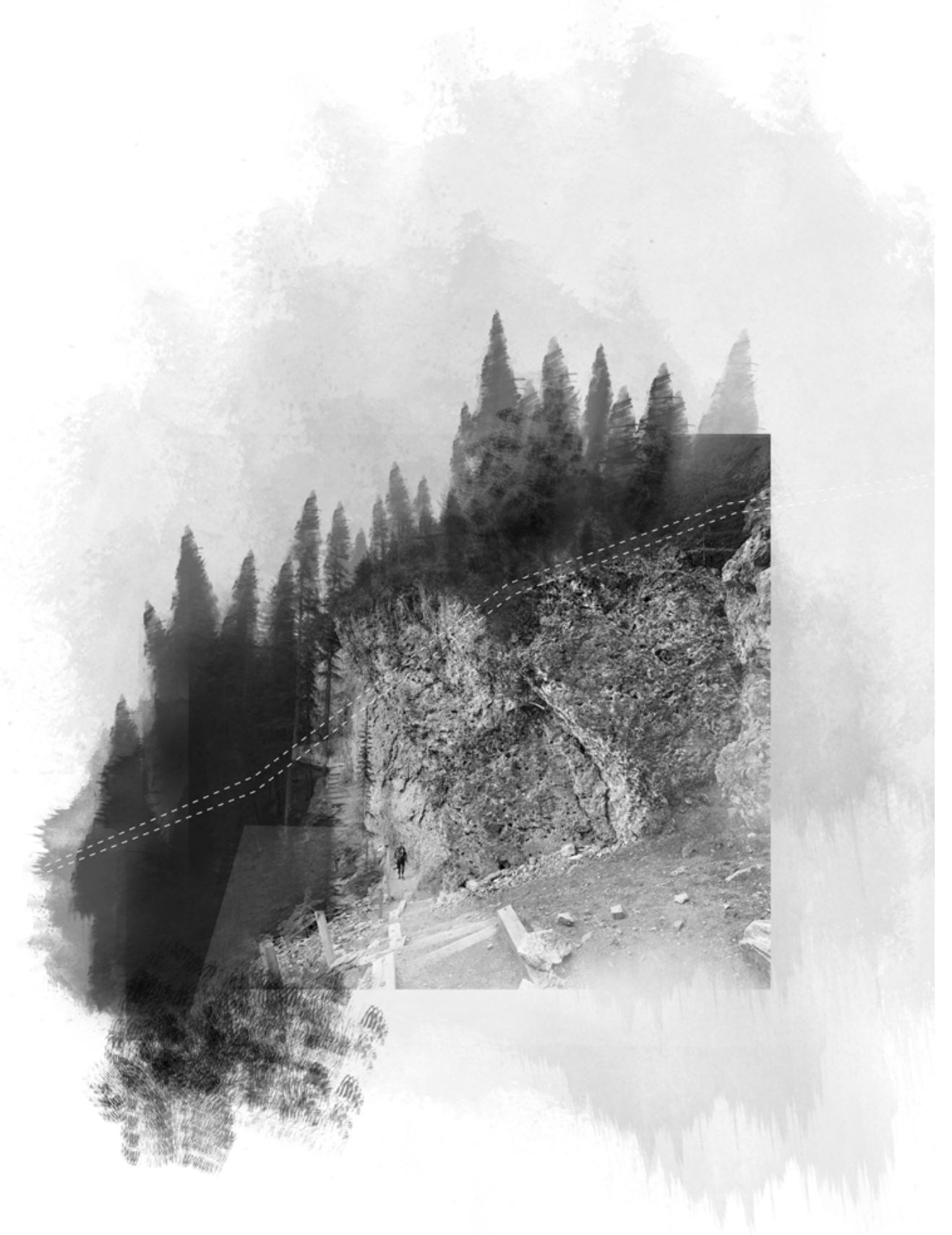

Parks department of Canada determining a doctrine of inviolability for National Parks, conceding territory to maintain the illusion of pure, untouched wilderness within its borders. Industrial sites that had sufficient economic viability would be removed from the park, such as the spray lakes facility or the mining facilities located close to the town of Canmore. This new policy reflected a renewed commitment to create a wilderness within the park that was absolute, absent of any visible industrialization. This incompatibility became a firm component of park policy, however, as with the Spray Lakes reservoir, the potential to redraw the borders of this cohesive zone still offered a certain capacity to adapt the territory as the Canadian government saw necessary. 


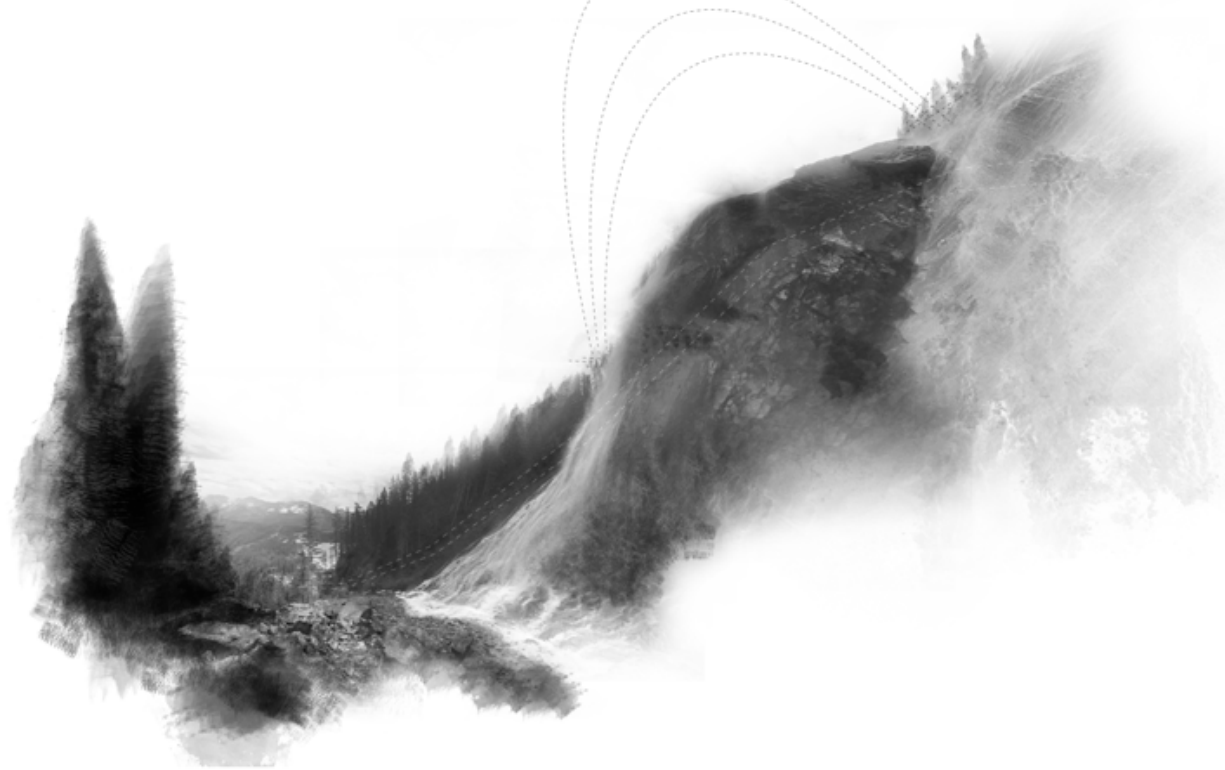

Fig. 2.3.7. Grassi Lakes Hike \& Hydro-Infrastructure V

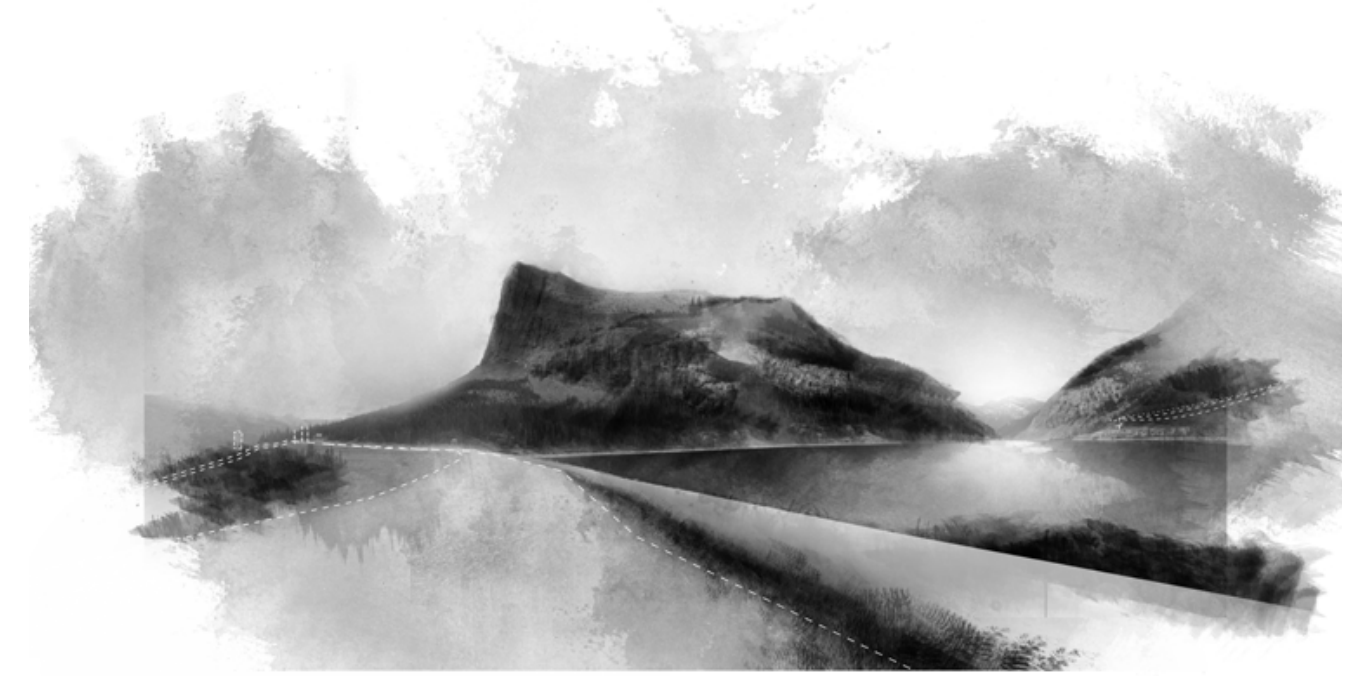

Fig. 2.3.8. Grassi Lakes Hike \& Hydro-Infrastructure VI
TIMELINE 02

AN UNDERSTANDING OF THE CURRENT THE BOUNDARIES, DICHOTOMIES AND INDSUTRIES THAT HAVE FORMED BANFF NATIONAL PARK AS IT EXISTS TODAY, 2021

1900-1910 - Hydropower developments proposed for within Banff National Park 1903 - Bankhead Coal Mine near Town of Banff Begins operations

- 1911 - Boundary Change - Park Redrawn up to Stoney Nakoda First Nations Reserve 1912 - Calgary Power Company Builds Dam at Lake Minnewanka, Flooding the

1922 Bankhead Coal Mine near Town of Banff is closed

HYDRO-DICHOTOMIES

- ATLAS ENTRY 09

ATLAS ENTRY 10

Series following the evolution of bydro-powe and its watershed

$$
\text { ATLAS ENTRY } 12
$$

$1930 \frac{\text { Boundary Change // Spray Lakes Area Removed From Park Boundary }}{\begin{array}{l}\text { Major changes in Park Parkicy lead to the removal of large territory containing } \\ \text { Exshaw mining facility, Spray Lakes Development and town of Canmore }\end{array}}$

\section{.... ATLAS ENTRY 13}

\section{- .}

1940s - Minining Restrictions within Park eased as a Wartime Measure

1947 - National Tourism Conference sets focus on the economic value of parks through

1947 - Last timbering operations in Banff National Park shut down

1954 - First ski lift constructed at Lake Louise

1962 - the United States hosts first world conference on national parks, conservationism

1972 - Lake Louise Village expansion proposal draws heavy criticism, provinical ov. opposes while feds want it

1972 - National and Provinical Parks Association opposes use of Banff for the 1872 olympics ATLAS ENTRY 15

.

1979 - Canmore Mines Ltd. ceases operations due to coal market diminishing

1980s - Lake Louise starts hosting the FIS alpine ski world cup 1988 - Calgary hosts the winter olympics, Canmore nordic center constructed in the
recently territory recently removed from Banff National Park

Fig.2.3.9. Atlas Timeline 02 


\section{ATLAS ENTRY 09 // HYDRO-DICHOTOMIES I}

The development of hydro-electrical industry, as well as the demand for cheap electricity throughout the early $20^{\text {th }}$ century placed a new press capacities to generate profit from the space and its resources through either industry or tourism caused much debate across different branches of the Canadian Government. Two of the most significant voices in this debate were William Pearce, who argued for economic efficiency through hydro-electrical developments, and Arthur Wheeler, who strongly opposed any such developments for national parks across Canada.

The issue finally came into focus, for both Wheeler and Pearce, with the proposal of 1923 to dam the Spray Lakes for bydro-development. Calgar Power Company [today Transalta], organized in 1889, already had power damns on the Bow River's Horseshoe Falls, at Lake Minnewank. and at Kananaskis Falls, all within Banff Park.

[... Lake Minnewanka retained its beauty and popularity, and supporters of the Spray Lake Proposals claimed this showed hydroelectric development could be consistent with park values. Another bydroelectric development was permitted in the Kananaskis Falls Agreement of 1912. But by 1923 Calgary Power again needed more power, and looked to opponents of hydroelectric development in the parks: $\underline{T}$ bave seen articles in American and Canadian Magazines about the profanity, the blasphemy of harnessing Niagara falls and thereby diminishing the flow of water down this great cataclysm of nature. Well, I consider and hands doing the work that the falls of Niagara are doing, in order that wedding couples couple see more water falling over the top. That seems to me ridiculous, and the same is true of Banff National park'. Calsary Power Company proposed instead to dam the Spray River, also in the park and east of the town of Banff.

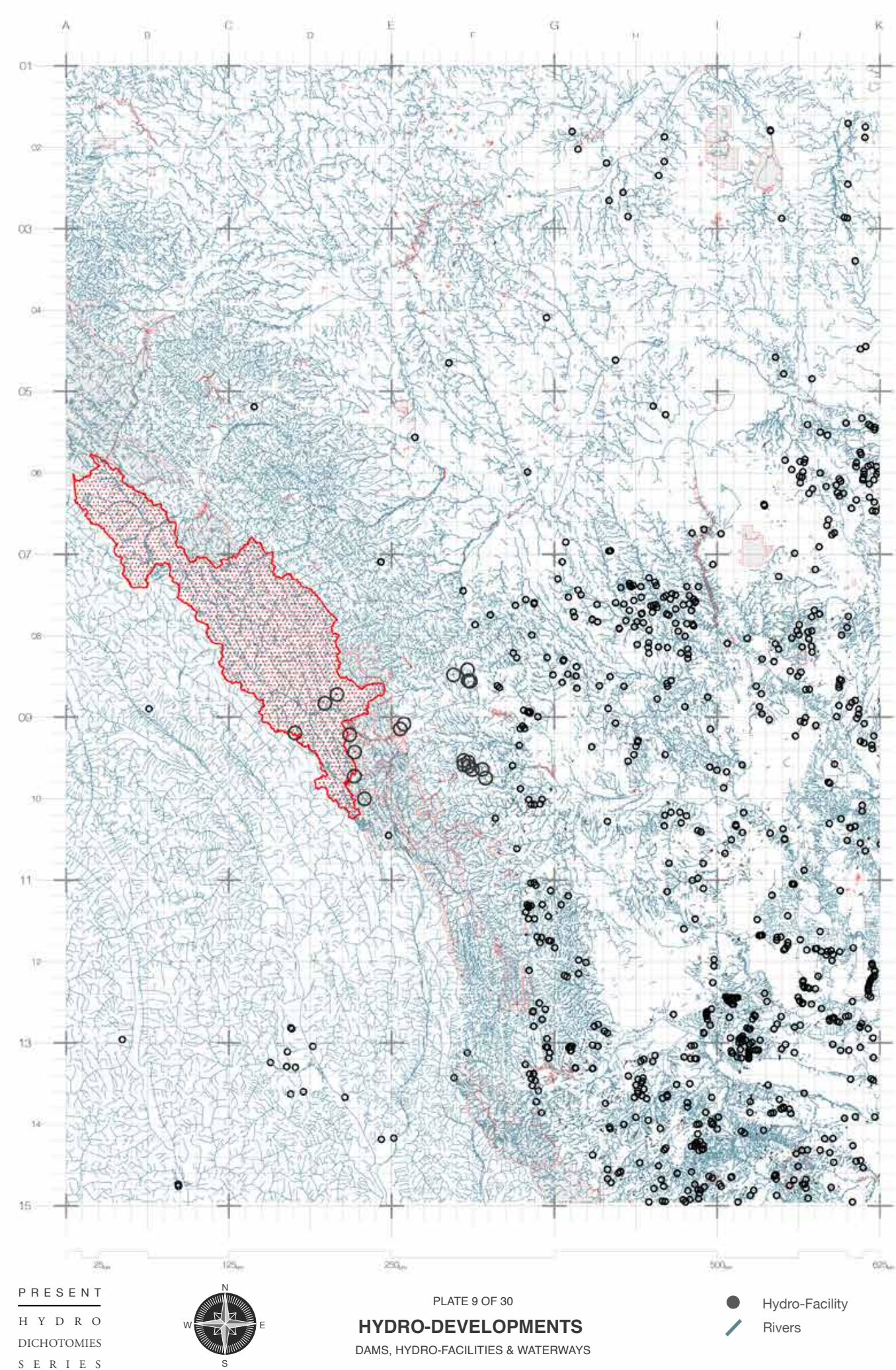

Fig. 2.3.10. Atlas Entry 09: Hydro-Dichotomies I 


\section{ATLAS ENTRY 10 // HYDRO-DICHOTOMIES II}

Much of the debate regarding the development of dams and hydropower within the park revolved around an ambiguous understanding of conservationism itself. Preserving Canada's natural beauty for some meant an absolute restriction of all resource extraction and industry, while others believed tourism industries and resource development operations could coexist. However, even the proponents of an absence of industry within national parks, such as Arthur Wheeler, used economic arguments tied to tourism industries to strength their positions.

But Wheeler was figbting for principle. He replied: It is not a question of opposing the Spray Lakes power scheme, but rather a desire on my part to carefully preserve the National Parks of Canada from spoliation, and I am now figbting for the recognition of a great principle which principle at the present is threatened.' Pearce found this illooical and absurd. People were obsessed with the idea that Parks should be maintained as nature left them. No one would be able to use them, except a few backpackers. There could be no fires and no tents. Nor any improvements, and in the Spray Valley the dam would be an improvement. A 'marshy, mosquito breeding area' would converted and maintained in perpetuity, summer and winter, as an attractive sheet of water with a firm margin all round. ${ }^{19}$

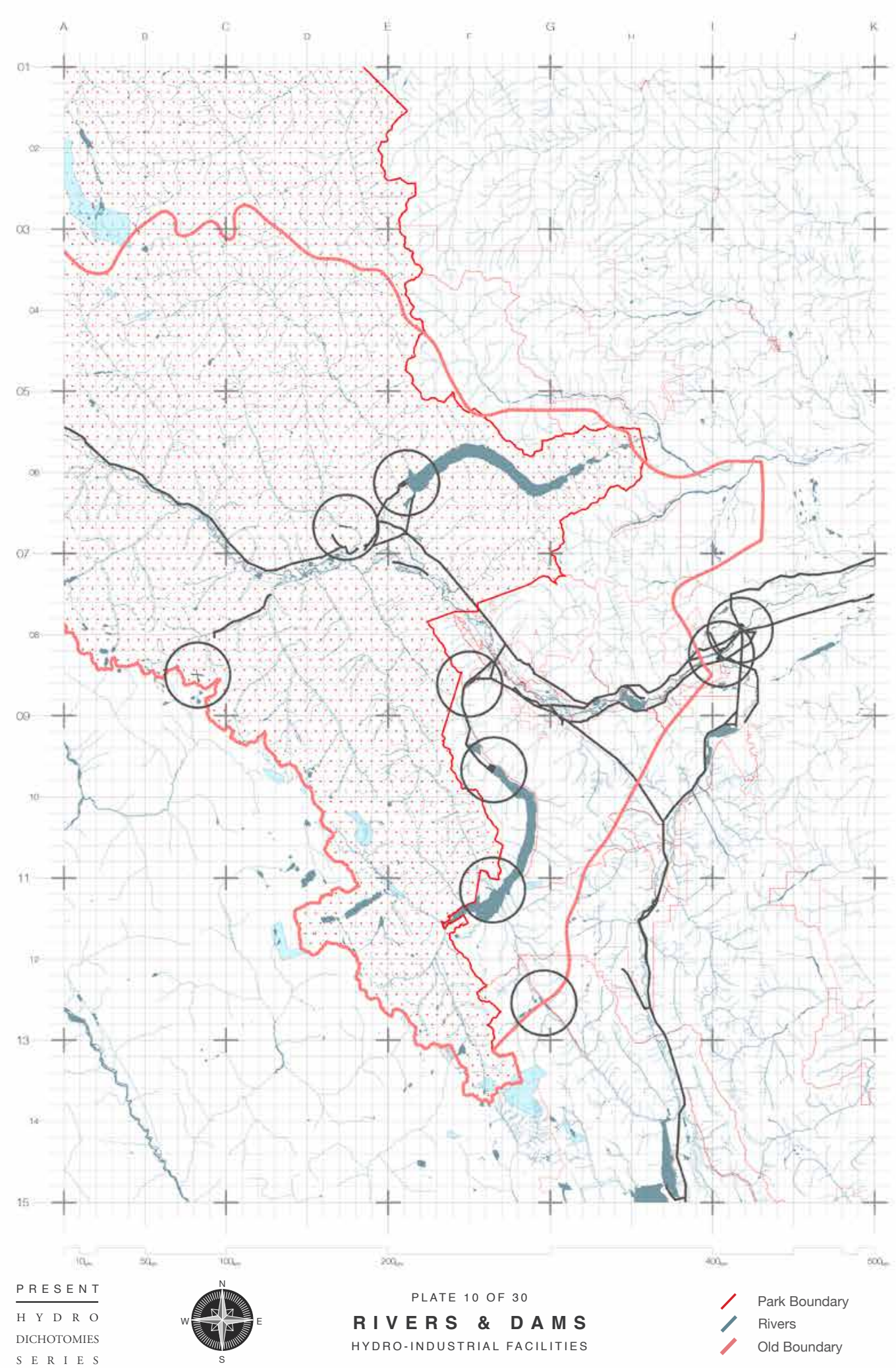

Fig.2.3.11. Atlas Entry 10: Hydro-Dichotomies I| 
ATLAS ENTRY 11 // HYDRO-DICHOTOMIES III

The need for an economic argument to justify setting aside national parks meant a constant affiliation of the spaces with tourism industries and infrastructure such as the chateaus of the CPR. With the future of the Canada's economic prosperity at stake, notions of romanticized wilderness alone were not enough to outweigh the potential profits from the valuable resources that national parks held within their landscapes. Instead, the profits that could be extracted from industries of "selling scenery" became the political lifeline of Banff National Park and national parks across Canada.

But even Wheeler was reluctant to defend the parks in purely non-economic terms. He cited the classic comments other Parkes Commissioner Harkin that pars are for profitthough profit 3 was fru "From a straight commercial standpoint, our parks are one of our most important resources. The public has no conception of their value". He calculated the value from tourists visiting the parks: "Capitalize that revenue (from tourists) at 5\%, and on that basis the Canadian National Parks are worth in actual dollars \$360, 000, 000... I Emphasize the commercial side because I find that the general public persists in the idea that National Parks are simply frills and luxuries. Nevertheless, on the basis of cold-blooded commercialism, I don't think. there is an institution in Canada that pays as big a dividend as the Canadian National Parks."

The parks contained the resource base for provincial economic development; timber, coal and hydro potential. Without control of the Rocky Mountain watersheds, the province would also be without water for irrigation and unable to control flooding. ${ }^{21}$

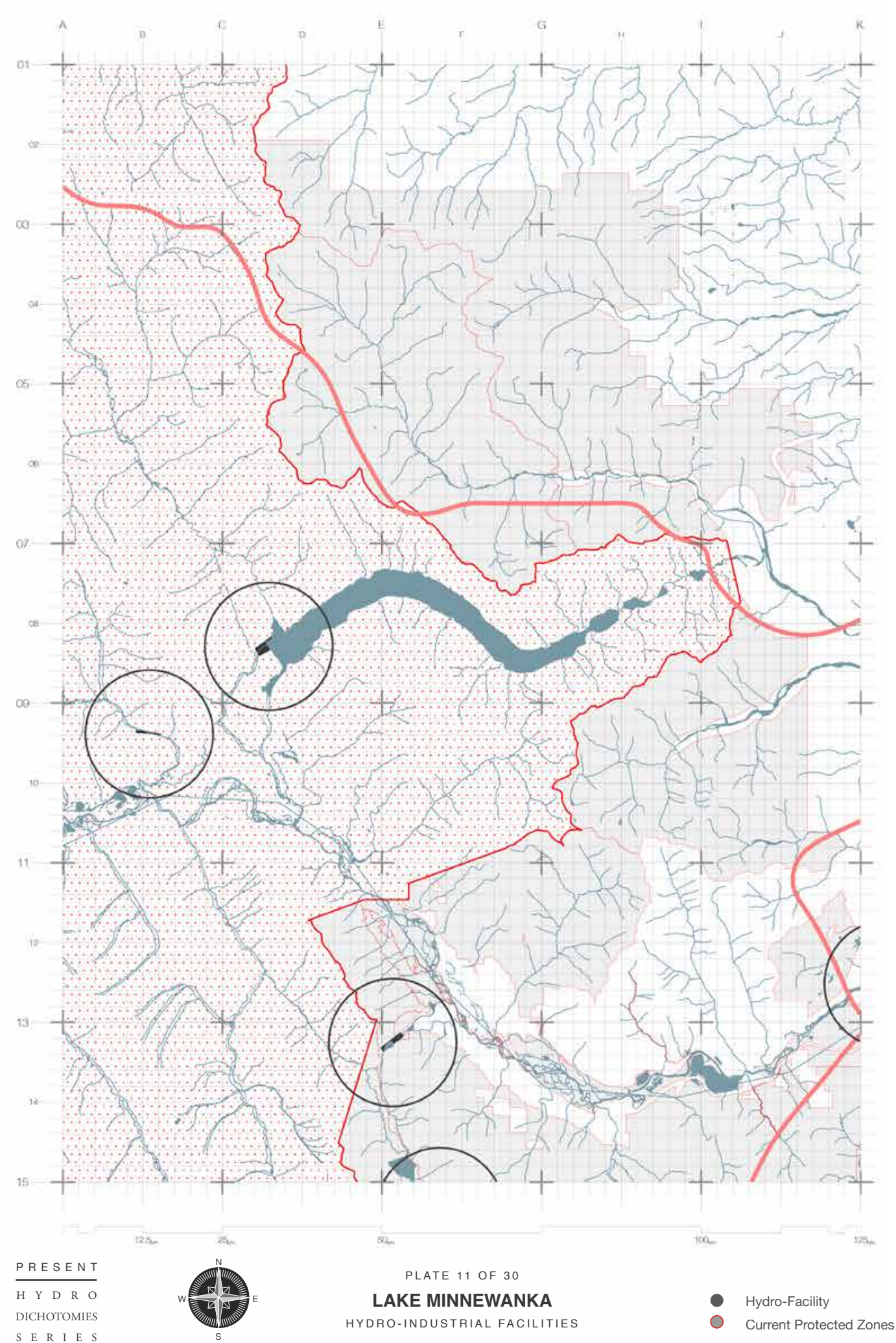

Fig.2.3.12. Atlas Entry 11: Hydro-Dichotomies II 


\section{ATLAS ENTRY 12 // HYDRO-DICHOTOMIES IV}

The development of the spray lakes reservoir in the 1920s would put an end to the ongoing debate concerning hydrodevelopments. Though the application was approved, it marked a turning point in park policies, which would henceforth significantly restrict any industrial uses of the park. The territory would be set aside from industry to preserve it for the use of future generations. However, even with these changes in policy, the manipulation of the park boundaries enabled developments with enough economic viability to cut out of the park through the re-drawing of park boundaries, allowing industry to be pursued just beyond park space.

Areas of "commercial value" included Canmore and its coal mines, and the coal mines east of Jasper. Exshaw, with its cement plant, was taken out of Banff Park. More than 1,300 square miles of timbered land was taken out of the parks, and contributed to Alberta's resource base. So also was the Spray valley, with its hydro-potential. Boundaries were redramm to exchude them all. WVilliam Pearce had been infuentiat for

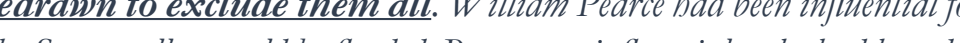

Politicians claimed that little of any value was left in the parks, except the scenery: 'This land is very desirable from a scenic point of view [but] as far as we know the are has no mineral value.' With commercially valuable land removed, the scenery in the parks could be preserved. At least, preserved from mining. lumbering and hydro-electric dams. But, Harkin and Wheeler had not argued purely for the intrinsic value of the scenery, for the preservation of natural landscape. They had used one economic argument to counter another, insisted that beautifu scenery was in itself a source of profit - a source of tourist dollars. This argument dominated decisions about Canada's national parks through the thirties and forties, and prevails even today. Wheeler and Harkin saved the national parks from one kind of exploitation, but by ensuring their exploitation from another. In 1930 the new National Parks Act entrenched a system and philosophy of parks for profit.

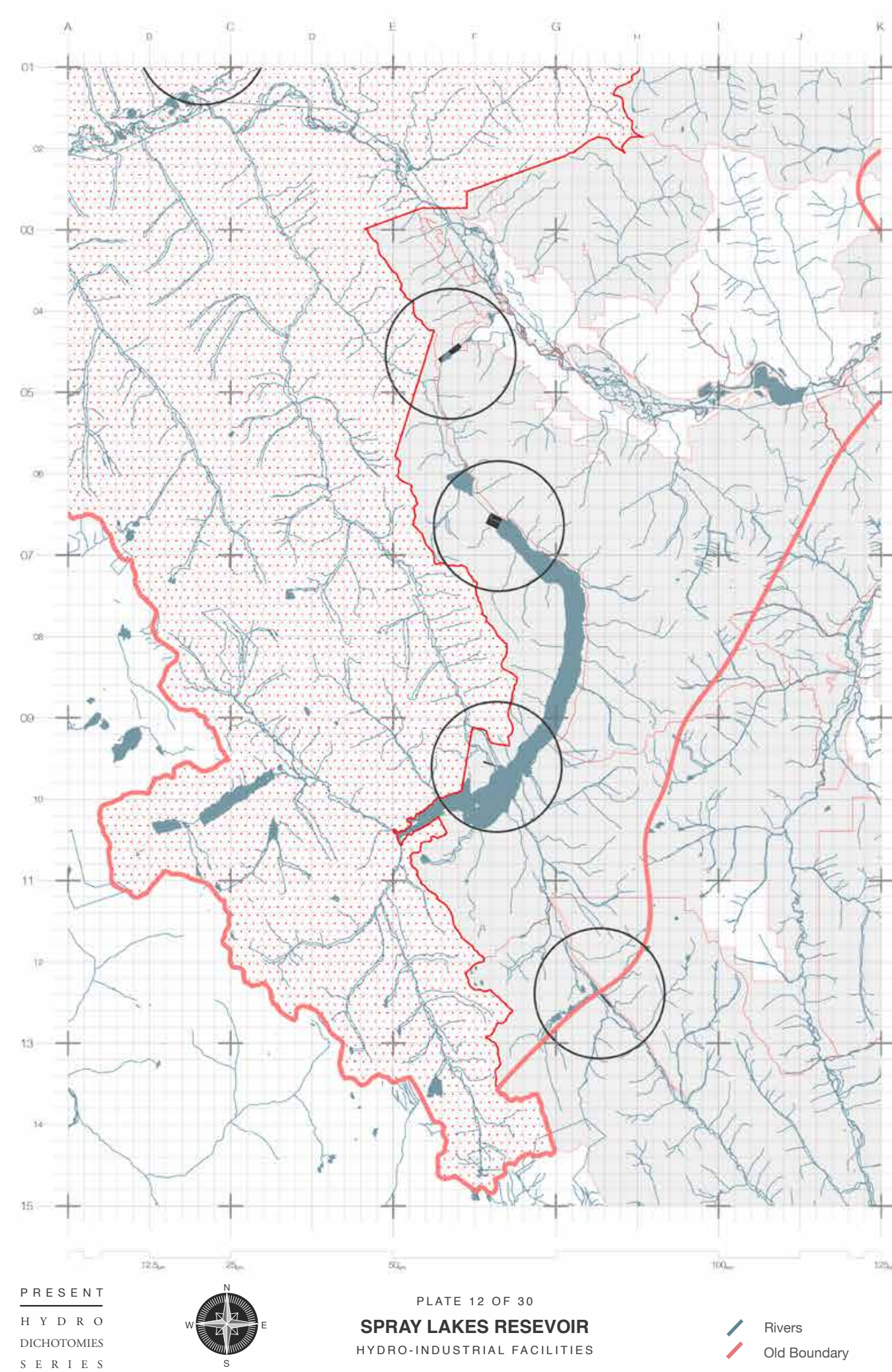

Fig.2.3.13. Atlas Entry 12: Hydro-Dichotomies IV 


\section{ATLAS ENTRY 13 // EXSHAW CEMENT PLANT}

Similar to the town of Canmore and the Spray Lakes Reservoir, the Exshaw cement plant was removed from the territory of Banff National Park in 1930 when the boundary was redrawn. The plant is located along Lac Des Arcs, a lake and valley that impressed William Van Horne so much that he initially wanted it to be the poday, the cement plant at Lac Des Arcs remains one of the most visible industrial sites in the area, with its proximity to the Trans-Canada Highway ensuring it is one of the first sites that visitors see as they enter the eastern front ranges of the Rocky Mountains.

In 1883, traveling west on his new railway, Van Horne saw the Bow Valley. He passed Lac des Arcs just after a fresh snow fall. The scenery impressed him. He asked William Pearce, a surveyor with the Canadian government's Department of the Interior, to arrange for reservation of a park. He suggested that title of the land for the park. could rest with the CPR or with bimself, to stop "despoliation by the advances of civilization in the guise of minders and lumbermen". Van Horne would then "build a fine bouse in the island in the lake". Surveys were incomplete, so a park could not be reserved. Van Horne changed his mind when he saw Lac des Arcs the following spring. [...

C...For some time people chuckled as the passed "Van Horne's Park." Today a huge cement plant stands at Exhsam, where Van Horne wanted to build his National Park. ${ }^{24}$

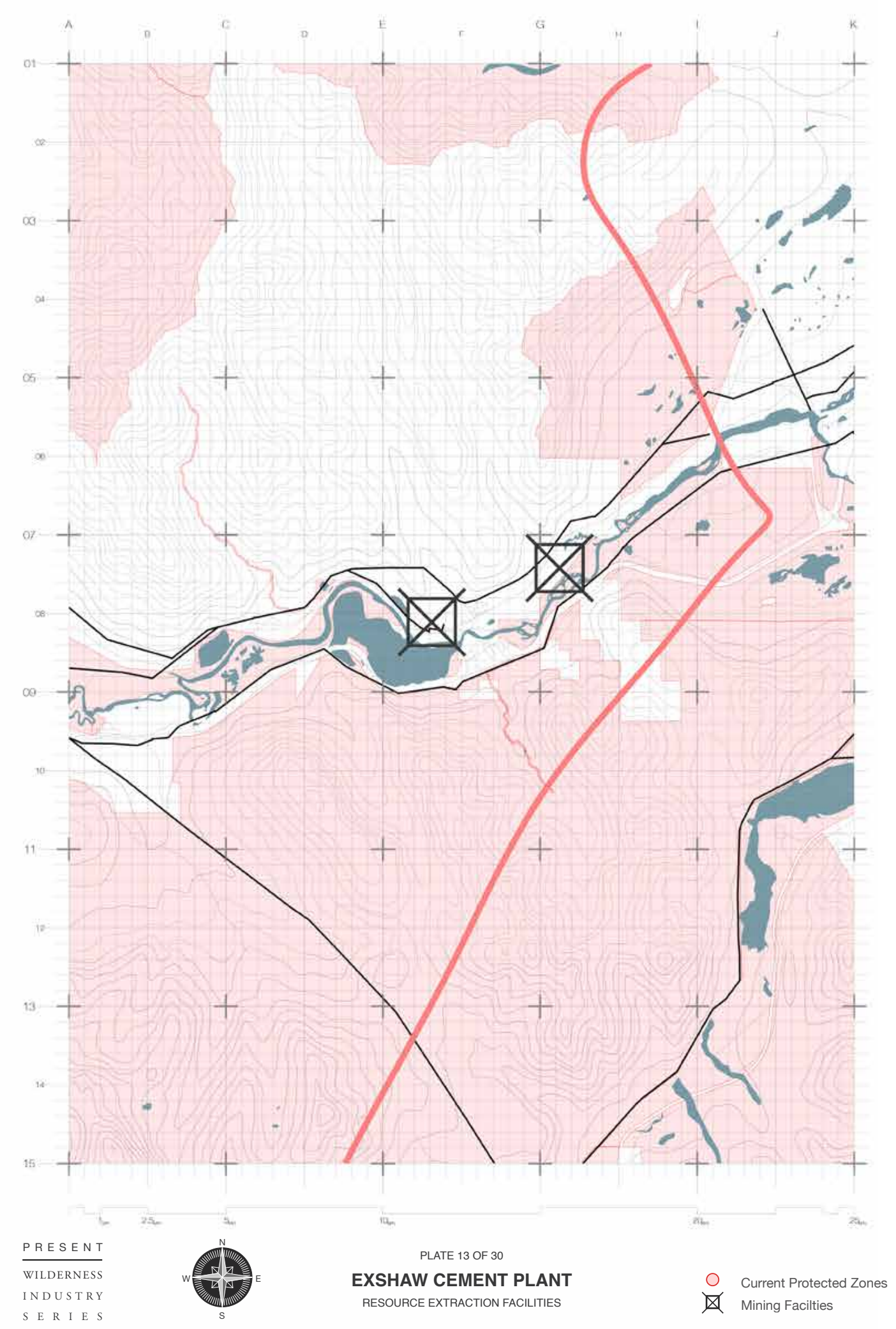

Fig.2.3.14. Atlas Entry 13: Resource Extraction 


\section{ATLAS ENTRY 14 // GRAVEL EXTRACTION}

Hydro-development was far from the only industrial use of Banff National Park. Mining and extractive industries have operated within Banff National Park since its establishment. These uses of the site remain potentially economically profitable even today, with large gravel deposits across the park suitable for use in construction industries and cement production.

Tourism in the mountain parks was financial icing on the CPR cake. In the 1890s less than half of the CPR earnings came from passenger traffic. Much of the remainder was from real estate, or from carrying freight. The most crucial source of $C P R$ income was to be from transporting western resaurces. Tourism could not be allowed to interfere with the exploitation of natural resources. Coal was needed for export, to fuel the CPR's own trains, for domestic use in the mountain towns, and to generate electricity. Coal mining continued in Jasper National Park until after the First world Warm and in Banff until after the Second. Access to other mineral resources was permitted in all the national parks - and extraction of oil, silver, copper, talc and potash was attempted. Gravel and limestone from the parks were used for local construction. Timber was culled from berths throughout the parks, for use by the mines, the railroads, and for bouse construction, freewood and fence posts. The national parks were to be a tourist attraction, but certainly not exclusivel?

Extensive extraction of gravel still continues in the parks. Most of it is used by Parks Canada itself, by the Public Works Department and in the case of the mountain parks, by the two railroad companies, $C N$ and $C P R$. A recent report acknowledged this damaged the parks, but did not recommend it be stopped. The more obvious forms of extraction, such as at Exshaw, no longer takes place in the park. But less obvious forms that be scattered in corners of the parks have been accepted. 26

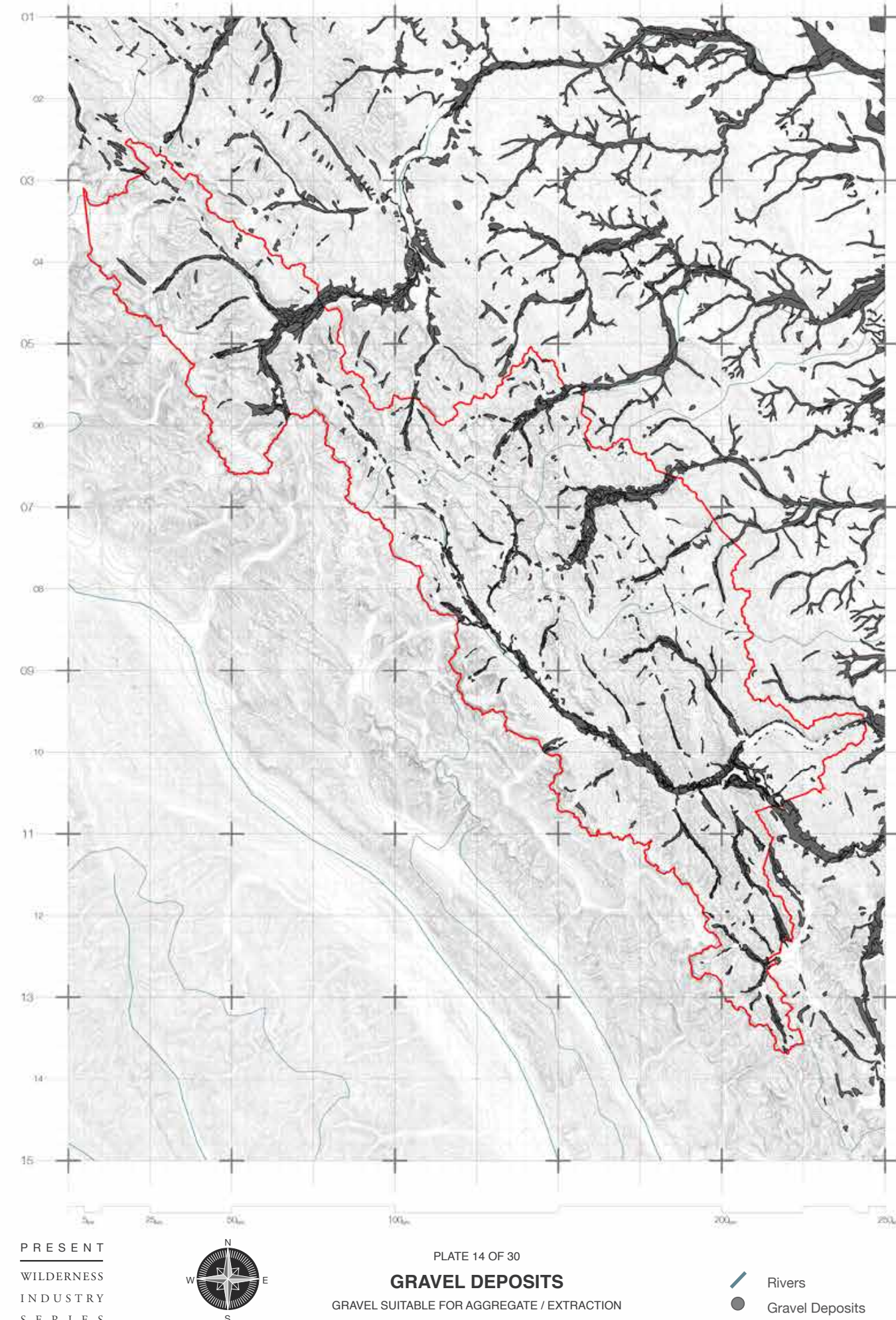

Fig.2.3.15. Atlas Entry 14: Resource Extraction I 


\section{ATLAS ENTRY 15 // MINING OPERATIONS}

The locations of mining facilities across the territory have been dictated by the location of resource deposits and their varying values over time. Similar to the Exshaw plant, mining operations that held enough financial promise were removed from Banff National Park in 1930. However, the fluctuating values of resources deposits has defined their inclusions and exclusions from the boundaries of the park. As markets fell, facilities were shut down and sacrificed to the inviolability of the national park, but as values rose, boundaries were redrawn to re-grant access to industrial sites. This pattern continues to this day, with the Albertan provincial government still seeking to regain access to provincial and national parks for extractive industries and economic profits.

Even today parks enthusiasts see the legislation of 1930 as a landmark achievement in protecting Canada's parks. And the elimination of mining, limbering and bydro-development was taken more seriously after 1930. However, for Wheeler and Harkin the decision was a major defeat. The agreement reduced the size of the Parks so that no minerals remained of economic value, and the Spray Lakes project could go abead, but just outside Banff Park. The legislation was explicit, if ponderous.

The mine at Canmore was not closed, and the town's future was settled in 1930, when the Prairie provinces took control of their natural resources. The boundaries of all the mountain national parks were redrawn, to exclude the working mine at Canmore, but leaving the closed mines of Anthracite, Bankhead and Pocahontas within the parks. Mining in Canmore continued until 1979.7

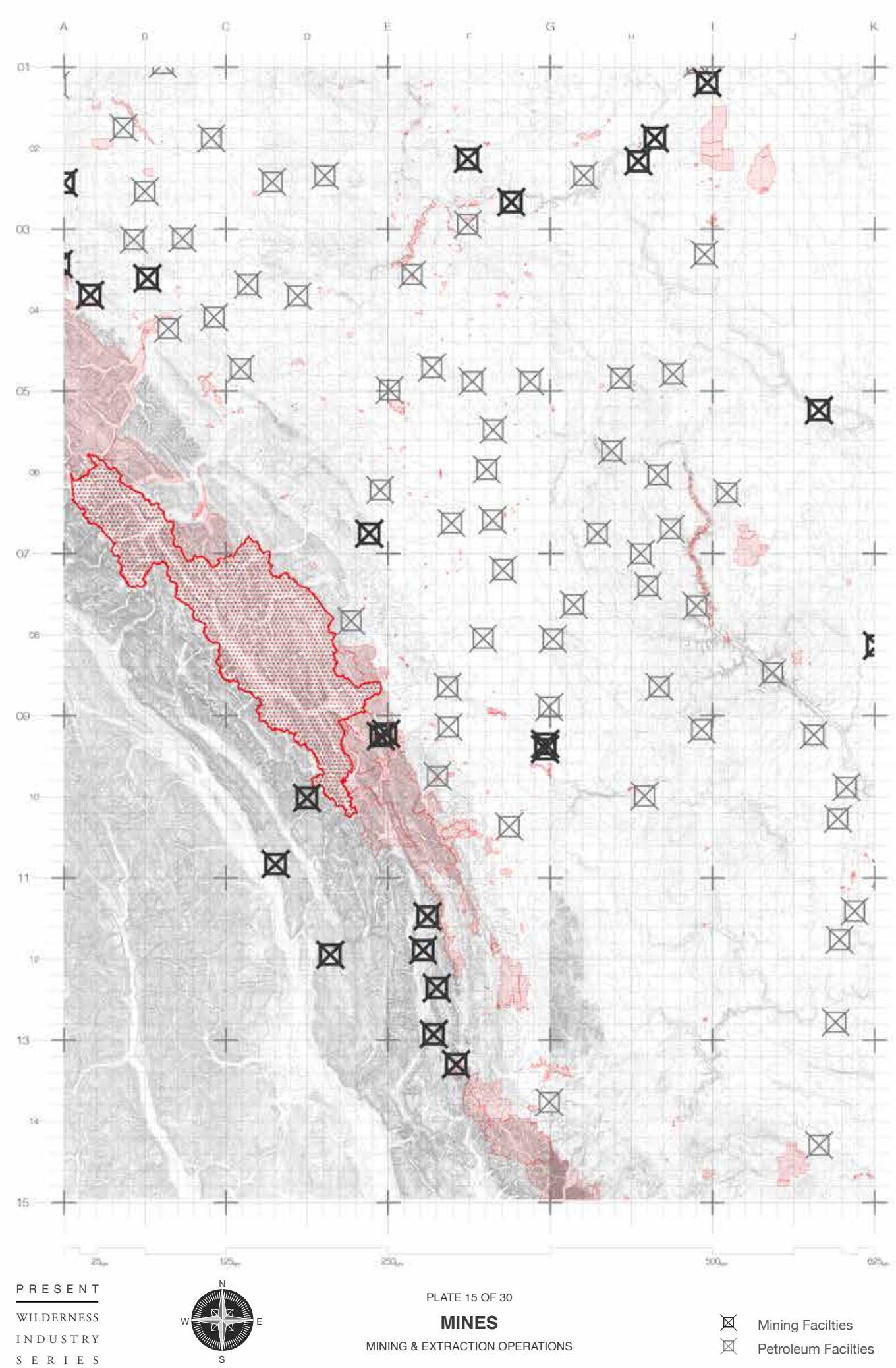

Fig.2.3.16. Atlas Entry 15: Resource Extraction II 


\section{ATLAS ENTRY 16 // PETROLEUM INDUSTRIES}

The oil wells that cover Alberta are perhaps the bestknown form of resource extraction within the province and, as an industry, have defined the economy of the region for decades. Similar to the mining operations within the area, the oil market is prone to dramatic fluctuations, leading to an abandonment of facilities as the market become less profitable. These abandoned wells and pumps across the province now pose a severe threat to the climate as they continue to leak methane and other pollutants into the landscape that surround the protected areas across the province.

Alberta, the heart of Canadian bydrocarbon extraction, has set a goal of a 45 percent drop in the industry's methan footprint from active infrastructure by 2025. But the inactive wells - the ones no longer troducing oil or natural gas but many still lingering in suspension like rombies — may be as big a threat to the planet [...

[...] After decades of booms and busts, an enormous backlog of these inactive wells has built up, and it grows about 6 percent each vear. There are now 97,920 wells, like the one on Romaniuk's land, that are licensed as temporarily suspended, compared to the province's 160,000 active wells. The inactive wells are unlikely to be switched on ever again but have not yet been decommissioned. No one knows how many are leaking methane and other pollutants [...

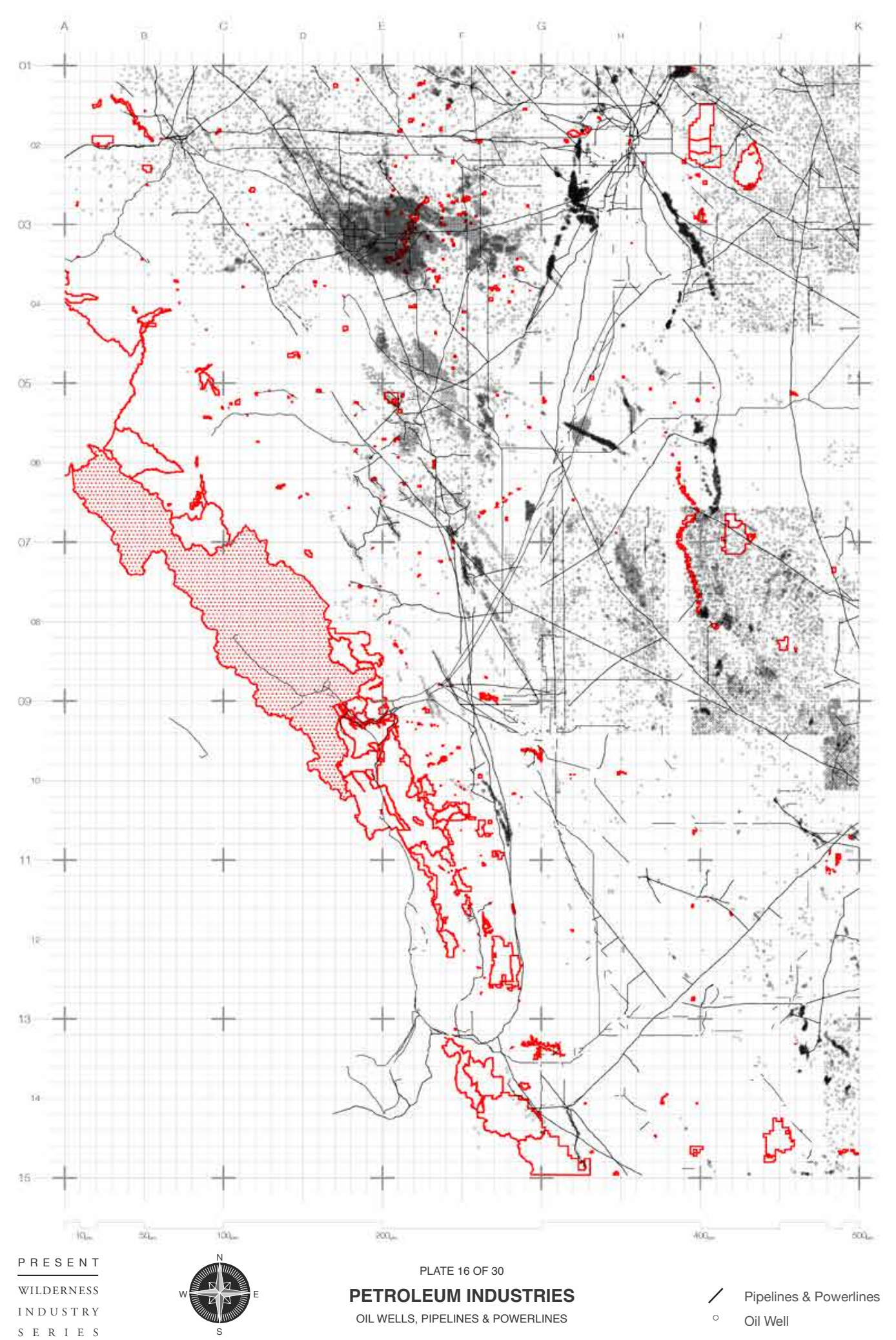

Fig.2.3.17. Atlas Entry 16: Resource Extraction IV 


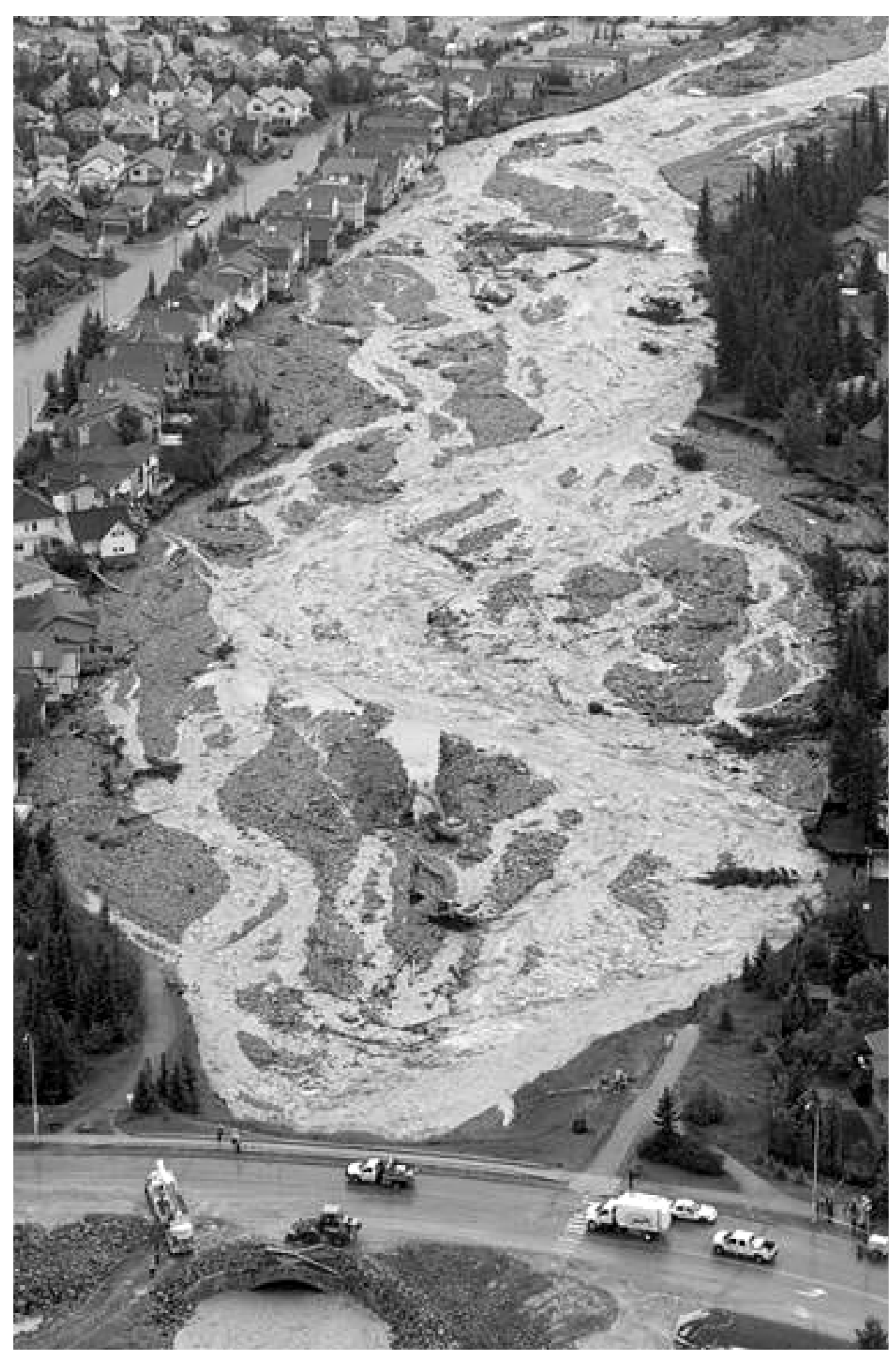

Fig.2.4.1. Canmore Flooding, 2013, CBC News
08 // FUTURE EROSIONS

Now that these bydroelectric structures have largely outlived their usefulness, who would propose pulling them down? They have become, in a strange way, part of the nature to be preserved. ${ }^{28}$

- Christopher Armstrong

Despite the long and complex history of Banff National Park being drawn and redefined, one of the essential tenants of the wilderness that it has come to represent is that it fundamentally exists beyond anthropogenic change. Aside from the infrastructure required to sustain tourism operations, the national park has often projected an image of a landscape that has withstood human intervention and industry unscathed, with any infrastructure that does exist in the park having been consistently concealed or obscured. This definition of unchanging and unaltered space, when it is applied to a landscape such as it has been to Banff, presents unique challenges in addressing anthropogenic influences over the territory and its future as a site of human industry. These challenges are exacerbated by human-driven climate change, 
with the Canadian Rocky Mountains projected to be one of the most severely affected ecological zones on the planet due to global warming, with drastic changes to the site already underway. ${ }^{29}$ Regardless of the varying ambitions and definitions of conservation, these ongoing changes to the ecological zone mean that Banff National Park, and its notion of space that was meant to be preserved from industry, is quickly becoming the most telling litmus test of its consequences.

The debates that have consumed Banff National Park and the best usage of its natural resources are already facing renewed interest. In 2020, proposals for areas within the national and provincial parks ranged from the establishment of a water-bottling facility at the Fortress Mountain Resort, to proposals of mountaintop coal mining within the Rocky Mountains. While these industrial uses continue to place pressures on the ecosystem of the site, increased tourist traffic and a rapidly changing climate are pushing Banff National Park, and its images of pristine wild space, to a precarious tipping point. Of all these pressures, the changes developing in the water-cycle and hydrological landscape of the region are perhaps the most aggressive and problematic. Some of these changes include an increased frequency of extreme climate events, such as seasonal flooding and lengthened fire seasons, as well as major changes in seasonal precipitation patterns. These changes are rapidly altering the physical landscapes of the park and its uses, and will likely be the defining force of wilderness within Banff National Park for the foreseeable future.

The third section of the New Atlas of Banff focuses on the projected future of Banff National Park and the changes that will continue to threaten the space and its established definitions. While the extent of these changes and impacts are difficult to predict with absolute accuracy, certain trends of the changing landscape can be projected with a reasonable degree of certainty, defining the space over its next one-hundred years...

Projections of future climate show confidence in continued warming throughout this century, and while there is more uncertainty on how precipitation might change on average, it is quite likely the area will see increased variability and extremes in the amount, type and intensity of precipitation. These changes are tied to a vastly and rapidly changing landscape ecosystem, and water cycle. ${ }^{30}$

The changes occurring on the site are far-reaching and complex. The atlas focuses primarily on understanding the impacts that a warming climate could have on the hydrological landscape of the site, where changes in precipitation patterns, snowmelt and seasonal flow rates are redefining the territory. The maps aim to explore how these changes will alter the space of the Park, once again redefining the experience 
of wilderness within the zone. The unique climate that defined the site, along with the images and industries it inspired, is disappearing. Temperatures in the area have increased by as much as 2 degrees Celsius since the 1960 s. ${ }^{31}$ As reported by studies conducted by the University of Calgary, these changes and have "led to an ongoing tendency towards more rainfall in place of snow in many parts of the Rockies, especially during the spring and fall seasons and at lower elevations. In association with long-term climatic changes, there have been extreme weather events in recent years, including flooding and drought, with major societal impacts." ${ }^{32}$

These new pressures, combined with the need to address the established dynamics of power and commodification that have defined Banff National Park in the past, leads to an inevitable questioning of its fate in the future and the capacity for the space to endure ever-increasing economic, industrial and ecological pressures. The dichotomies of commodifying landscapes that Banff National Park has built around an experience of untouched landscape may soon start to conflict with a need to mitigate these climate-change-driven events and their impacts. Inevitably, the central role of Banff in these various contexts will force a re-evaluation of the zone, its uses, its future significance as a water source and its role in broader re-defining of conservationism in a world where climate change has become a defining global force.

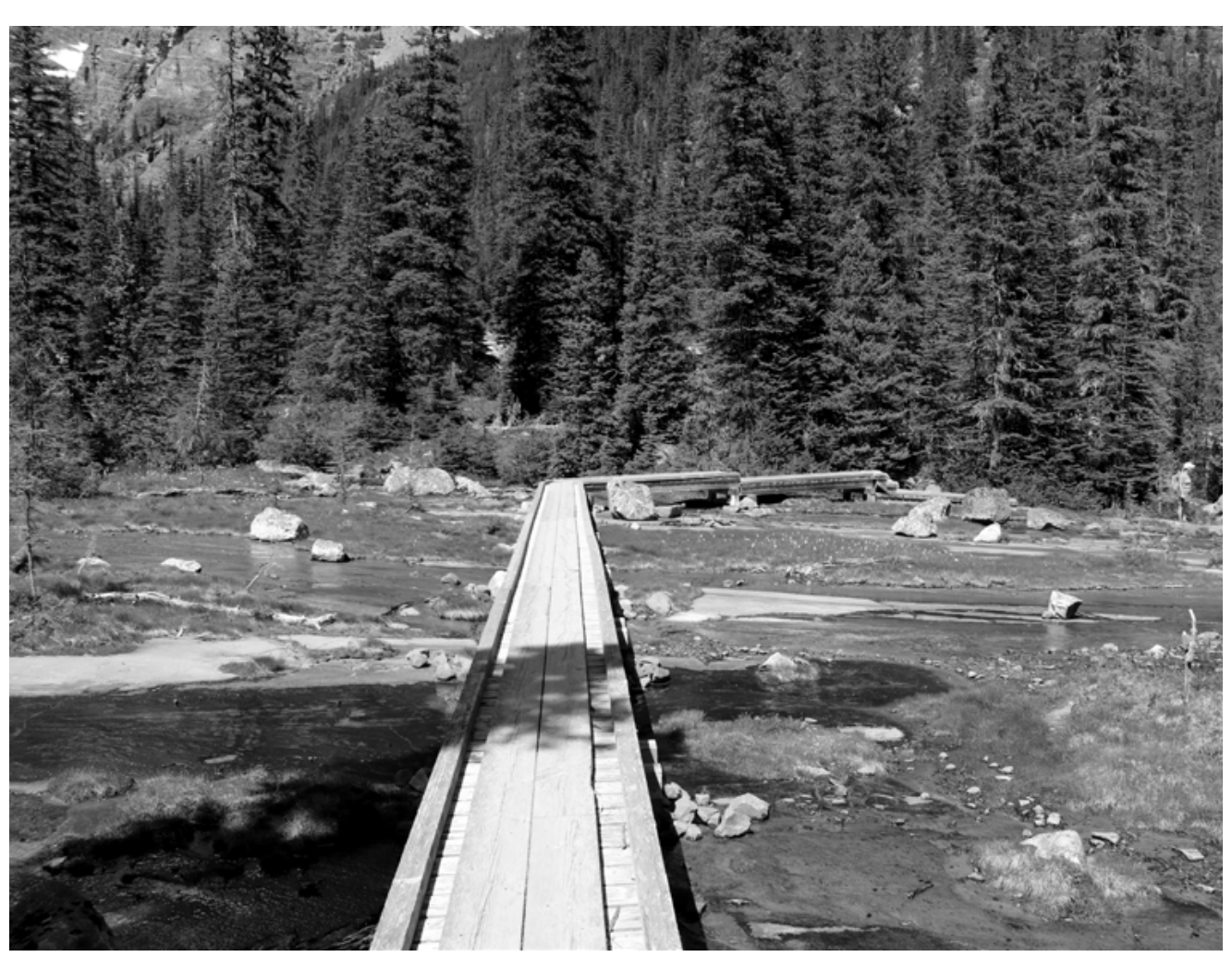

Fig.2.4.1. Hiking Trail \& Bridge in Paradise Valley, Banff 


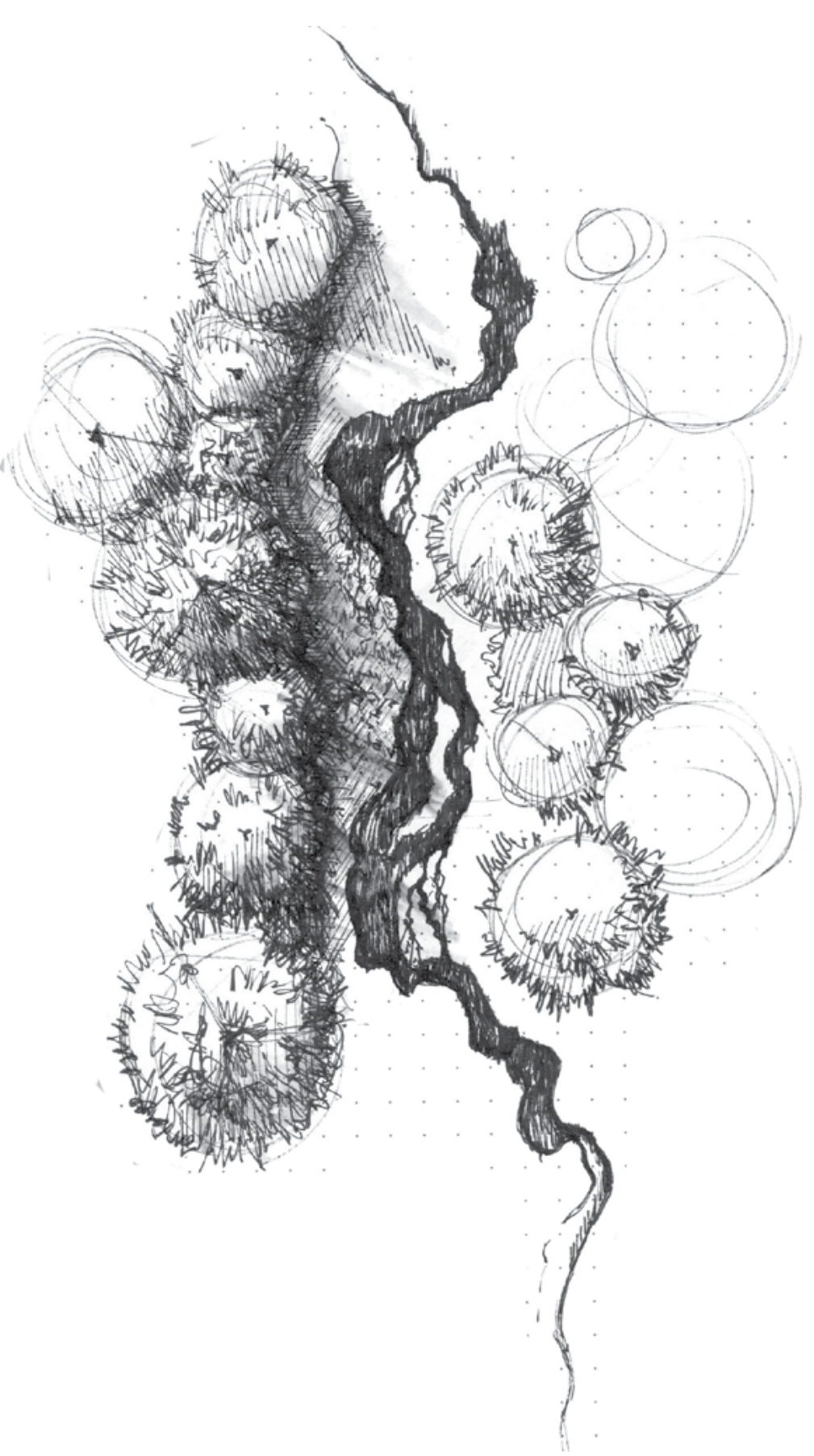

Fig.2.4.2. Creek Sketch

\section{TIMELINE 03}

A PROJECTION OF THE FUTURE OF THE LANDSCAPE OF BANFF NATIONAL PARK AND THE CHANGES OCCURING IN THE ECOLOGICAL ZONE 2013 - Flooding event devastates Bow River Valley and downstream communities,
one of the most costly natural disasters in Canada's history

2016 - Fort McMurray Willfires, the largest wildfire evacuation in Albertas history

2019 - Fortress Mountain Holdings LTD. files license to bottle and sell glacier water from kananaskis provincial park

2020 - Alberta government proposes closing 20 parks and removing 165 from alberta parks system

2020 - Policy that prohibited coal mining in parts of the rocky mountains rescinded by Alberta provincial government 2021 PRESENT

2021-2051 - Three Sisters Development proposed for Canmore, likely to nearly double 2035 - Warmer seasonal temperatures, spring arrives 5-20 days sooner in the Rocky Mountains (10)

$\begin{array}{c:c}\text { FLOOD } & \cdots \text { ATLAS ENTRY } 17 \\ \text { STUDIES } & \cdots \text { ATLAS ENTRY } 18 \\ \text { STLAS ENTRY }\end{array}$

frequency

ATLAS ENTRY 19

and severit

of seasonal

flooding events

occuring over

the next 100

years

ATLAS ENTRY 20

ATLAS ENTRY 21

ATLAS ENTRY 22

ATLAS ENTRY 23

FIRE

DROUGHT

STUIES

overlays of past

drought events and

projected changes

ATLAS ENTRY 24

lengths over the

next 50 years

2070 - 80\% of Glaciers within Alberta oै B.C. expected to dissappear

2080 - Temperatures Increased by 2-8 degrees celsius

2080 - 1 in 20 year extreme heat events now occur ever 5 years

2100 - 95\% of Glaciers within Alberta \& B.C. expected to dissappear

Fig.2.4.3. Timeline 03 


\section{ATLAS ENTRY 17 // FUTURE FLOOD SERIES I}

Canada is well-known for its expansive wilderness and abundance of natural resources, particularly freshwater. The challenges and opportunities presented by the landscapes across the country have been a constant source of political debate and economic interests. Flooding events and anthropogenic climate change now pose a new challenge to the established infrastructures that have sought to capitalize from these landscapes and their natural resources, with dams and reservoirs now a significant factor in how these events occur.

Canada has vast amounts of freshwater, in the form of lakes, rivers, and wetlands, aquifers with groundwater reserves, as well as water stored in snowpacks, glaciers, and the soil. There are over 8500 rivers and more than 2 million lakes covering almost 9\% of Canada (Monk and Baird, 2011), while wetlands occupy an estimated 16\% of the country's landmass (National Wetlands Working Group, 1988, 1997). This freshwater is fundamental to the environment (e.g., aquatic ecosystems) and to many social and economic activities, including agriculture, industry, hydroelectricity generation, provision of drinking water, and recreation. [..

... Human water management - including dams, reservoirs, and water withdrawals — has also become an important component of the water cycle. ${ }^{33}$

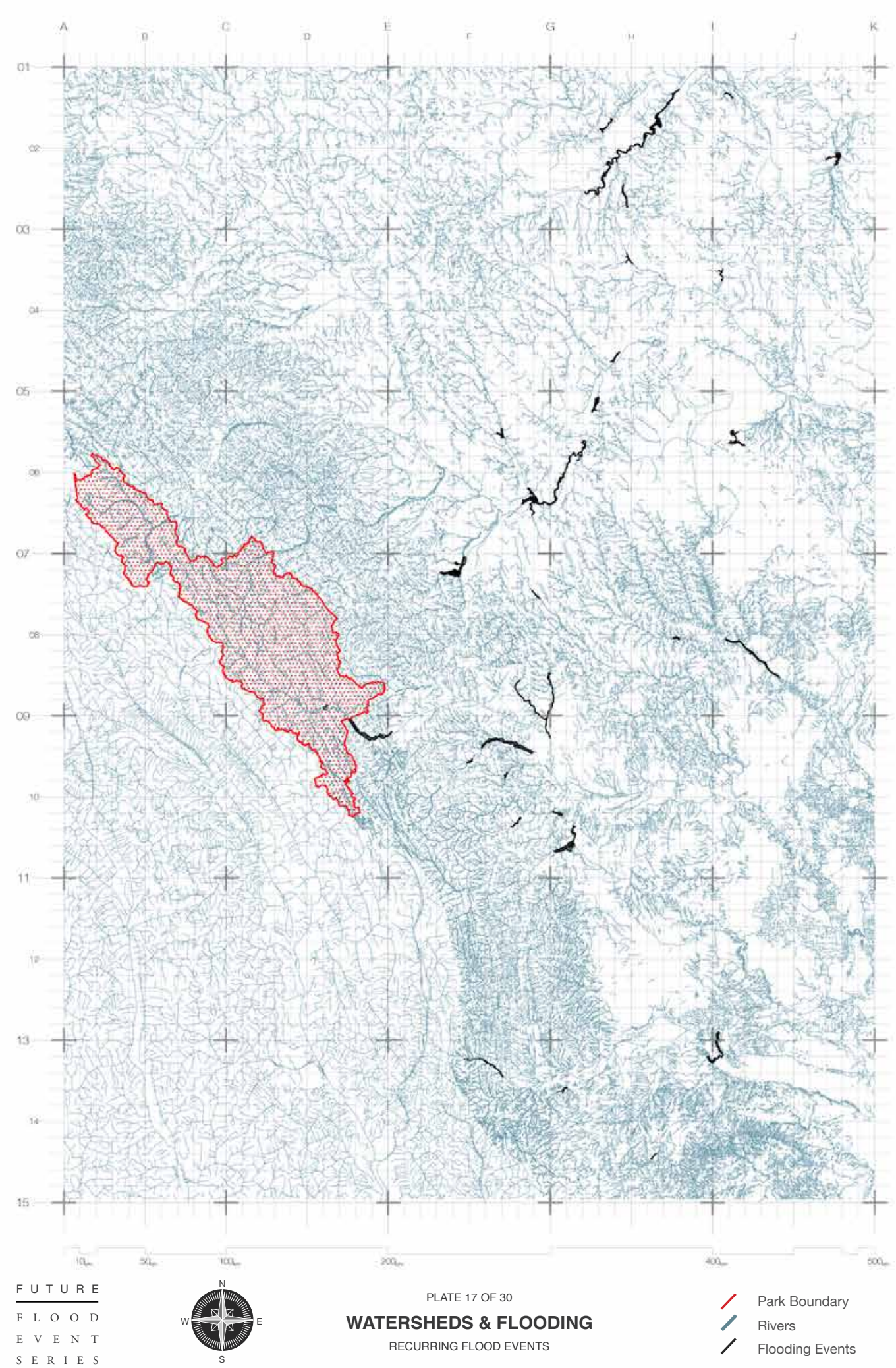




\section{ATLAS ENTRY 18 / FUTURE FLOOD SERIES ॥}

The increasing frequency in extreme weather events across Canada is already beginning to affect the area surrounding Banff National Park. Large-scale disasters that have been designated as " 1 in 50 " or " 1 in 100 " year events are becoming more common, and events that have previously been considered anomalies, such as springtime flooding or summer wildfires are becoming a regular and recurring feature of the landscape.

In the future, extreme precipitation is projected to increase in Canada. Averaged for Canada, extreme precipitation with a return period 20 of 20 years in the late century climate is projected to become a once in about 10-year event in 2031-2050 under a bigh emission scenario (RCP8.5) (see Figure 4.20). Beyond mid-century, these changes are projected to stabilize under the Lowe emiscion scom crio (RCP2.6), but to continue under the bigh emission scenarios (RCP8.5). An extreme event that currently occurs once in 20 years is projected to become about a once in five-year event by late century under the bigh emission scenario (RCP8.5). In other words, extreme precipitation of a given magnitude is projected to become more frequent. Moreover, the relative change in event frequency is larger for more extreme and rarer events. For example, an event that currently occurs once in 50 years is projected to occur once in 10 years by late 21st century under a high emission scenario (RCP8.5). The amount of precipitation with a certain recurrence interval is projected to increase. ${ }^{34}$
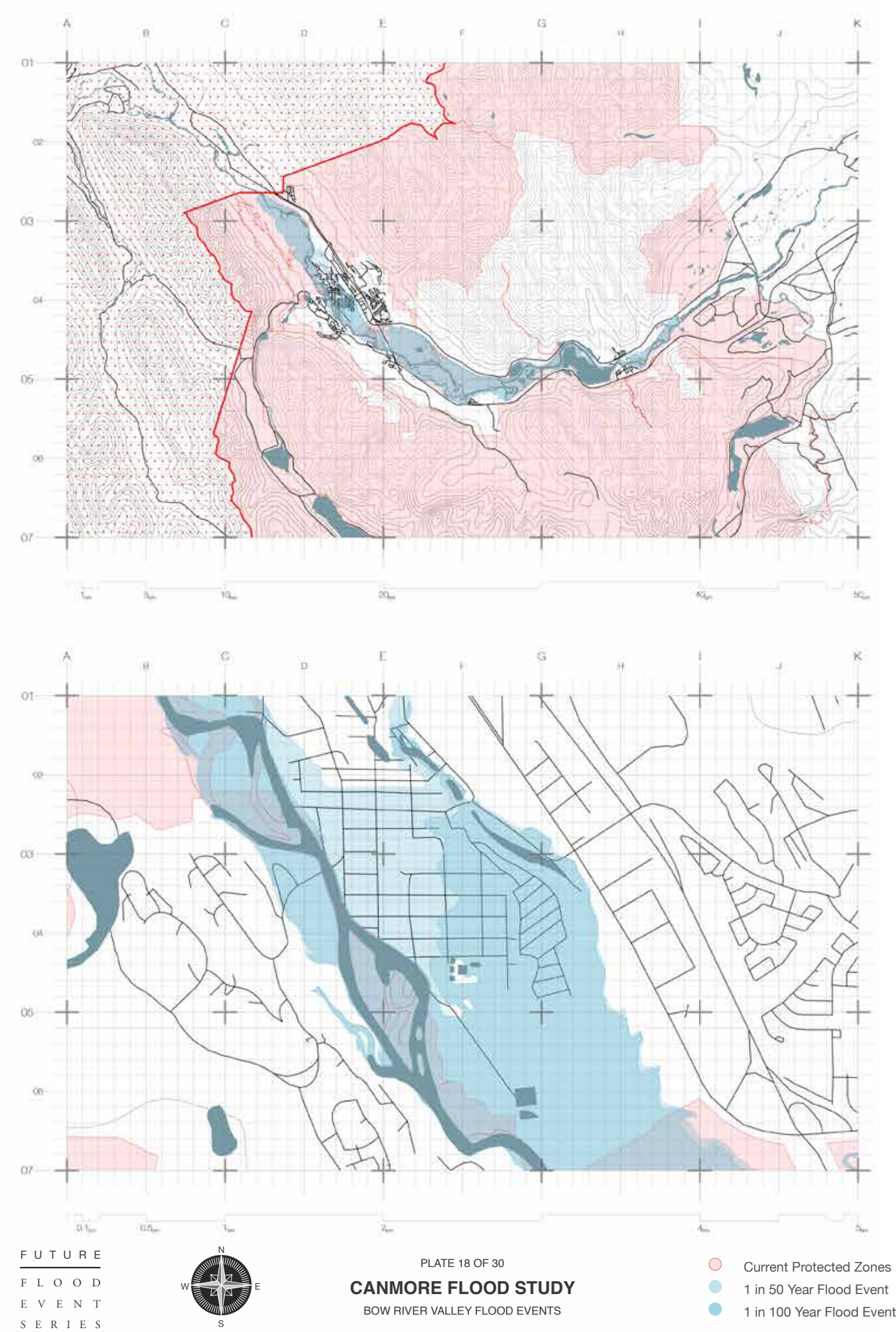

Fig.2.4.5. Atlas Entry 18: Future Flood Series | 


\section{ATLAS ENTRY 19 // FUTURE FLOOD SERIES II}

While flooding events can be difficult to attribute specific causes due to the complexity of water cycles, there is reason to believe that anthropogenic climate change is a significant contributor to these events. Under varying projected emission scenarios, these events are likely to increase in severity and frequency in the future. Communities located in the foothills and prairies downstream of the Banff National Park, located along the creeks and rivers within its watershed, will continue to be affected by the changes in climate upstream as glaciers melt and precipitation patterns at higher elevations continue to change.

A warmer climate will intensify some weather extremes in the future. Extreme hot temperatures will become more frequent and more intense. This will increase the severity of heatwaves, and contribute to increased drought and wildfire risks. While inland flooding results from multiple factors, more intense rainfalls will increase urban flood risks. It is uncertain how warmer temperatures and smaller snowpacks will combine to affect the frequency and magnitude of snowmelt-related flooding.

The changing frequency of temperature and precipitation extremes can be expected to lead to a change in the likelibood of events such as wildfires, droughts, and floods. The emerging field of "event attribution" provides insights about bow climate change may bave affected the likeelihood of events such as the 2013 food in southern Alberta or the 2016 For McMurray wildfire. In both cases, buman-caused greenhouse gas emissions may have increased the risk of such extreme events relative to their risk, in a pre-industrial climate.

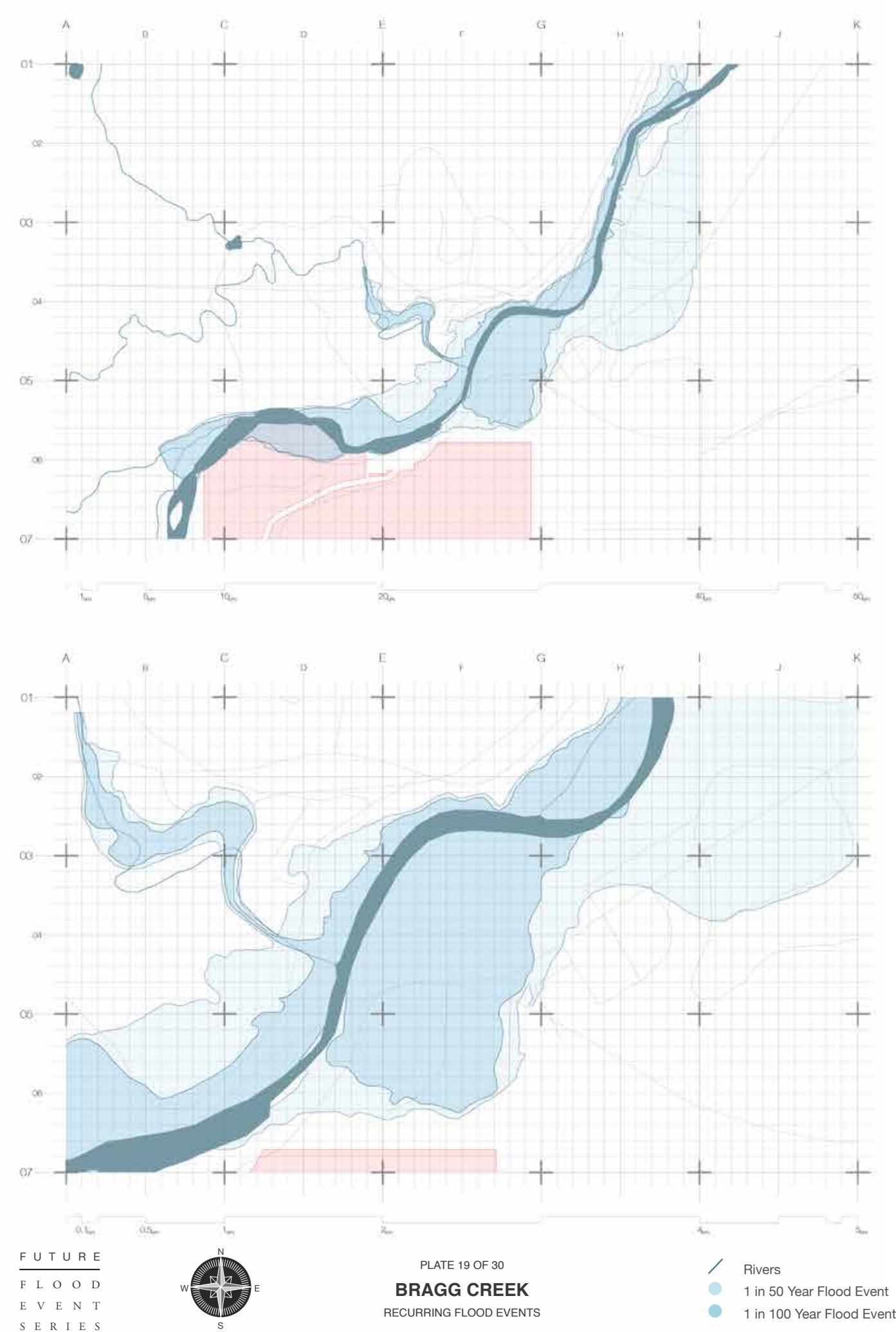

Fig.2.4.6. Atlas Entry 19: Future Flood Series III 


\section{ATLAS ENTRY 20 // FUTURE FLOOD SERIES IV}

The delicate climate of the Rocky Mountains and Banff National Park, much of which is determined by its higher elevations, is expected to change dramatically under current climate projections. The shift in

temperatures is likely to change precipitation at higher elevations from snow to rain, causing a lower degree of water retention within the zone as soil is unable to absorb water during extreme precipitation events. This effect is compounded by any existing snowpack being washed away, leading to flooding downstream.

These datasets show that temperature in Canada has increased at roughly double the global mean rate, with Canada's mean annual temperature having risen about $1.7^{\circ} \mathrm{C}$ (likely range $1.1^{\circ} \mathrm{C}-2.3^{\circ} \mathrm{C}$ ) over the $1948-2016$ period. Temperatures have increased more in northern Canada than in southern Canada, and more in winter than in summer. Annual mean temperature over northern Canada increased by $2.3^{\circ} \mathrm{C}$ (likely range $1.7^{\circ} \mathrm{C}-3.0^{\circ} \mathrm{C}$ ) from 1948 to 2016 , or roughly three times the global mean warming rate. More than balf of the warming can be attributed to human-caused emissions of greenhouse gases. Climate models project similar patterns of change in the future, with the amount of warming dependent on future greenhouse gas emissions. ${ }^{37}$

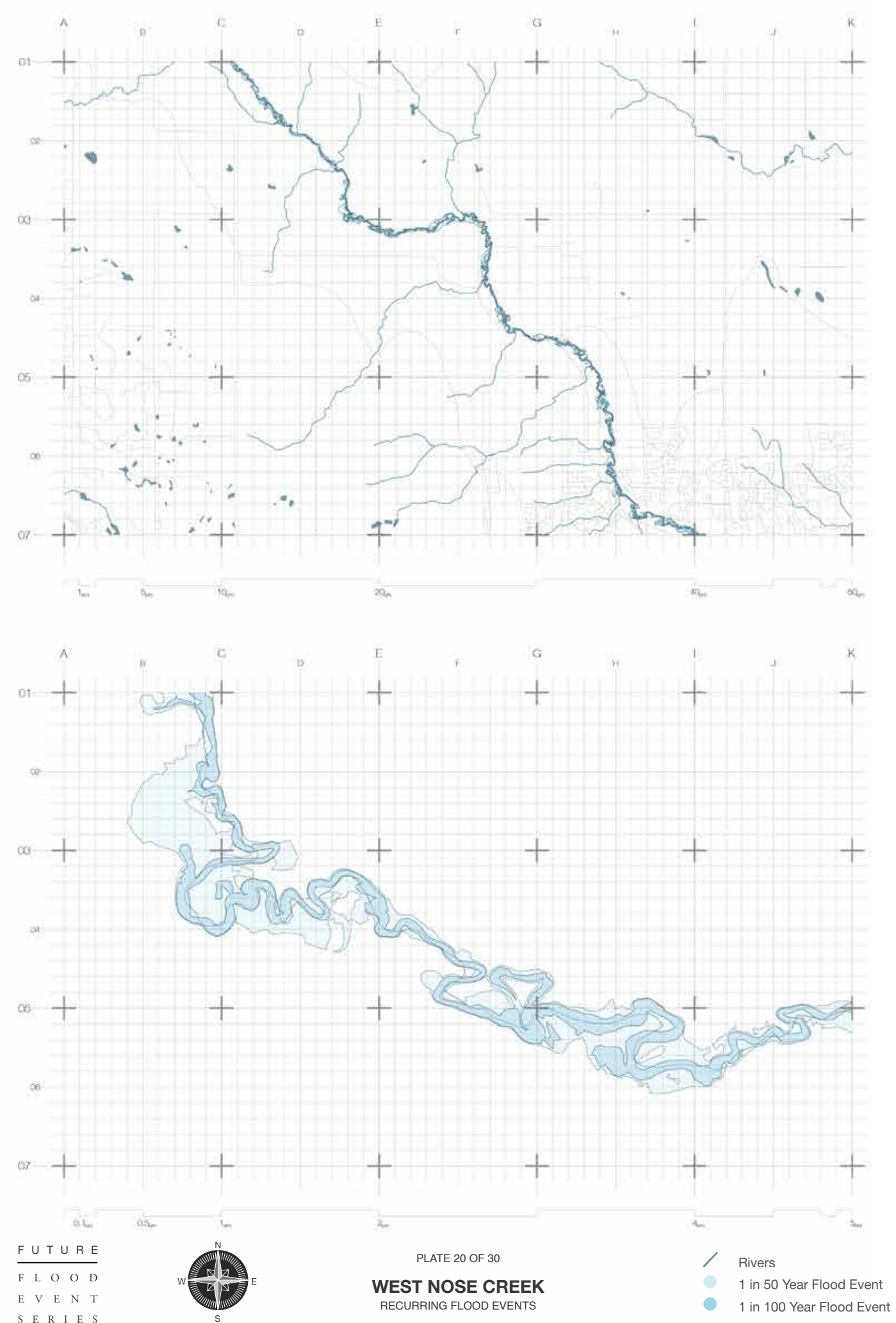




\section{ATLAS ENTRY 21 // FIRE SEASON SERIES}

Fire seasons across the province of Alberta have already increased significantly over the past 30 years. The increased length in fire seasons is expected to continue in the future, with regions across Southern Alberta and Saskatchewan being significantly affected.

In early May 2016, a large wildfire burned almost 600,000 ba (a land area covering 6000 square kilometres) in northern Alberta $\ldots$...

[...Insured losses are estimated at $\$ 3.5$ billion (IBC, 2016). The total cost of the event is still being determined, but it is expected to be considerably higher. The fire ignited near the Horse River amid very dry fuel conditions. High winds a few days later resulted in rapid spread and fire growth.....

Increasing temperatures, like those observed across Canada (see Section 4.2), will lead to drier fuels, and thus increased fire potential, as well as longer fire seasons. It would require increases in precipitation well beyond what is expected with climate change to offset increasing temperatures in terms of the FWI indices (Flannigan et al., 2016). The study demonstrated that the extreme Alberta wildfire of 2016 occurred in a world where anthropogenic warming has increased fire risk, fire spread potential, and the length of fire seasons across parts of Alberta and Saskatchewan. ${ }^{38}$

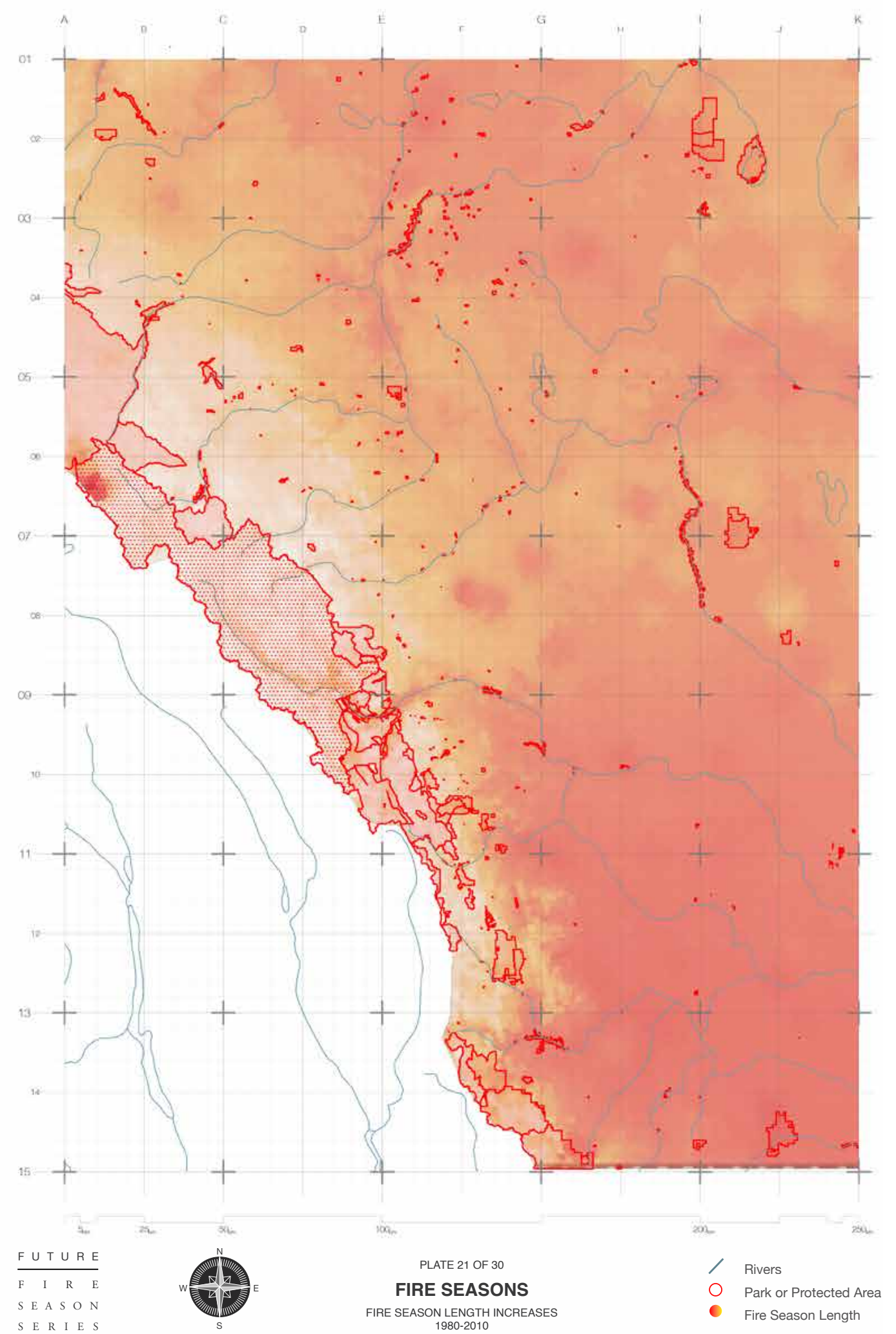

Fig.2.4.8. Atlas Entry 21: Future Fire Series I 


\section{ATLAS ENTRY 22 // FIRE SEASON SERIES ॥}

While projections for increased fire season lengths vary, regions directly east of the Rocky Mountains are expected to face more severe conditions over the next 30 years as the water-cycles of the area become less reliable throughout warmer seasons.

Antbropogenic climate change has increased the likelihood of some types of extreme events, such as the 2016 Fort McMurray wildfire (medium confidence) and the extreme precipitation that produced the 2013 southern Alberta flood (low confidence). 39

Higher temperatures in the future will contribute to increased fire potential ("fire weather"). Extreme precipitation is also projected to increase in the future although the observationel record has not yet shown evidence of consistent changes in shortduration precipitation extremes across the country. ${ }^{40}$

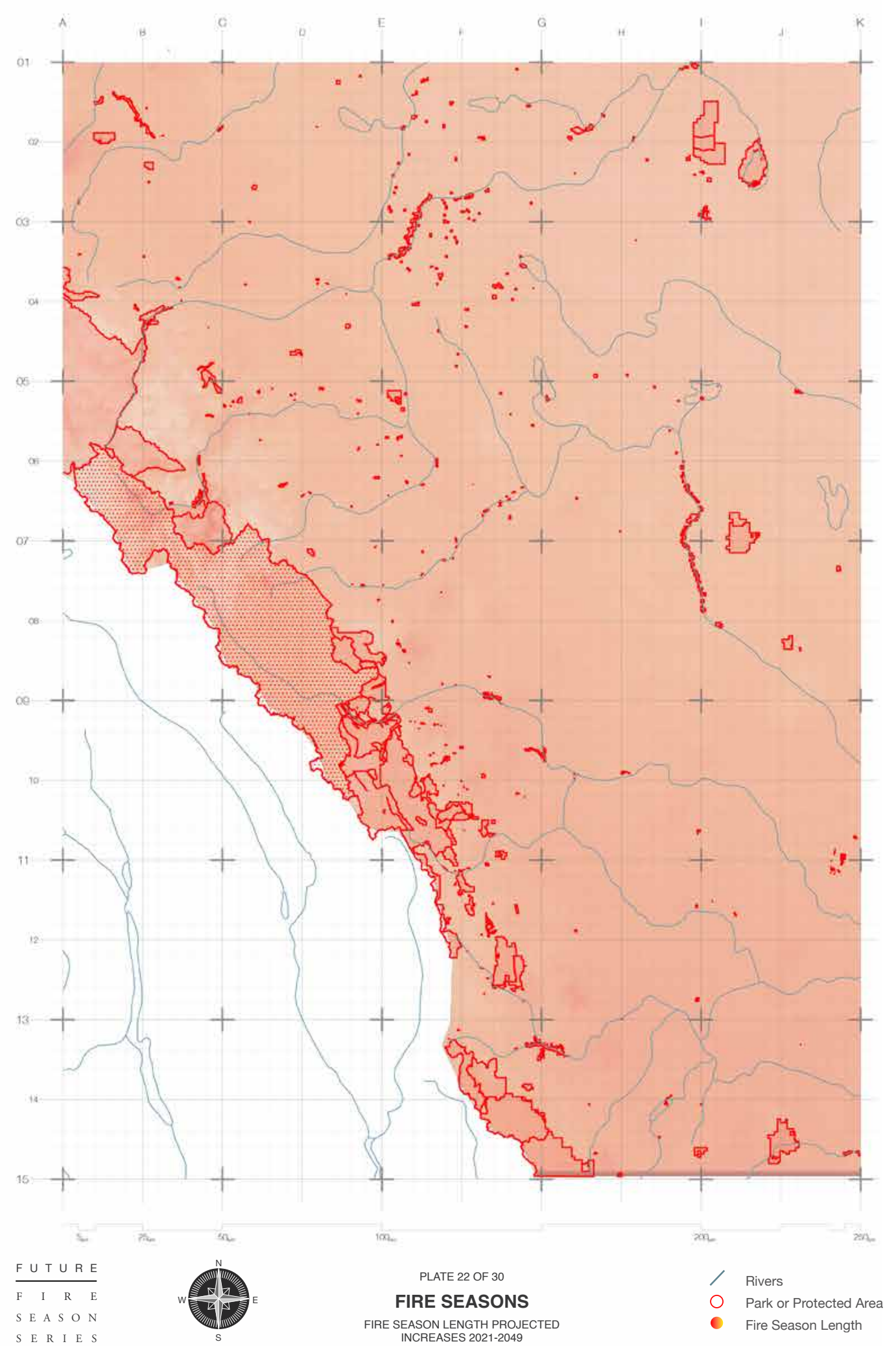

Fig.2.4.9. Atlas Entry 22: Future Fire Series II 


\section{ATLAS ENTRY 23 // DROUGHT SERIES I}

Droughts and dry seasons have affected farmlands across Alberta since the beginning of the $20^{\text {th }}$ century. These conditions have sparked numerous debates about using the glacial waters of the Rocky Mountains for irrigation. As seasonal drought conditions continue plague regions across Southern Alberta, the dependency of the province on the success of future growing seasons and farming industries may soon place renewed pressures on these debates.

Canada's Arctic and alpine glaciers have thinned over the past five decades due to increasing surface temperatures; recent mass loss rates are unprecedented over several millenniWa (very high confidence). Mass loss from glaciers and ice caps in the Canadian Arctic represent the third largest cryosphere contributor to global sea level rise (after the Greenland and Antarctic ice sheets) (very bigh confidence). Under a medium emission scenario, it is projected that glaciers across the Western Cordillera will lose $74 \%$ to $96 \%$ of their volume by late century (bigh confidence). An associated decline in glacial meltwater supply to rivers and streams (with impacts on freshwater availability) will emerge by mid-century (medium confidence). Most small ice caps and ice shelves in the Canadian Arctic will disappear by 2100 (very bigh confidence).4

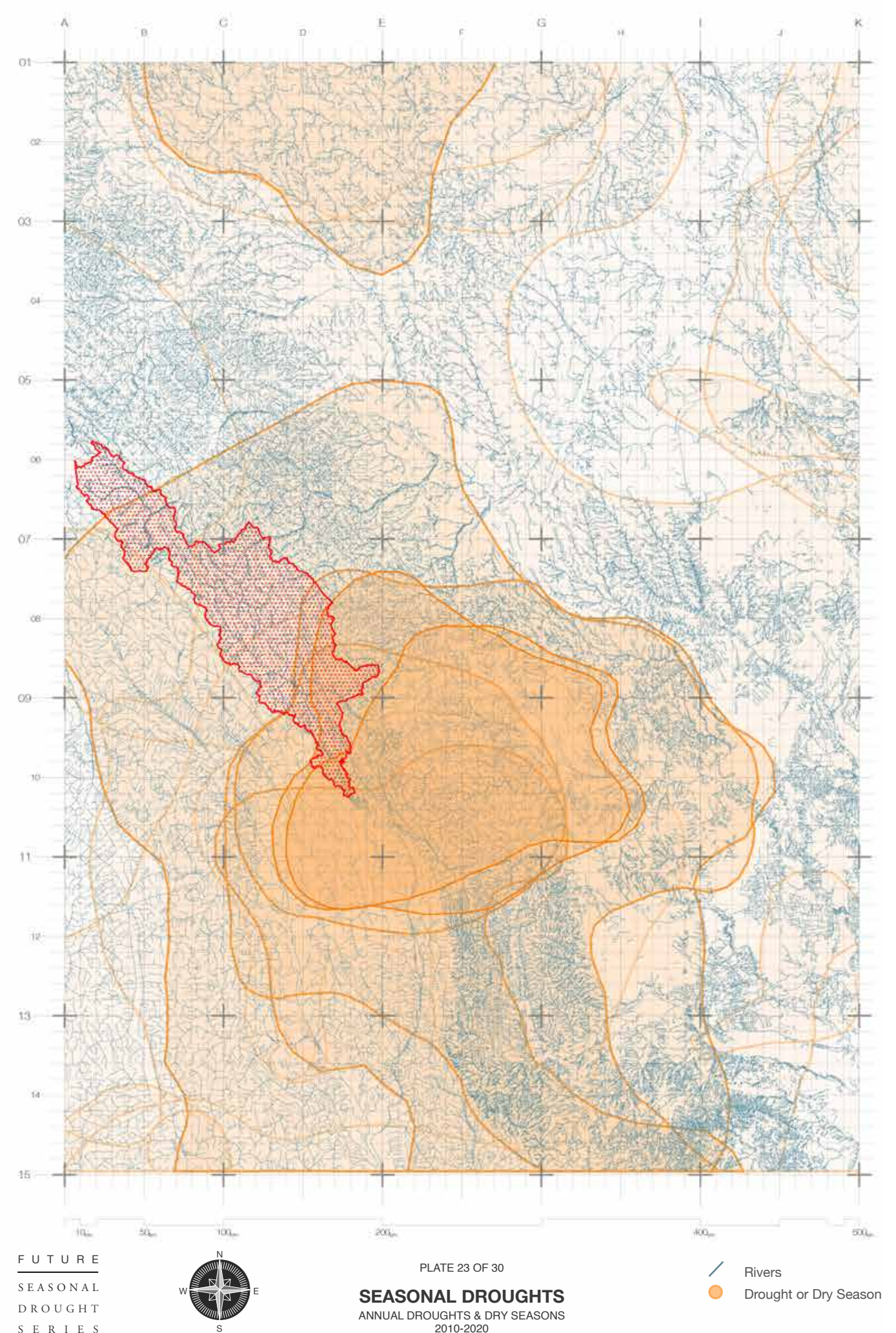




\section{ATLAS ENTRY 24 // DROUGHT SERIES ॥}

Banff National Park and much of the region located in its watershed relies on regular snowmelt patterns for human industry and usage. As these patterns destabilize and become defined by an increase in extreme events, both tourism industries and industrial operations will struggle to adapt to this new environment. A single extreme event, such as the 2013 floods that devastated Banff National Park and Southern Alberta, can destroy established park infrastructure and lead to significant economic losses. From washed out trail networks and campfire bans within Banff National Park, to impacts on crop production downstream, a warming climate will continue to redefine the landscape and its established industries.

Future increases in drought and decreases in surface soil moisture are anticipated during summer in the southern Canadian prairies and interior British Columbia, where moisture deficits from increased evapotranspiration are projected to be greater than precipitation increases. These changes are expected to be more prominent toward the end of this century under higher emission scenarios; however, there is considerable uncertainty in their magnitude Grounduater vstems are complex and, although it is expected that chande. to temperature and precipitation will influence future levels, the magnitude and even direction of change is not clear. However, in the future, spring recharge of groundwater aquifers over most of the country is anticipated to occur earlier, as a result of earlier snowmelt.

These anticipated changes from anthropogenic climate warming will directly affect the timing and amount of future freshwater supplies, and they mas be exacerbated by human management alterations to freshwater systems. The impacts are expected to be more prominent toward the end of this century under higher emission scenarios, given the larger associated climate changes. Of particular concern are impacts in regions that currenty rely on snow and ice melt as freshwater sources as well as continental interior

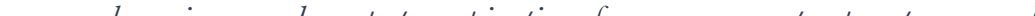

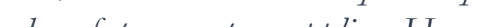
Canada are expected to be affected in one way or another. It is also anticipated that water-related extremes, such as droughts and floods, will intensiff these impacts. ${ }^{4}$

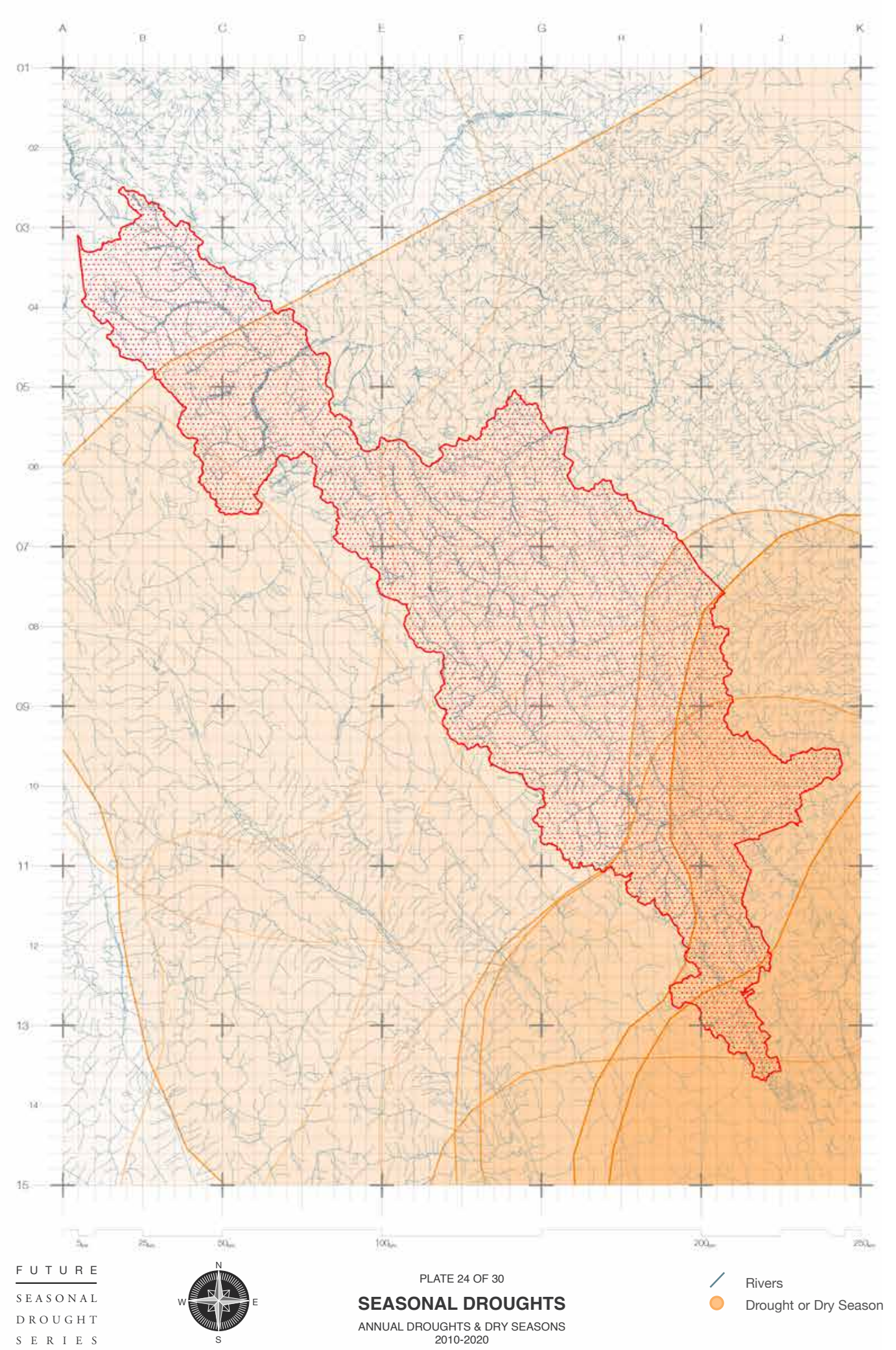

Fig.2.4.11. Atlas Entry 24: Future Drought Series II 


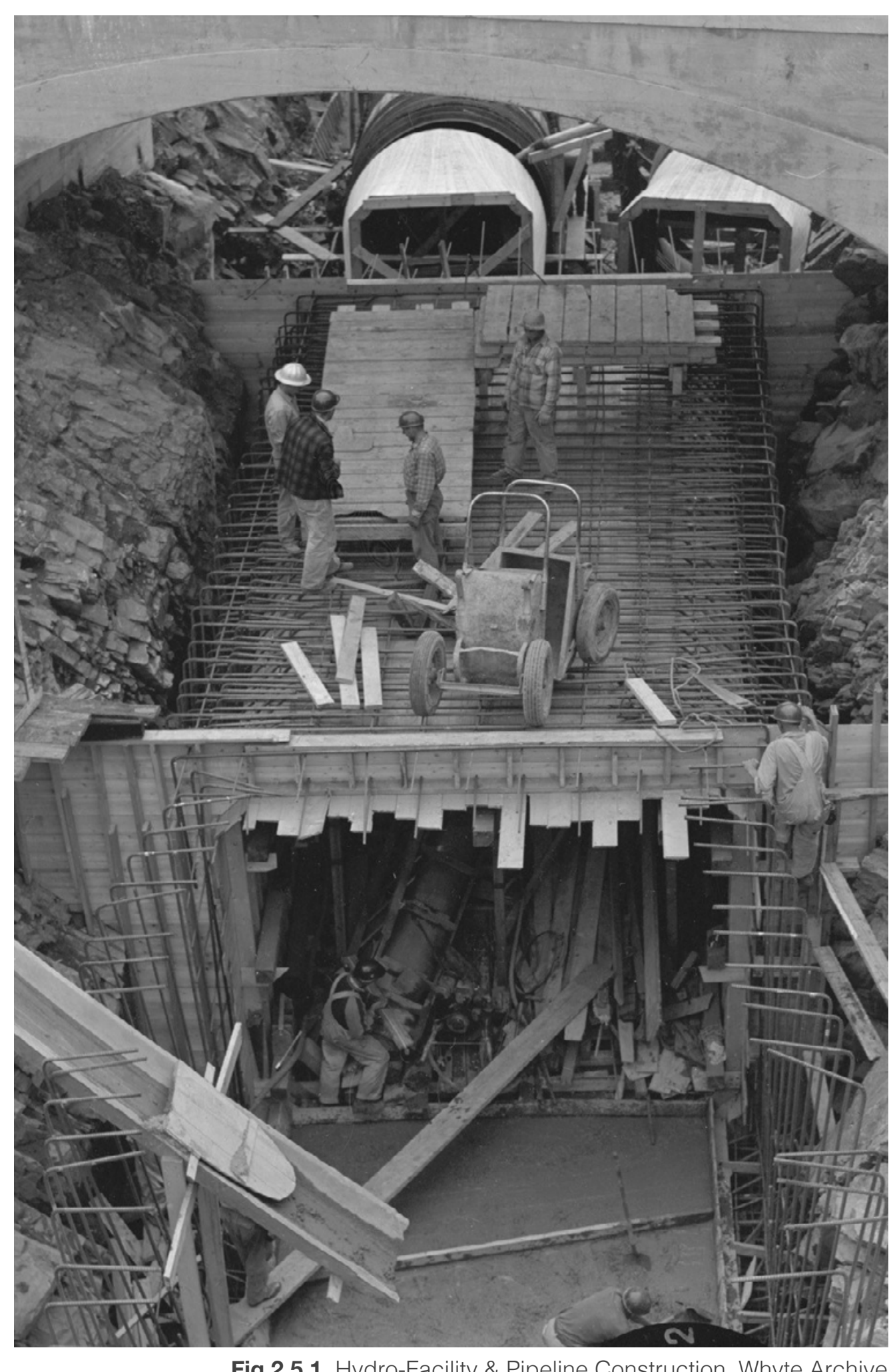

Fig.2.5.1. Hydro-Facility \& Pipeline Construction, Whyte Archive

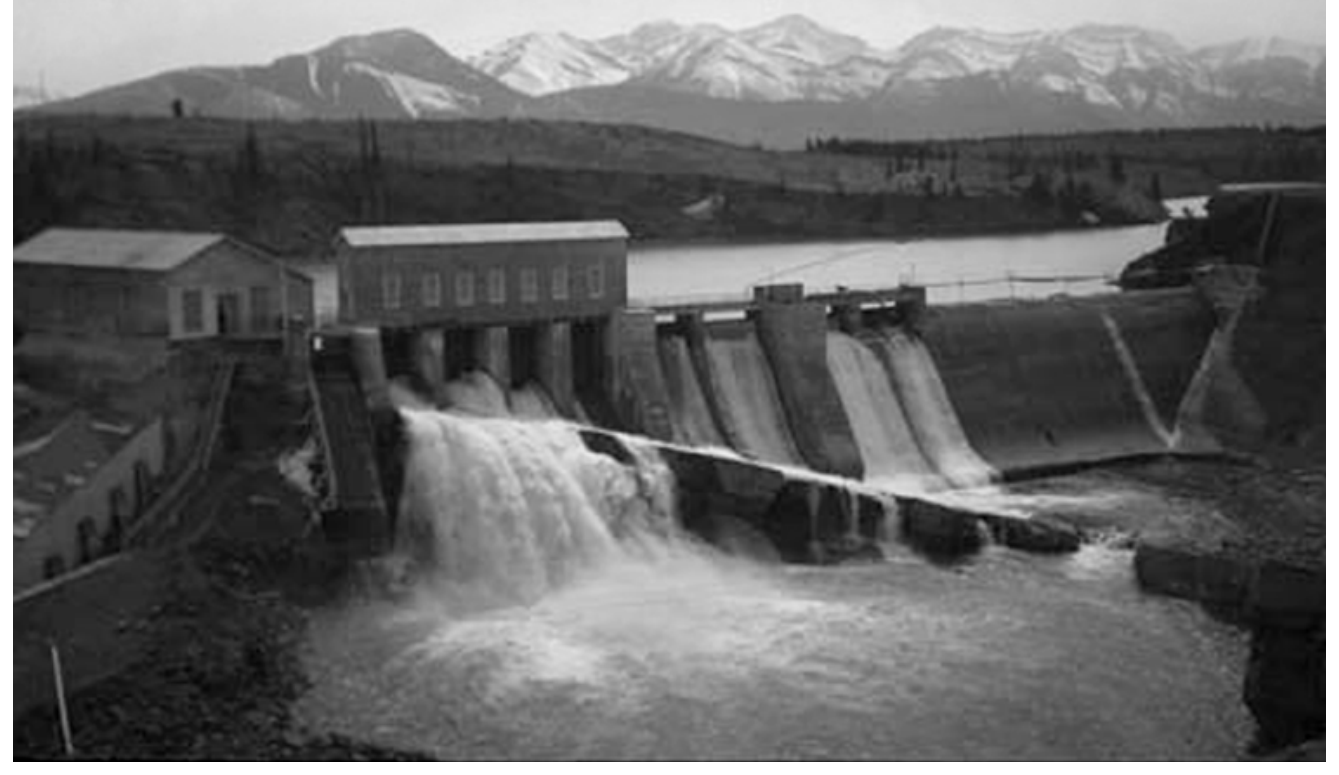

Fig.2.5.2. Horseshoe Falls \& Hydro-Facility, Whyte Archive 


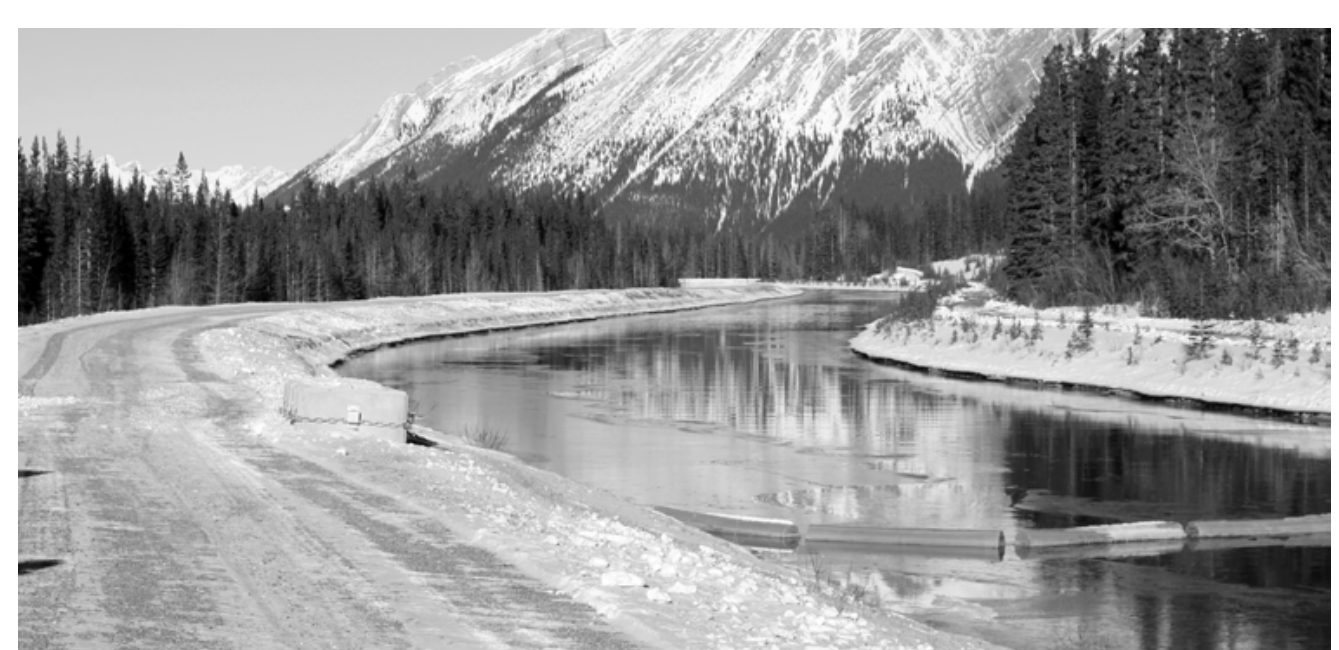

Fig.2.5.3. Spray Lakes Reservoir, Canal

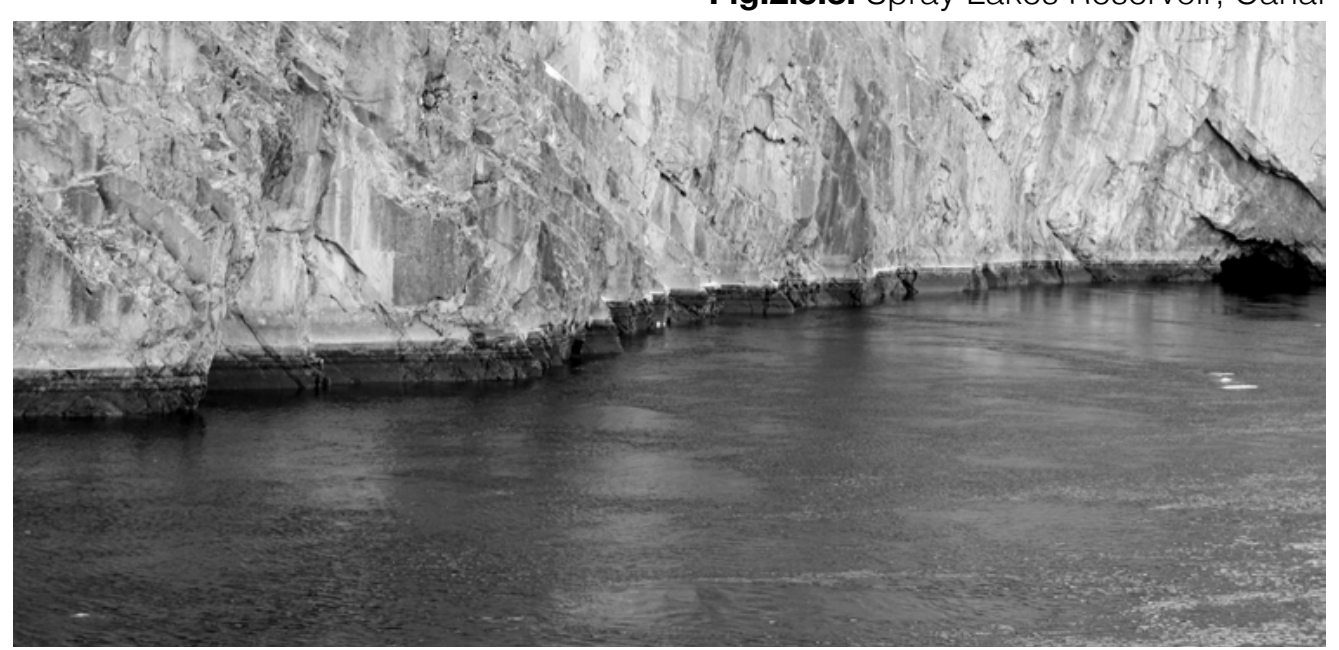

Fig.2.5.4. Spray Lakes Reservoir, Canal

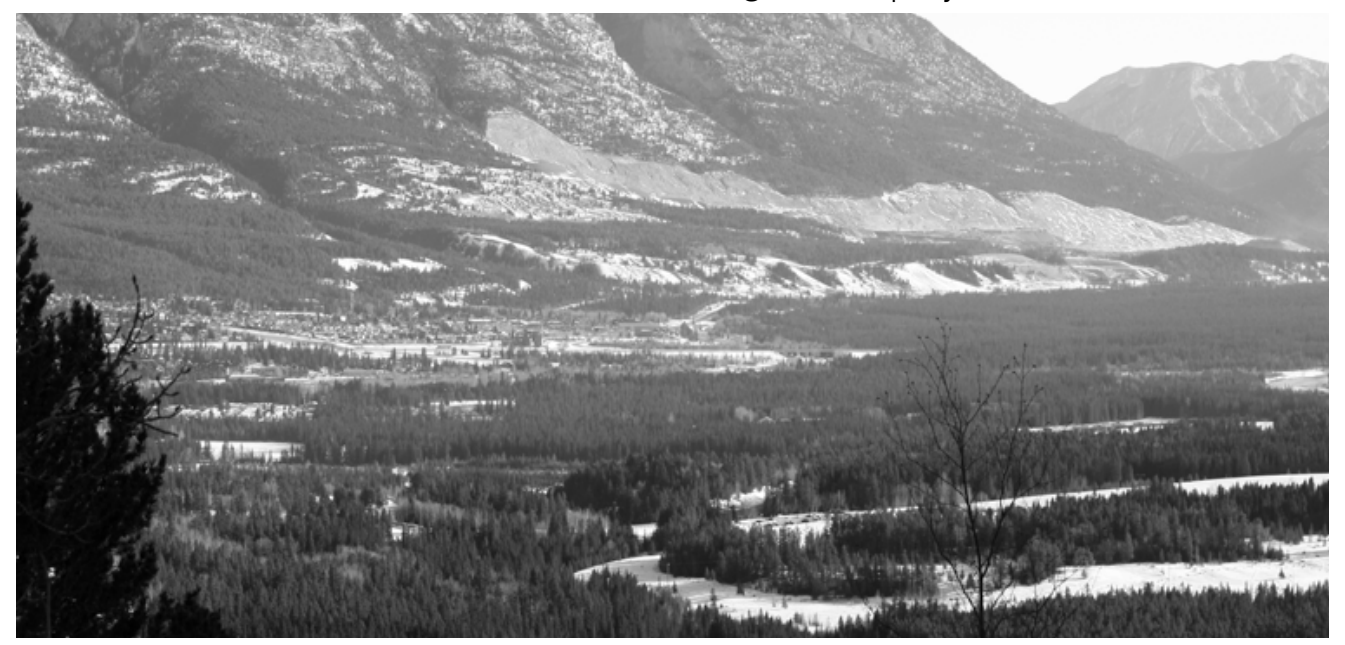

Fig.2.5.4. Canmore \& Mining Operations, Bow River Valley

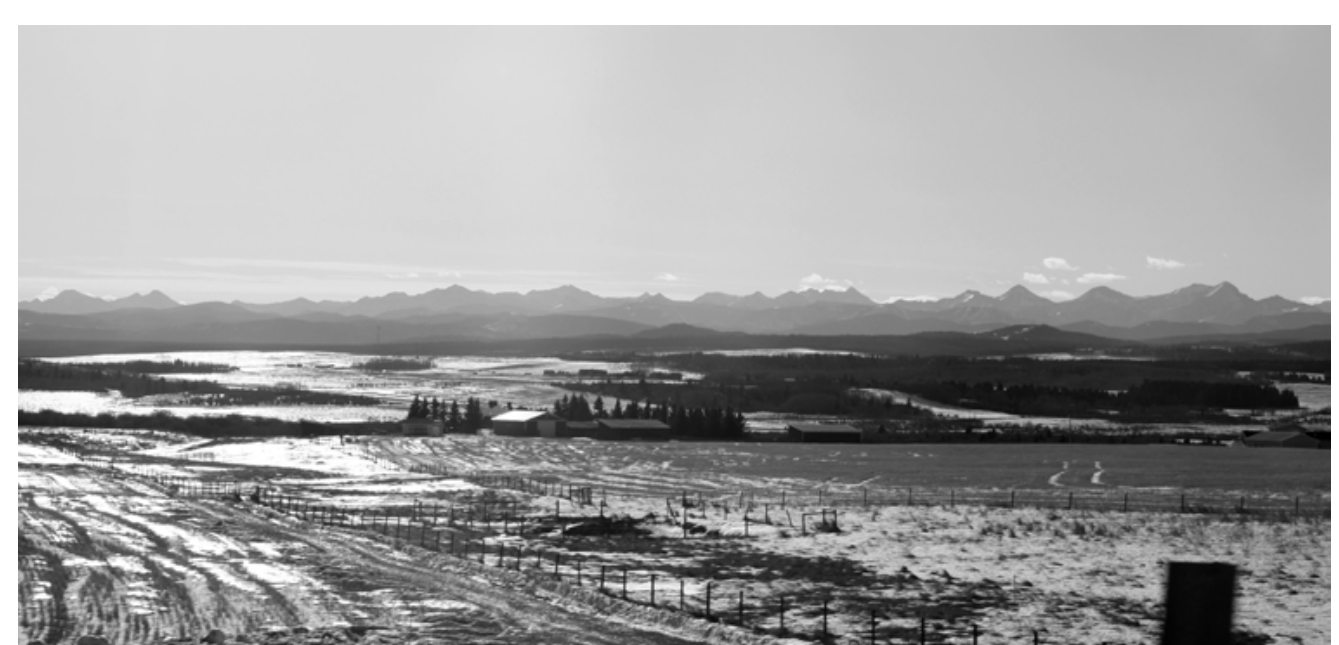

Fig.2.5.6. Rocky Mountains \& Foothills from $\mathrm{TCH}-1$

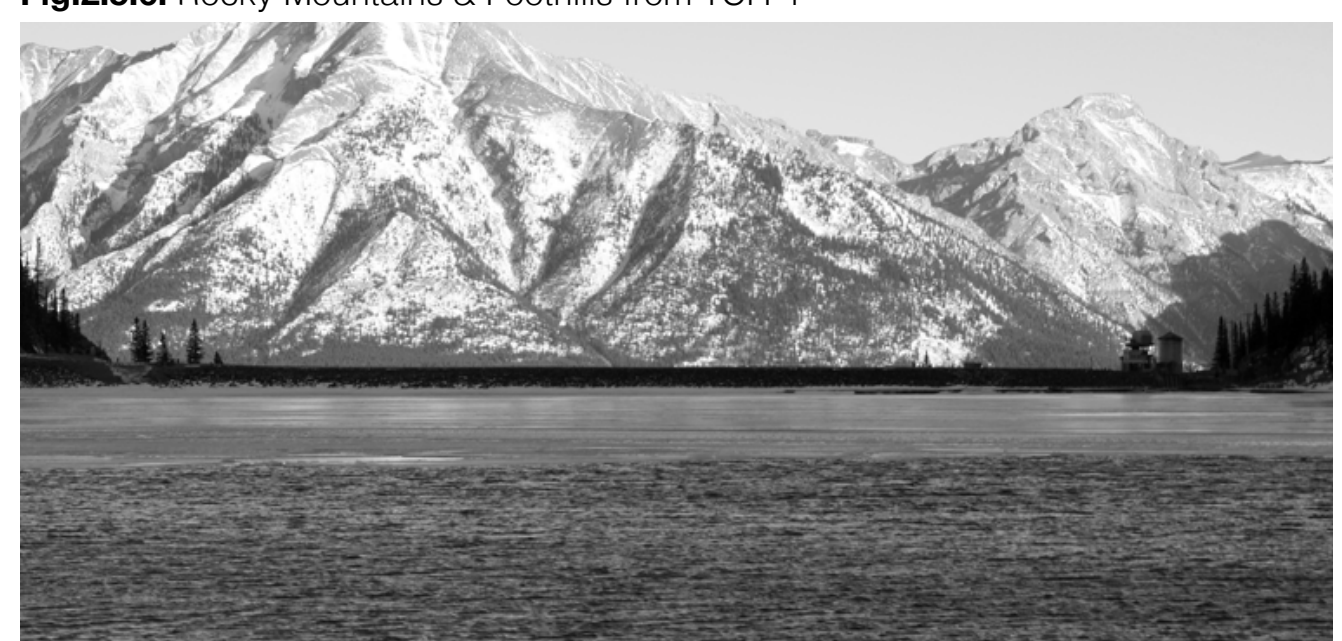

Fig.2.5.7. Spray Lakes Reservoir Infrastructure \& Dam

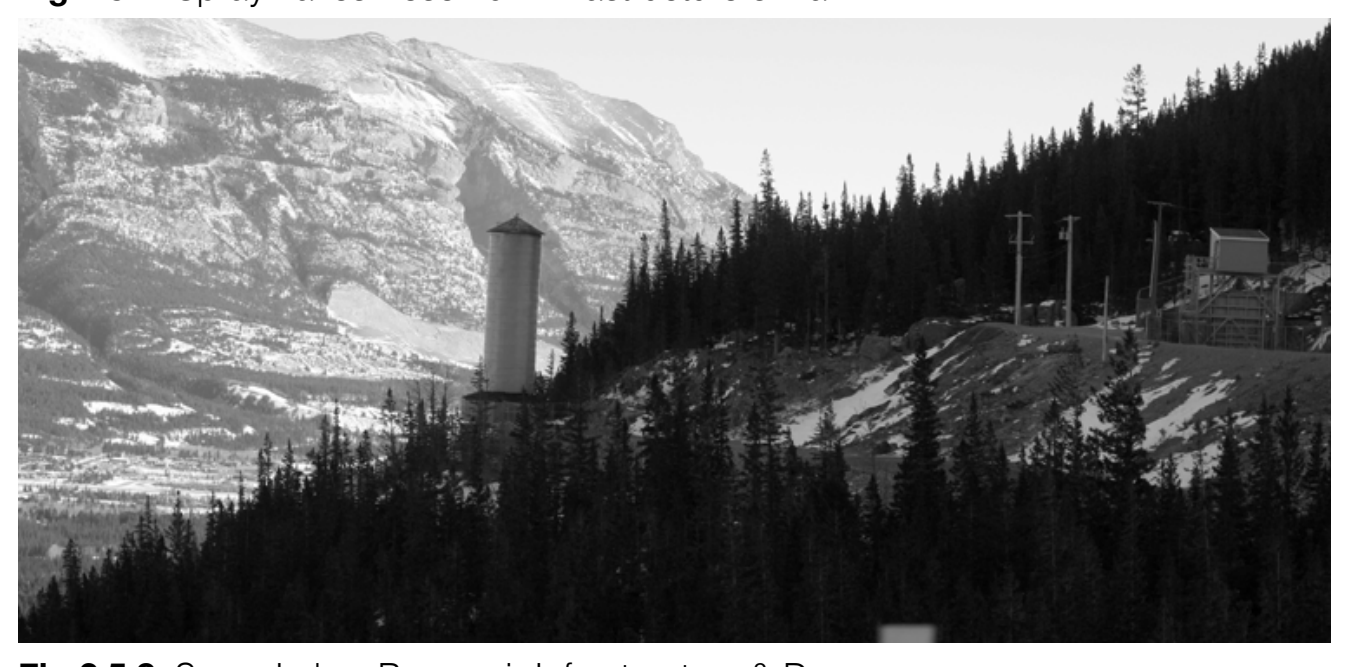

Fig.2.5.8. Spray Lakes Reservoir Infrastructure \& Dam 

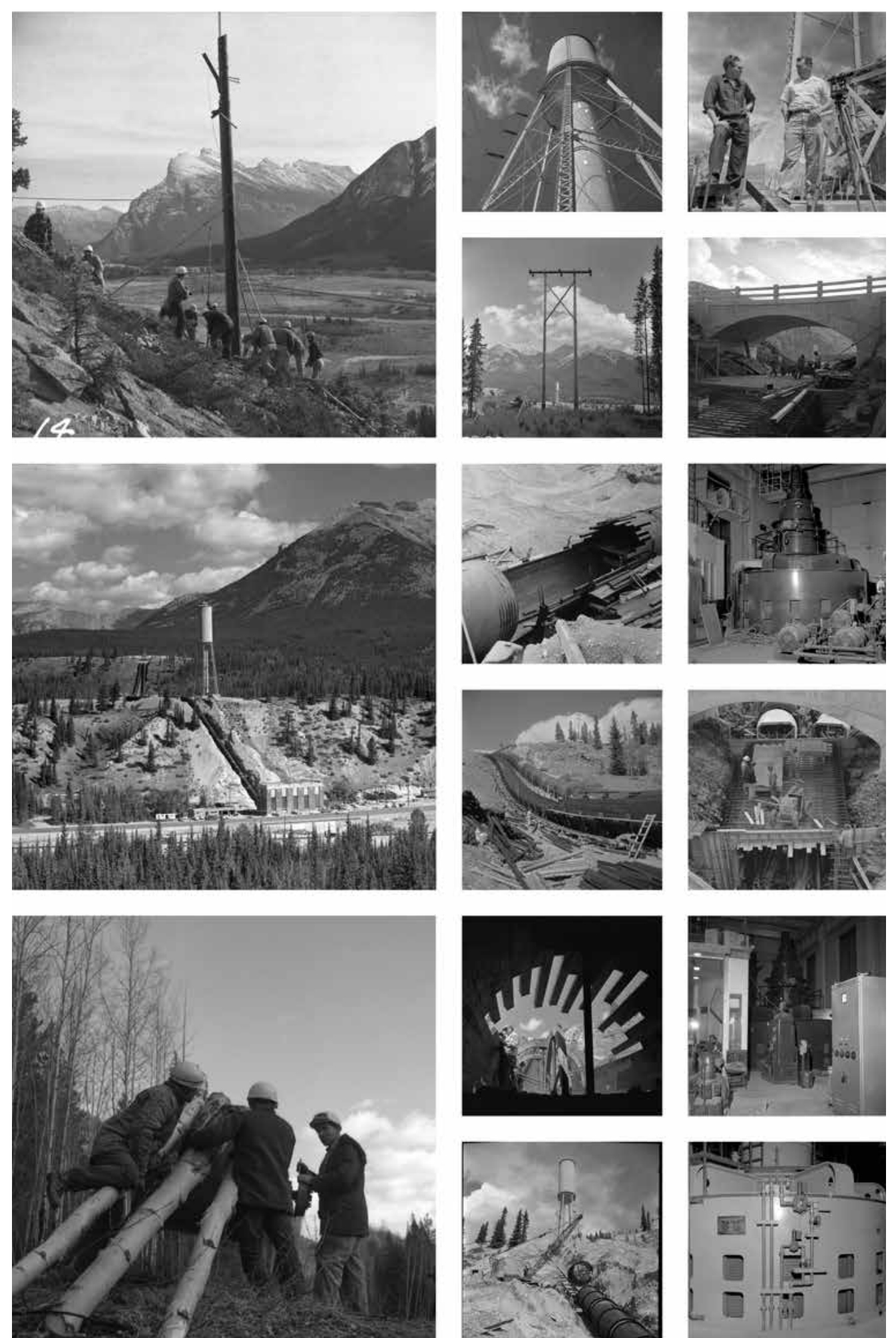

Fig.2.5.9. Hydro-Facility at Lake Minnewanka, Whyte Archives 144

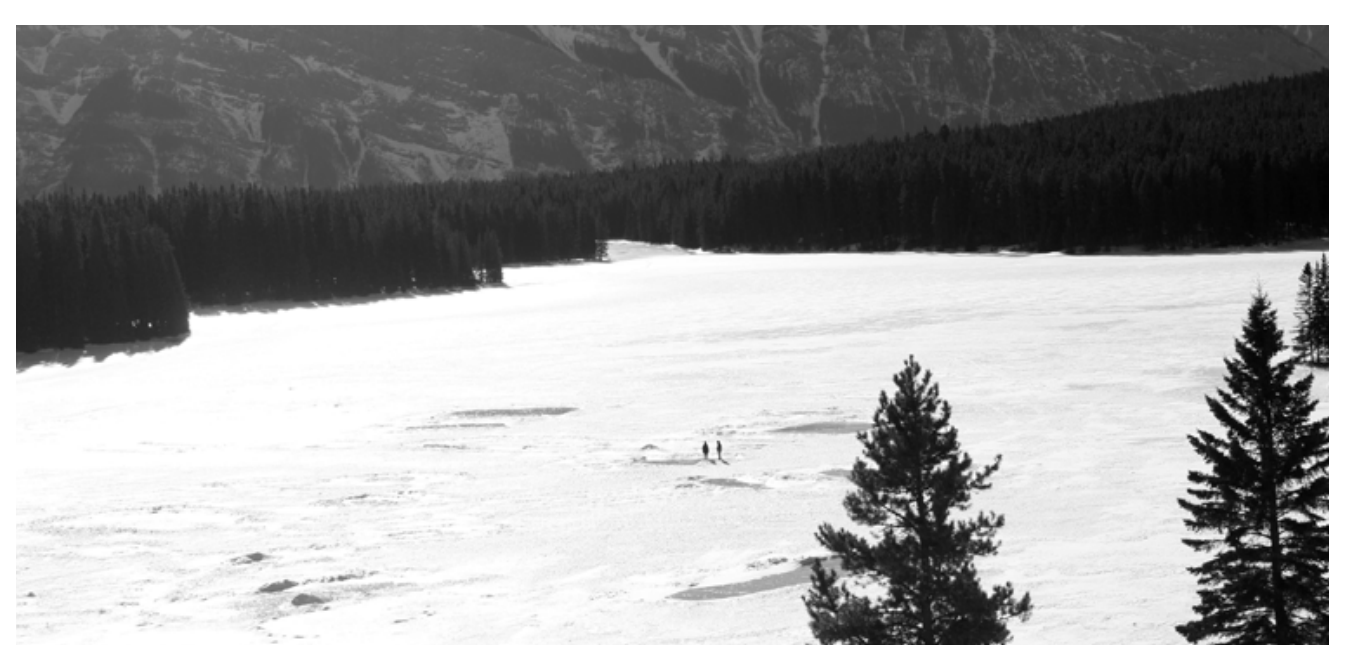

Fig.2.5.10. Lake Minnewanka Hydro-Infrastructure \& Reservoir

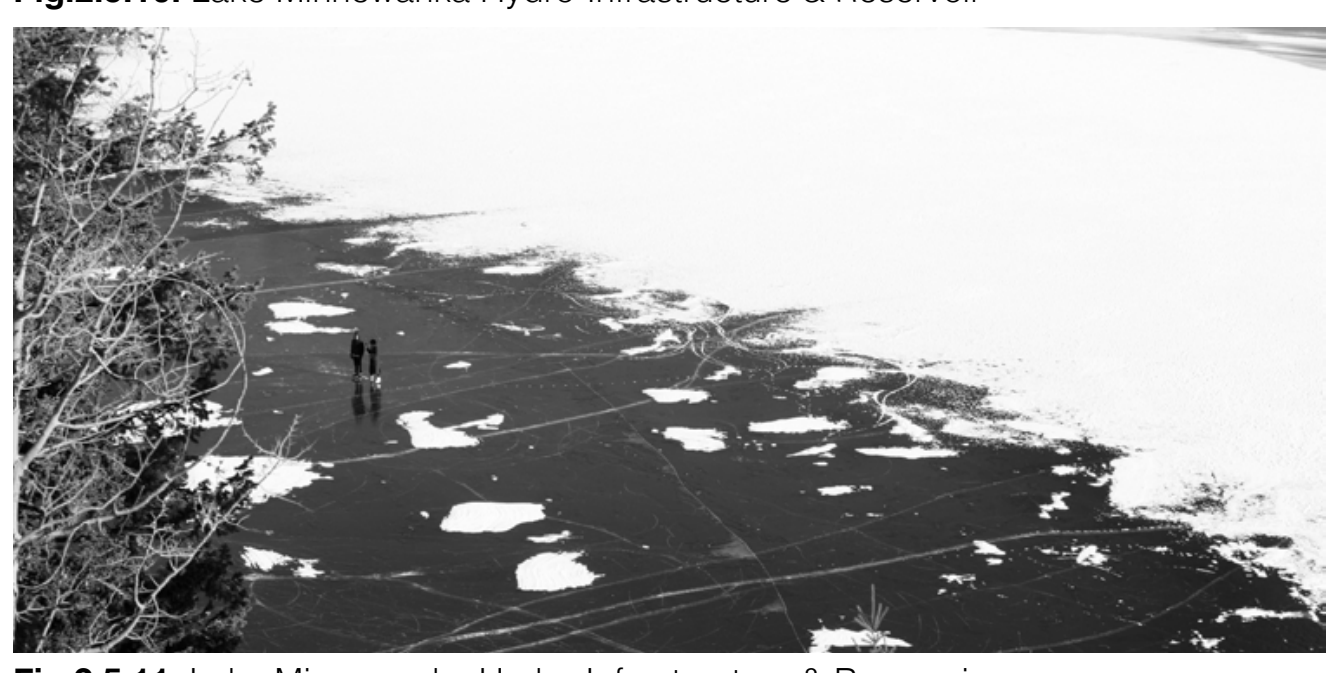

Fig.2.5.11. Lake Minnewanka Hydro-Infrastructure \& Reservoir

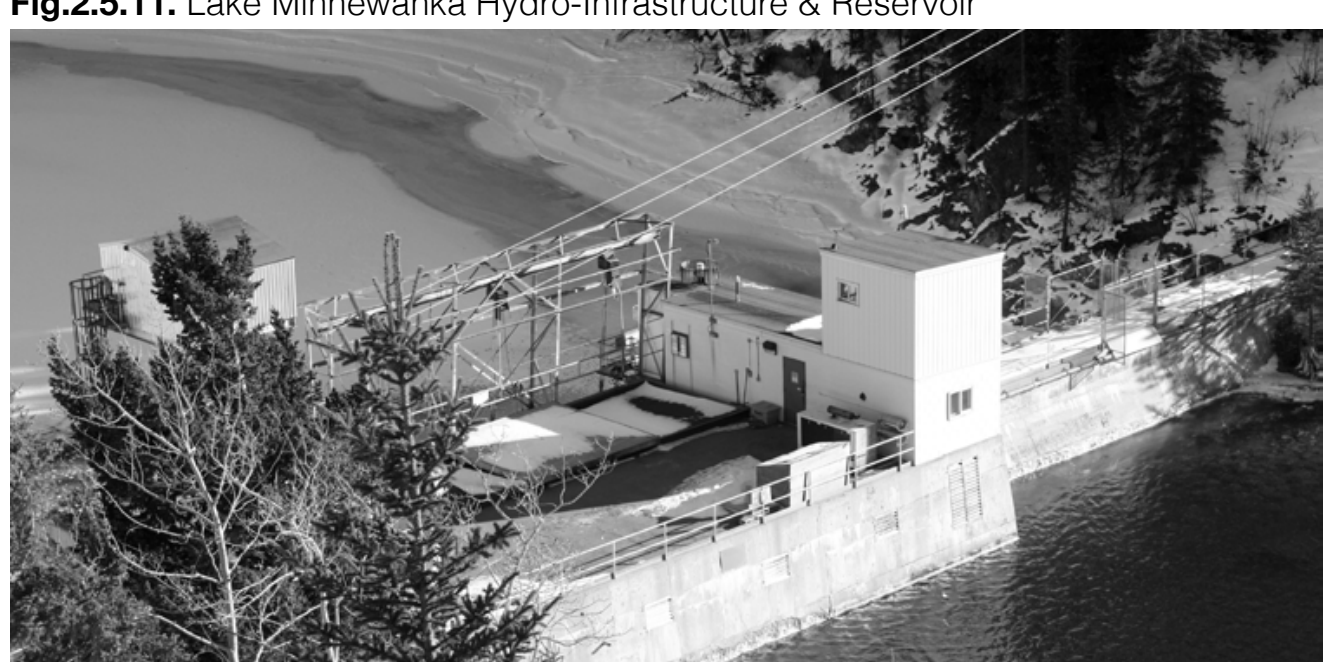

Fig.2.5.12. Lake Minnewanka Hydro-Infrastructure \& Reservoir 

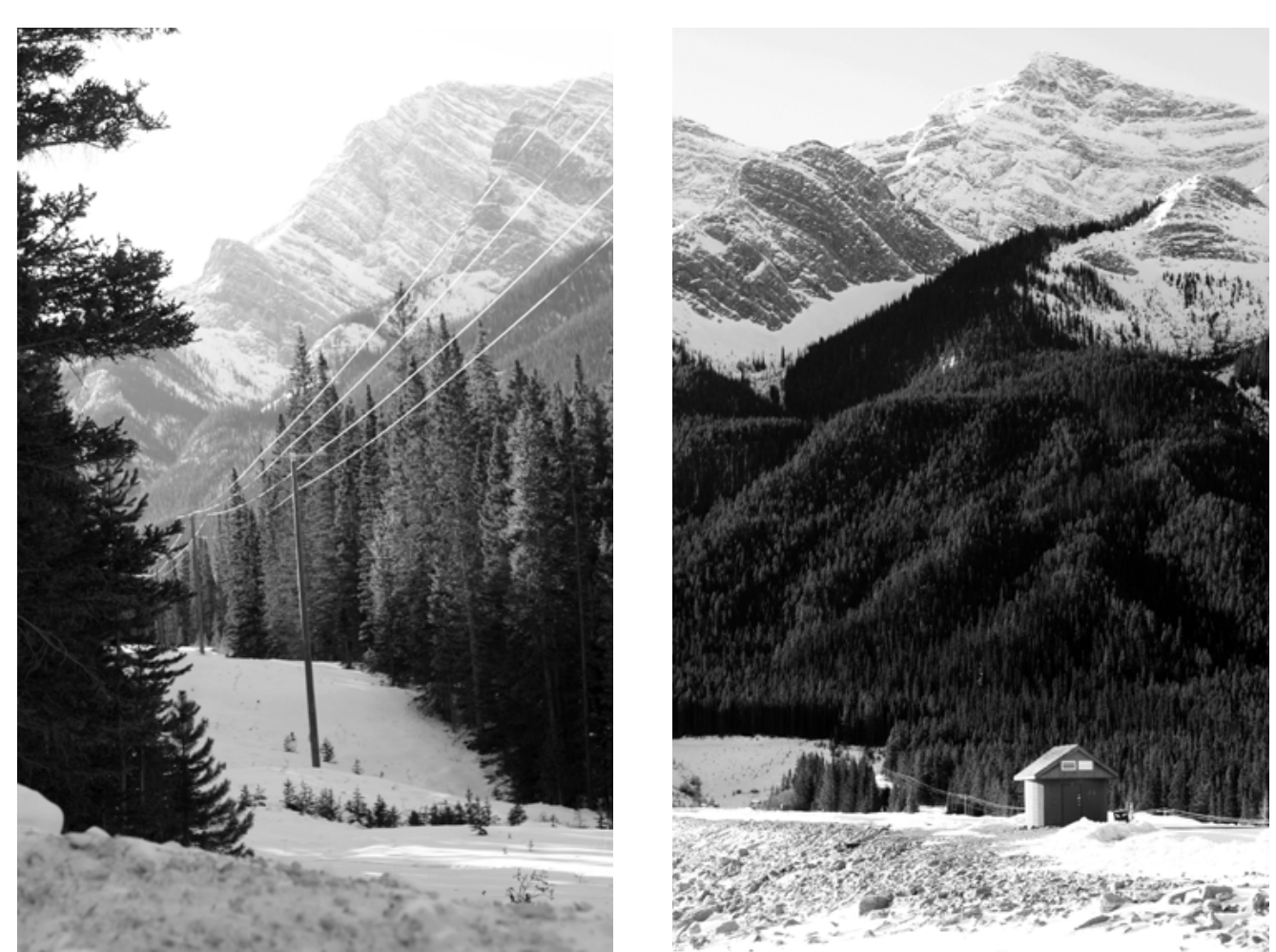

Fig.2.5.13. Spray Lakes Reservoir, Powerlines

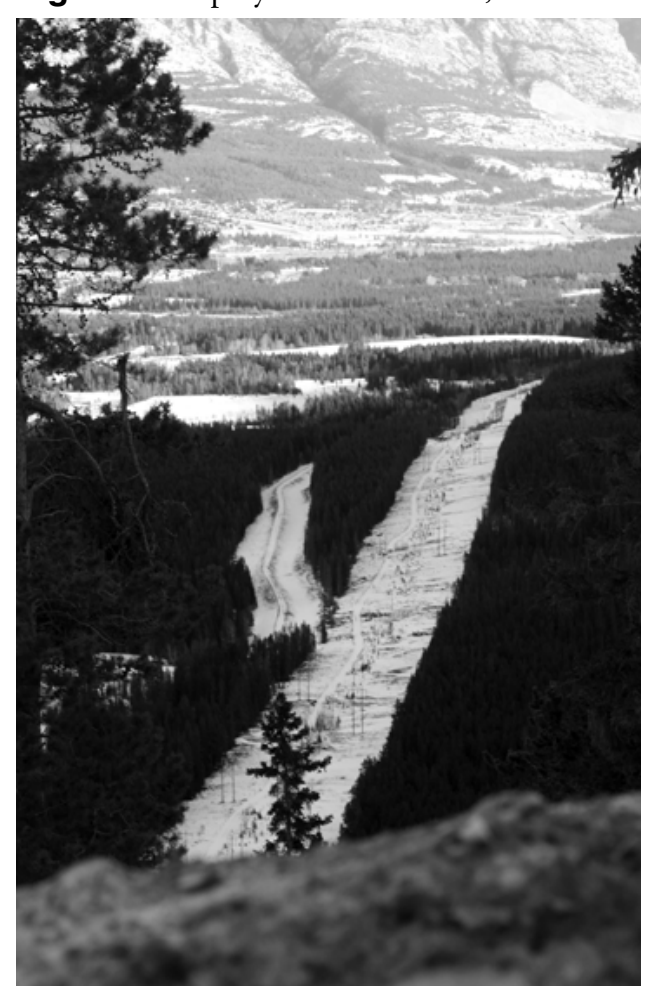

Fig. 25.15. Spray Lakes Reservoir, Powerlines 146
Fig.2.5.14. Spray Lakes Reservoir, Dam $\quad$ Fig.2.5.17. Trans-Alta Hydro-Facility
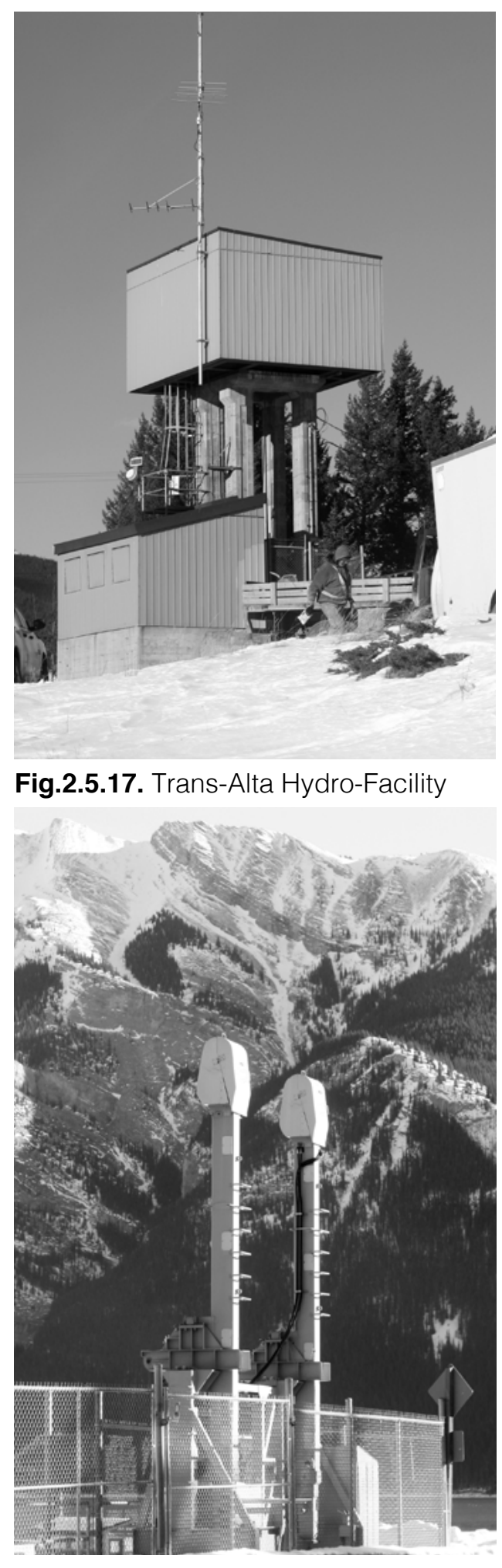

Fig. 2.5.19. Lake Minnewanka Dam

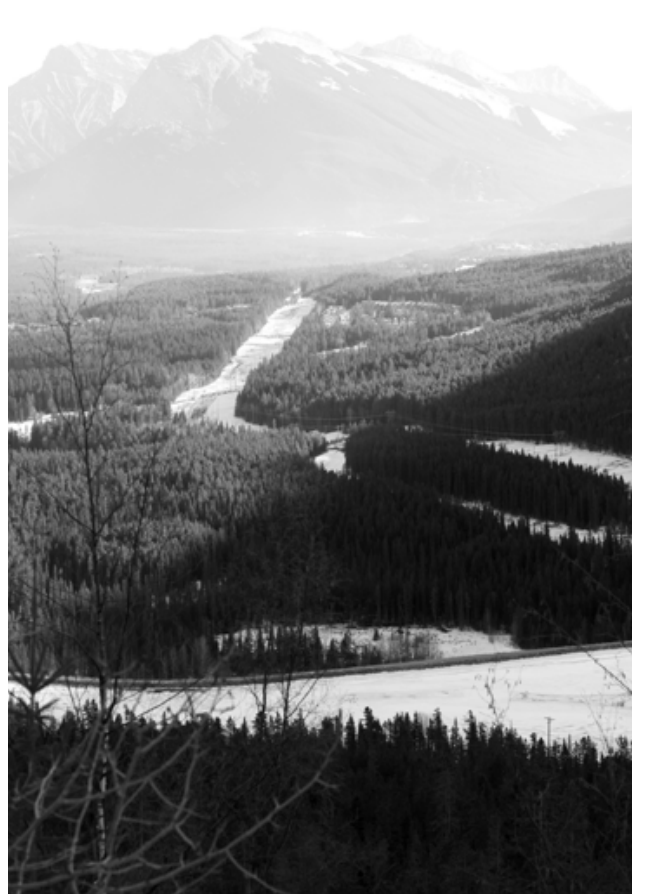

Fig.2.5.18. Spray Lakes Reservoir

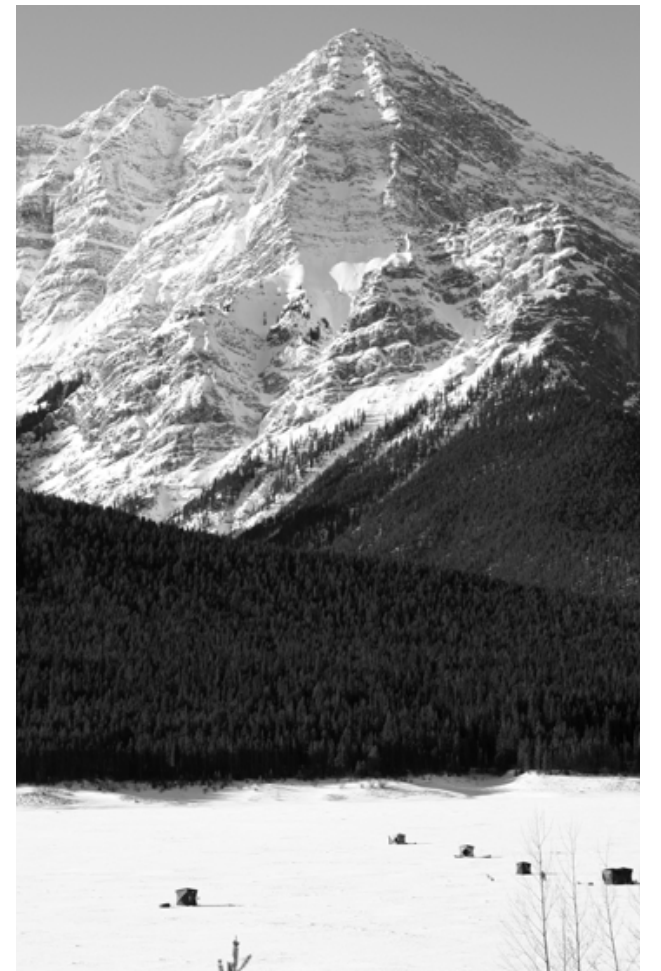

Fig.2.5.20. Spray Lake Reservoir Ice Fishers 
Part II

\section{ENDNOTES}

1 James Corner, "The Agency of Mapping, Speculation, Critique, and Invention," In Mappings. Denis E Cosgrove (Londor: Reakion, 2002), 227.

James Corner, "The Agency of Mapping," 230.

Robert Macfarlane, The Wild Places (London: Penguin Books, 2008), 10

James Corner, "The Agency of Mapping," 230.

Roger Scoon, The Geotraveller: Geologry of Famous Geosites and Areas of Historical Interest (New

York: Springer International Publishing, 2021), 35

Roger Scoon, The Geotraveller, 36.

Ibid, 36.

Chief John Snow, These Mountains Are Our Sacred Places: The Storey of the Stoney People (Toronto Fifth House, 2005), 49.

Donald Smith, Seen But Not Seen: Infuential Canadians and the First Nations from the 1840s to Today (Toronto: University of Toronto Press, 2021), 40.

Chief John Snow, These Mountains Are Our Sacred Places, VII

12 Courtney, Mason. All of Our Secrets are in These Mountains: Problemativing Colonial Power Relations, Tourism Productions and Histories of the Cultural Practices of Nakoda Peoples in the BanffBow Valley (Edmonton: University of Alberta, 2010), 166

Donald Smith, Seen But Not Seen, 14

Armstrong, Christopher, and H.V. Nelles. Wilderness and Waterpower: How Banff National Park Became A Hydroelectric Storage Reservoir (Calgary: University of Calgary Press, 2013), 1.

Armstrong and Nelles, Wilderness and Waterpower, 18.

Ibid, 63.

Leslie Bella. Parkes for Profit (Montreal: Harvest House, 1987) 55.

Ibid, 53-54

Ibid, 57 .

Ibid, 58 .

Ibid, 11 .

Ibid, 11 .

Ibid, 33 .

Ibid, 32 .

Armstrong and Nelles, Wilderness and Waterpower, 18.

Bush, E., and D.S. Lemmen, Canada's Changing Climate Report (Ottawa: Government of Canada, 2019) 223.

30 CCRN Network Canada. "The Changing Environment of Western Canada: Canadian Rocks, Mountains.” Accessed November 25, 2020. http://www.ccrnetwork.ca/outputs/informa tion-products/docs/Rockies_Change.pdf
CCRN Network Canada, "The Changing Environment of Western Canada"

32 CCRN Network Canada "The Changing Environment of Western Cannd"

33 Bush and Lemmen, Canada's Changing Climate Report, 269.

34 Ibid, 169

36 Ibid, 119

37 Ibid, 199

38 Ibid, 181

40 Ibid, 199 .

41 Ibid, 199

42 Ibid, 266. 
For years, the difference between walking and galloping on a borse was our measure of change; now it's between walking and soaring in luxury jets at supersonic speeds. This all happened in the last fifty years, yet the buman body and land-laden psyche is tens of thousands years old.

Part III // TRAILS \& MECHANISMS

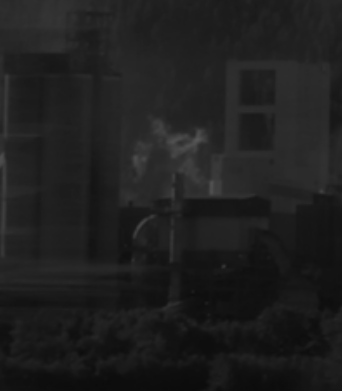
It's because of this that we're no longer able to comprehend the current rate of metamorphosis: we are acceleration, unprecedented and overwhelming culture shock and awe. We've got to be a part of it: it is here and it is $u$ s. $^{1}$

- Travis Price 


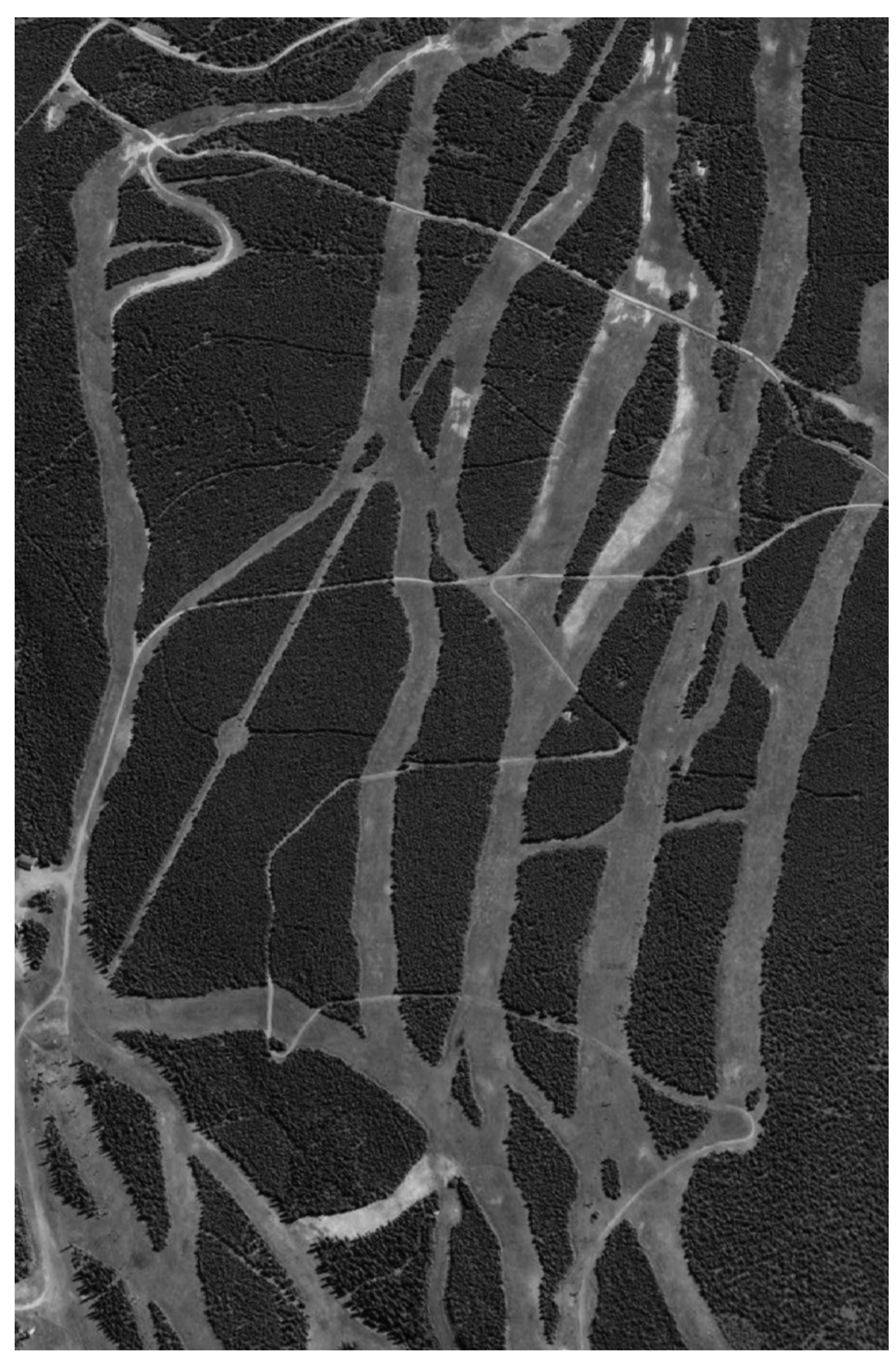

Fig.3.1.2. Ski Resort Infrastructure Satellite Image, Banff
09 // A NEW WILDERNESS

Architecture imitates this extensive chaos: society reacts equally with fear and fascination. ${ }^{2}$

- Travis Price

The final section of this thesis is a speculation of the future of Banff National Park, its changing landscapes, and the human infrastructures and industries that might inhabit it. The speculation visualizes how Banff National Park will evolve into a new wilderness, one that is defined by a changing climate, human influence and economic pressures. This section of the thesis examines how the need to address this shifting reality of the landscape will collide with the identities, narratives and histories of the past of Banff National Park. This study is conducted through the proposal of two new fictional design elements, a new trail network and a series of mechanisms, which situate themselves within broader discussions of ecological design and theory. The proposed trail and the mechanisms are manifestations of the pressures, industries 
and changes that are collapsing in on the site, forcing a re-evaluation of wilderness as physical space and a cultural construct. Over the next 100 years Banff National Park will face increasing challenges as the effects of anthropogenic climate change dramatically alter the landscape of the territory. A higher frequency of extreme weather events will cause an increased number of natural disasters, such as the flooding events that have already begun to affect the area, while warmer temperatures will drastically change seasonal precipitation patterns. These changes, as well as the increasing significance of the natural resources of the site to both extractive industries and ever-expanding tourism operations will push the site, its boundaries, and its notions of wilderness conservation to a breaking point.

This collision of anthropogenic climate change with romanticised notions of wilderness is a topic deeply connected to environmental and ecological design theory. The final section of this thesis situates itself within these works, particularly notions of the age of the Anthropocene, as presented by ecological historian and theorist Lydia Kallipoliti in her article, The History of Ecological Design. Within this work, Kallipoliti outlines the emerging ecological theories used to describe the challenges of this new ecological era. As the very notion of human and non-human worlds as separate entities is undermined by the omnipresence of human influence over the planet, the current definition of wild spaces becomes obsolete. As stated by Kallipoliti in her discussion of the age of the Anthropocene,

$$
\begin{aligned}
& \text { Ecological design can no longer be conceptualized } \\
& \text { exclusively as a combative tool against aggravating climatic } \\
& \text { conditions. Technology, as weaponry and as defense, is not } \\
& \text { the sole option; neither is an exclusive engagement with } \\
& \text { teleology. The new geological era of the Anthropocene } \\
& \text { raises not only material problems, but also cultural and } \\
& \text { aesthetic issues. Our perception of the environment and } \\
& \text { orientation in the world is irreversibly displaced, as the } \\
& \text { fantasy of our habitation outside of nature, or even the } \\
& \text { very existence of nature itself, is no longer tenable. }
\end{aligned}
$$

It is this untenable separation of human and non-human worlds that the final project aims to interpret, imagining a future in which even our most sacred wild spaces have become so altered by human activity, that yet another re-definition of wilderness is required to address the alterations of the landscape. Through the proposal of new design interventions that reflect these shifts, this thesis seeks to understand the imminent collisions of these worlds and the challenges of the future over the idealized and romanticized histories of the site that have been crafted, primarily for economic profits, in the past.

The Anthropocene, a proposed new geological and ecological age defined by human industry as the dominant force on Earth, 


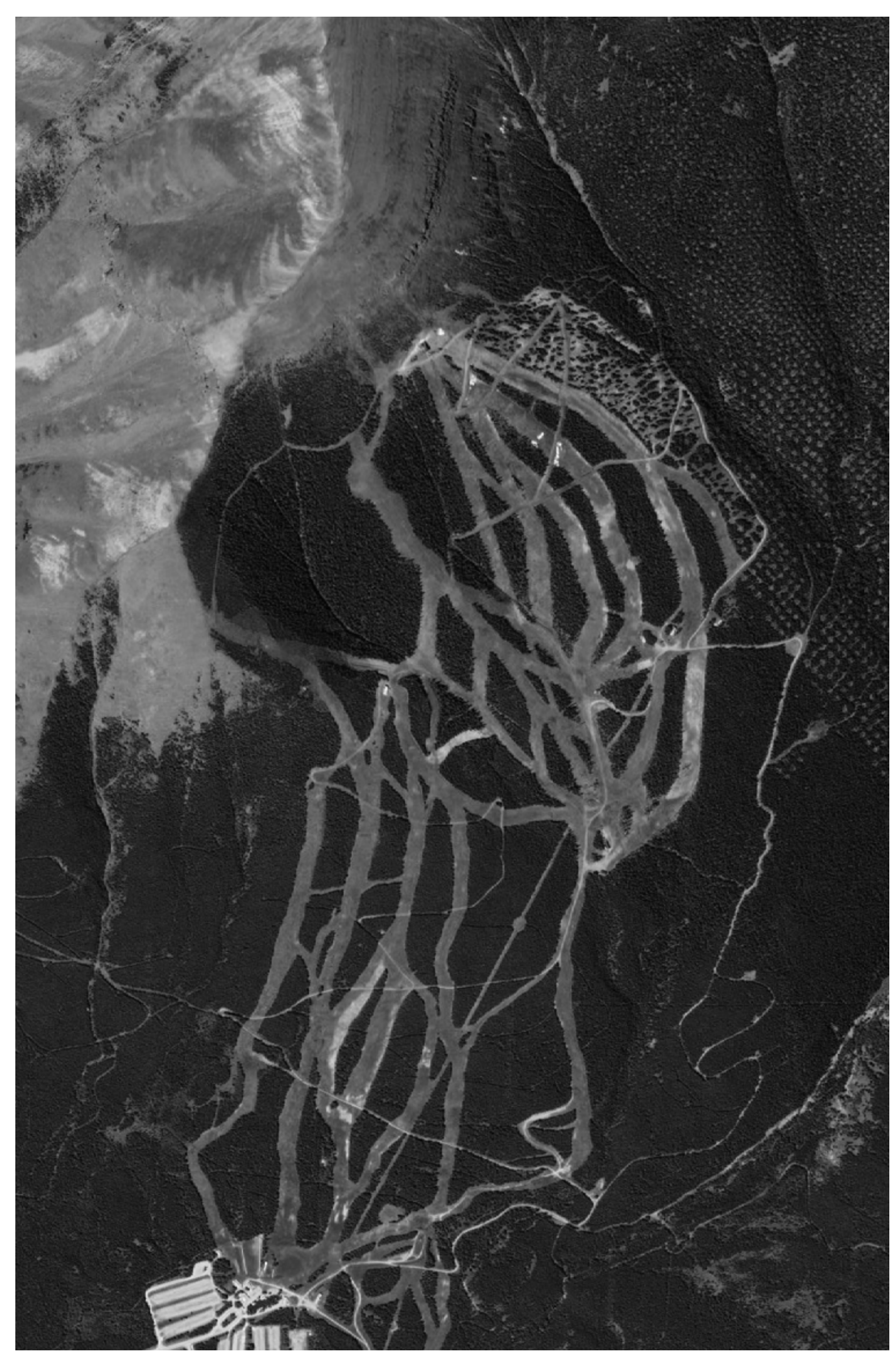

Fig.3.1.3. Ski Resort Infrastructure Satellite Image, Banff expresses the notion of how pervasively human worlds have encroached on non-human. This term and proposed new age, however, has been contested and still presents certain challenges in viewing these forces as opposing and binary systems. Prominent Science Historian, Donna Haraway, instead suggests the use of her term, the Chthulucene, to describe our current epoch as one where human and nonhuman worlds are inextricably linked in "tentacular" practices. ${ }^{4}$ These connections form a singular, indivisible fabric across our planet, requiring design and knowledge grounded in making-with our reality, rather than selfmaking. ${ }^{5}$ According to Haraway, in the age of the Chthulucene it is essential to understand the strangeness of our current reality above all else and to treat design as an endeavor completely dedicated to interpreting the problems of the real, rather than the projection of an idealized or outdated notion of whole environments. ${ }^{6}$ As discussed by Kallipoliti,

The Chthulucene is not about constructing fictions and fantasies of wholeness. Rather, it is about closely observing the ubiquity of pollution, asking questions and instrumentalizing one's findings in a creative way, without being unaware of their uncertainty and complexity.

The concept of instrumentalizing one's findings proves 
challenging in a context that has, in the past, so often been dedicated to fictionalized narrative of space, with romanticized imagery of the Canadian landscape informing our understanding of place over ecological realities. As this research has outlined, wilderness has seldom been about representing the summation of all of the various parts of the site, but rather a selective celebration of the virtues it might represent, while supressing our own roles and influence within its evolution. Now, a holistic understanding of landscapes and our presence within them is proving essential to projecting our future and the climate-driven challenges that it might hold. Faced with these challenges, the construction of new mechanisms of interpretation is an essential tool and industry that must not only become part of wilderness physically, but also begin to inhabit the cultural values of the space that been attached to it.

These mechanisms represent the reality of the future, one in which the separation of human and non-human worlds has become impossible to maintain. The impossibility of separating human from nonhuman elements from one another is outlined within the work of political theorist Jane Bennet. Bennet suggests the notion of dead orinert matter surrounding us has fed into the human ego and has empowered earth-destroying tendencies by placing us at the top of a planetary hierarchy. ${ }^{8}$ This egocentrism, according to Bennet, is preventing us from detecting and acknowledging a large range of nonhuman powers and influences with which we interact. The proposed mechanisms for Banff National Park aim to re-establish these powers and influences within the landscape and an experience of the site.

\section{A New Landscape}

The history of Banff National Park demonstrates a pattern of wilderness and conservation being influenced by varying forces, both political and economic. The evolving boundaries of the park give clear precedent for manipulating the space as cultural interests and policies shift. Whether it has been due to technological developments, such as the advent of hydro-electrical technology, or political agendas, such as marketing Canadian landscapes to a global tourism industry, as notions of wilderness have changed and evolved, so too has the national park. Now, faced with ubiquitous and accelerating changes occurring due to warming climates and human industry, wilderness and its significance in Canadian culture is shifting once again. A new industry, one of measuring, interpreting, and mitigating the effects of climate change must now find its place within wild space and the romanticized landscapes that Canada has so often set at the core of its cultural fabric. In the same way that hydro-industrial developments 

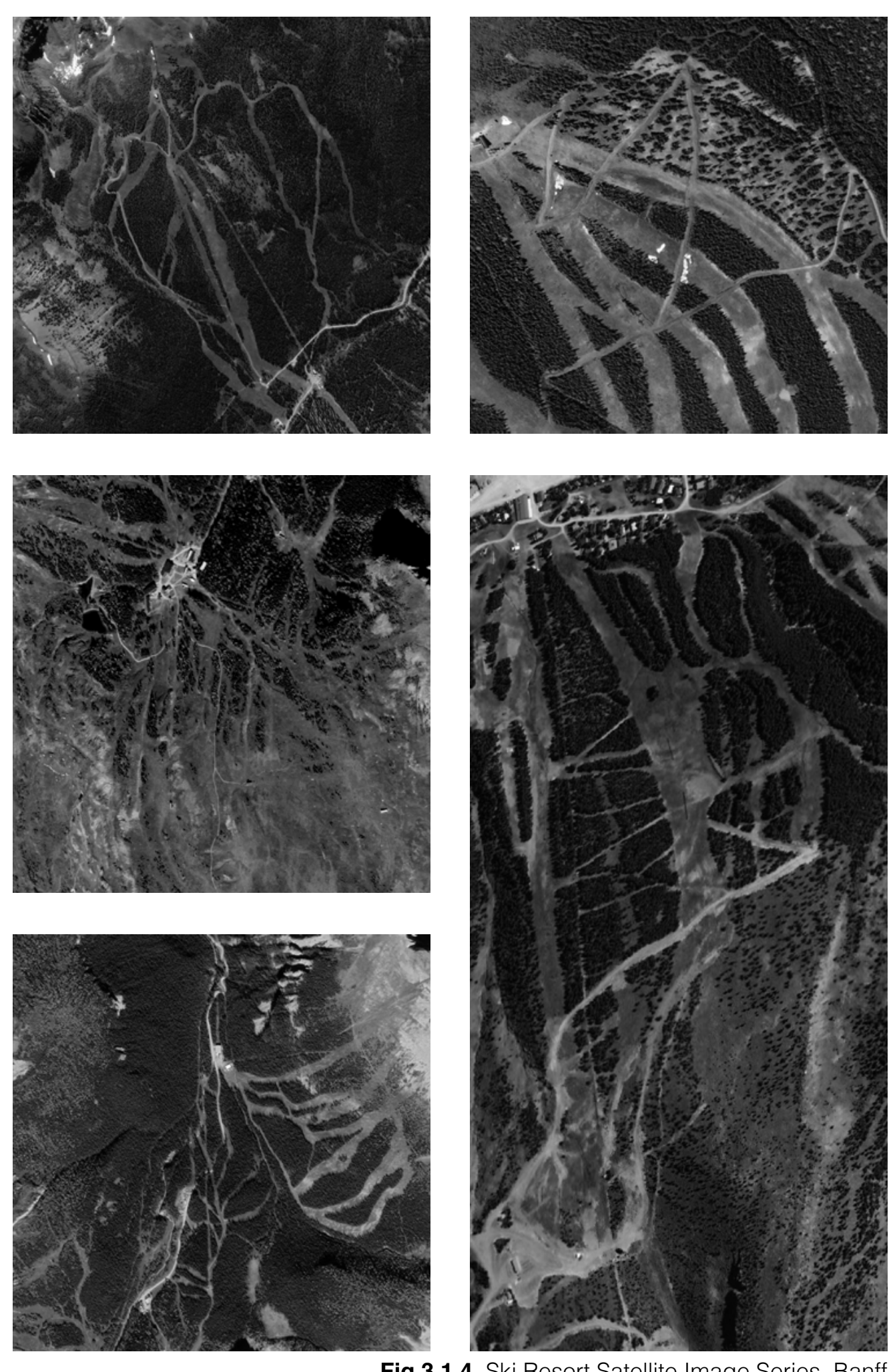

Fig.3.1.4. Ski Resort Satellite Image Series, Banff began to find a place within park space after the invention of hydroelectric technologies, new infrastructure that is necessitated by climate change must now situate itself within wilderness.

As outlined by the proposed ages on the Anthropocene and the Chthulucene, this shift in wilderness is not merely physical or industrial, but is omnipresent in how we understand our role as a species and human industry as globally defining force. Banff National Park, and National Parks across Canada, are uniquely situated within Canadian culture to address this changing definition of nature and to interpret erosion patterns not merely as ecological anomalies, but as the new fundamental reality of our age. The history of the park has repeatedly shown its capacity to shape a collective notion of wilderness, which must now be oriented towards addressing a new understanding of the landscape, not as a zone set apart from human uses, but as part of a larger, singular landscape stewarded by global human activities. Notions of conservation and preservation must be thoroughly reexamined as we enter an age of global change that does not distinguish environments along constructed boundaries or dichotomies of preserved and industrialized territories.

Hydropower, resource extraction, tourism commodification, all are forces that have at varying times been deemed an accepted part 


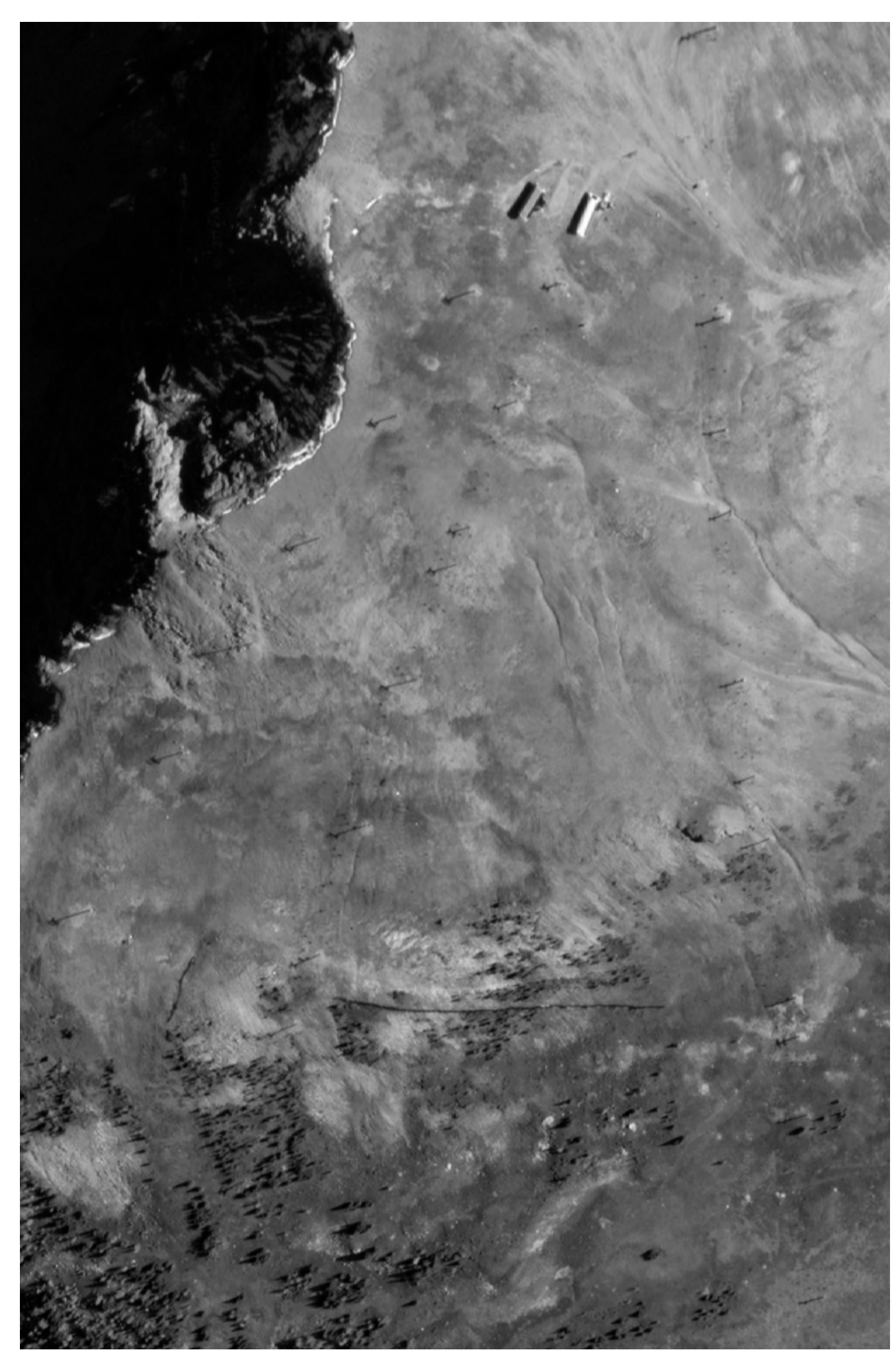

of wilderness. Trying to separate wilderness from human industry, when wilderness itself has become a commodity and resource of industry, is an endeavor that is not only destructive, but is in direct conflict with any efforts of understanding climate change. The challenges that will continue to affect the site, and the need to for further intervention to mitigate the damages of these changes, are not a question of if, but of when. Embracing the changes of the future now might give us an opportunity to learn from these developments as they occur, to understand our own role within them, and to adapt outdated notions of site and wilderness to our new realities.

Fig.3.1.5. Ski Resort Satellite Image, Banff 


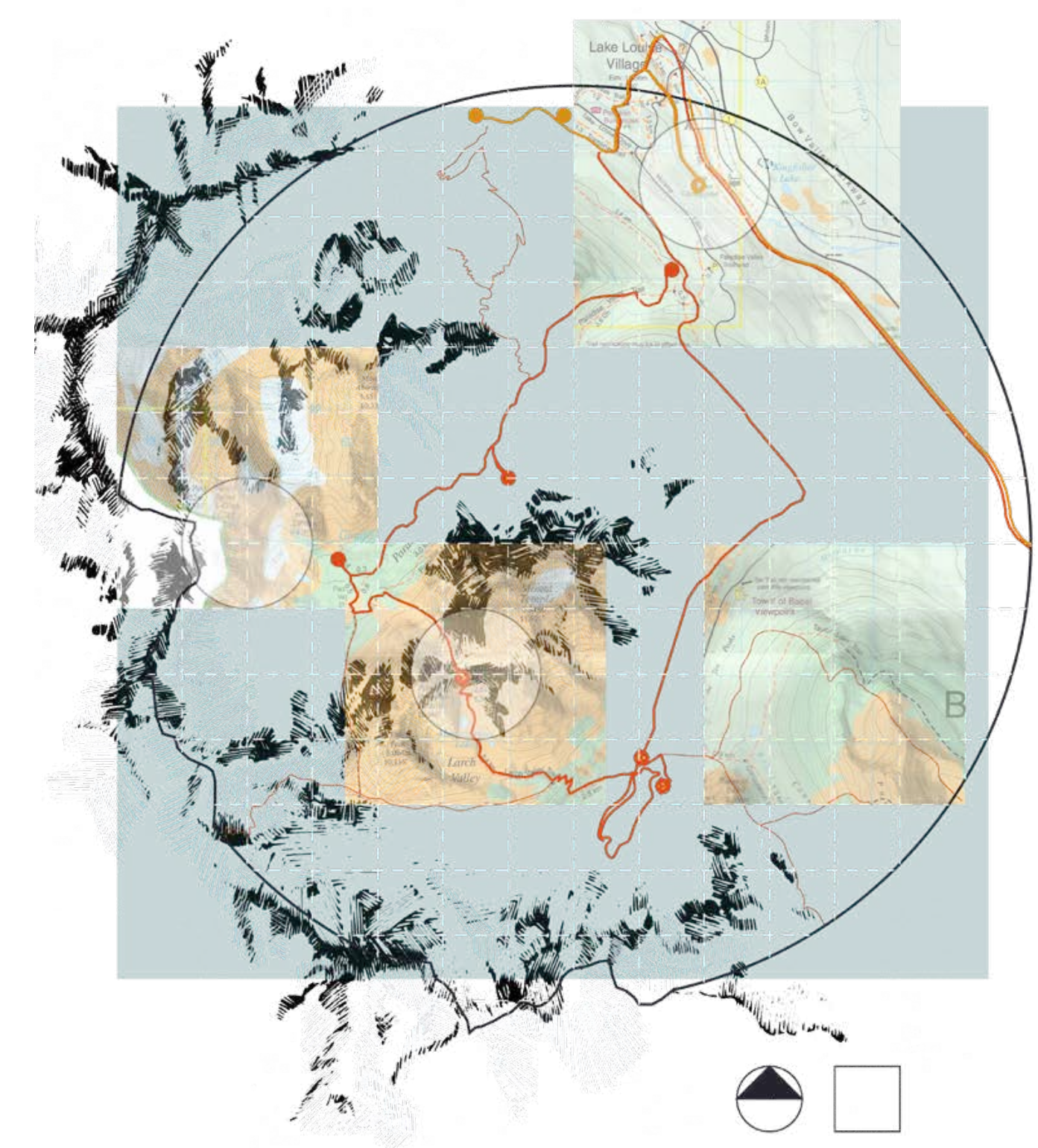

Fig.3.1.6. Paradise Valley Trail Map Collage

\section{A New Atlas}

The speculative design project presented throughout the final section of this thesis is an extension of the New Atlas of Banff, aiming to depict and dissect the theoretical landscapes of the future. These projections continue the research from the atlas, aiming to deconstruct wilderness within Canadian culture and the role that it has in shaping physical space and an understanding of site. Through a study of evolving park boundaries, the New Atlas of Banff has illustrated the power that imagery and idealized notions of landscape have had in shaping the identity of the site. It has examined how abstract concepts of sacred wilderness have directly informed legal policies and the boundaries of the park. The mapping explorations sought to catalogue these consequences, visualizing how efforts of conservation have steered the history of the park, dictating the development of the industries that have sought access to the site, the tourism-driven economies that the space has embraced, and the cultural narratives and histories that it has suppressed.

The final proposal of this thesis continues with this research, creating six new theoretical atlas entries that are projections of the park as it continues to evolve, reacting to the various forces that will continue to alter and commodify the landscape. The projective atlas 
entries document a new trail network, proposed along the existing boundary of the park, identifying the exclusive nature of these protected landscapes. The new atlas entries also show the future constructions that will occupy this landscape as a means to regulate industry, natural resources, and react to the inevitable consequences of climate change. This final series is a speculation on the future landscape of the park, exploring the new infrastructure of wilderness that will inhabit it as the site, and its definitions, continue to change. Informed by the seasonal flood, fire and drought studies conducted in the second section of this research, the projected future of the park is an extrapolation of the climatic, cultural, economic, political, and environmental pressures that Banff National Park will need to navigate throughout the next 100 years.

The proposed timeframe of documenting landscape over the next 100 years aligns with climate projections and flood studies conducted for the territory, while placing the year 2021 in the approximate center of the timeline Banff National Park and the New Atlas of Banff, giving opportunity to equally explore the wilderness of the future and the wilderness of the past. The final speculative design proposal uses this timeframe to situate the new trail, as well as the accompanying mechanisms, at varying points in time over the next century of Banff National Park. This theoretical tracking of different mechanisms over time enables a speculation of how the park might evolve throughout the future as the changes and pressures of the landscape escalate. 

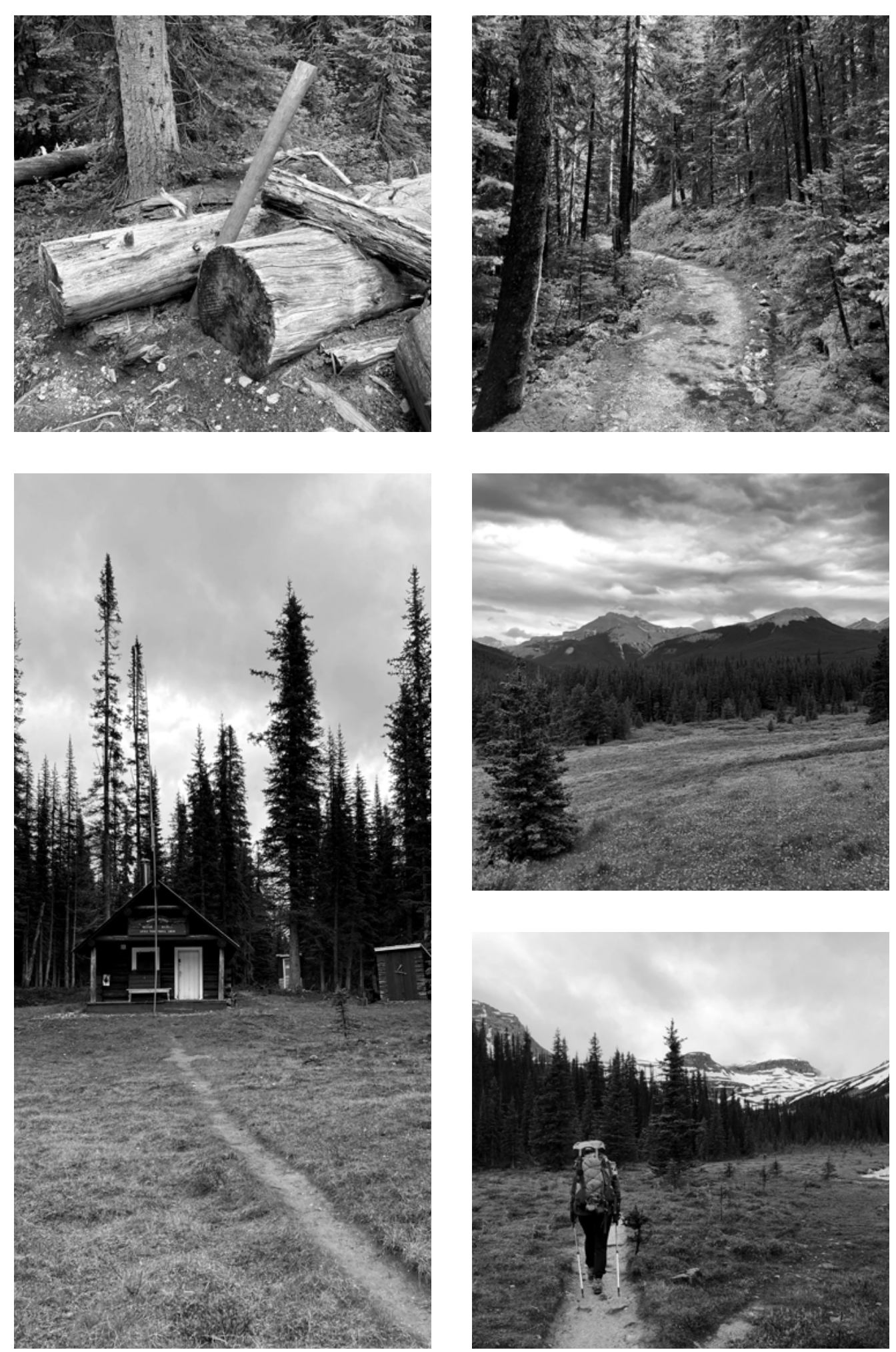

Fig.3.1.7. Hiking Trails Photo Series

\section{A New Trail}

The final section of this thesis is a dialogue between the current uses of the space and the challenges of the future, told through two opposing archetypes that represent the dichotomies and dualities that have been built throughout the history of Banff National Park. The documentation of the opposing archetypes of the future trail and the three mechanisms is a means to present both halves of this evolving conversation. The trail, a tool to interpret the site that has been employed by the National Park since its earliest beginnings, offers a new route to tourists and locals to meander through the landscape and encounter the charged boundary edge of the park. In Banff's history, walking trails have been used as a tool to explain wilderness to the visitor, guiding curious tourists from urban centers through a space that was alien and unfamiliar. As stated by Mason Courtney in his history of the cultural practices of Banff National Park...

Arriving from urban centers throughout North America and Europe, tourists were not necessarily familiar with the local environment. As a result, nature was often interpreted for tourists. Everything, from animal populations, mountain weather, glaciers, and especially local Aboriginal peoples required explanations[...]

[...] In 1915, park rangers at Banff began a process of institutionalizing nature by creating an interpretive trail, the first of thousands that soon developed all over the 

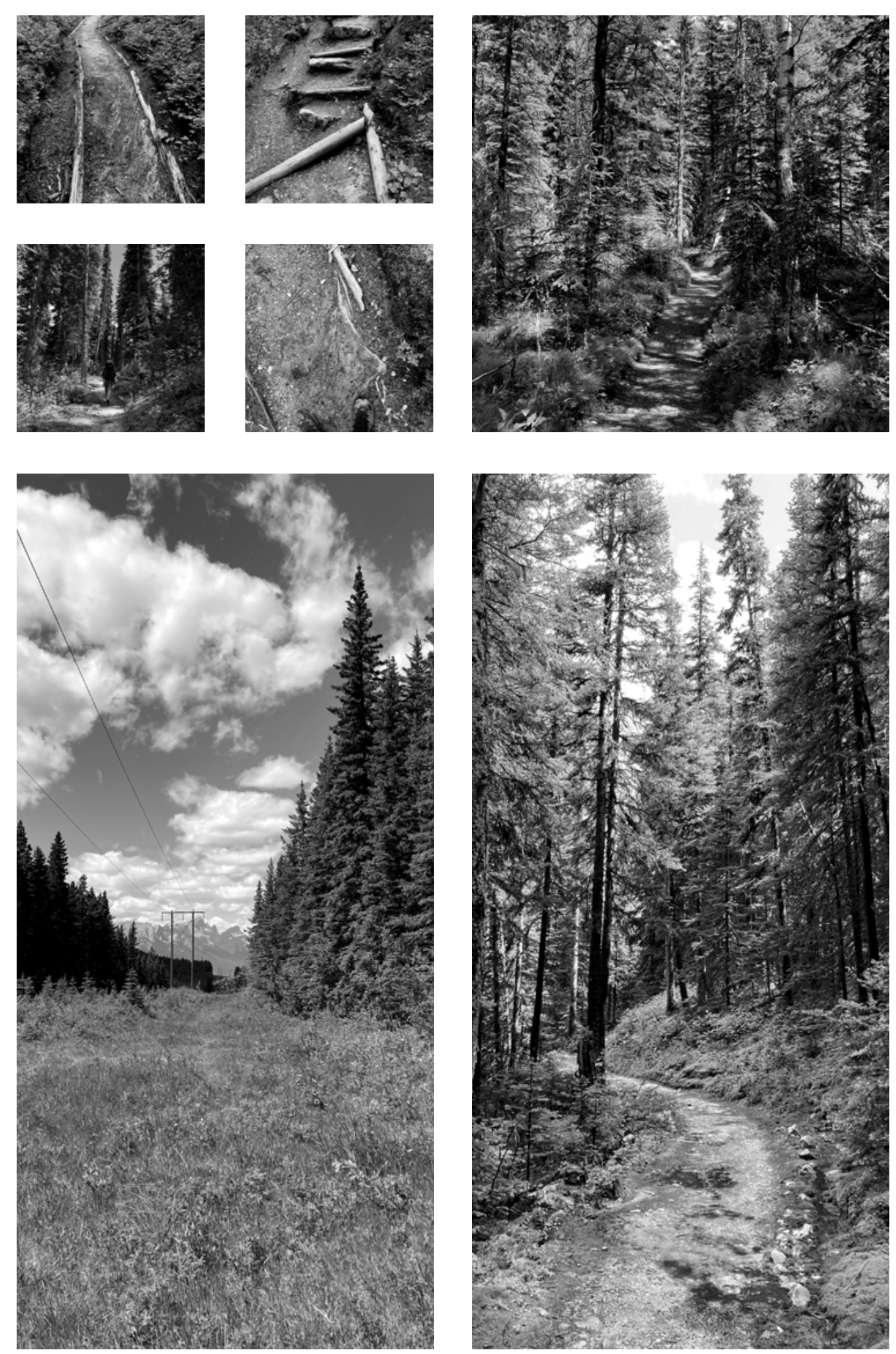

Fig.3.1.8. Hiking Trails Photo Series continent Influential entrepreneurs capitalized on the desire for interpretation and the growth of the mass tourism industry. Tourism producers benefited as they were able to position themselves as the local experts of all things "natural".

Hiking trails typically guided tourists through scenic landscapes to critical and empowering views and historic sites. The speculative trail uses this experience of space to explore the new landscape of the future, including the industrial nature of the park that has been concealed in the past. The trail weaves in and out of the existing park boundary, challenging the notion of a wilderness that can be separated from the industrial landscapes that surround it. Encountering industry and the "outside" to the park, the trail connects into the new speculative mechanisms that exist to help regulate and maintain this new wilderness. This speculative fiction uses the trail as a means to access the future of the site, imagining what scenery and challenges it will continue to interpret as wild space in the future, and the new industries that it will need to negotiate and confront. A means of interpreting the site and the wilderness it has represented in the past, the trail will now enable access to the wilderness of the future, one defined by a new climate that has been created by anthropogenic forces. 


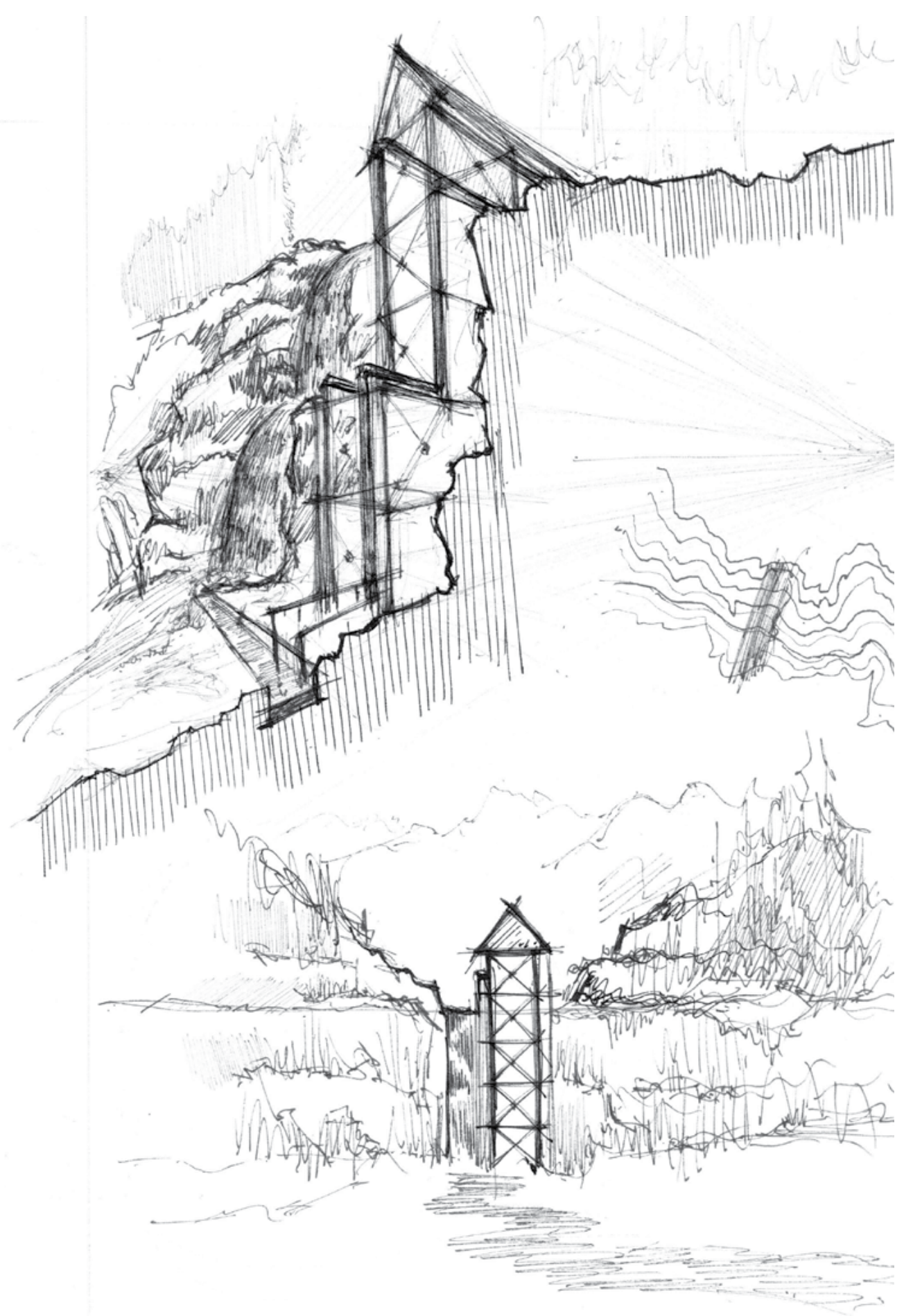

Fig.3.1.9. Trail \& Mechanisms Concept Sketches

\section{An Allegory}

The last portion of this thesis continues the narrative of the New Atlas of Banff and seeks to fabricate a speculative future image of Banff. Rather than seeking to deconstruct wilderness itself, it aims to deconstruct the duality of the definition that has in the past directly informed the park boundary. These explorations are framed as interactions between the trail and the mechanisms of the future landscape that it encounters. Within this speculative narrative, the mechanisms are proposed as mediators across Banff National Park, encountering and countering the ecological shifts expected due to climate change, along the length of the trail. The mechanism constructs are a commentary on the power of industry and preservation over the wilderness of Banff National Park. They represent not only how the site will continue to change in the future, but also how the constructed notions of wilderness and tourism industries might adapt to these new circumstances. They are speculative responses to the varying industries and experiences of site that have dictated the evolution of the national park and its narratives, as well as the rigid definitions of space and territories which are now beginning to collapse in on the site. These collapsing definitions are both physical and theoretical, as the new reality of a changing climate undermines the boundaries that have 


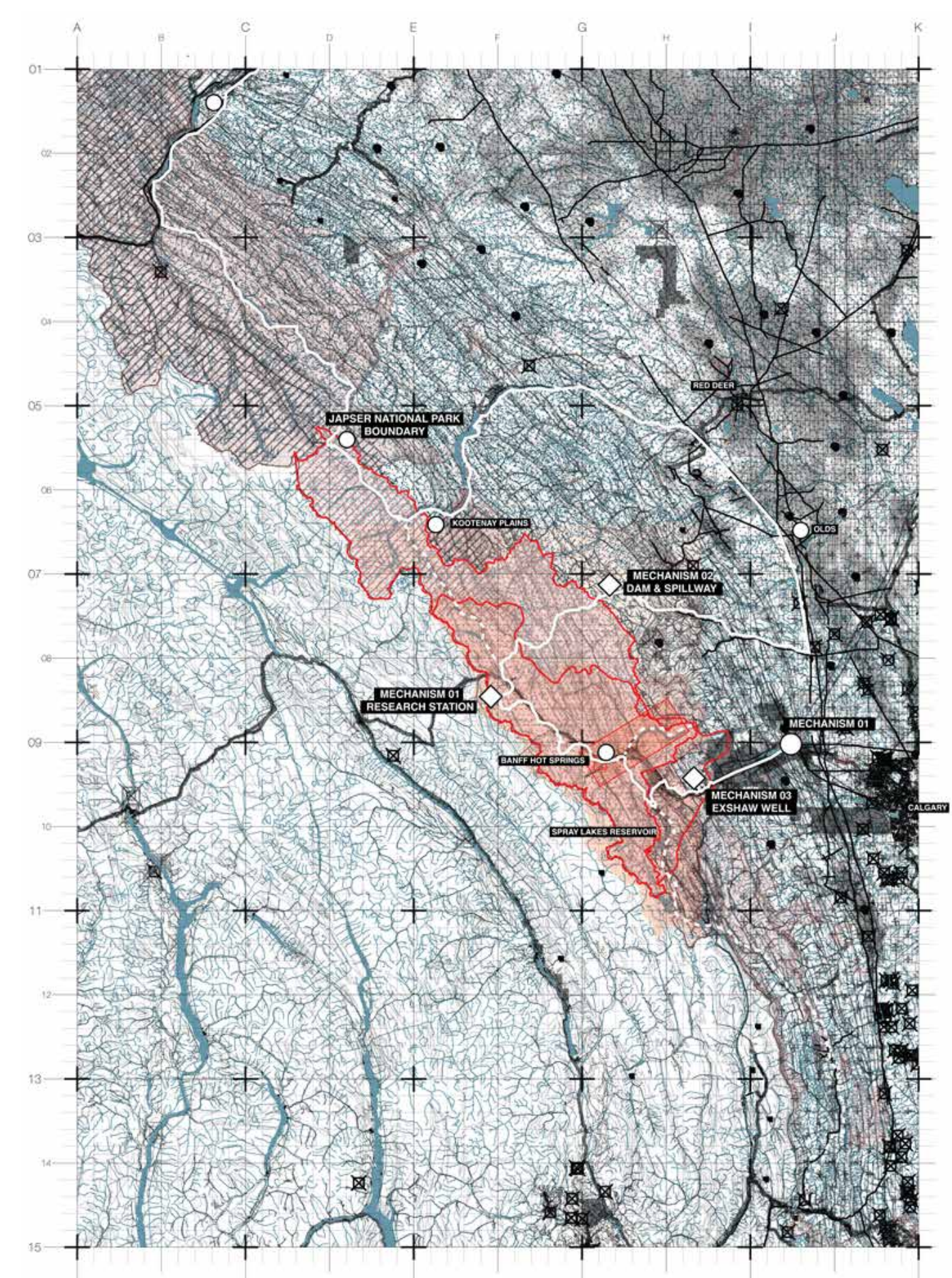

Fig.3.1.10. New Trail Map \& Existing Networks I been drawn to preserve landscapes inside the park while industrializing those on the outside. These varying definitions and divisions of space have, in light of a global climate crisis with unilateral consequences, become unsustainable. The final atlas entries aim to express the notion that in the age of climate change, all landscapes will become industrial and all landscapes will become a new wilderness. This new wilderness is one that is defined by an increasingly undeniable human stewardship over the site, where the strict dichotomy that has been drawn in the past between human and non-human worlds begins to blur and lose significance. Expressing these definitions of industrial and nonindustrial, human and non-human, as a duality that is present in every territory, rather than a dichotomy that can be falsely separated, is an essential aspect of embracing climate change not only empirically, but culturally and psychologically.

The remaining entries into the New Atlas of Banff act as an allegory for the far-reaching consequences of these changes within physical and cultural Canadian landscapes. It is a speculative future narrative told through reactive mechanisms to the environmental changes of the future. These proposals each express the duality of the site, as they balance an economic tourism industry that has commodified an experience of wilderness, while aiming to reconcile these 


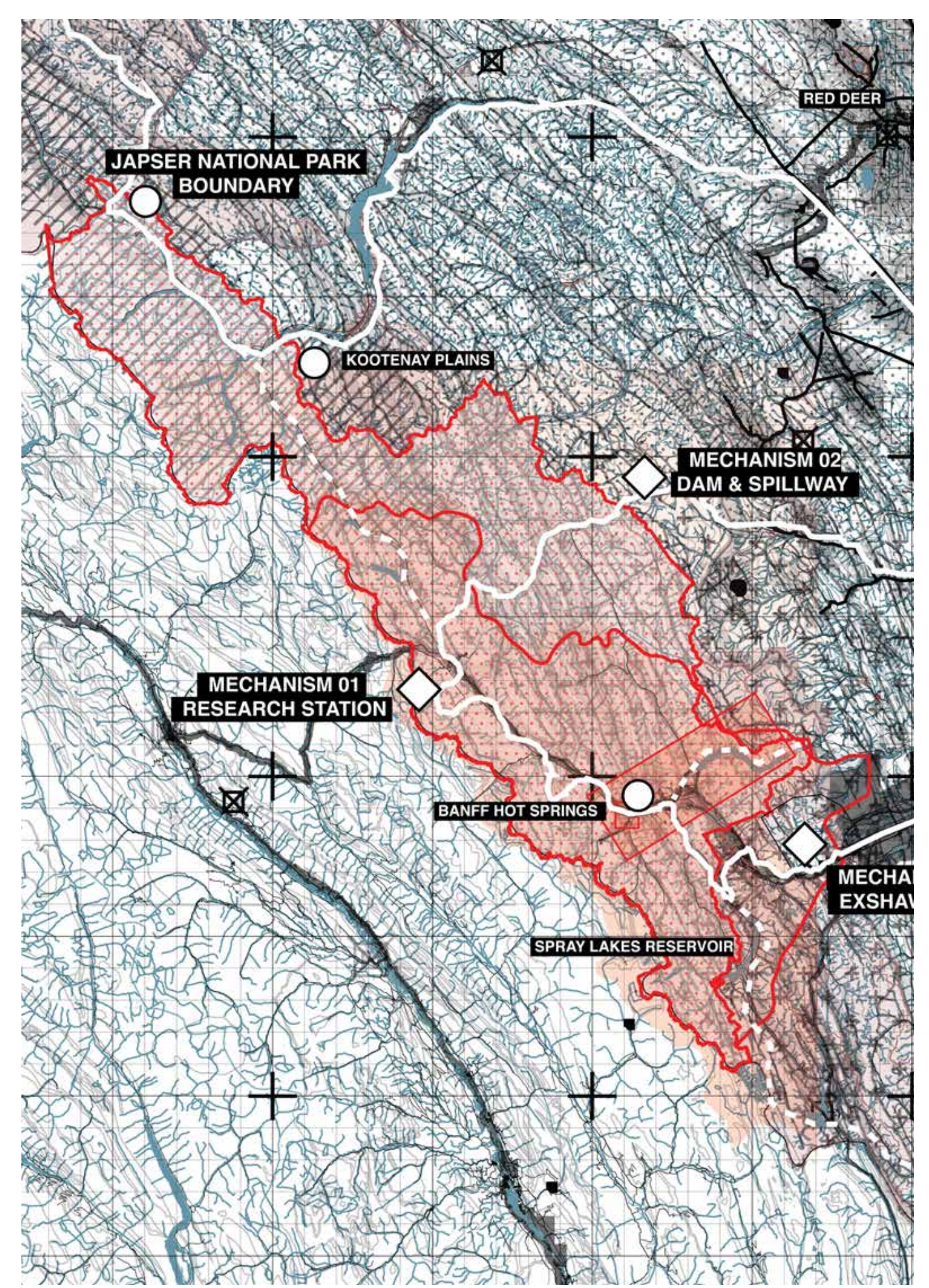

uses with an eroding and destabilizing landscape. Each intervention is a response to these conflicting pressures, embracing both the industrial and the romanticized interpretations of Banff National Park. They are prompts for understanding change not just in an ecological sense, but as a fundamental aspect of the site that has been previously supressed and must now become a visible force within the territory and wilderness, both physically and culturally. 


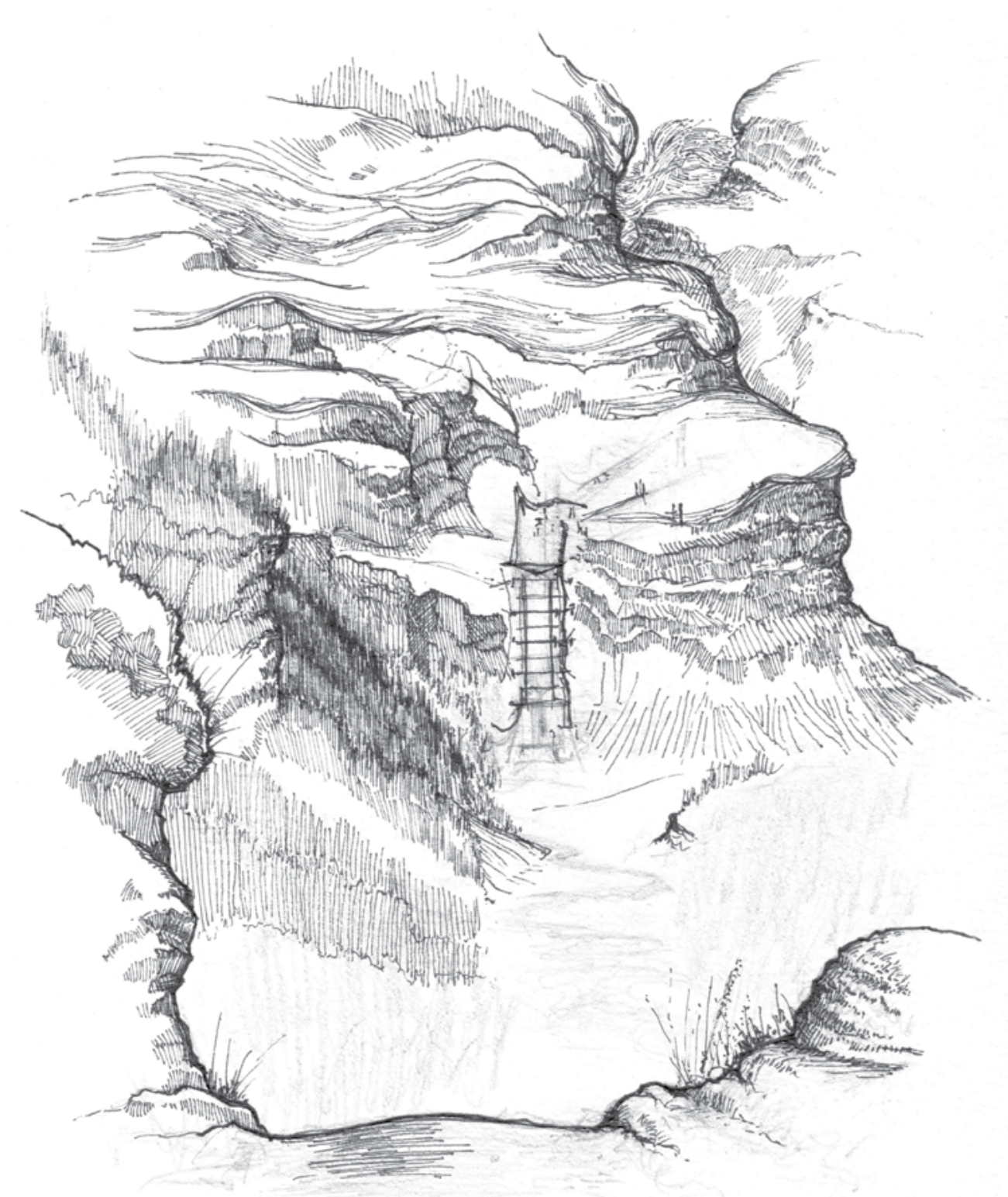

Fig.3.2.1. Mechanism 01 Site Vignette

\begin{abstract}
Here we are preserving part of the natural heritage of this planet, protected from the impact of resource exploitation and pollution. In these parks, future generations will find a lifeline to their own past, and a heritage to leave their own cbildren. ${ }^{10}$
\end{abstract}

- Leslie Bella

The first mechanism, set in the year 2030, is research station and hydro-facility located underneath a melting glacier in Paradise Valley, just south of Lake Louise. The glaciers in the valley have already begun to recede at a rapid rate, a trend happening across the Rocky Mountains as warmer temperatures at higher elevations are causing the disappearance of alpine glaciers. The mechanism is a hydro-facility and research station, designed to measure the rate at which the glaciers within the valley are melting. Established in 2030 to track the changes occurring within the climate of the higher region, it uses the meltwater from the glaciers to power the facility while documenting the speed at which the glaciers are disappearing. The facility remains operational for several years, functioning as a tourist point of interest, a research 


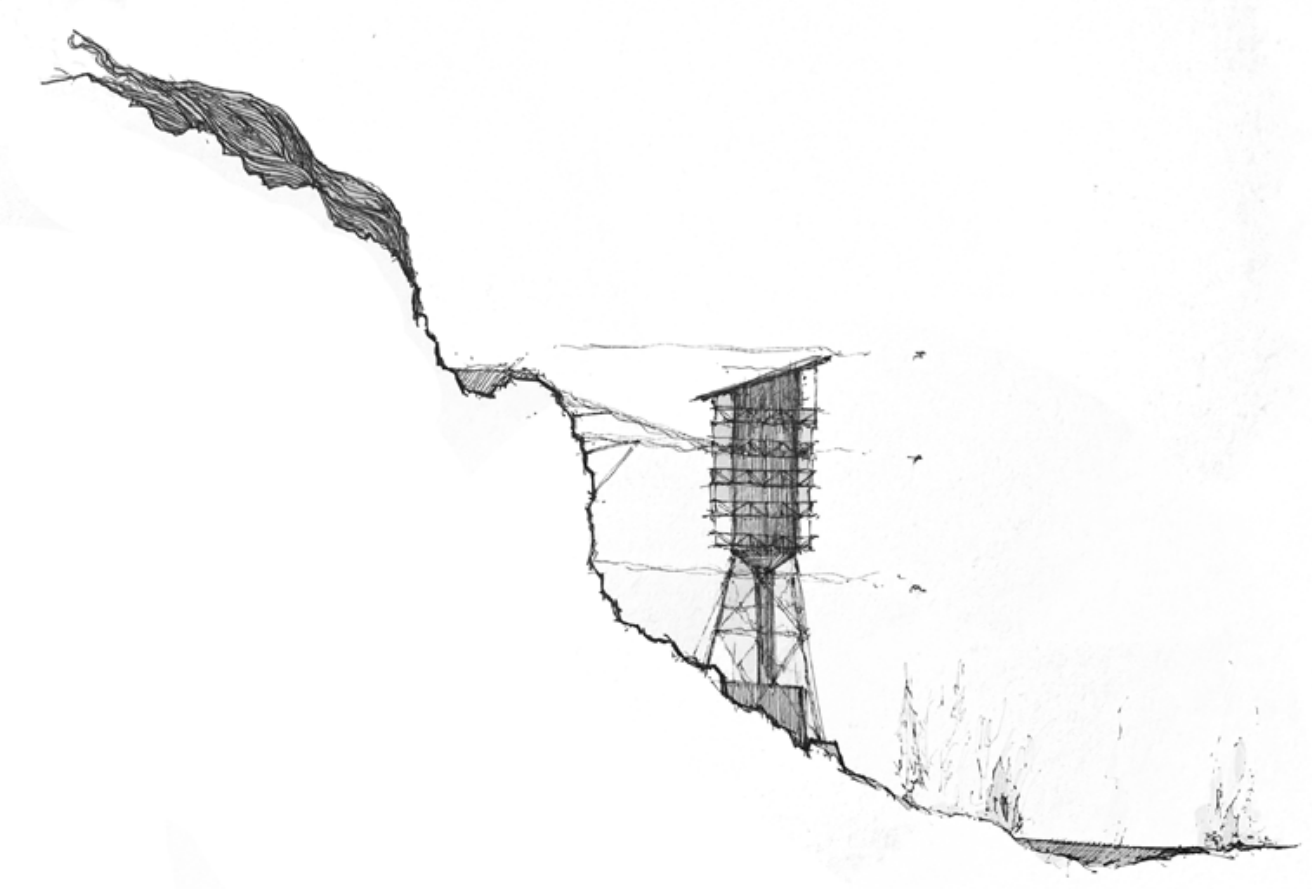

station and a field school. However, as the glaciers within the valley disappear at an accelerated rate, the station eventually outlives the phenomena that it was meant to measure and document. By the year 2070 , the industrial nature of the facility means that is removed from the park and that the boundary is redrawn around it, relegating the defunct station to the industrial landscape just outside of the national park.

The mechanism reflects the changing definitions that surround not only concepts of wilderness, but also notions of preservation and conservation. For some aspects of the landscape, such as the alpine glaciers that are already beginning to disappear, a the notion of a perfect preservation of the landscape already seems an outdated concept, with changes and erosions to ecological phenomena already well underway. The mechanism acts as a means to explore how these erosions in the landscape might be measured or documented in the future, to what extent these activities will conflict with idealized notions of wilderness within the national Park, and what might happen to these instruments of measuring change should they outlast the phenomena that they are created to document. 

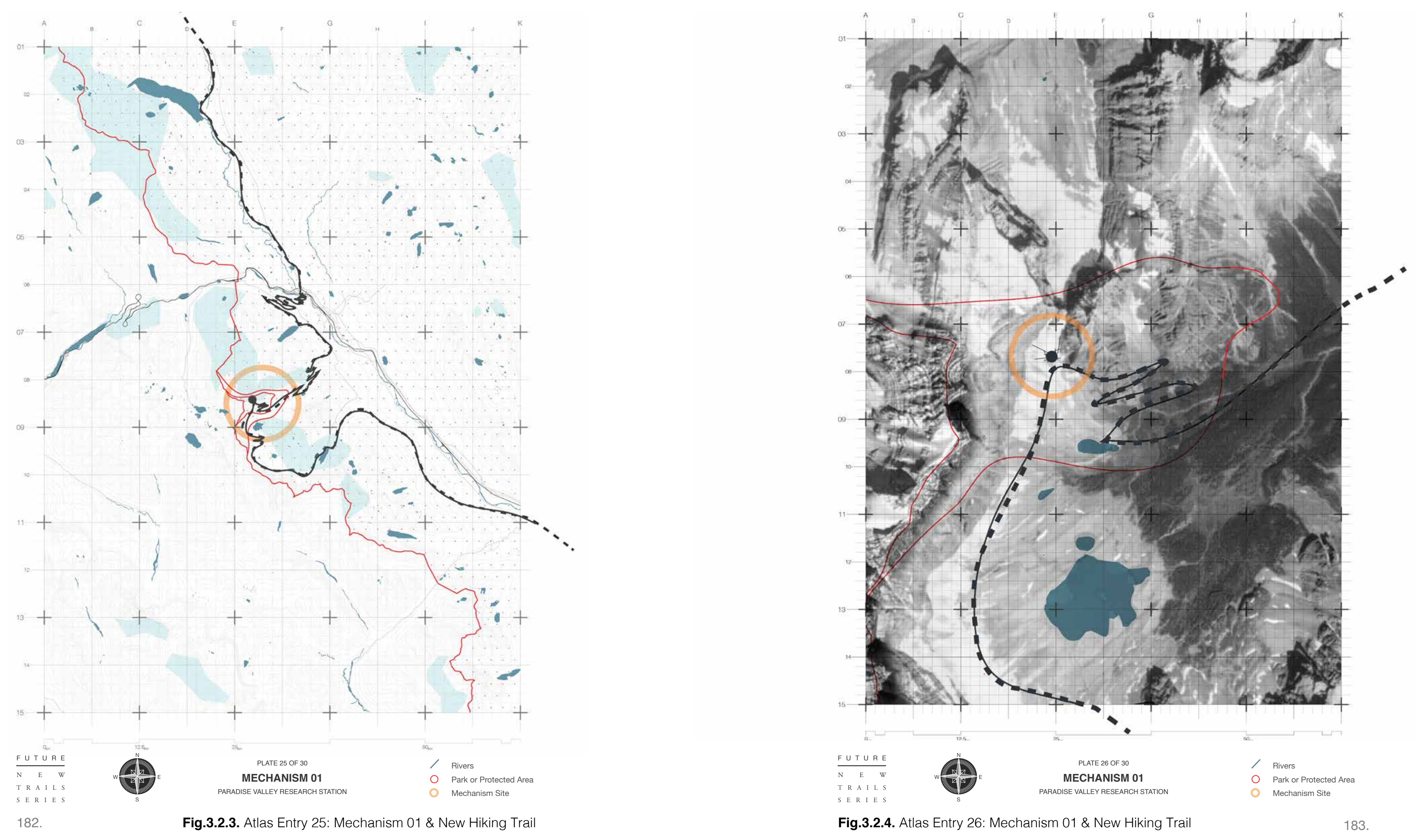

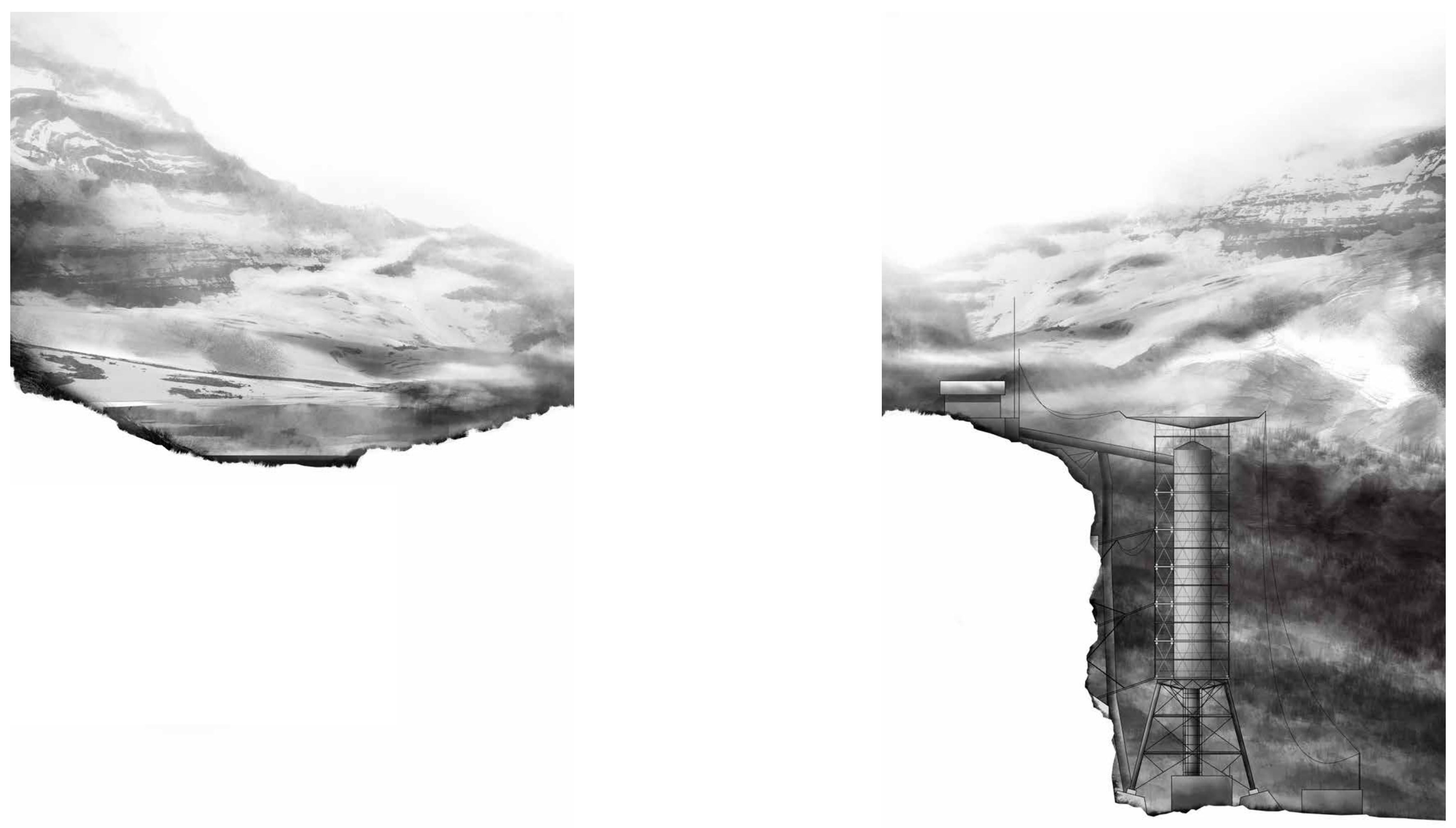


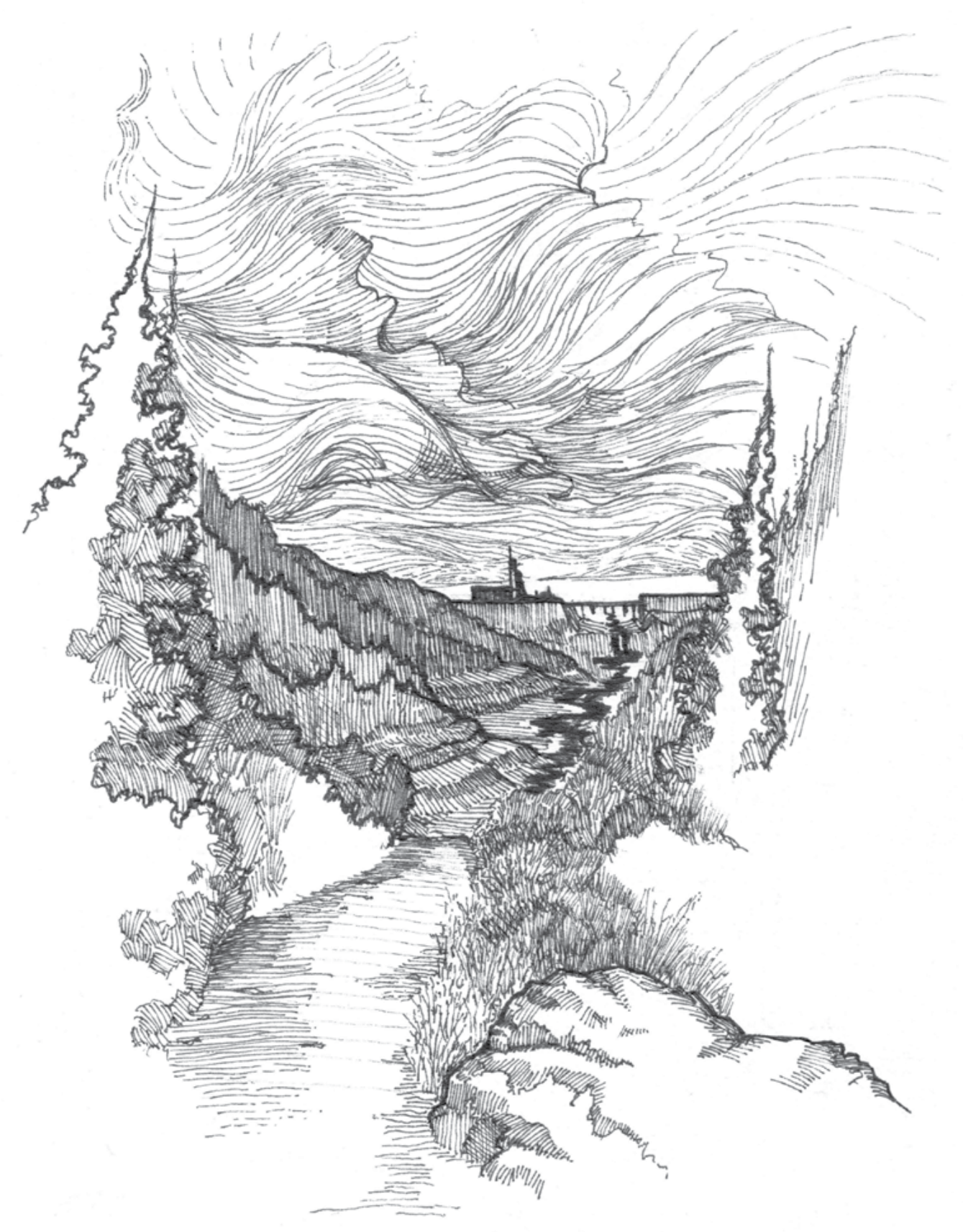

Fig.3.3.1. Site Vignette, Mechanism 02
11 // MECHANISM 02

A person with a clear beart and open mind can experience the wilderness anywhere on earth. It is a quality of one's own consciousness. The planet is a wild place and always will be."

Gary Synder

The second mechanism, set in 2055, is a dam and spillway construction which mitigates springtime flooding events east of the Rocky Mountains by diverting water during seasonal snowmelt events. Usually occurring in the late spring and early summer months, these recurring floods are often a result of rapid snowmelt and increased rainfall at higher elevations due to warmer springtime temperatures. During these months, the facility might be used to divert water from major tributaries, aiming to mitigate the damages to communities downstream. While not in use as a spillway, the construction diverts a small amount of water from the river valley to create a new creek that acts a recreational area and tourist point of interest. Despite its industrial nature, the popularity of the site as a recreational facility and 


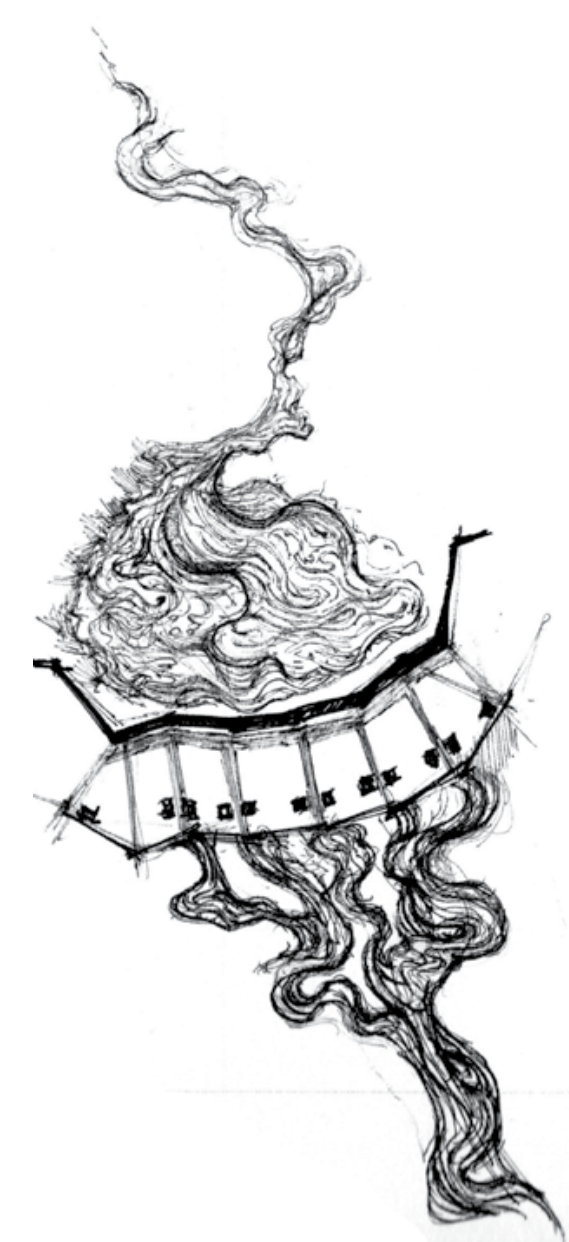

its potential economic development through tourist-based industry means that in 2070 the spillway and dam is incorporated back into the National Park after the boundary is redrawn.

The second mechanism is a reflection of the changing mandates of National Parks over time, and how tourism-based industries have often dictated the evolution of park space and its compatibility with certain forms of industrial development. Similar to the hydro-development at Lake Minnewanka, which was argued would not only allow for hydro-electrical industry but also aesthetically ameliorate the lake valley for the benefit of the tourist, the dam and spillway construction proposal is an exploration of how the aesthetic values of the sublime might continue to have influence over industrial developments within Wilderness. When these developments are closely enough aligned with the scenic expectations and values that wilderness has come to represent, their development is permitted or even encouraged within the space of the national park. This mechanism is a reflection on how industry and potential economic incentives, such as the mitigation of costly natural disasters within the region, often depend on an aesthetic metric to be deemed compatible with collective understandings of wilderness. 


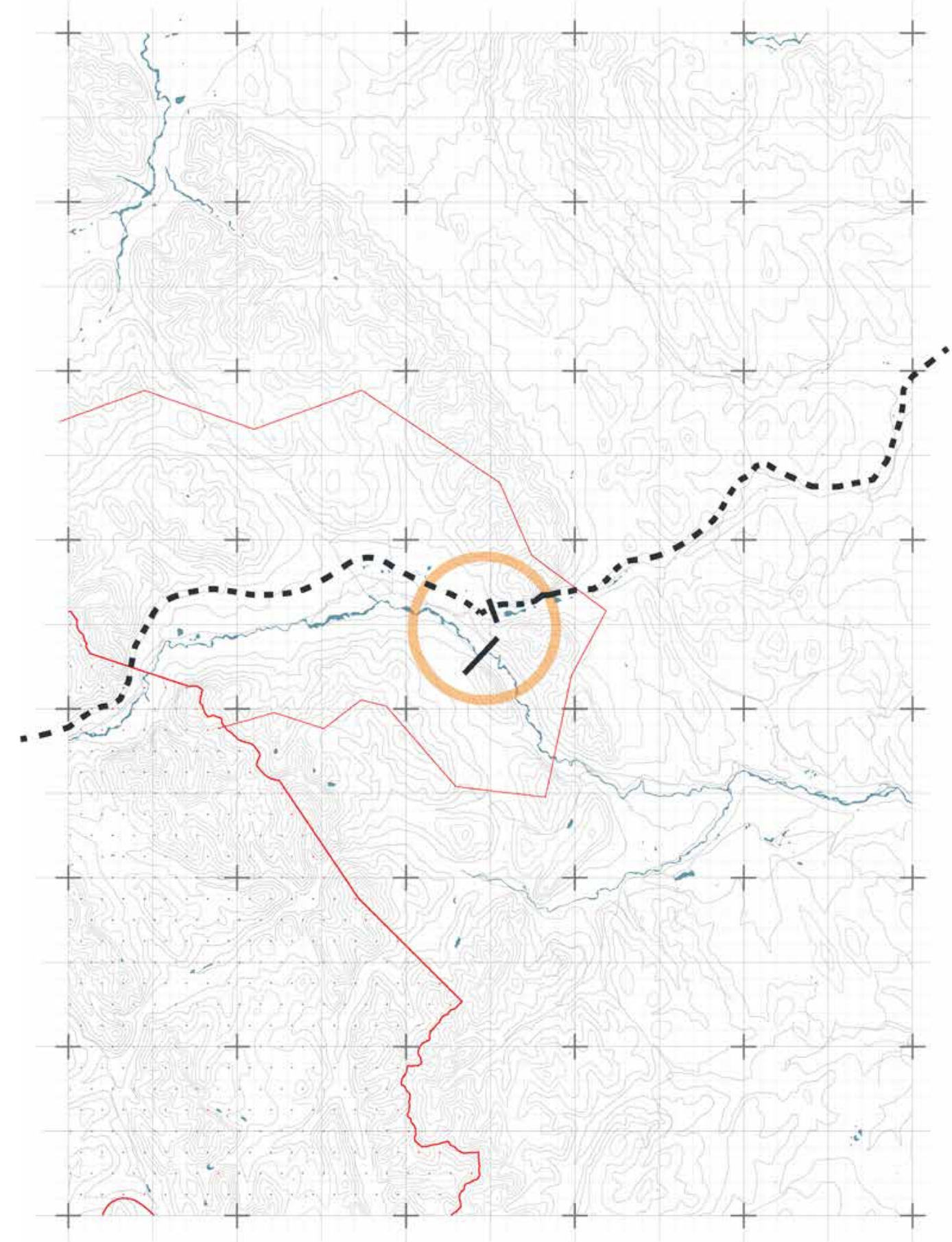

\begin{tabular}{l} 
FUTURE \\
\hline N E W W \\
TRAILS \\
SERIES
\end{tabular}

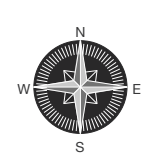

MECHANISM 02

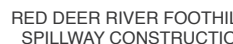

Fig.3.2.3. Atlas Entry 27: Mechanism 02 Location Plan

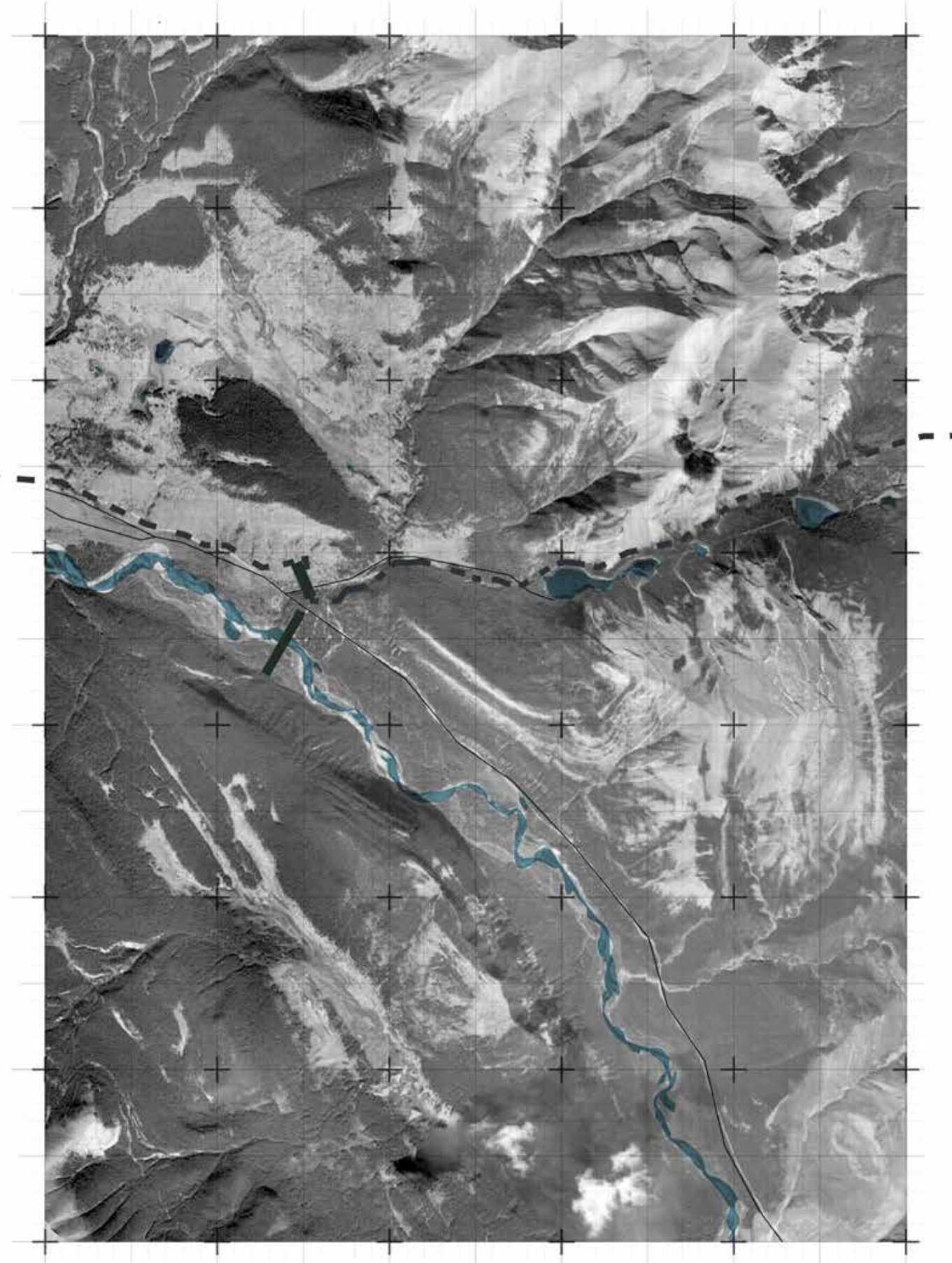

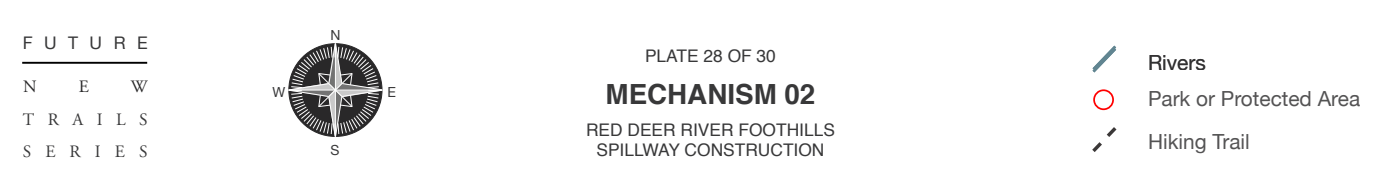

Fig.3.2.4. Atlas Entry 28: Mechanism 02 Site Plan

191 

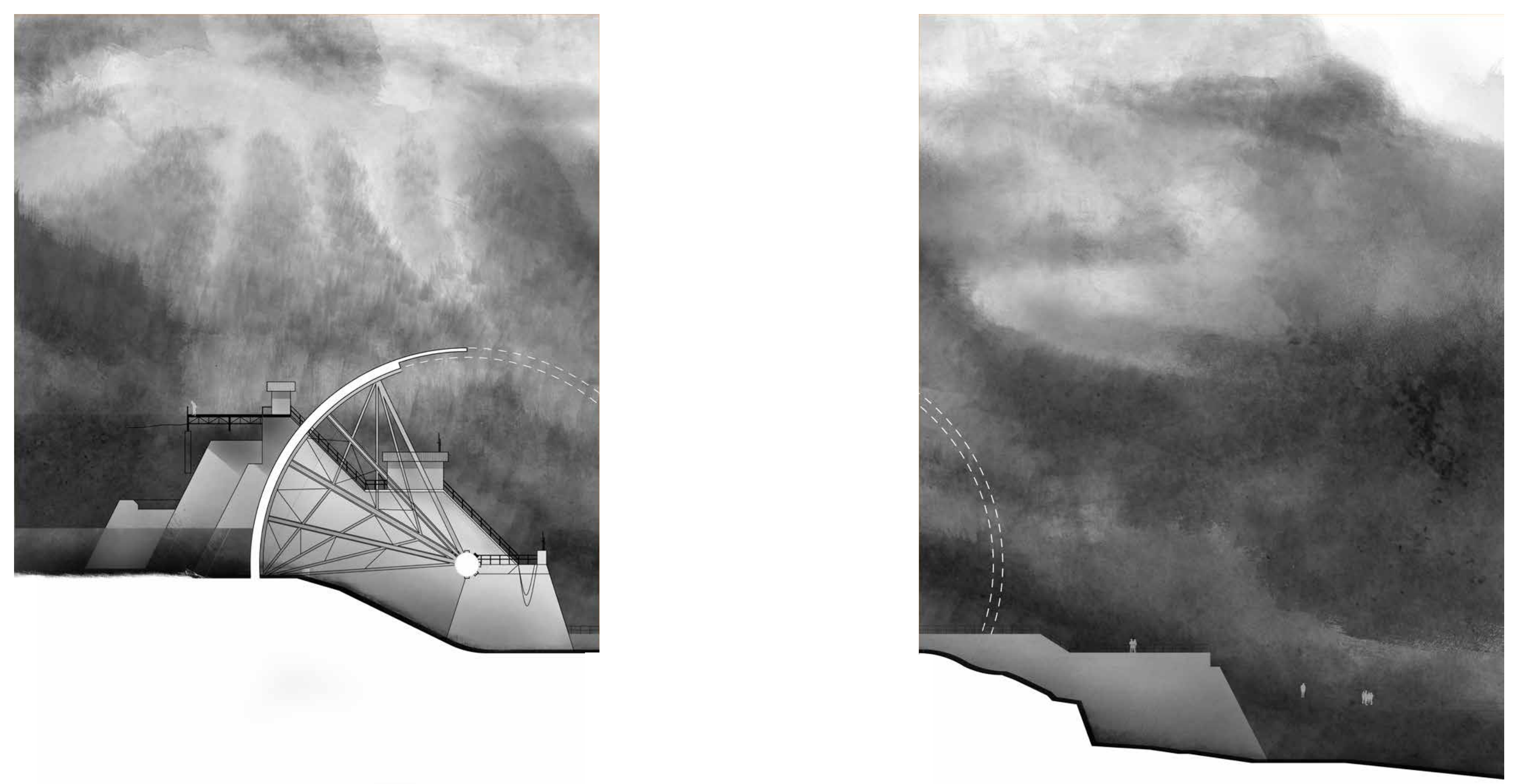


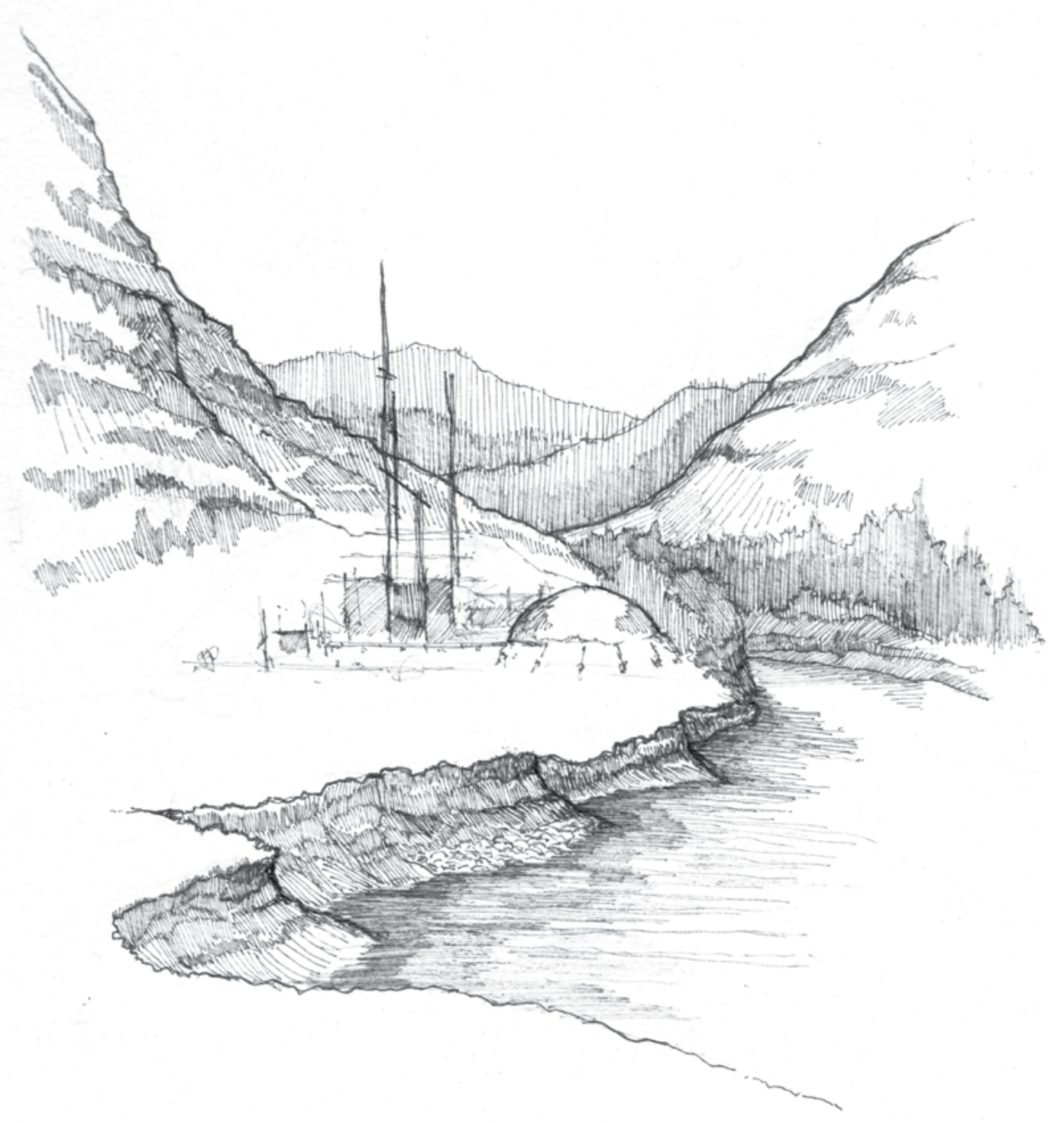

Fig.3.4.1. Site Vignette, Mechanism 03

\begin{abstract}
If wildness can stop being (just) out there and start being (also) in here, if it can start being as bumane as it is natural, then perbaps we can get on with the unending task of struggling to live rightly in the world-not just in the garden, not just in the wilderness, but in the home that encompasses them botb. ${ }^{12}$
\end{abstract}

\section{-William Cronnon}

The last mechanism, set in 2085, is a water well construction at the Exhsaw cement plant, meant to help protect the facility from the recurring seasonal flooding events that have become more and more common in the Bow River Valley. Originally intended to protect the economically valuable facility from these flooding events, the mechanism also enables the industry of the cement plant to access the water of the Bow River, which is normally within a protected territory that traces the river itself. During these seasonal flooding events when the river expands past these protected boundaries, the water can be incorporated into industrial uses of the cement plant, acting as a coolant for the heating and cooling processes used to convert the raw, extracted resources into cement and aggregate. 


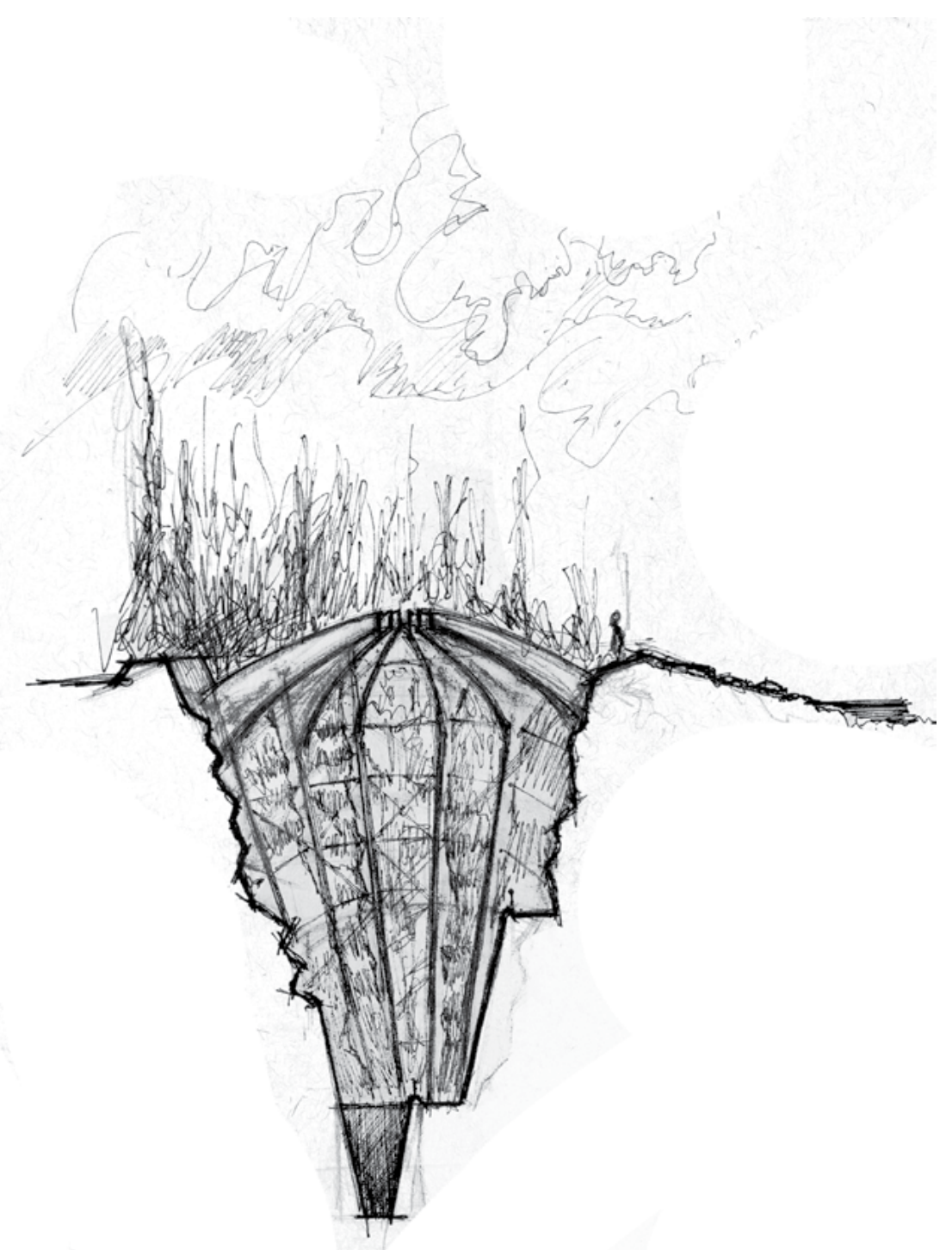

The last mechanism is a reflection of the constant tension that exists within the park between the direct economic processes of commodifying a landscape through tourism or through industry. With many valuable resources still locked away within the boundaries of national parks, this tension is likely to increase in the future as the value of controlling these natural resources increases. The duality of these values creates an equal and opposing competition which, over time, has come to be defined by the park boundary. The project explores these parallel uses and commodification's of natural resources, the economic incentives or industries that might steer future developments designed to mitigate the effects of climate change, and how changes within the climate might begin to undermine established boundaries and methods of conservation. 

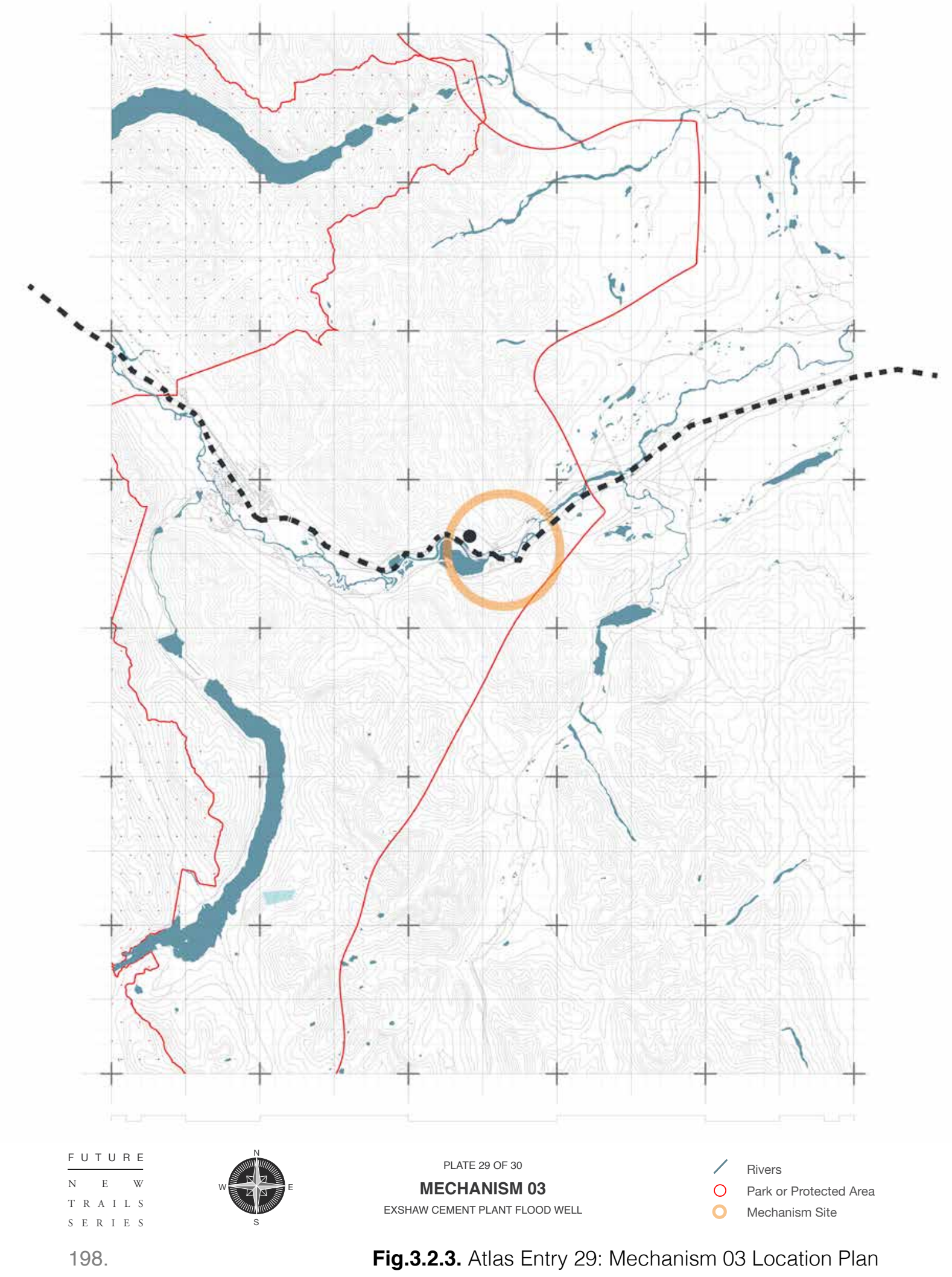

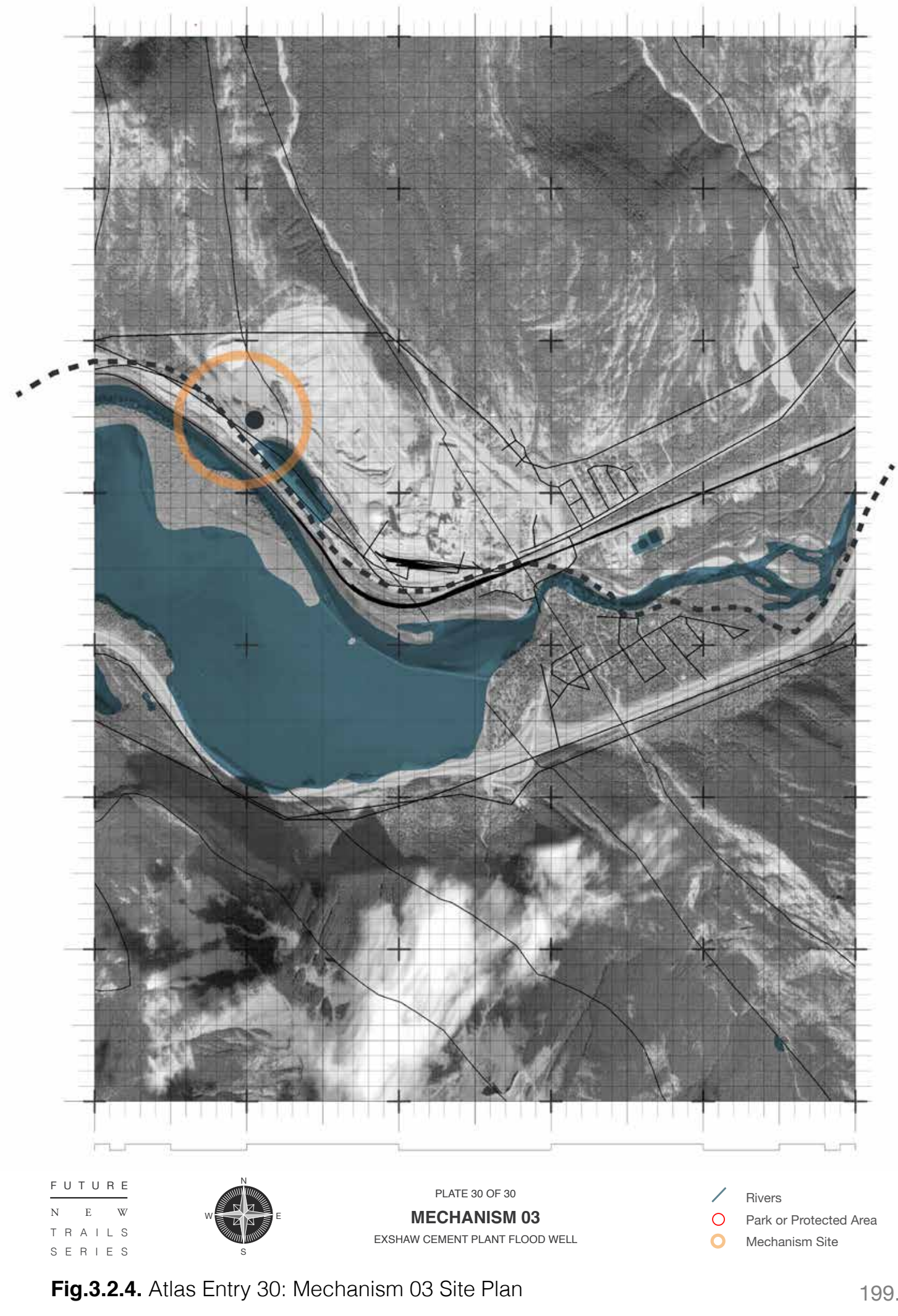




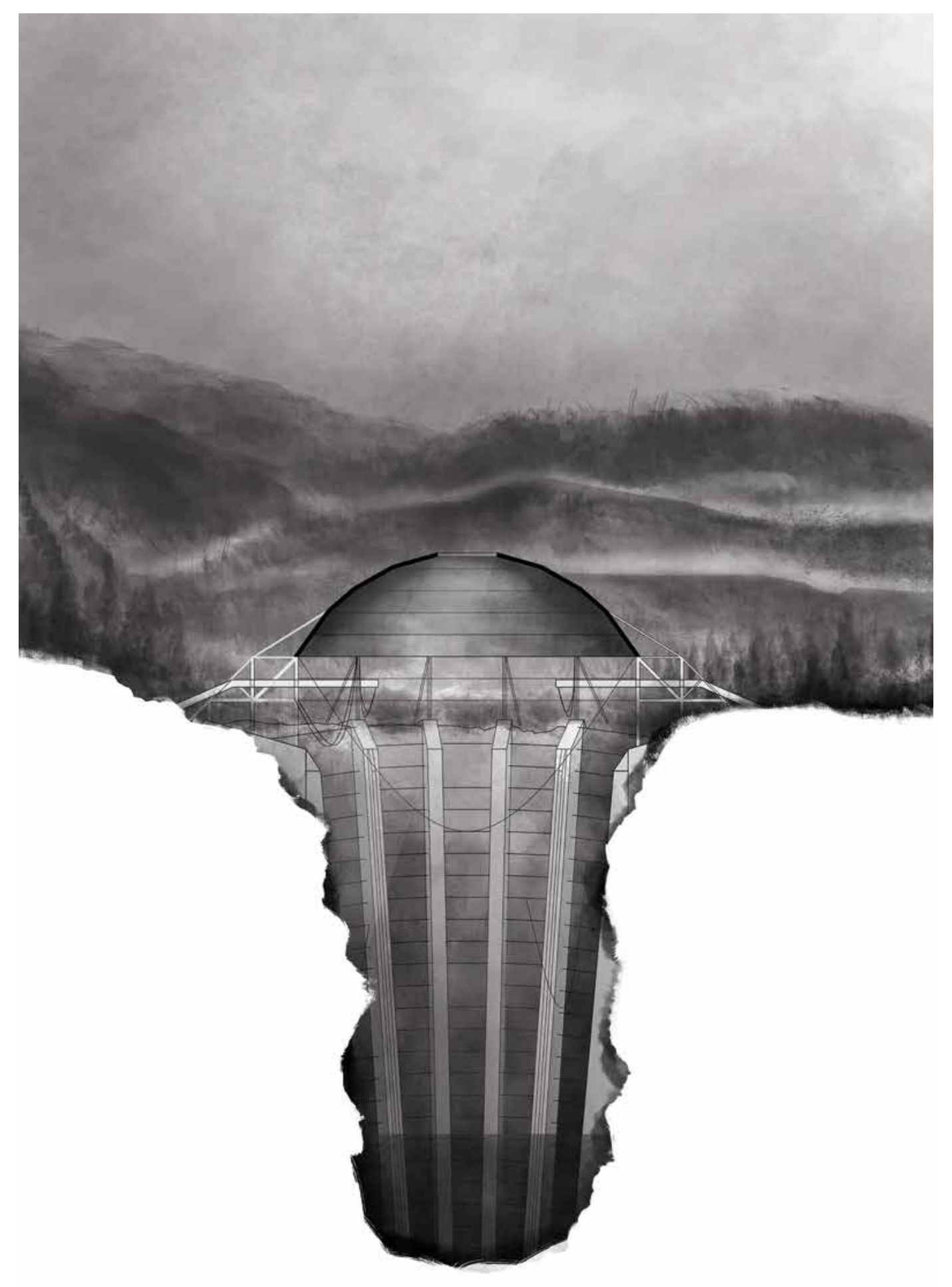

Fig.3.4.5. Mechanism Diptych 3-1

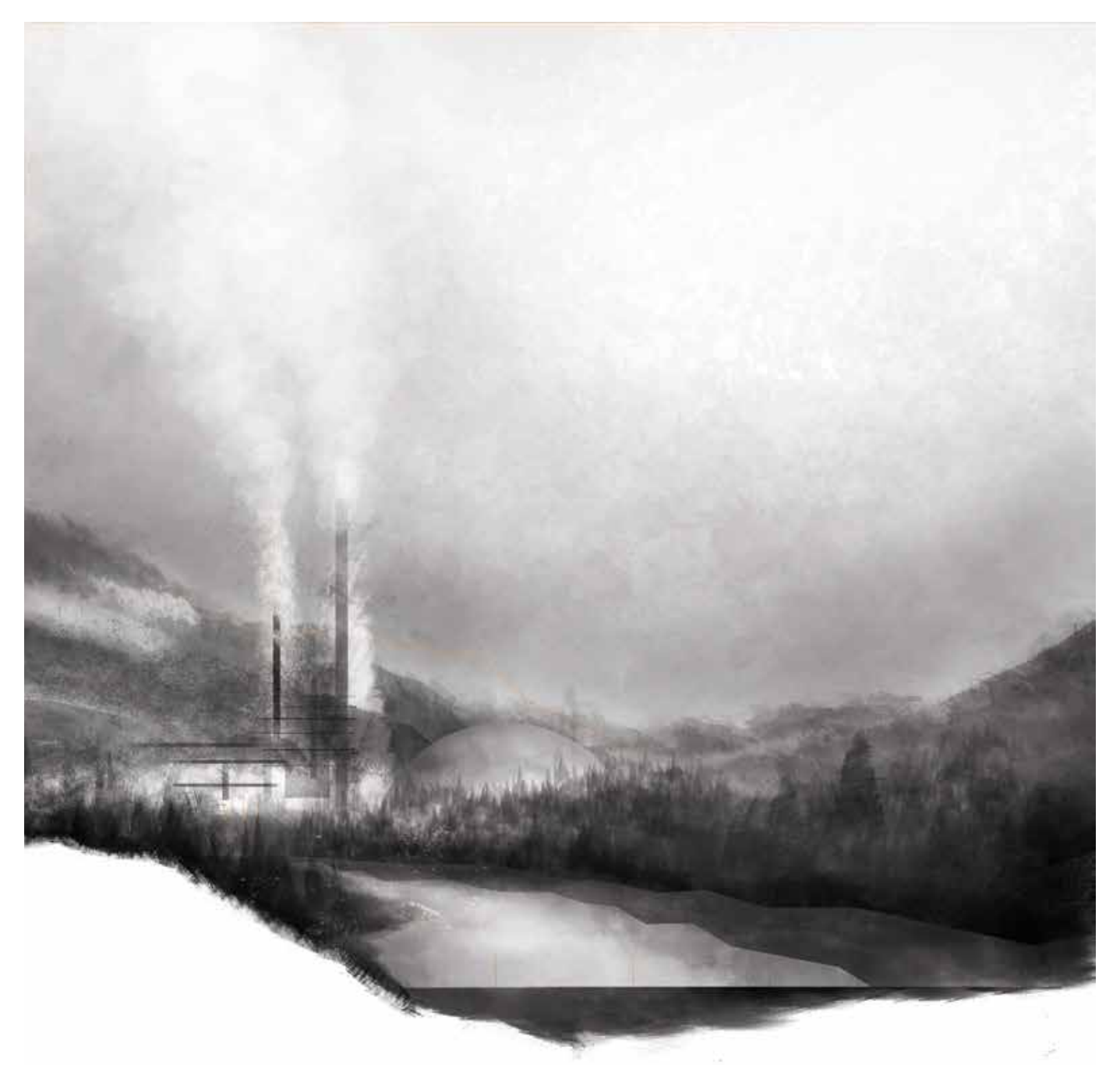




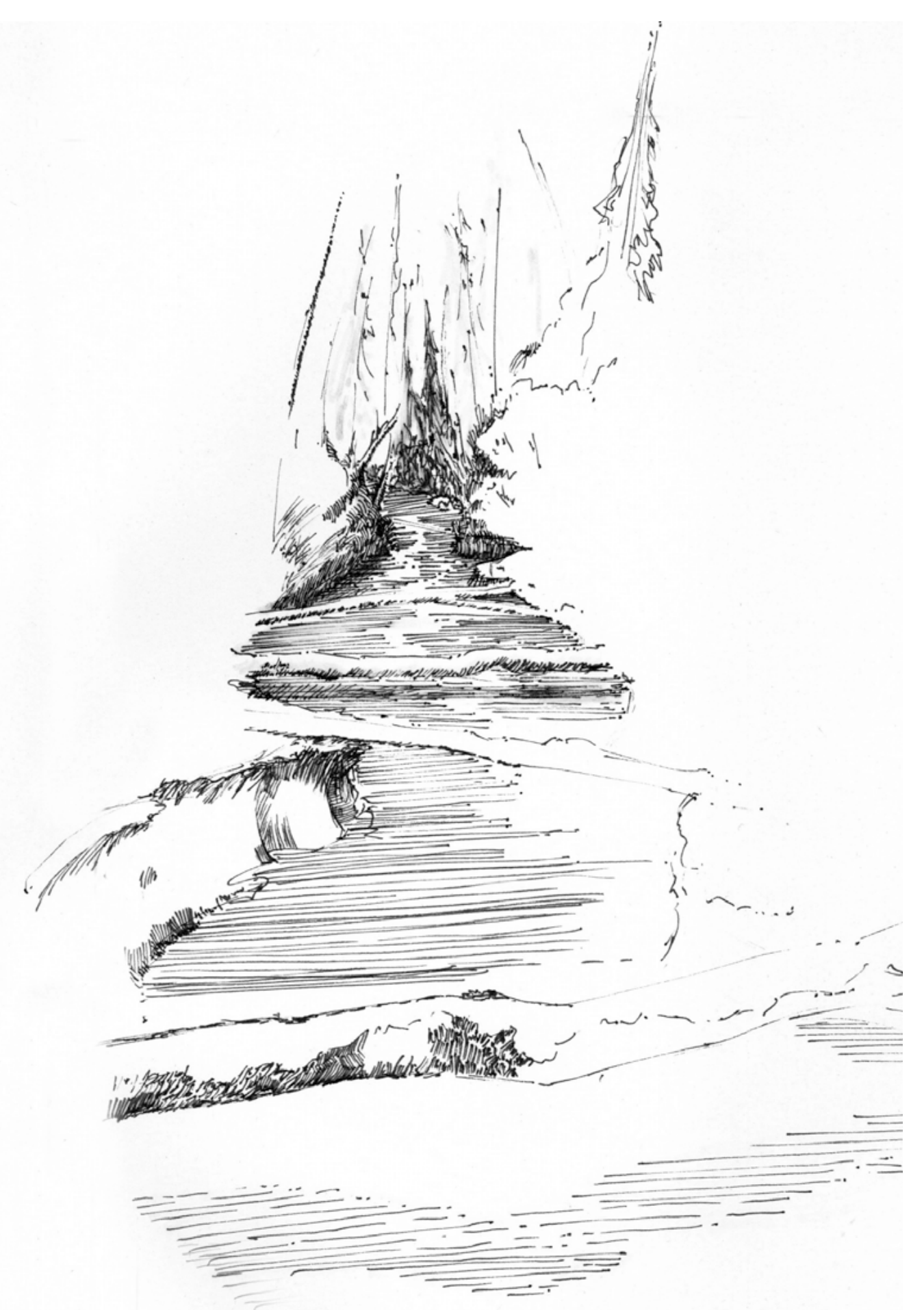

Fig.3.5.1. Creek Sketch

\section{CONCLUSION}

The first two sections of this thesis have sought to dissect the unique conditions, both psychically and culturally, that Banff National Park has crafted through its continued pursuit of defining wilderness. It has explored the unique imagery and mythos of National Park space, and the relevance of wild space to Canadian culture and history. The beautiful, scenic landscapes of the park prove to be more fraught than what meets the eye. It has examined, through a series of mapping explorations, the physical conditions that this understanding of space has created at multiple scales, and its roles within broader systems and networks of power. Lastly, this work sought to understand the future challenges and erosions that now threaten to undermine these definitions of space, along with the physical and legal boundaries that have been built around them. The design proposal has been a speculative reflection on wilderness as a cultural phenomenon and as an intangible space.

Wilderness is a term that continues to evolve, a notion of "uninhabited" space, being defined and redefined over and over. Notions of wilderness have had a profound significance in shaping entire landscapes and cultures. In the pursuit of its creation and commercialization, territories have been claimed, lakes and rivers have been moved, and sacred spaces have been decimated. This thesis has sought to un- 
derstand what wilderness means within Canadian culture through the mechanism of the national park, dissecting its past, its present and its potential futures. Banff National Park and its evolution demonstrate that wilderness is an abstract and ambiguous idea of space that evolves through its current culture, taking the form of the antithesis of the society that constructs it. Within the past 200 years in Canada alone it has been cast as both the antagonist to efforts of expansion and settlement, as well as the protagonist of escapism from a modernised world. Wilderness, and the spaces that celebrate it across Canada such as Banff National Park, must now be redefined once more, not as an escape from the challenges of our modern age, but of the most fundamental and significant reminder of the implications of ever-expanding human industries.

This project is neither a critique of the National Park, nor of wilderness, but of the broader implications of both that create fundamentally untenable divisions of space in an eroding world consumed by challenging realties. Culturally celebrating wilderness while flagrantly consuming it has become a calculated ritual in Canada, weighing cultural and aesthetic desires along economic metrics to inform conservation. The luxury of having both of these treatments and versions of space neatly separated into industrial landscapes and preserved pockets of nature is a dichotomy that is already proving unsustainable as floods, droughts and wildfires move indiscriminately across landscapes. Either all space is sacred wilderness, or none of it is.

In the year 2021, in one corner of Alberta exists a string of national and provincial parks dedicated to protecting wilderness, and in the opposite corner sits the Alberta oil sands, fields of pollution and industry so massive that they are visible from space. In 2013, floods washed through the bow river valley and Banff National Park, devastating the towns and cities downstream. In 2016, wildfires tore through Fort MacMurray, the township at the center of the Athabasca Oil Sands in Northern Alberta, requiring mass evacuations. These sites are both wild spaces. They are both industrial landscapes. Both are products of Canadian cultural values. Both are our environmental legacies for future generations. Both are sacred. One is a reckless engine of consumption, the other an eroding shrine to an abstract idealism. Both are constructs that will seem equally absurd in a world that can afford to operate neither 
Part III

ENDNOTES

Travis Price, The Archaeology of Tomorrow: Architecture and the Spirit of Place (San Rafael: Earth

Aware Editions, 2006) 111.
Travis Price, The Archaeology of Tomorrow, 112.

Lydia Kallipoliti, History of Ecological Design (Oxford: Oxford Research Encyclopedias, 2018),

30.

Lydia Kall

Ibid, 24 .

Ibid, 31 .

Ibid, 30 .

Mason Courtney, All of Our Secrets are in These Mountains: Problematizing Colonial Power Relations Tourism Productions and Histories of the Cultural Practices of Nakoda Peoples in the Banff-Bow Valley (Edmonton AB: University of Alberta, 2010) 221.

Leslie Bella. Parks for Profit (Montreal: Harvest House, 1987) 162

Gary Snyder, "Week in Review,' New York Times, September 18 $8^{\text {th }}$ 1994, 6.

Cronon, William. "The Trouble With Wilderness: Or, Getting Back to the Wrong Nature." Environmental History, Vol. 1, No. 1 (Jan., 1996): 7-28. 


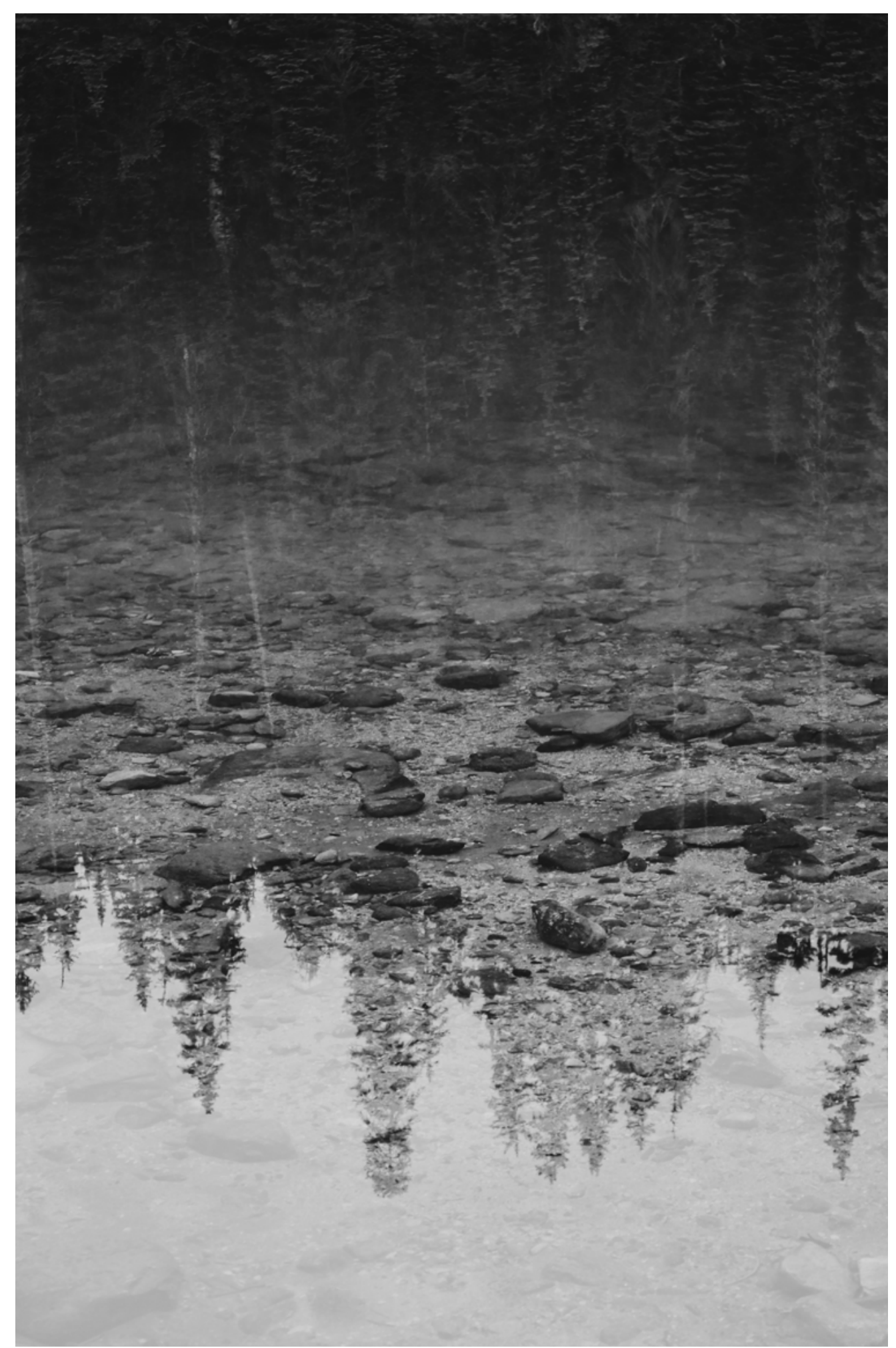

Fig.3.5.2. Lake Reflection, Lake Louise

\section{EPILOGUE}

This thesis began with the idea of trying to better understand a topic and a place that I had always found interesting. Throughout my adolescence and childhood, weekend trips to Banff National Park were a year-round staple: skiing every weekend in the winters, hiking every weekend in the summers. Growing up in Calgary, so close to the Rocky Mountains, while constantly hearing from relatives in Germany how envious they were of Canada's vast untouched Wilderness, instilled a perspective of having special access to some unique place or thing. I didn't fully understand what that thing was, but I knew that for some people, experiencing it was a lifelong dream, whether that meant getting to go skiing in the Rocky Mountains or seeing a Grizzly Bear. I wanted to try and think critically of what Wilderness meant, and to understand this idea of space that I had been unwittingly consuming my whole life. Now, reflecting on this thesis as is concludes, I am left with a few final thoughts and reflections....

Firstly, this thesis has allowed me to study and better understand a place that has been a huge influence in my life. It allowed me to take what I had learned throughout my education and apply it to a place in which I had personal investment and a space that had a profound significance to me. Completing a thesis on Banff felt like a unique opportunity to study something both as an insider and as an outsider, 
coming back to a familiar place, but with a new perspective. In this sense, the thesis has allowed me to not only think about a space and topic that I find fascinating, but to also understand the ways in which I am a product of this place and its culture, learning a bit about my own worldview in the process.

Secondly, the more I have researched the topic of Wilderness and its connections to conservation and the claiming or demarcation of landscapes, the more I realize how central it is to important conversations happening across Canada today. Though I knew that this topic had a personal interest for me when I began the project, I did not expect that it would speak to so many important issues that Canadian and North-American culture are currently struggling to address. These conversations range from addressing Canada's colonial past, to how arguments of conservation have been used to disenfranchise indigenous communities throughout the country's history, to the politics and economics of developing Canada's vast natural resources in a world of ever-expanding human industrial pressures. The Atlas of Banff National Park has sought to examine how the treatment of a landscape can reveal these tensions, and how the drawing of a boundary can begin to tell some of these stories. It has sought to contrast culturally held notions of wilderness and the sublime with issues of resource exploitation, colonial land claims, and economic development, and their concealed influences in the fabrication and evolution of park boundaries. Banff National Park, and all national parks, are themselves an industry, an occupation and a use of landscape that present their own unique challenges and dangers, reinforcing the idea that human beings are distinct or separate from the natural world that we depend on, a part of nature and wilderness only when it suits us. This thesis is, fundamentally, a negotiation and study of control being exercised over a landscape, within which colonialism has played a central role, and an examination of the spaces, dichotomies and anomalies that it has crafted over time along invisible boundaries and false dichotomies. Though the project has only scraped the surface of these complex histories and issues, it has given me some understanding and appreciation of the forces that can dictate nearly every aspect of a landscape and its development, and how political machinations and economic power struggles can define territories when new value is found within a landscape.

Thirdly, I am left with an appreciation for the complexity and tension that can be found in things that, at first glance, appear neutral. Through this thesis I have discovered how a landscape that seems absent of human influence or industry can, in fact, be a product 
of it, and how a space that is meant to be neutral might be revealed to be made up of a complex struggle of competing interests that seem destined to tear it apart. Tensions between conservation and commercialization, between history and fictionalized romanticism, and between industrialization and preservation. This has, in many ways, been the aspiration of this thesis and of the Atlas project: to make these invisible tensions tangible, and to draw and understand them in their bizarre and contradictory complexity. Though these forces, at times, seem to create an inescapable labyrinth of inevitably commodifying landscapes, either through celebrating scenery or through consuming resources, it is not meant to merely lament the current uses of these spaces. Though the final speculative design entries are meant to underscore the future that these forces might create, the project aims to draw attention to this possible evolution as a cautioning against the continued deliberate mischaracterization of wilderness that is often reinforced through the national park. Through these fictions the false dichotomies that have been built into the boundary of the national park might begin to be deconstructed. Only through exploring and understanding the complexities of these competing forces and the invisible networks, barriers and boundaries that they have crafted and manipulated over time, can the challenging future of this place begin

\section{to be addressed.}

Ironically, since defending my thesis I have spent much of my time going back to Banff National Park, excited to finally escape my computer and spend some time outside. However, when I go there now I notice the little markers that exist in the landscape of strange things that I had never noticed before. On the drive out to the mountains I notice how the highway cuts directly through the middle of the Stoney Nakoda First Nations Reserve, and how the boundary of the Reserve stops exactly where a provincial park begins. I notice the powerlines that trace across the foothills, back to the dams and hydro-stations that are hidden in valleys just out of site from the highway. I think of the rivers and lakes that I now know are manmade, and the things that might be hidden below their surface. I think of the images that I used to have in my head of quaint little hamlets with small fires heating log houses, and how they now sit next to cement plants and abandoned coal mines that had previously been just out of frame. I think of which peaks have kept their indigenous names, and which ones are named after British battleships. I'll think of how I now see a landscape that I, and countless other people like me, have and are continuously altering, redrawing and reinventing with our own narratives. 
Whether it's through the dictating force of tourist dollars, the spiritual value that might be found in the sublime, or simply its capacity to help visitors escape some stressful day-to-day reality, the endless values of the landscape in Banff National Park lead to endless complexities. Now, understanding the push and pull of the forces that continue to claim, commodify or preserve this space is an indispensable aspect of tackling the challenges that the future of this place will hold. The illusion that I held of Banff as some forgotten, Wild sanctuary might be gone, but with that comes both a loss of personal affinity to the site and an increased sense of responsibility for a space, and an understanding of landscapes, which I am inescapably a part of. This, to me, seems like it might be the ultimate goal of this thesis: to encourage some new appreciation or enfranchisement into this strange, uniquely Canadian ritual of consuming landscapes so eagerly while celebrating their virtues. To grant some degree of agency or understanding into how spaces across Canada have been claimed, defined, commercialized or manipulated in the name of Wilderness, and the environmental and cultural legacies that we inevitably leave behind through our landscapes. 


\section{BIBLIOGRAPHY}

Armstrong, Christopher, and H.V. Nelles. Wilderness and Waterpower: How Banff National Park Became A Hydroelectric Storage Reservoir. Calgary AB: University of Calgary Press, 2013.

Bella, Leslie. Parks for Profit. Montreal: Harvest House, 1987.

Binnema, Theodore, and M. Niemi, “'Let the Line Be Drawn Now': Wilderness, Consevation, and the Exclusion of Aboriginal People from Banff National Park in Canada." Emironmental History 11, no. 4 (2006): 724-50.

Boulet, Roger. Vistas: Artists on the Canadian Pacific Railway. Calgary AB: The Glenbow Museum Press, 2009

Bush, E. and Lemmen, D.S., Canada's Changing Climate Report, Ottawa ON: Government of Canada, 2019.

Canadian Pacific Railway Company. "The Canadian Pacific: The New Highway to Chung Textual Materials, 1887. Doi:http://dx.doi.org/10.14288/1.0226248.

CCRN Network Canada. “The Changing Environment of Western Canada Canadian Rocky Mountains." Accessed November 25, 2020. http:// www.ccrnetwork ca/outputs/information-products/docs/Rockies Change.pdf

Christensen, Lisa. Truth and Beauty in the Canadian Rockies. Markham ON: Fifth House, 2019.

Choko, Marc H., and David L. Jones. Posters of the Canadian Pacific. Buffalo: Firefly 2004

Corner, James. "The Agency of Mapping, Speculation, Critique, and Invention" In Mappings, edited by Denis E. Cosgrove, 213-52. London: Reaktion, 2002.

Courtney, Mason. All of Our Secrets are in These Mountains: Problematizing Colonial Pon er Relations, Tourism Productions and Histories of the Cultural Practices of Nakoda Peoples in the Banff-Bow Valley. Edmonton AB: University of Alberta, 2010.

CPR Connecting Canada. "Building the Railway.” Accessed November 25, 2020. Timeline. https://cpconnectingcanada.ca/

Cronon, William. "The Trouble With Wilderness: Or, Getting Back to the Wrong Nature." Emvironmental History, Vol. 1, No. 1 (Jan., 1996): 7-28.
Cronon, William. Uncommon Ground: Toward Reimventing Nature. New York:Norton, 1995.

Ralph Waldo. Nature and Selected Essays. New York, New York: Penguin,

Hawthorne, Nathaniel. The Celestial Railroad and Other Stories. London: Signet Classics, 2006.

King, Thomas. The Inconvenient Indian: A Curious Account of Native People in North America. Toronto ON : Anchor Canada, 2013.

Macfarlane, Robert. Mountains of the Mind: Adventures in Reacbing the Summit. New York: Vintage, 2004.

Macfarlane, Robert. The Wild Places. London: Penguin Books, 2008.

Mackey, E., “' "Death by Landscape”: Race, Nature, and Gender in Canadian N tionalist Mythology." Canadian Woman Studies 20 (2000): n. page 125-130.

Macy, Christine, and Sarah Bonnemaison. Architecture and Nature Creating the American Landscape. London: Routledge, 2003.

Mastin, Catherine. The Group of Seven in Western Canada. Toronto: Prospero Books,

McHarg, Ian. L. Design with Nature. Garden City, N.Y: John Wiley \& Sons, 1992.

Nash, Roderick F. Wilderness and the American Mind. New Haven, Conn: Yale University Press: 1967

Patin, Thomas. Observation Points: The Visual Poetics of National Parks. Minneapolis: Univerity of Minnesota Press, 2012 .

Price, Travis, and Wade Davis. The Archaeology of Tomorrow: Arcbitecture and the Spirit of Place. San Rafael: Earth Aware Editions, 2006.

Ross, Rupert. Dancing with a Ghost. Exploring Indian Reality. Markham, Ont.: Octopus Books, 1992. 
Rudofsky, Bernard. Architecture Without Architects: a Short Introduction to Non-Pedigreed Arcbitecture. New York: Museum of Modern Art; distributed by Doubleday, Garden City, N.Y., 1964.

Schama, Simon. Landscape and Memory. New York: Vantage, 1996.

Scoon, Roger. The Geotraveller: Geology of Famous Geosites and Areas of Historical Interest. Ney York: Springer International Publishing, 2021.

Smith, Donald. Seen But Not Seen: Influential Canadians and the First Nations from the 1840s to Today. Toronto: University of Toronto Press, 2021.

Spence, Mark David. Dispossessing the Wilderness: Indian Removal and the Making of the National Parks. New York, New York: Oxford University Press, 1999.

Thoreau, Henry David. Walden. London: Penguin Books, 2016.

Thoreau, Henry David, Walking. San Francisco :Sierra Club, 1962.

Valcourt, Tracy. "It's All Happening So Fast: A Counter-History of the Modern Canadian Environment." Border Crossings 36, no. 3 (September 1, 2017): 117-118. http://search.proquest.com/docview/1942238142/.

Sandlos, John. Hunters at the Margins: Native People and Wildlife Conservation in the Northwest Territories. Vancouver: UBC Press, 2007.

Snow, John. These Mountains are our Sacred Places: The Story of the Stoney People. Markham ON: Fifth House, 2005. 